\title{
Eine FUnKTIONELle CHARAKTERISIERUNG DER FRÜHENDOSOMALEN SNARE-PROTEINE
}

\author{
Dissertation \\ zur Erlangung des Doktorgrades \\ der Mathematisch-Naturwissenschaftlichen Fakultäten \\ der Georg-August-Universität zu Göttingen
}

vorgelegt von

Ulf Geumann 
Komitee-Mitglieder:

Professor Dr. Reinhard Jahn (Betreuer), Professor Dr. Nils Brose, Professor Dr. Michael Thumm

Referent: Professor Dr. Reinhard Jahn

Koreferent: Professor Dr. Ralf Ficner 
Eidesstattliche Erklärung:

Hiermit erkläre ich, dass ich die vorliegende Dissertation „Eine funktionelle Charakterisierung der frühendosomalen SNARE-Proteine" selbständig angefertigt habe und keine anderen als die angegebenen Hilfsmittel und Hilfen benutzt wurden.

Göttingen, den 18.3.2009

\section{Ulf Geumann}

Teile dieser Arbeit wurden bereits vorab veröffentlicht:

Geumann, U., S. V. Barysch, P. Hoopmann, R. Jahn, und S. O. Rizzoli: 2008, 'SNARE function is not involved in early endosome docking.' Mol Biol Cell 19(12), 5327-5337.

ein weiteres Manuskript befindet sich in Vorbereitung. 


\section{Inhaltsverzeichnis}

Abbildungsverzeichnis viii

$\begin{array}{ll}\text { Abkürzungsverzeichnis } & \text { ix }\end{array}$

1 Einleitung $\quad 1$

1.1 SNARE-Proteine und Membranfusion . . . . . . . . . . . . . . . 1

1.2 SNARE-Proteine und Docking . . . . . . . . . . . . . . . . 4

1.3 SNARE-Domänen . . . . . . . . . . . . . . . . . . 5

1.4 Frühe Endosomen . . . . . . . . . . . . . . . . . . 6

1.4.1 Frühendosomale SNAREs in der endosomalen Fusion . . . . . 8

1.4.2 Das Docking früher Endosomen . . . . . . . . . . . . . . . 9

1.5 STED Mikroskopie . . . . . . . . . . . . . . . . . 11

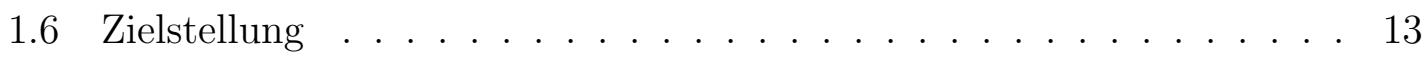

2 Material und Methoden 15

2.1 Chemikalien . . . . . . . . . . . . . . . . . . . . . 15

2.2 Puffer . . . . . . . . . . . . . . . . . . 17

2.3 Antikörper . . . . . . . . . . . . . . . . . . . 18

2.4 Klonierung . . . . . . . . . . . . . . . . . . . . . . 18

2.5 Proteinmethoden . . . . . . . . . . . . . . . . . . 19

2.5 .1 SDS-PAGE . . . . . . . . . . . . . . . . 19

2.5 .2 Coomassie Färbung . . . . . . . . . . . . . . . . . . 19

2.5.3 Westernblot . . . . . . . . . . . . . . . 19

2.5.4 Proteinreinigung . . . . . . . . . . . . . . . 19

2.5.5 Proteinbestimmung . . . . . . . . . . . . . 20

2.6 Liposomen . . . . . . . . . . . . . . . . . . . . . . . . . 21

2.6.1 Liposomenherstellung . . . . . . . . . . . . . . . . . 21

2.6.1.1 Gelfiltration mit EconoSäulen (Methode 1) . . . . 21

2.6.1.2 Dialyse (Methode 2) . . . . . . . . . . . . 21

2.6.1.3 Umkehrphasen Evaporation (Methode 3) . . . . . . 21

2.6.2 Dequenchingassay . . . . . . . . . . . . . . 22

2.6.3 Liposomenflotierung .................. . . 22 
2.6.4 Bestimmung der Proteinorientierung auf Liposomen . . . . . . 22

2.7 Endosomen . . . . . . . . . . . . . . . . . . . . . . . . . 23

2.7.1 Zellkultur, Zytosolgewinnung und Endosomenmarkierung . . . 23

2.7.2 Endosomenisolierung . . . . . . . . . . . . . . . . . 23

2.7.3 Analyse der Kolokalisation von Endosomen und Liposomen . . 23

2.7.4 Aggregationsassay für Endosomen . . . . . . . . . . . . . . . . 24

2.7.5 Endosomen-Interaktionsassay . . . . . . . . . . . . 25

2.7.5.1 Durchführung . . . . . . . . . . . . . 25

2.7.5.2 Datenanalyse . . . . . . . . . . . . . 25

2.7.6 Proteinbindung an die endosomale Membran . . . . . . . . . 26

2.7 .7 Immunfärbung . . . . . . . . . . . . . . . . . . . . . 26

2.8 STED-Mikroskopie . . . . . . . . . . . . . . . . . . 27

2.8.1 Größenbestimmung mittels STED-Mikroskopie . . . . . . . . . 27

2.8.2 Datenanalyse des Clustering . . . . . . . . . . . . 27

2.9 Elektronenmikroskopie . . . . . . . . . . . . . . . . . . . 28

3 Ergebnisse 29

3.1 Das Docking früher Endosomen . . . . . . . . . . . . . . . . . . 29

3.1.1 Aggregationsassay . . . . . . . . . . . . . . . . . 29

3.1.2 Charakterisierung der Endosomen . . . . . . . . . . . . 31

3.1.3 Die Entwicklung des Endosomen-Interaktionsassays . . . . . . 34

3.1.4 Grundlegende Eigenschaften des Dockings . . . . . . . . . . . 37

3.1.5 Sterische Kontrollen und Verdünnung . . . . . . . . . . . . . . 38

3.1.6 Die Rolle von SNARE-Proteinen . . . . . . . . . . . . . . . . 42

3.1.7 Rabs und EEA1 . . . . . . . . . . . . . . . 46

3.2 Die Fusion früher Endosomen . . . . . . . . . . . . . . . . . . . . 49

3.2.1 Die Liposomenfusion mittels frühendosomaler SNAREs . . . . 49

3.2.2 Die Fusion von Proteoliposomen mit Endosomen . . . . . . . . 50

3.2.3 Rekonstituierte Endosomen _. . . . . . . . . . . . . . . . . 64

3.3 Endosomale Proteindomänen _. . . . . . . . . . . . . . . . . 65

3.3.1 Der Einfluss von Lipiden auf die Domänen . . . . . . . . . . . 68

3.3.2 Der Einfluss von Proteinen auf die endosomalen Domänen . 71

4 Diskussion $\quad 79$

4.1 Ein neues Docking-Assay . . . . . . . . . . . . . . . . . . . . . . . . . 79

4.2 Der Einfluss von SNARE-Proteinen auf das Docking . . . . . . . . . . 80

4.3 Der Einfluss von SNARE Proteinen auf die Fusion . . . . . . . . . . . 81

4.3.1 Die Fusion von Liposomen und Endosomen . . . . . . . . . . . 82

4.3.2 Unterschiede zwischen Liposomen und Endosomen . . . . . . . 82

4.4 Regulation und Funktion des SNARE-Clustering . . . . . . . . . . . . 84 
4.4.1 Der Einfluss von Lipiden auf die Domänenstruktur . . . . . . 84

4.4.1.1 Die Beziehung zwischen Cholesterin und lipid rafts . 85

4.4.1.2 Cholesterin und SNARE-Cluster . . . . . . . . . 85

4.4.2 Die Regulation der Cluster durch Protein-Protein-Interaktionen 86 4.4.2.1 Homotypische Interaktionen . . . . . . . . . . 87

4.4.2.2 Heterotypische Interaktionen . . . . . . . . . 87

4.5 Schlussfolgerungen . . . . . . . . . . . . . . . . . . . 89

$\begin{array}{lll}5 & \text { Kurzfassung } & 91\end{array}$

$\begin{array}{ll}\text { Literaturverzeichnis } & 95\end{array}$

6 Anhang 109

6.1 Rayleigh Verteilung von Abständen zwischen Intensitätzentren . . . . 109

6.2 Endosomen-Interaktionsprogramm . . . . . . . . . . . . . . . . 110

6.3 Programm zur Domänenanalyse . . . . . . . . . . . . . . . . . . 120 
Inhaltsverzeichnis 


\section{Abbildungsverzeichnis}

1.1 SNAREs von unterschiedlichen Membranen bilden einen core complex . . . . . . . . . . . . . . . . . . . 2

1.2 SNAREs als Vermittler der Membranfusion . . . . . . . . . . . . 3

1.3 Frühe Endosomen bilden eine zentrale Sortierungsstelle . . . . . . 7

1.4 Der frühendosomale SNARE-Komplex . . . . . . . . . . . . . . . . 9

1.5 Durch Rab5 induzierte Membrandomänen ． . . . . . . . . . . . . 10

1.6 Grundlage der STED-Mikroskopie . . . . . . . . . . . . . . . 11

3.1 Vergleich der Aggregation und Fusion früher Endosomen . . . . . 30

3.2 Die Größenverteilung der markierten Endosomen . . . . . . . . . 32

3.3 Kolokalisation von Alexa-Dextran-markierten Endosomen mit Markerproteinen . . . . . . . . . . . . . . . . . . . . 33

3.4 Endosomen kolokalisieren nur in Gegenwart von ATP . . . . . . . 34

3.5 Beispielverteilung der Endosomenabstände . . . . . . . . . . . 35

3.6 Abstandsverteilung mit fluoreszierenden Beads . . . . . . . . . . . 36

3.7 Abstandsverteilung der Endosomen bei unterschiedlichen Bedingungen . . . . . . . . . . . . . . . . . . 37

3.8 Die Zugabe von BAPTA reduziert nur die Fusion, aber nicht das Docking von Endosomen . . . . . . . . . . . . . . . . . . . . 38

3.9 Das Docking früher Endosomen ist stabil . . . . . . . . . . . . . . 39

3.10 Kontrollexperimente mit Antikörpern und BSA . . . . . . . . . . 40

3.11 Verdünnung reduziert die Fusion aber nicht das Docking von Endosomen . . . . . . . . . . . . . . . . . . . . . 41

3.12 Der Einfluss von Präinkubation auf die Endosomen-Interaktion . 42

3.13 Docking ist resistent gegenüber NSF-Inhibition . . . . . . . . . . 43

3.14 SNARE-Fragmente inhibieren das Docking nicht . . . . . . . . . . 44

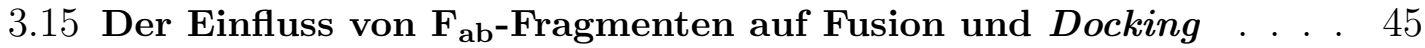

3.16 Der Einfluss von Wortmannin und $\mathbf{G T P}_{\gamma} \mathbf{S} \ldots \ldots$. . . . . . . . 46

3.17 Analyse potentieller Einflussfaktoren auf Docking und Fusion . . 47

3.18 Membranfreisetzung von Rab5 und EEA1 . . . . . . . . . . . . . . 48

3.19 Liposomenfusion mit endosomalen SNARE-Proteinen . . . . . . . 51

3.20 Der Einfluss von Zytosol auf die Reaktion . . . . . . . . . . . . . . 52 
3.21 Die Endosom-Liposom-Fusion lässt sich kaum stoppen . . . . . 53

3.22 Proteinfreie Liposomen fusionieren mit Endosomen . . . . . . . . 54

3.23 Der Einfluss von Trypsin auf die Reaktion . . . . . . . . . . . . . . 54

3.24 Der Einfluss von BAPTA auf die Liposom-Endosom-Fusion . . . 55

3.25 Endosomale und liposomale Proteine finden sich nach der Fusion in derselben Membran . . . . . . . . . . . . . . . . 5 56

3.26 Der Einfluss von Trypsin auf Kolokalisation von Endosomen mit Liposomen . . . . . . . . . . . . . . . . . . . . . 57

3.27 LPC inhibiert die Bildung des fusion stalks . . . . . . . . . . . . 58

3.28 Der Einfluss von LPC auf die Fusion von Endosomen mit Liposomen . . . . . . . . . . . . . . . . . . . 5 59

3.29 Der Einfluss von Cholesterin auf die Fusion von Endosomen mit Liposomen . . . . . . . . . . . . . . . . . . . . . 60 60

3.30 VAMP4-Einbau und Orientierung in großen Liposomen . . . . . 61

3.31 Die Fusion großer und kleiner Liposomen im Vergleich . . . . . . 62

3.32 Analyse der nach Methode 3 hergestellten Liposomen . . . . . . . 63

3.33 Trypsinierte Endosomen neigen zum Verklumpen . . . . . . . . . 64

3.34 Rekonstitutionseffizienz nach Solubilisierung . . . . . . . . . 65

3.35 Proteoliposomen mit endosomenähnlicher Zusammensetzung . . 66

3.36 STED-Mikroskopie macht Synaptophysindomänen sichtbar . . . . 67

3.37 Der Einfluss von Cyclodextrin auf die Fusion von Endosomen . . 68

3.38 Die Kolokalisation von Endosomen mit Liposomen unterschiedlicher Zusammensetzung . . . . . . . . . . . . . . . . . . . . . . . . 69

3.39 Die Fusion von Endosomen mit Liposomen unterschiedlicher Lipidzusammensetzung . . . . . . . . . . . . 70

3.40 Analyse der Synaptophysindomänen nach Fusion mit Liposomen 72

3.41 Größenzunahme der Endosomen durch Fusion mit Liposomen . . 73

3.42 Der Einfluss von Cyclodextrin auf die Anzahl der Synaptophysindomänen . . . . . . . . . . . . . . . . . . . . . . . . 74

3.43 Der Einfluss von GDI auf SNARE-Domänen . . . . . . . . . . . . 75

3.44 HA-tag VAMP4 ist funktional . . . . . . . . . . . . . 76

3.45 Die HA-VAMP4-Struktur auf Liposomen und Endosomen ähnelt sich . . . . . . . . . . . . . . . . . 77

3.46 Myc-Syntaxin-1 formt mehr Domänen auf Endosomen als auf Liposomen . . . . . . . . . . . . . . . . . . . . . . 78

6.1 Rayleighverteilung . . . . . . . . . . . . . . . . . . . 109 


\title{
Abkürzungsverzeichnis
}

\author{
Ak Antikörper \\ BAPTA 1,2-bis(o-aminophenoxy)ethane- $N, N, N^{\prime}, N^{\prime}$-tetraacetic acid \\ BHK Baby Hamster Kidney \\ BSA Rinderserumalbumin \\ CMC kritische mizellare Konzentration \\ CURL compartment for the uncoupling of receptor and ligand \\ EDTA Ethylendiamintetraessigsäure \\ EEA1 early endosomal autoantigen 1 \\ EGTA Ethylenglycoltetraessigsäure \\ FPLC Fast protein liquid chromatography \\ FRET Förster-Resonanz-Energietransfer \\ FWHM Full-width at half maximum \\ FYVE zuerst in den Proteinen Fab1p, YOTB, Vac1p und EEA1 gefundene Zink- \\ Finger-Domäne \\ GARP Golgi-associated retrograde protein \\ GDI GDP-Dissoziationsinhibitor \\ GEF GDP-exchange factor \\ GPI Glycosylphosphatidylinositol \\ GTP $\gamma$ S Guanosin-5'-O-(3'-Thiotriphosphat) \\ HB HEPES-Puffer mit der angegebenen Salzkonzentration \\ HEPES N-(2-Hydroxyethyl-)piperazin-N²-2-Ethansulfonsäure \\ HRP Merretichperoxidase \\ HOPS homotypic fusion and vacuolar protein sorting \\ i.e. dass heisst
}


LDL Lipoprotein geringer Dichte

LPC Lysophosphatidylcholin

NBD (N-(7-nitrobenz-2-oxa-1,3-diazol-4-yl)-1,2-dihexadecanoyl-glycero-3-PE, triethylammoniumsalz)

NSF NEM-sesitive factor

PBS Phosphatgepufferte Salzlösung

PC Phosphatidylcholin

PE Phosphatidylethanolamin

PFA Paraformaldehyd

PNS postnukleärer Überstand

PI Phosphatidylinositol

$\mathrm{PIP}_{2} \quad$ Phosphatidylinositol-3,4-bisphosphat

PS Phosphatidylserin

PSF point spread function

Rab Ras-like protein from brain

SEM Standardfehler

SNAP soluble NSF-attachment protein

SNAP-25 synaptosomal associated protein of $25 \mathrm{kDa}$

SNARE soluble NSF attachment protein receptor

STED stimulated emission depletion

TRAPP transport protein particle

VAMP vesicle-associated membrane protein

$\mathrm{v} / \mathrm{v} \quad$ Volumenprozent

$\mathrm{w} / \mathrm{v} \quad$ Masseprozent 


\section{Einleitung}

Der korrekte Transport von Stoffen zwischen unterschiedlichen Kompartimenten ist eine zentrale Voraussetzung für das Leben von Zellen und damit auch Organismen. Dies macht die ausgefeilte Regulation dieser Prozesse verständlich und zu einem spannenden Forschungsgebiet.

\subsection{SNARE-Proteine und Membranfusion}

Der intrazelluläre Transport zwischen Organellen erfolgt über Vesikel, die von einem Donorkompartiment abgeschnürt werden (Budding) und mit einem Akzeptorkompartiment fusionieren. Die ersten Faktoren für die eine Rolle in der Membranfusion beschrieben wurde, waren die AAA-ATPase NSF (NEM-sensitive factor) (Block et al., 1988) und ihr Kofaktor SNAP (soluble NSF-attachment protein), der in den Isoformen $\alpha, \beta$ und $\gamma$ vorkommt (Clary et al., 1990; Waters et al., 1992; Whiteheart et al., 1993). Unter Einsatz eines Komplexes aus myc-tag NSF und SNAP konnten VAMP2 (Vesicle-associated membrane protein), Syntaxin-1 und SNAP-25 aus Rindergehirn isoliert werden (Söllner et al., 1993). Die Eigenschaft der SNAPBindung wurde namens gebend für diese neue Klasse von Proteinen, den soluble NSF-attachment protein receptors oder kurz SNAREs. SNARE-Proteine bilden den Kern der Maschinerie, die für alle zellulären Membranfusionen mit Ausnahme der vergleichsweise wenig verstandenen mitochondrialen und peroxisomalen Fusion verantwortlich ist (Hermann et al., 1998; Titorenko \& Rachubinski, 2000; Sesaki \& Jensen, 2001). Sie zeichnen sich durch den Besitz eines oder mehrerer 60-70 Aminosäuren langer SNARE-Motive aus und enthalten in der Regel eine Transmembrandomäne (siehe (Jahn \& Scheller, 2006) zur Übersicht). Es kommen allerdings auch lipidverankerte SNARE-Proteine wie SNAP-25 (Hess et al., 1992) vor oder lösliche wie SNAP-29 und Vam7p, die über ihre PX-Domäne an die Membran binden (Cheever et al., 2001).

SNAREs von unterschiedlichen Membranen, z.B. von synaptischen Vesikeln und Plasmamembran, können über ihre SNARE-Motive miteinander interagieren, wobei aus der Zusammenlagerung von vier isoliert eher unstrukturierten SNARE-Motiven 


\section{Einleitung}

ein tetrahelikaler Bereich, der sogenannte core complex (siehe Abbildung 1.1), entsteht, welcher eine sehr hohe Stabilität aufweist (Poirier et al., 1998). Die Kom-

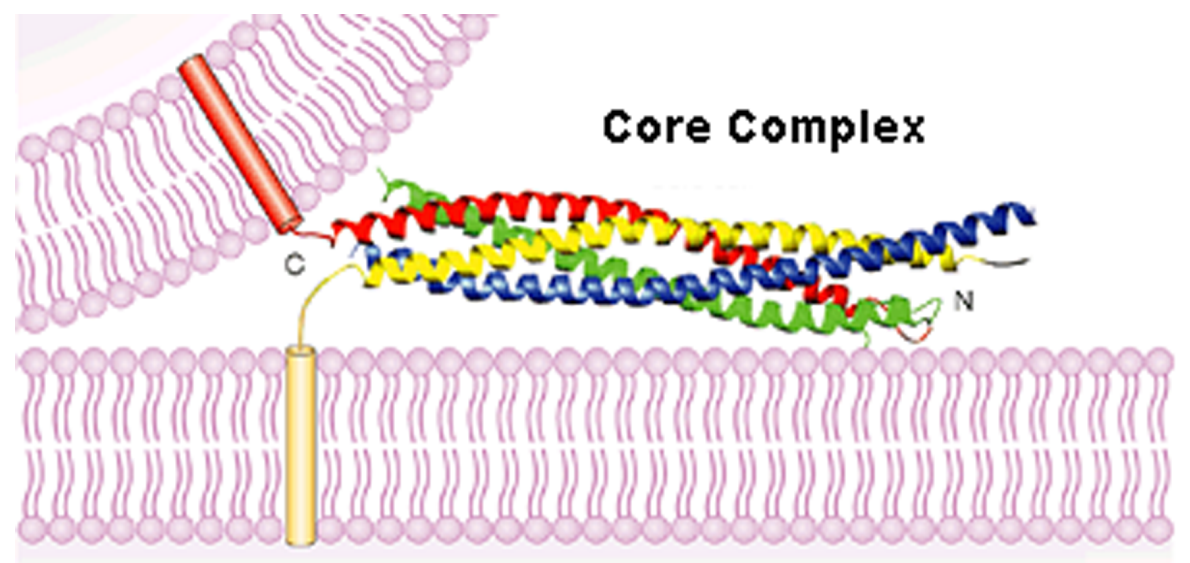

Abbildung 1.1: SNAREs von unterschiedlichen Membranen bilden einen core complex

Durch die reißverschlußartige Bildung des gezeigten core complex aus SNARE-Motiven von unterschiedlichen Membranen werden diese zusammengezogen, was schließlich zur Fusion führt. (Rizo \& Südhof, 2002)

plexbildung beginnt am N-terminus, d.h. in der von der Membran entfernten Region und setzt sich zum membrannahen C-terminus fort, wodurch die Membranen reißverschlußartig zueinander gezogen werden (siehe Abbildung 1.2). Ein Prozess, der mit der Membranfusion endet, wobei die genauen Mechanismen noch unklar sind. So könnte die Komplexbildung neben der Überwindung der hydrophoben Abstoßung auch dazu dienen, über die Transmembrandomänen der SNARE-Proteine einen lokalen Stress auf die Membranen auszuüben, um ihre Fusion zu begünstigen (Langosch et al., 2007). Nach der Fusion werden die entstandenen cis-Komplexe durch die AAA-ATPase NSF und ihren Kofaktor $\alpha$ SNAP wieder dissoziiert, so dass sie für weitere Fusionsreaktionen zur Verfügung stehen.

Die SNARE-Motive können in vier unterschiedliche Klassen, Qa, Qb Qc und R eingeteilt werden, die sich evolutionär früh getrennt haben (Fasshauer et al., 1998; Kloepper et al., 2007), wobei ein Komplex immer aus je einem dieser Motive besteht und mindestens eine Transmembrandomäne in jeder der beiden Membranen besitzen muss (Grote et al., 2000; McNew et al., 2000b). In Säugern existieren über 35 unterschiedliche SNAREs (Bock et al., 2001), was zu der Hypothese geführt hat, dass die Spezifität der intrazellulären Fusionsreaktionen durch die SNARE-Komplexbildung bestimmt wird (Söllner et al., 1993; McNew et al., 2000a; Parlati et al., 2000). Inzwischen konnte jedoch gezeigt werden, dass ein SNARE nicht nur mit Partnern desselben Fusionsschrittes Komplexe bildet und diese SNARE-Partner auch nicht stark bevorzugt werden (Fasshauer et al., 1999; Yang et al., 1999). Das schließt eine rein SNARE-vermittelte Spezifität aus. 


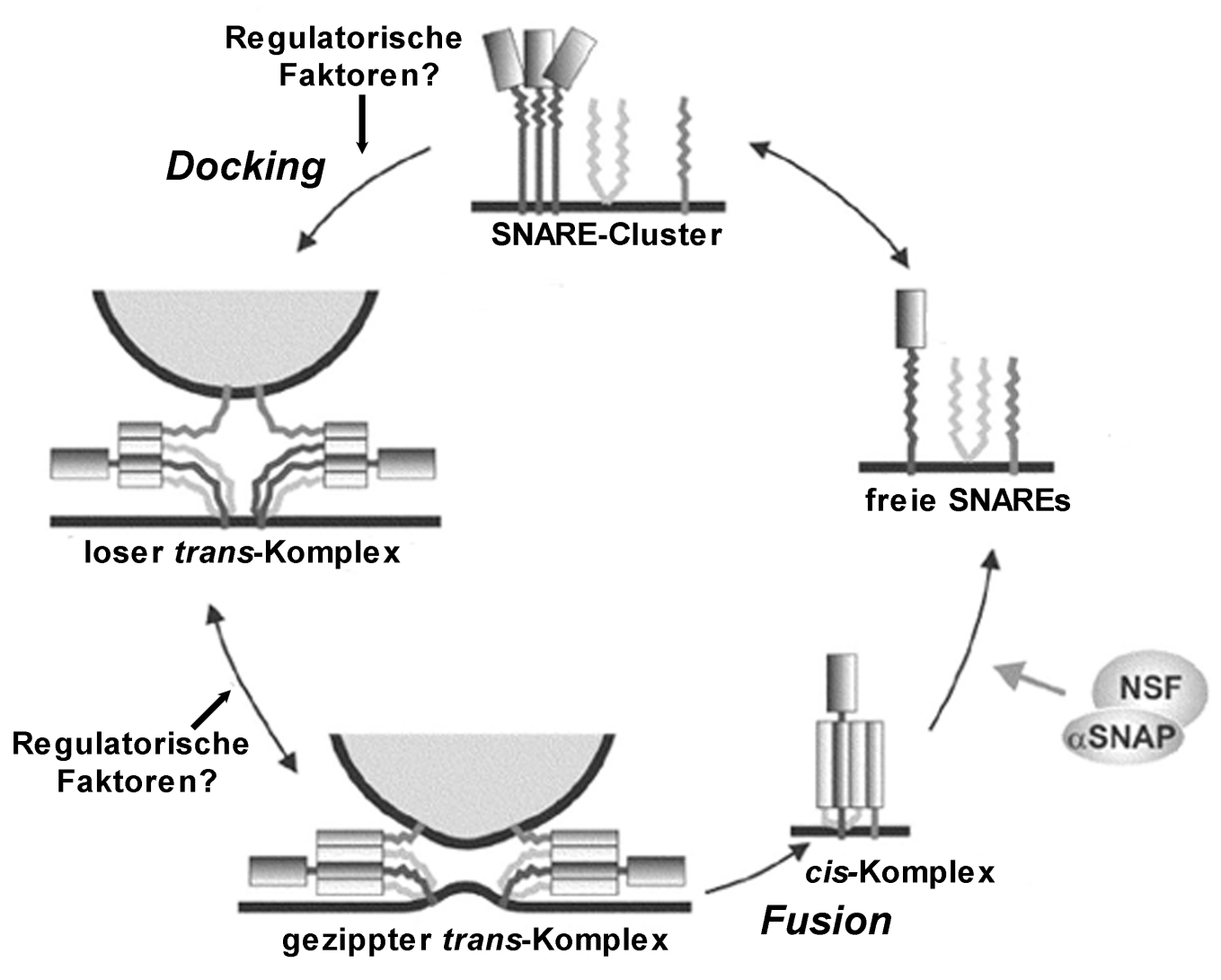

Abbildung 1.2: SNAREs als Vermittler der Membranfusion

Nach ihrer Aktivierung durch NSF und $\alpha$ SNAP befinden sich die SNARE Proteine zunächst frei auf der Membran. Es folgt wahrscheinlich ein Schritt, in dem sich SNAREs in speziellen Membrandomänen anreichern und Akzeptorkomplexe bilden. Zeitgleich mit oder in Folge des Membrandockings (siehe nächsten Abschnitt) assoziieren die SNARE-Motive lose miteinander, gefolgt von einer festen reißverschlußartigen Komplexbildung, welche die Membranen zueinander zieht und schlussendlich zur Membranfusion führt (modifiziert nach (Jahn, 2004)). 


\section{Einleitung}

Während die Mechanismen der SNARE-Komplexbildung inzwischen gut verstanden sind (Jahn \& Scheller, 2006; Brandhorst et al., 2006; Bethani et al., 2007) ist die Grundlage ihrer Regulation noch relativ unklar. Neben dem als Kalziumsensor dienenden Syntaptotagmin (Brose et al., 1992), spielen die sogenannten SM(Sec1/Munc18)-Proteine eine zentrale Rolle, wobei teils widersprüchliche Beobachtungen gemacht worden sind (Gerst, 2003), d.h. sowohl eine fusionsfördernde als auch inhibierende Wirkung beschrieben wurde, was sich nur langsam aufzuklären scheint (Burkhardt et al., 2008). Andere intrazelluläre Fusionsreaktionen unterliegen wahrscheinlich einer etwas weniger komplexen Steuerung und könnten dadurch vielleicht einen leichteren Zugang zu grundlegenden Mechanismen der SNARE-Regulation ermöglichen.

\subsection{SNARE-Proteine und Docking}

Der Membranfusion voraus geht das sogenannte Docking, das üblicherweise morphologisch als der enge Kontakt zweier Membranen definiert wird (Klenchin \& Martin, 2000). Das Docking wird überwiegend durch die Interaktion kleiner GTPasen - der Rab-(Ras-like protein from brain) Proteine bzw. ihrer Hefeanaloga, der Yptps - mit Tetheringmolekülen kontrolliert (siehe (Cai et al., 2007) zur Übersicht). Bei den Tethering-Faktoren handelt es sich entweder um große coiled-coil Proteine wie p115 (Allan et al., 2000) oder Komplexe, wie Dsl1 (Kraynack et al., 2005), die aus mehreren Untereinheiten bestehen. Sie interagieren mit den Rab-Proteinen auf unterschiedliche Weise. Zum Beispiel wird der GARP-(Golgi-associated retrograde protein)-Komplex, welcher eine Rolle im retrograden Transport vom Golgi-Apparat zum Endoplasmatischen Retikulum spielt (Conibear \& Stevens, 2000), durch Ypt6p zur Membran rekrutiert (Sztul \& Lupashin, 2006). Der TRAPP 1 (Transport protein particle) Komplex hingegen wirkt als GEF (GDP-exchange factor) für Ypt1p, d.h. er fördert den Austausch von GDP gegen GTP (Sacher et al., 2001) und führt damit zur Aktivierung von Ypt1p, welches wie TRAPP1 eine Rolle im Transport vom ER zum Golgi spielt. Der vakuoläre HOPS (homotypic fusion and vacuolar protein sorting) Komplex vereint beide Eigenschaften, d.h. er dient nicht nur als Ypt7p-Effektor, sondern stimuliert auch dessen Aktivität über einen Austausch von GDP gegen GTP (Cai et al., 2007).

Für einige der Tethering-Faktoren wie HOPS und Dsl1 ist außerdem eine SNAREInteraktion beschrieben worden, was eine Verbindung vom Docking zur Fusion darstellen könnte. So soll Dsl1 einen SNARE-Komplex aus Use1p, Ufe1p und Sec20p auf dem endoplasmatischen Retikulum stabilisieren (Kraynack et al., 2005), während HOPS Vamp7p bindet (Stroupe et al., 2006). Eine direkte Rolle von SNARE- 
Proteinen, insbesondere Syntaxin-1, im Docking schien lange unwahrscheinlich, so hatte z.B. weder die Injektion von SNARE-spaltendem Neurotoxin noch ein Syntaxin 1A knock-out einen Einfluss auf die Anzahl gedockter synaptischer Vesikel (Broadie et al., 1995; O'Connor et al., 1997; Fujiwara et al., 2006). Neuere Untersuchungen, die Hochdruckgefriertechniken für die Elektronenmikroskopie einsetzten, kamen jedoch zu entgegengesetzten Ergebnissen und zeigten ein deutlich vermindertes Docking in Abwesenheit von Syntaxin-1 in Neuronen von C. elegans (Hammarlund et al., 2007, 2008). Und auch für das Docking von Hefevakuolen ist ein Einfluss von SNAREProteinen beschrieben worden (Mayer \& Wickner, 1997; Ungermann et al., 1998). Ob SNARE-Proteine eine Rolle beim Docking-Prozess spielen, ist daher nach wie vor unklar und sollte im Rahmen dieser Arbeit näher untersucht werden. Sowohl die Fusion als auch das Docking erfordern das Zusammenspiel zahlreicher Proteine, die hierzu in bestimmten Membranregionen konzentriert werden (Ohara-Imaizumi et al., 2004).

\subsection{SNARE-Domänen}

Die Existenz von spezialisierten Domänen in biologischen Membranen ist ein vergleichsweise neues Konzept. 1972 war von Singer und Nicolson das Fluid-mosaic model entwickelt worden, welches von einer freien lateralen Bewegung der Proteine und Lipide in Membranen ausging (Singer \& Nicolson, 1972). Es zeigte sich jedoch, dass die meisten Proteine nicht völlig frei in der Membran diffundieren können (Jacobson et al., 1995). Kurze Zeit später wurde von Simons und Ikonen (Simons \& Ikonen, 1997), in der so genannten lipid raft-Hypothese postuliert, dass sich über die Interaktion von Cholesterin und Sphingolipiden stabile „Flöße” in der Membran bilden, in denen sich z.B. Glycosylphosphatidylinositol (GPI)-verankerte Proteine anreichern. Zu ihrer Identifikation diente ursprünglich die Unlöslichkeit dieser lipid rafts in kaltem Triton X-100; ein inzwischen sehr umstrittenes Verfahren, da Triton X-100 auch in Modellmembranen Domänen induzieren kann, die zuvor nicht vorhanden waren (Heerklotz, 2002). Die meisten SNAREs der Plasmamembran, d.h. Syntaxin-1 bis Syntaxin-4, SNAP-25 und SNAP-23 befinden sich in unterschiedlichen Domänen, die bis auf die Syntaxin-4-Cluster cholesterolabhängig sind (Lang, 2007). Diese Cluster scheinen auch eine funktionelle Bedeutung zu haben, so stellen Syntaxin-1- und Syntaxin-4-Cluster Regionen für das Docking und die Fusion sekretorischer Granula bzw. Caveolae dar (Lang et al., 2001; Ohara-Imaizumi et al., 2004; Predescu et al., 2005). Die Mechanismen dieser Domänenbildung sind jedoch noch weitgehend unklar und scheinen einer ausgeklügelten Regulation zu unterliegen. So hängt z.B. die Integrität der Syntaxin-3-Cluster von Mikrotubuli ab, während Syntaxin-4-Cluster 


\section{Einleitung}

intakte Aktinfilamente voraussetzen (Low et al., 2006). Einer der bestuntersuchten Cluster ist der von Syntaxin-1 gebildete, der sich aus der homotypischen Interaktion der Syntaxin-1 Moleküle ergibt und durch Cholesterin stabilisiert wird (Sieber et al., 2006, 2007). Ob die Cholesterolabhängigkeit vieler SNARE-Cluster auf eine lipid raft-Lokalisation schließen lässt, ist jedoch umstritten (siehe (Lang, 2007) zur Diskussion). So zeigten Studien an Modellmembranen z.B. eine Präferenz von SNAREs für die ungeordnete, raft-unähnliche Lipidphase (Bacia et al., 2004). Selbst für Cholesterin als das am besten untersuchte Lipid bleiben also noch viele Fragen offen und über den potentiellen Einfluss anderer Lipide ist praktisch nichts bekannt, was mit dieser Arbeit geändert werden sollte. Ein ideales System um diese und auch die unter Abschnitt 1.1 sowie 1.2 besprochenen Fragen zu beantworten stellen frühe Endosomen dar.

\subsection{Frühe Endosomen}

Frühe Endosomen wurden vor 26 Jahren zum ersten Mal von Geuze und Kollegen als CURL (Compartment for the uncoupling of receptor and ligand) beschrieben (Geuze et al., 1983). In ihnen laufen fast alle Clathrin-abhängigen und unabhängigen Endozytoserouten zusammen. Sie bilden eine zentrale Verzweigungsstelle im intrazellulären Transport (siehe Abbildung 1.3). Neben dem direkten Rücktransport zur Plasmamembran erfolgt hier eine Sortierung zu spezialisierten Recyclingendosomen, welche im perinukleären Bereich konzentriert sind, sowie ein Austausch mit dem Trans-Golgi-Netzwerk (Itin et al., 1997; Cook et al., 2004), während zum Abbau bestimmte Stoffe in sogenannte späte Endosomen und Lysosomen gelangen. Der genaue Ablauf dieses Transportweges ist noch umstritten. Neben einer fortschreitenden Reifung der frühen Endosomen zu späten Endosomen wird auch die Abschnürung von Transportvesikeln durch frühe Endosomen diskutiert, welche dann mit späten Endosomen fusionieren (Diskussion in (Brandhorst und Jahn, 2006)). Abhängig vom Zelltyp werden frühe Endosomen etwa 1-5 Minuten nach der Internalisierung über die Plasmamembran erreicht (Roth, 2006). In ihrem leicht sauren Milieu (pH 6) erfolgt für einige Rezeptoren, die ihren Liganden pH-abhängig binden wie der LDLRezeptor, bereits eine Dissoziation, die für den ursprünglichen Namen "CURL" verantwortlich war (s.o.). Die Morphologie früher Endosomen ist komplex, sie bestehen aus eher runden, vakuolären Bereichen sowie längeren Tubuli (Gruenberg, 2001).

Frühe Endosomen können, wahrscheinlich als Teil ihrer Sortierungsfunktion, miteinander fusionieren. Diese Reaktion ist in der Vergangenheit intensiv untersucht worden, um einen Einblick in intrazelluläre Fusionsmechanismen zu erhalten, wobei sowohl biochemische Methoden, die z.B. auf der Interaktion von Biotin und 


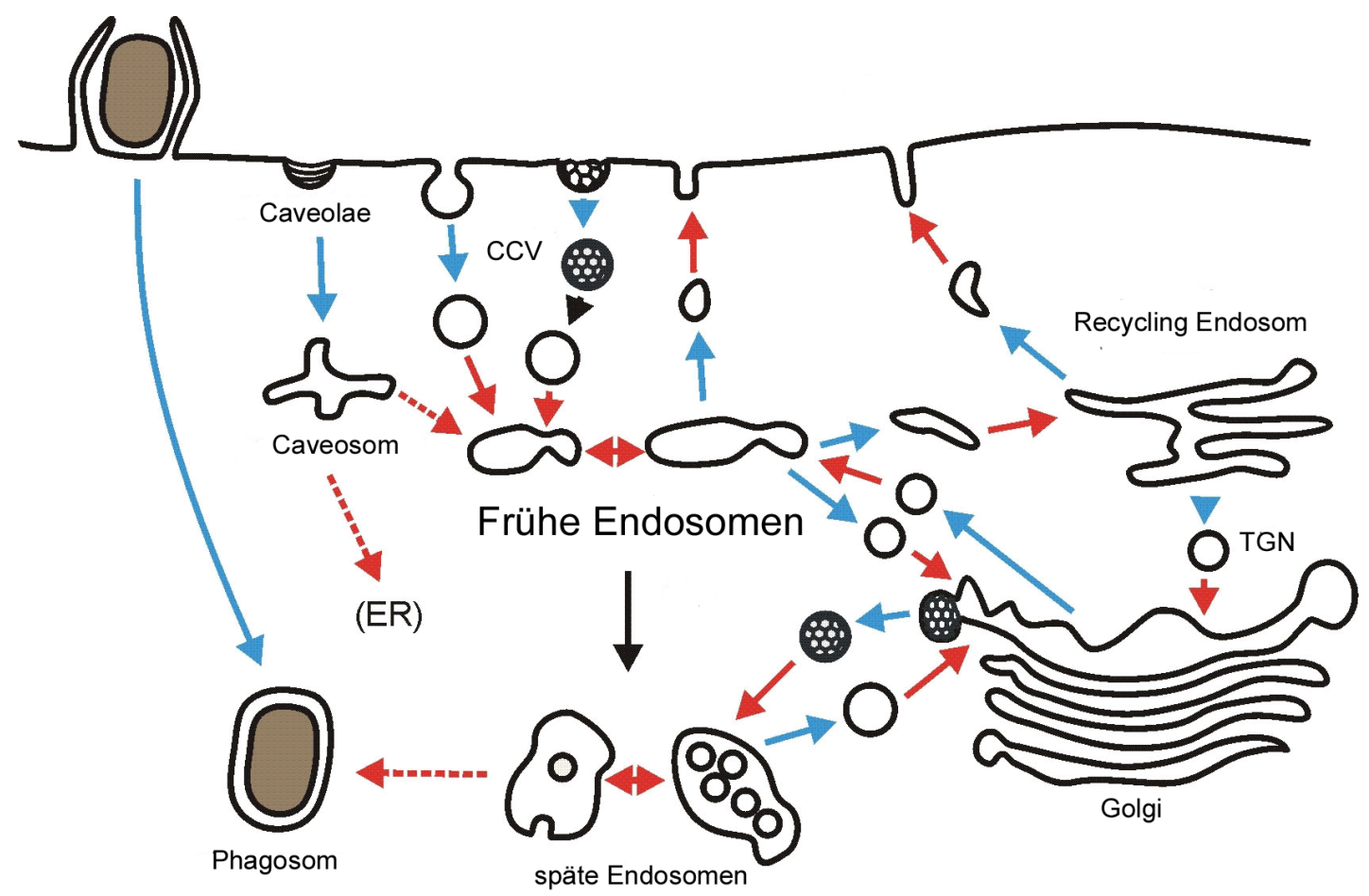

Abbildung 1.3: Frühe Endosomen bilden eine zentrale Sortierungsstelle Die meisten Endozytoserouten führen zu frühen Endosomen, von wo aus ein Recycling zur Plasmamembran, ein Austausch mit dem Recyclingendosom und dem Golgi-Apparat oder ein Weitertransport zu späten Endosomen erfolgt. Buddingschritte sind durch blaue, Fusionsschritte durch rote Pfeile gekennzeichnet (modifiziert nach Brandhorst und Jahn, 2006). 


\section{Einleitung}

Streptavidin-HRP beruhten (Braell, 1987) als auch mikroskopische Methoden mit unterschiedlich farbig markierten Organellen (Brandhorst et al., 2006; Rizzoli et al., 2006) zum Einsatz gekommen sind. Die Fusion benötigt neben zytosolischen Faktoren und ATP (Braell, 1987) auch Kalzium (Mayorga et al., 1994). Das Kalzium stammt hierbei wahrscheinlich aus dem endosomalen Lumen, da der Chelator EGTA trotz seiner hohen Kalziumaffinität keinen Einfluß auf die Fusion hat, wohingegen der ungefähr hundertfach schnellere Chelator BAPTA (Smith et al., 1984; Tsien, 1980), welcher das freigesetzte Kalzium sofort binden kann, die Reaktion inhibiert (Holroyd et al., 1999). Neben den SNARE-Proteinen, die im folgenden Abschnitt näher diskutiert werden sollen, hat sich auch die GTPase Rab5 als zentral für die Fusion erwiesen. Rab-Proteine besitzen keine Membrandomäne, sondern binden über einen Lipidanker (Geranylgeranyl im Falle von Rab5) an die Membran. Sie unterliegen einem ständigen Zyklus zwischen aktiver (GTP-gebundener) und inaktiver (GDPgebundener) Form, wobei letztere durch den GDP-dissociation inhibitor (GDI) von der Membran entfernt wird (Ullrich et al., 1994). Die Expression einer konstitutiv aktiven Variante von Rab5 (Q79L), welche eine verminderte intrinsische GTPaseAktivität aufweist, führt zu stark vergrößerten Endosomen und sie stimuliert auch die Fusion in vitro (Stenmark et al., 1994; Roberts et al., 1999). Während eine direkte Beteiligung von Rab5 an der Fusion unwahrscheinlich ist, gibt es zahlreiche Belege für seine Bindung an fusionsassoziierte Proteine (siehe (Zerial \& McBride, 2001) zur Übersicht) und die Rekrutierung von Dockingfaktoren (siehe unten).

\subsubsection{Frühendosomale SNAREs in der endosomalen Fusion}

Da frühe Endosomen das erste Kompartiment bilden, welches von den endozytierten Vesikeln erreicht wird, also noch keine Sortierung stattgefunden hat, findet sich auf ihnen eine Vielzahl von unterschiedlichen SNARE-Proteinen (siehe z.B. (Bethani et al., 2007)). Aufgrund der großen Anzahl von Kandidaten war lange umstritten, welche SNAREs für die homotypische Fusion von frühen Endosomen verantwortlich sind; so wurde z.B. eine Rolle der neuronalen SNAREs SNAP-25 und Synaptobrevin (Sun et al., 2003) oder auch des spätendosomalen VAMP8 (Antonin et al., 2000) vorgeschlagen. Mit Hilfe eines funktionellen Assays wurde jedoch vor kurzem gezeigt, dass Syntaxin 6, Syntaxin 13, Vti1a und VAMP4 die wahrscheinlichsten Kandidaten sind, da lösliche Fragmente dieser SNAREs die endosomale Fusion am effizientesten inhibieren (Brandhorst et al., 2006). Ein Komplex dieser SNAREs konnte, wie Abbildung 1.4 zeigt, auch kristallisiert werden (Zwilling et al., 2007).

Das Qa-SNARE des frühendosomalen Komplexes, Syntaxin 13 befindet sich hauptsächlich im Gehirn (Advani et al., 1998) und bindet an EEA1 (McBride et al., 1999). Das Qb-SNARE, Vtila (eins der humanen Homologe von Vti1p) findet sich 


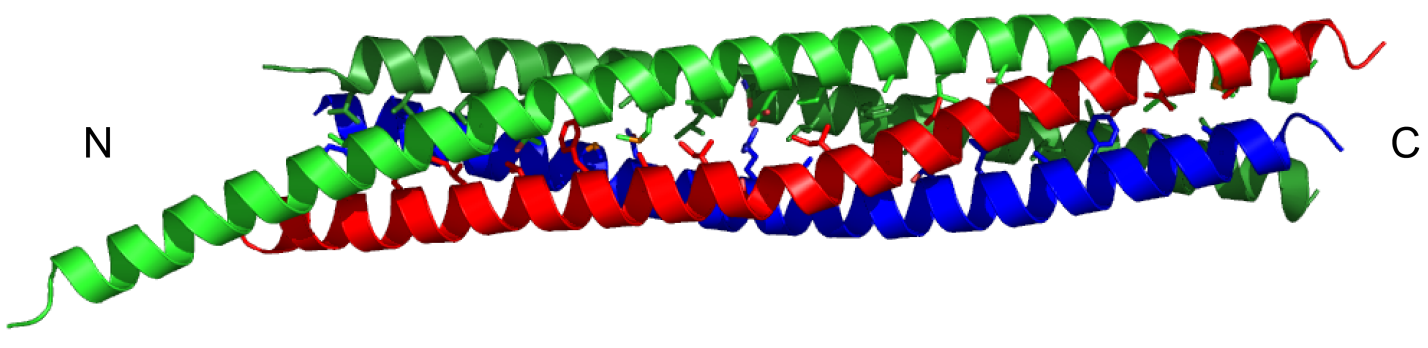

Abbildung 1.4: Der frühendosomale SNARE-Komplex

VAMP4, Syntaxin 6, Syntaxin 13 und Vti1a bilden den frühendosomalen SNARE-Komplex (Zwilling et al., 2007).

überwiegend im Bereich des Golgi und in geringerem Maße auf frühen Endosomen (Kreykenbohm et al., 2002). Aufgrund seiner starken Homologie zum C-terminalen SNARE-Motiv von SNAP-25 handelt es sich bei Syntaxin 6 um ein Qc-SNARE. Syntaxin 6 kann sein Homolog bei der in vitro Komplexbildung ersetzen (Choudhury et al., 2006). Man hat es auch als „dandy” (Wendler \& Tooze, 2001) bezeichnet, da es eine Vielzahl von Interaktionen mit anderen SNARE Proteinen eingeht, so wurden Bindungen an VAMP2, VAMP3, VAMP4, VAMP7 und VAMP8 beschrieben, um nur einige zu nennen. Syntaxin 6 kommt in zahlreichen Geweben vor, wobei sich eine besonders hohe Expression im Gehirn, der Lunge und der Niere zeigt. Es befindet sich überwiegend am Golgi-Apparat und auf frühen Endosomen (Bock et al., 1997). Neben seinen zahlreichen Interaktionen mit anderen SNAREs wurde auch eine Bindung an $\alpha$ SNAP (Wendler \& Tooze, 2001), EEA1 (Simonsen et al., 1999; Mills et al., 2001) und Calmodulin (Mills et al., 2001) beschrieben. Trotz seiner wahrscheinlichen Rolle in der frühendosomalen Fusion führt eine Überexpression des löslichen Fragments (d.h. ohne Transmembrandomäne) nur zu einer Inhibition der Caveolae-vermittelten Endozytose. Hierfür wurde ein indirekter Mechanismus vorgeschlagen, der eine Beteiligung von Syntaxin 6 am Transport von Caveolae-assoziierten Proteinen und Lipiden zur Plasmamembran vermutet, d.h. mehr auf die Rolle von Syntaxin 6 im Golgi abzielt (Choudhury et al., 2006). Das R-SNARE VAMP4 findet sich nicht nur auf frühen Endosomen, sondern auch im Trans-Golgi-Netzwerk und auf unreifen sekretorischen Granula (Hinners et al., 2003). Seine korrekte Lokalisation wird durch ein di-Leucin-Motiv und zwei saure Aminosäure-Cluster im N-terminus erreicht (Zeng et al., 2003). Für VAMP4 ist auch eine Bindung an das Adaptorprotein AP-1 beschrieben worden (Hinners et al., 2003).

\subsubsection{Das Docking früher Endosomen}

Es wird vermutet, dass Rab5 durch zahlreiche Rückkopplungsreaktionen Domänen auf frühen Endosomen bildet (siehe (Zerial \& McBride, 2001) zur Diskussion). So 


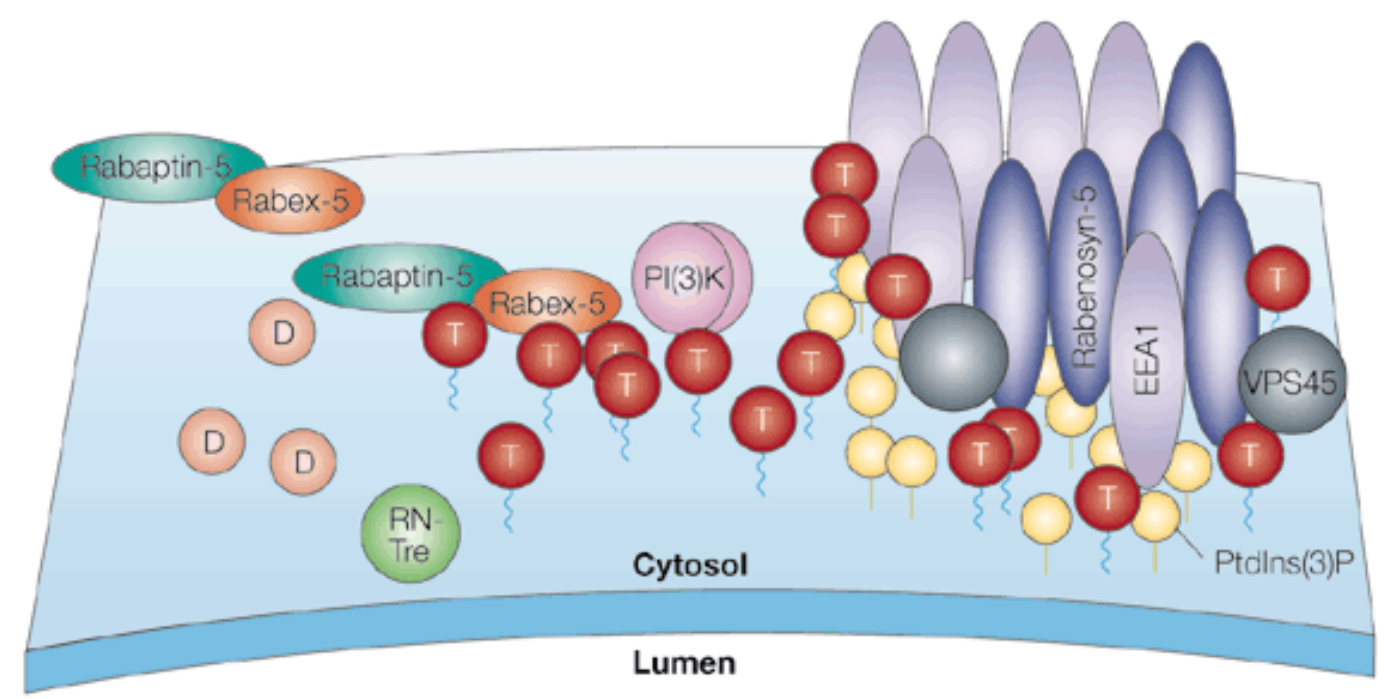

Abbildung 1.5: Durch Rab5 induzierte Membrandomänen

Rab5-GTP bindet an Rabex-5 und Rabaptin-5 und bringt sie dadurch an die endosomale Membran, wo sie bei inaktivem Rab5 den Austausch von GDP gegen GTP fördern, wodurch auch dieses aktiviert wird und wiederum Rabex-5 und Rabaptin-5 rekrutiert, d.h. es ergibt sich ein positiver Rückkopplungsmechanismus. Die Bindung weiterer Rab-Effektoren wie EEA1 und Rabenosyn wird durch die Rekrutierung von PI3-Kinase gefördert (Zerial \& McBride, 2001).

rekrutiert aktives, d.h. GTP-gebundenes Rab5, z.B. Rabaptin-5 zur endosomalen Membran, welches die GEF-Aktivität von Rabex-5 erhöht (Horiuchi et al., 1997), d.h. einen vermehrten Austausch des Rab5-gebundenen GDPs durch GTP bewirkt, und damit zu einer Aktivierung weiterer Rab-Proteine führt. Wird Rabaptin-5 von der Membran entfernt, folgt daraus eine verringerte Fusionsrate (Stenmark et al., 1995), während eine Überexpression die Bildung vergrößerter Endosomen verursacht. Neben der Rekrutierung von Rabaptin-5 erhöht Rab5 die Membranlokalisation der PI-3 Kinase p150/Vps34 (Christoforidis et al., 1999b), wobei es sich (im Gegensatz zu früheren Vermutungen) wahrscheinlich um einen indirekten Mechanismus handelt (Murray et al., 2002).

Die verstärkte Bildung von PI-3 Phosphat auf der endosomalen Membran führt zur Rekrutierung weiterer Rab5-Effektoren, wie der langen coiled-coil Proteine Rabenosyn-5, Rabankyrin-5 und EEA1 (early endosomal autoantigen 1), die alle eine PI3P-bindende FYVE-Domäne besitzen. Für das Docking von Endosomen scheint hierbei besonders EEA1 von Bedeutung zu sein, welches als einziges Protein in der Lage ist, Zytosol in der endosomalen Fusion zumindest teilweise zu ersetzen (Christoforidis et al., 1999a). Die Frage, ob die direkte Rekrutierung durch Rab5 oder die Bindung an PI3-Phosphat der entscheidende Faktor für die Membranbindung von EEA1 ist, ist immer noch umstritten, da die FYVE-Domäne von EEA1 nicht ausreicht, um 
GFP zu frühen Endosomen zu lokalisieren, sondern auch die Rab5-Bindungsdomäne und ein Stück der coiled coil Region erforderlich sind (Stenmark et al., 1996). Andererseits befindet sich EEA1 auch nach Mutation der Rab5-Bindungsstelle noch auf frühen Endosomen (Lawe et al., 2002).

\subsection{STED Mikroskopie}

Trotz ihrer regulatorischen Bedeutung ist über Membrandomänen auf frühen Endosomen bisher nur sehr wenig bekannt, da die Größe der Endosomen selbst mit ca. 200 nm bereits im Bereich der Aufösungsgrenze konventioneller Fluoreszenzmikroskopie liegt. Im Rahmen der vorliegenden Arbeit konnte jedoch auf die Stimulierte Emissions Depletions (STED)-Mikroskopie zurückgegriffen werden. Es handelt sich hierbei um eine von Stefan Hell entwickelte Methode, welche das Auflösungsvermögen konventioneller Fluoreszenzmikroskopie stark erhöht (Klar et al., 2000). So erreicht das im Rahmen dieser Arbeit eingesetzte Leica Gerät eine Auflösung von 70-90 nm, wodurch sich selbst auf Endosomen Membrandomänen voneinander unterscheiden lassen. Die theoretische Grundlage für die STED-Mikroskopie besteht

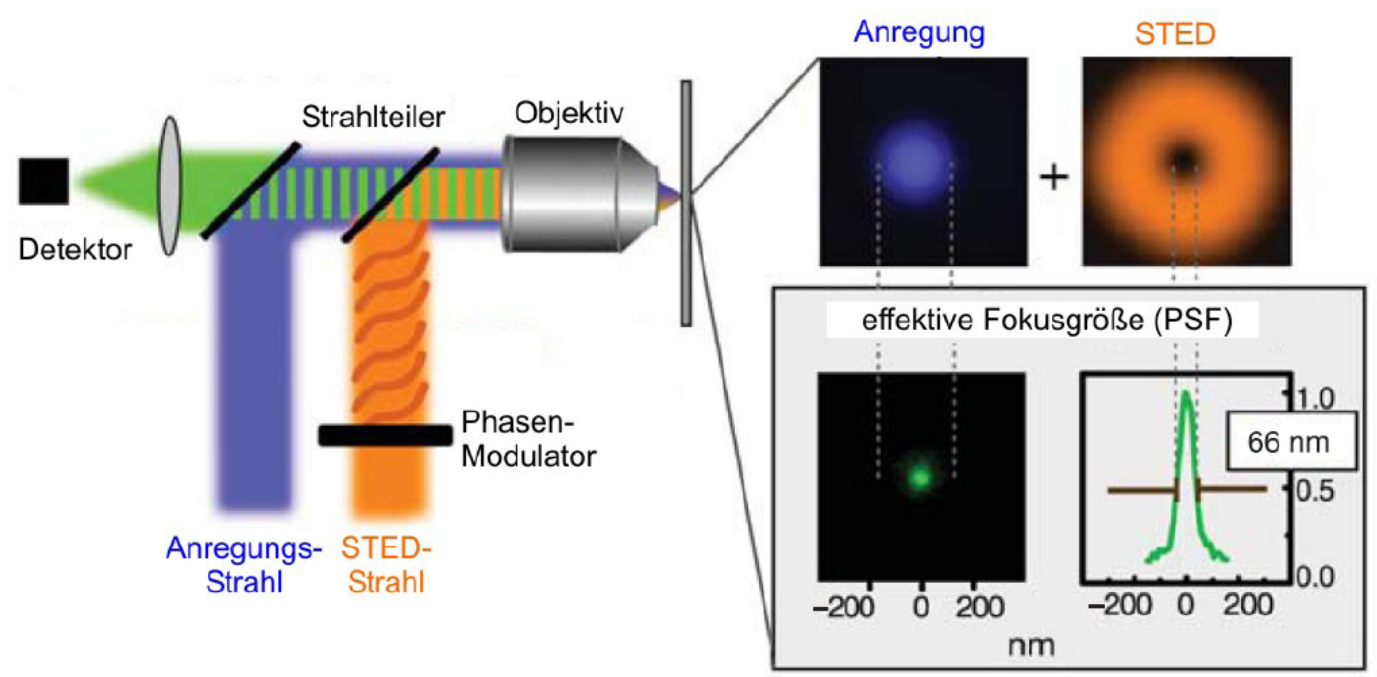

\section{Abbildung 1.6: Grundlage der STED-Mikroskopie}

Das STED-Mikroskop ist gegenüber einem normalen konfokalen Mikroskop um einen zweiten Laser erweitert, dessen Intensitätsverteilung durch Phasenmodulation eine toroidförmige Struktur bekommt. Dieser STED-Strahl zwingt die vom ersten Laser angeregten Elektronen wieder in den Grundzustand (stimulierte Emission), so dass nur von der Mitte des Toroid ein Signal detektiert wird. Es resultiert eine deutlich verbesserte Auflösung von ungefähr $70 \mathrm{~nm}$ (modifiziert nach (Willig et al., 2006)).

darin, dass der Bereich um das Anregungszentrum von einem zweiten Laser gelöscht wird, dessen Intensitätsverteilung aufgrund einer Phasenmodulation eine toroidale Struktur aufweist, d.h. im Anregungszentrum selbst null ist, wie Abbildung 1.6 
zeigt. Das Quenching wird dadurch erreicht, dass der zweite Laser eine Wellenlänge besitzt, die dem Energiegehalt der durch den ersten Laser angeregten Elektronen entspricht. Werden die bereits angeregten Elektronen von Licht dieser Wellenlänge getroffen, werden sie zur Abgabe eines Photons angeregt (stimulierte Depletion) und kehren dadurch in den Grundzustand zurück. Dabei wird durch eine spezielle Modulation des löschenden Lasers eine erneute Anregung verhindert (Klar et al., 2000). 


\subsection{Zielstellung}

Im Rahmen dieser Arbeit sollte untersucht werden, über welche Mechanismen die frühendosomalen SNAREs reguliert werden und ob ihnen neben ihrer Funktion in der Fusion von Endosomen auch eine Rolle bei deren Docking zukommt. Für letztere Fragestellung war es erforderlich, dass bereits etablierte Endosomen-Fusionsassay zu einem vollständigen Endosomen-Interaktionsassay zu erweitern. Hierzu musste ein Weg gefunden werden, die genauen Abstände zwischen den Endosomen zu ermitteln und unter anderem sichergestellt werden, dass es sich bei einem engen Kontakt zwischen Endosomen um echtes Docking, d.h. einen regulierten Prozess, und nicht um unspezifisches Verklumpen handelte.

Der Einfluss von SNARE-Regulatoren auf die Fusion sollte in einem minimalen, leicht manipulierbaren System analysiert werden. Statt der Fusion zweier Endosomen miteinander war also die Fusion von Endosomen mit künstlichen Vesikeln (Liposomen), welche zunächst nur die SNARE-Proteine enthielten, zu analysieren, wobei auch zytosolische Faktoren in die Untersuchung eingeschlossen werden sollten.

Als ein wichtiges Element der SNARE-Regulation hat sich auch ihr Clustering, d.h. die Bildung von spezialisierten Membrandomänen herausgestellt (siehe oben). Es sollte daher untersucht werden von welchen Faktoren die SNARE-Clusterbildung auf Endosomen abhängt. Vorangegangene Untersuchungen an der Plasmamembran legten nahe, mit Veränderungen der Lipidzusammensetzung, insbesondere des Cholesterinanteils, zu beginnen. Die Analyse der Nanodomänen sollte durch Einsatz superhochauflösender STED-Mikroskopie ermöglicht werden und auch den Einfluss der membranorganisierenden Rab-Proteine umfassen. Weitere Aufschlüsse waren auch von einem Vergleich der SNARE-Cluster auf der nativen endosomalen Membran und künstlichen ansonsten proteinfreien Membranen zu erwarten. 
1 Einleitung 


\section{Material und Methoden}

\subsection{Chemikalien}

Acrylamid/Bisacrylamid Lösung

Roth (Karlsruhe)

Agarose

AppliChem (Darmstadt)

Alexa-gekoppeltes Dextran

Invitrogen (Karlsruhe)

Ammoniumpersulfat (APS)

Sigma (Deisenhofen)

Aminodextran

Sigma

Bradford-Reagenz

Biorad (Richmond)

Coomassie Brilliant Blue R-250

Serva (Heidelberg)

Cholat $3 \alpha 7 \alpha 12 \alpha$ Trihydroxy5 $\beta$-cholan-24oic-säure Natriumsalz Sigma

Dithiothreitol (DTT)

Roth

EDTA Titriplex III

Merck (Darmstadt)

Glysin

Sigma

Harnstoff

Merck

HEPES

Gerbu (Gaiberg)

Imidazol

Sigma

Isopropyl- $\beta$-D-thiogalactosid (IPTG)

Roth

Kaliumchlorid

Merck

Natriumchlorid

Merck

N,N,N',N'- Tetramethylethylendiamin (TEMED)

Biorad

Nycodenz

Nycomed Pharma (Oslo)

n-Octyl- $\beta$-D-glucopyranosid

Glycon (Luckenwalde)

Octadecylrhodamin

Invitrogen

Paraformaldehyd

Sigma-Aldrich (St. Louis)

PMSF

Roth

Saccharose

Merck

Tris (hydroxymethyl)-aminomethan (Tris)

Merck 
Lipide Avanti Polar lipids (Alabaster):

Cholesterol (Gehirn)

L- $\alpha$-Phosphatidylcholin (Gehirn)

Phosphatidylethanolamin (Gehirn)

Phosphatidylserin Natriumsalz (Gehirn)

Phosphatidylinositol Natriumsalz (Rinderleber)

Oregon Green@ 488 DHPE Oregon Green@ 488 1,2-dihexadecanoyl-glycero-3-phosphoethanolamin

Rhodamine DHPE Lissamine ${ }^{T M}$ rhodamin B 1,2-dihexadecanoyl-glycero-3-phosphoethanolamine, triethylammoniumsalz

NBD-PE N-(7-nitrobenz-2-oxa-1,3-diazol-4-yl)-1,2-dihexadecanoyl-glycero-3-phosphoethanolamine, triethylammoniumsalz

Lipid Mix Phosphatidylcholin (PC), Phosphatidylethanolamin (PE), Phosphatidylserin (PS), Phosphatidylinositol (PI) und Cholesterol (Chol) in einem molaren Verhältnis von 5:2:1:1:1 und einer Gesamtkonzentration von $13,5 \mathrm{mM}$

\section{Enzyme:}

CIAP Fermentas

DNase AppliChem

NdeI New England Biolabs

Ligase Fermentas

Lysozym AppliChem

Thrombin Merck

Trypsin Sigma

Bakterienstämme (Stratagene, La Jolla):

Escherichia coli BL21 (DE3) und DH5 $\alpha$

Filtersätze (AHF Analysentechnik, Zeiss):

Alexa 488 (grün) Anregung: 565/30X - HQ Strahlenteiler: 595 DCLP - Q Emission: $645 / 75 \mathrm{M}-\mathrm{HQ}$

Alexa 594 (rot) Anregung: 480/40X - HQ Strahlenteiler: 505 DCLP - Q Emission: $527 / 30 \mathrm{M}-\mathrm{HQ}$ 
blauer Kanal Anregung: 360/50X - D Strahlenteiler: 400 DCLP Emission: 460/50M $-\mathrm{D}$

\section{Sonstige}

$\begin{array}{ll}\text { ÄKTA -System } & \text { Amersham Pharmacia Biotech (Uppsala) } \\ \text { Biofuge fresco } & \text { Heraeus (Waltham, USA) } \\ \text { BioBeads } & \text { Biorad (Hercules, USA) } \\ \text { FluoroMax-2 } & \text { Jobin Yvon-Spex (Edison, USA) } \\ \text { LAS } & \text { Fujifilm (Tokyo, Japan) } \\ \text { Matlab } & \text { The Mathworks Company (Natick, USA) } \\ \text { MetaMorph } & \text { Molecular Devices (Sunnyvale, USA) } \\ \text { SigmaPlot } & \text { Systat Software (San Jose, USA) } \\ \text { TL100-Ultrazentrifuge } & \text { Beckman (Fullerton, USA) }\end{array}$

\subsection{Puffer}

PC12-Zellkultur-Medium: DMEM („Dulbecco's modified eagle medium“) mit 4,5 $\mathrm{g} / \mathrm{l}$ Glukose (Cambrex, Verviers, Belgien) mit zugesetzten 10\% (v/v) Pferdeserum (Biochrom, Berlin), 5\% (v/v) fötalem Kälberserum (PAA Laboratories, Clöbe), 4 $\mathrm{mM}$ L-Glutamin (Cambrex) und $60 \mathrm{U} / \mathrm{ml}$ Penicillin und $60 \mu \mathrm{g} / \mathrm{ml}$ Streptomycin (Cambrex).

Internalisierungsmedium: OptiMEM (Invitrogen) mit 10 mM Glukose

PFA-Lösung: $10 \%(\mathrm{w} / \mathrm{v})$ Paraformaldehyd (PFA) wurde unter Erhitzen in PBS gelöst, nach dem Abkühlen auf Raumtemperatur auf $\mathrm{pH}$ 7,4 eingestellt und bei $-20^{\circ}$ C gelagert. Vor dem Gebrauch wurde die Lösung mit PBS auf 4\% (w/v) verdünnt.

PBS: $150 \mathrm{mM} \mathrm{NaCl}, 20 \mathrm{mM} \mathrm{Na} 2 \mathrm{HPO}_{4}$, pH 7,4

Western Blot-Transferpuffer: $200 \mathrm{mM}$ Glycin, $25 \mathrm{mM}$ Tris, 0,04\% SDS, 20\% Methanol

Kathodenpuffer: $100 \mathrm{mM}$ Tris, $100 \mathrm{mM}$ Tricin, 0,1\% SDS

Anodenpuffer: $2 \mathrm{M}$ Tris $\mathrm{pH} 8,9$

Gelpuffer: 3 M Tris, 0,3\% SDS, pH 8,45

Resuspendierungspuffer-His: $50 \mathrm{mM}$ Tris, $500 \mathrm{mM} \mathrm{NaCl}, 10 \mathrm{~m} \mathrm{M}$ Imidazol

Resuspendierungspuffer-GST: $50 \mathrm{mM}$ Tris, $150 \mathrm{mM} \mathrm{NaCl}, 1 \mathrm{mM}$ DTT, $1 \mathrm{mM}$ EDTA

Waschpuffer-His: $150 \mathrm{mM} \mathrm{NaCl,} 10$ mM Imindazol, 20 mM Tris, pH 7,4

Waschpuffer-GST: 150 mM NaCl, 1 mM EDTA, 1 mM DTT, 20 mM Tris, pH 7,4 
Elutionspuffer: $500 \mathrm{mM} \mathrm{NaCl}, 400 \mathrm{mM}$ Imidazol, $1 \mathrm{mM}$ EDTA, 1 mM DTT, $20 \mathrm{mM}$ Tris, $\mathrm{pH} 7,4$

Äkta Puffer A: 1 mM DTT, 1 mM EDTA, 20 mM Tris, pH 7,4

Äkta Puffer B: 1 M NaCl, 1 mM DTT, 1 mM EDTA, 20 mM Tris, pH 7,4

\subsection{Antikörper}

Die monoklonalen Antikörper anti-Synaptobrevin Cl 69.1 (Edelmann et al., 1995) und anti-Synaptophysin Cl 7.2 (Jahn et al., 1985), sowie die polyklonalen Antikörper G96 anti-Synaptophysin (Jahn et al., 1985), anti-Syntaxin 6 (Brandhorst et al., 2006) und anti-VAMP4 (Steegmaier et al., 1999) wurden bereits beschrieben. Das anti-EEA1 Serum für die funktionalen Studien wurde durch die Injektion des Peptids CLRRILQRTPGRV in Kaninchen hergestellt (Takamori et al., 2006). Für die Western Blots wurden monoklonale Antikörper gegen Rab5 (Cl 621.1) (Fischer von Mollard et al., 1994) und EEA1 (BD Biosciences) eingesetzt. $\mathrm{F}_{a b}$-fragmente gegen Syntaxin 6, Syntaxin 13, Vtila and VAMP4 waren ein Geschenk von Dr. D. Zwilling. Die monoklonalen Antikörper gegen Caveolin und Rab4 wurden von Abcam gekauft. Die fluoreszenzmarkierten sekundären Antikörper stammten von Jackson Immunoresearch Europe.

\subsection{Klonierung}

Ein HA-tag wurde N-terminal an VAMP4 angefügt. Hierzu wurde eine DNA-Synthese in Auftrag gegeben, welche neben der für HA-kodierenden Sequenz auch N-, sowie C-terminal eine NdeI-Schnittstelle umfasste (5'-T ATG TAC CCA TAC GAT GTT CCA GAT TAC GCT CA-3'). Der VAMP4-haltige pet28-Vektor wurde mit NdeI, geschnitten, dephosphoryliert und über DNA-Gelelektrophorese aufgereinigt. Der geschnittene Vektor wurden dann mit der ebenfalls NdeI-geschnittenen DNA und Ligase für $1 \mathrm{~h}$ bei $37^{\circ} \mathrm{C}$ inkubiert und $400 \mu \mathrm{g}$ der ligierten DNA in DH5 $\alpha$-Zellen transformiert und zum Wachsen auf Kanamycinplatten gebracht. Die gewachsenen Kolonien, wurden zum Inokulieren von kanamycinhaltigen Flüssigkulturen verwendet aus denen DNA isoliert und sequenziert wurde, was den erfolgreichen Einbau bestätigte. 


\subsection{Proteinmethoden}

\subsubsection{SDS-PAGE}

SDS-PAGE wurde durchgeführt wie zuvor von Schägger und von Jagow beschrieben (Schägger \& von Jagow, 1987). Der Probenpuffer enthielt $50 \mathrm{mM}$ Tris/HCl, 4\% (w/v) SDS, 0,01\% Serva Blue G, 12\% (w/v) Glycerol, $2 \%$ (v/v) und $\beta$ - Mercaptoethanol $(\mathrm{pH} 6,8)$.

\subsubsection{Coomassie Färbung}

Das Sammelgel wurde entfernt und das Trenngel für $1 \mathrm{~h}$ in $50 \%$ (v/v) Methanol, $10 \%$ (v/v) Essigsäure und 0,2\% (w/v) Coomassie Brilliant Blue R-250 unter Schütteln gefärbt. Anschließend wurde das Gel zunächst für 20 Minuten in 50\% (v/v) Ethanol and $10 \%(\mathrm{v} / \mathrm{v})$ Essigsäure und anschließend in $10 \%(\mathrm{v} / \mathrm{v})$ Ethanol and $5 \%(\mathrm{v} / \mathrm{v})$ Essigsäure entfärbt bis der Hintergrund verschwand. Das Gel wurde dann mit einem Geltrockner in Zellophan eingeschweißt.

\subsubsection{Westernblot}

Die Proteine wurden aus dem Gel mittels einer Semi-dry Blotapparatur bei 45 mA für 60 Minuten auf eine Nitrozellulosemembran transferiert (Towbin et al., 1989), welche zuvor mit Blot-Puffer äquilibriert wurde. Die Membran wurde mit $5 \%$-Trockenmilch in PBS für mindestens $1 \mathrm{~h}$ blockiert, bevor der primäre Antikörper 1:500-1:1000 (ebenfalls in PBS-Milch) für 1-2 h bei Raumtemperatur zugegeben wurde. Nach dreimaligem Waschen mit PBS-Milch wurde der sekundäre HRPgekoppelte Antikörper 1:2000 für 1h zugegeben und anschließend dreimal mit PBS gewaschen bevor der Blot mit verstärkter Chemilumineszenz (Pierce) entwickelt und auf einem LAS1000-System (Fujifilm) aufgenommen wurde.

\subsubsection{Proteinreinigung}

pGEX (GST-tag) oder pET28a (6xHis-tag) Plasmide der gewünschten Proteine wurden in Bl21-Zellen transformiert, die Hauptkultur wurde 1:80 mit einer Übernachtkultur angeimpft und bis zu einer $\mathrm{OD}_{600}$ von 0,6-0,8 wachsen gelassen, bis mit 0,5 mM IPTG für Transmembranproteine bzw. 0,25 mM IPTG für lösliche Proteine induziert wurde. Nach 3-4 Stunden wurde die Kultur abzentrifugiert, in Resuspendierungspuffer aufgenommen und eingefroren. Der Aufschluß erfolgte nachdem Zusetzen 
von PMSF (1 mM Endkonzentration) durch Zugabe von Lysozym für 20 min bei Raumtemperatur und anschließende Behandlung mit 5 x 45 s Ultraschall (Stab). Für Transmembranproteine wurde cholathaltiger Resuspendierungspuffer $(10 \%)$ bis zu einer Endkonzentration von 5\% Cholat zugegeben, der Wasch-, Elutions- , Dialyse-

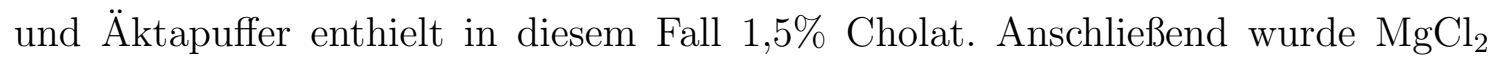
(1 mM Endkonzentration) und eine Spatelspitze DNase zugegeben. Für zur Präzipitation neigende Proteine wurde noch Harnstoff bis zu einer Konzentration von maximal $6 \mathrm{M}$ zuführt. Anschließend wurde $2 \mathrm{~h}$ bei $4^{\circ} \mathrm{C}$ solubilisiert. Der unlösliche Teil wurde abzentrifugiert (30 min $14.000 \mathrm{U} / \mathrm{min}, \mathrm{SS} 34$ ), der Überstand mit 0,5 ml Nickel bzw. GST-Sepharose-Beads pro Liter Kultur versetzt und $2 \mathrm{~h}$ bei $4^{\circ} \mathrm{C}$ rotiert. Anschließend wurden die Beads auf eine Säule gegeben und mit mindestestens 30 Säulenvolumen gewaschen bevor entweder über nacht auf der Säule mit thrombinhaltigem Puffer geschnitten (GST-tag) oder mit $25 \mathrm{ml}$ eluiert wurde. Das Eluat wurde mit $100 \mathrm{U}$ Thrombin versetzt, in eine Spectra Por Membran gegeben und in 2 Schritten für insgesamt 16 h gegen 1 l (50 mM NaCl, 1 mM EDTA, 1 mM DTT) dialysiert. Die Aufreinigung wurde mit einer MonoQ bzw. MonoS Ionenaustauschersäule an einem Äkta FPLC System fortgesetzt. Die Säule wurde zunächst mit salzfreiem Puffer A äquilibriert, das Protein geladen und dann ungebundene Probe mit Puffer A entfernt. Die Elution erfolgte über einen Gradienten mit Puffer B (1 M NaCl, $20 \mathrm{mM}$ Tris, $1 \mathrm{mM}$ DTT, $1 \mathrm{mM}$ EDTA). Die proteinenthaltende Fraktionen wurden mit SDS-PAGE analysiert und die reinen Fraktionen aufkonzentriert, aliquotiert und in Stickstoff eingefroren. Die Expression und Aufreinigung von His-tag Rab-GDI erfolgte wie zuvor beschrieben (Peter et al., 1995).

\subsubsection{Proteinbestimmung}

Die Proteinkonzentration der Endosomen wurde mittels eines Bradfordassay be-

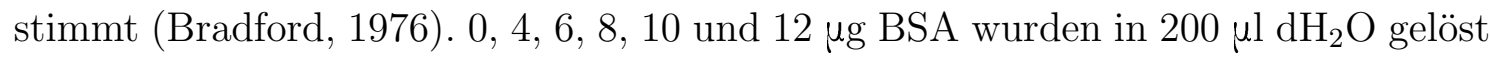
und mit $800 \mu \mathrm{l}$ Bradfordreagenz gemischt. Die nach 5 minütiger Inkubation bestimmten Absorptionen bei $595 \mathrm{~nm}$ dienten zur Erstellung einer Standardkurve aus der sich die gemessenen Werte dann bestimmen ließen. Die Konzentration rekombinant hergestellter Proteine wurde in der Regel über ihren Extinktionskoeffizienten durch die Absorption bei $280 \mathrm{~nm}$ bestimmt. 


\subsection{Liposomen}

\subsubsection{Liposomenherstellung}

Es wurden insgesamt drei unterschiedliche Methoden zur Liposomenherstellung angewandt, um deren Einfluß auf die Fusionseigenschaften zu untersuchen.

\subsubsection{Gelfiltration mit EconoSäulen (Methode 1)}

Eine BioRad Econo Säule (Durchmesser 0,7 cm, Länge $15 \mathrm{~cm}$ ) wurde mit Sephadex G50 superfine gepackt, welches zuvor in HB100, 500 oder 1000 gequollen und entgast wurde. $50 \mu$ l Lipidmix wurden so mit Proteinen gemischt, dass ein Verhältnis von SNARE bzw. SNARE-Akzeptorkomplex zu Lipid von 1:100 entstand, wobei 100 pl als Endvolumen nicht überschritten wurde. Diese Mischung wurde auf die Säule gegeben, um das Cholat zu entfernen und ab dem Erscheinen von Proteinen (Bradford) oder fluoreszierenden Lipiden wurden $400 \mu$ l aufgefangen, die anschließend bei $13.000 \mathrm{U} / \mathrm{min}$ zentrifugiert wurden, um verklumpte Liposomen zu entfernen.

\subsubsection{Dialyse (Methode 2)}

12 millimolarer Lipidmix in 5\% Octylglucosid wurde 1:200 mit Proteinen (1\% Octylglucosid) versetzt und mit HB500 5\% Octylglucosid auf ein Volumen von $300 \mu \mathrm{l}$ aufgefüllt, so dass die finale Lipidkonzentration bei $4 \mathrm{mM}$ lag bzw. für die im Abschnitt 3.3 beschriebenen Experimente bei $160 \mu \mathrm{M}$, da hier weniger Material benötigt wurde. Diese Lösung wurde gegen methanolgewaschene BioBeads in 11 HB500 über Nacht bei Raumtemperatur dialysiert.

\subsubsection{Umkehrphasen Evaporation (Methode 3)}

$4 \mu \mathrm{Mol}$ Lipidmix wurden unter Stickstoff getrocknet und in 1,5 ml Äther plus 0,5 ml HB500 aufgenommen. Die Lösung wurde auf Eis dreimal für eine Minute mit Ultraschall behandelt. Anschließend wurde der Äther über $3 \mathrm{~h}$ langsam im Rotationsverdampfer abgezogen, ohne einen Druck von 200 mbar zu unterschreiten. Die wässrige Liposomenlösung wurde dann zunächst durch einen $400 \mathrm{~nm}$ Filter und anschließend durch einen $100 \mathrm{~nm}$ Filter gepresst. Zur Herstellung von Proteoliposomen wurde in Octylglucosid befindliches Protein im Protein zu Lipid-Verhältnis von 1:200 bzw. 1:500 hinzugegeben und mit Puffer auf ein Detergens zu Proteinverhältnis von 3 zu 1 über der kritischen mizellaren Konzentration (CMC) eingestellt. Diese Lösung wurde gegen methanolgewaschene BioBeads in 11 HB500 über Nacht 
bei Raumtemperatur dialysiert. Um besonders große Liposomen herzustellen, wurde auf die 100 nm Filterung verzichtet und ein Detergens zu Proteinverhältnis von 3,5 zu 1 gewählt (siehe Abschnitt 3.3.2).

\subsubsection{Dequenchingassay}

Das Dequenchingassay zur Liposomenfusion wurde eingesetzt wie von Struck beschrieben (Struck et al., 1981). Liposomen wurden mit einer der oben beschriebenen Methoden hergestellt, so dass sie 1,5\% NBD- und 1,5\% Rhodomanin-PE enthielten. Aus der hohen Flurophorkonzentration resultiert ein enger Kontakt, welcher eine Energieübertragung von NBD zu Rhodamin durch Förster Resonanz-EnergieTransfer (FRET) ermöglicht, was zum Quenching der NBD-Fluroreszenz führt. Fusion und Lipidvermischung mit unmarkierten Liposomen oder Endosomen vergrößert den Abstand der Flurophore und führt dadurch zu geringerem FRET und höherem Donorsignal. Die Mischung der NBD/Rhodamin-haltigen Liposomen mit unmarkierten Liposomen oder Endosomen wurde so gewählt, dass sich ein gutes Signal zu Rausch Verhältnis ergab und die Fusionsreaktion bei $37^{\circ} \mathrm{C}$ verfolgt. Das NBD Signal wurde hierzu (bei einer Anregungswellenlänge von $460 \mathrm{~nm}$ ) bei 538 $\mathrm{nm}$ detektiert. Die Fluoreszenz in Prozent des maximalen Signals errechnet sich aus

$\frac{F_{\text {Reaktionsende }}-F_{\text {Reaktionsbeginn }}}{F_{\text {max.Verduennung }}-F_{\text {Rekationsbeginn }}} \bullet 100$, wobei $F_{\text {max Verduennung }}$ durch Zugabe von $0,2 \mathrm{mg} / \mathrm{ml}$ Triton X-100 erhalten wird, da die vollständige Solubilisierung zum maximal möglichen Flurophorabstand führt.

\subsubsection{Liposomenflotierung}

Liposomen wurden 1:1 mit 80\% Nycodenz in dem entsprechenden Puffer gemischt, mit 35\% Nycodenz und Puffer überschichtet und für $4 \mathrm{~h}$ bei $165.000 \mathrm{x} g$ in einem TLS 55 Rotor zentrifugiert. Die Liposomen konnten anschließend aus der wässrigen Phase (obere Schicht) des Gradienten gesammelt werden.

\subsubsection{Bestimmung der Proteinorientierung auf Liposomen}

Zur Bestimmung der Proteinorientierung wurden Proteoliposomen für $1 \mathrm{~h}$ bei $37^{\circ} \mathrm{C}$ mit $0,1 \mathrm{mg} / \mathrm{ml}$ Trypsin behandelt. Da Trypsin nicht membrangängig ist, sind falsch, d.h. mit ihrem N-terminus nach innen orientierte SNAREs vor dem Abbau geschützt und werden erst bei Zugabe von Triton X-100, welches die Membran auflöst, ebenfalls verdaut. Die Analyse erfolgte mittels Westernblot. 


\subsection{Endosomen}

\subsubsection{Zellkultur, Zytosolgewinnung und Endosomenmarkierung}

Rattenhirnzytosol wurde aus der Fraktion S2 durch halbstündige Zentrifugation bei 300.000 x $g$ gewonnen (Huttner et al., 1983). Die Endosomenmarkierung erfolgte wie bereits beschrieben (Brandhorst et al., 2006; Geumann et al., 2008). PC12 Zellen [Klon 251 (Heumann et al., 1983)] wurden in 15-cm Kulturschalen mit Zellkulturmedium (DMEM mit 5\% FCS, 10\% Pferdeserum, 4 mM Glutamin und je 100 units $/ \mathrm{ml}$ Penicillin und Streptomycin) bei $37^{\circ} \mathrm{C}$ in $10 \% \mathrm{CO}_{2}$ bis zur Konfluenz wachsen gelassen. Das Ernten erfolgte durch Waschen mit PBS und anschließende Inkubation mit Trypsin/EDTA (2 ml pro Platte; Lonza). Die Reaktion wurde mit Zellkulturmedium gestoppt und die Zellen mit Internalisierungsmedium (OptiMEM mit $10 \mathrm{mM}$ Glukose) gewaschen. Anschließend wurde das Zellpellet auf $37^{\circ} \mathrm{C}$ vorgewärmt und danach für 5 Minuten unter sanftem Schütteln mit dem in Internalsierungsmedium gelösten Marker inkubiert (Alexa488 bzw. Alexa594 gekoppeltes 10kDa Dextran; Invitrogen). Die Aufnahme wurden durch Verdünnung mit $10 \mathrm{ml}$ eiskaltem PBS (0,5\% BSA) gestoppt und die Zellen dreimal mit dieser Lösung gewaschen.

\subsubsection{Endosomenisolierung}

Frühe Endosomen wurden aus PC12 Zellen isoliert wie zuvor beschrieben (Brandhorst et al., 2006; Bethani et al., 2007). Nach fünfminütiger Inkubation bei $37^{\circ} \mathrm{C}$ in OptiMEM wurde die Reaktion auf Eis gestoppt. Die Zellen wurden mit PBS und Homogenisierungspuffer (3 mM Imidazol, $250 \mathrm{mM}$ Saccharose) gewaschen und anschließend mit einem Kugel-Homogenisator aufgeschlossen. Der entstandene postnukleäre Überstand (PNS) wurde für 15 min bei 1200 x $g$ zentrifugiert. Der Überstand wurde mit $62 \%$ iger Saccharoselösung in einem Ultrazentrifugenröhrchen gemischt (1:1, $3 \mathrm{ml}$ total) und mit $3 \mathrm{ml}$ 35\%iger sowie $3 \mathrm{ml}$ 25\%iger Saccharoselösung und $2 \mathrm{ml}$ Homogenisierungspuffer überschichtet. Die Gradienten wurden 90 Minuten bei 35.000 $\mathrm{U} / \mathrm{min}$ in einem SW41 Rotor zentrifugiert. Danach konnten die Endosomen als Interphase zwischen der 35\%igen und der 25\%igen Saccharose isoliert, aliquotiert und in flüssigem Stickstoff eingefroren werden.

\subsubsection{Analyse der Kolokalisation von Endosomen und Liposomen}

Octadecylrhodamin-markierte Endosomen wurden mit 5\% OregonGreen-PE haltigen Liposomen für die angegebenen Zeiträume inkubiert, mit flüssiger, niedrigschmelzender Agaroselösung gemischt und auf einen eiskalten Objektträger gebracht, 
um die Agarose fest werden zu lassen. Die Proben wurden anschließend fluoreszenzmikroskopisch erfasst und in ein Mathlab Programm eingelesen. Es erfolgte eine schrittweise Anhebung der Intensitätsschwelle, um den Hintergrund zu entfernen, die für alle Vergleichsproben gleich war. Im Fokus liegende Endosomen wurden anschließend manuell für line scans ausgewählt, d.h. über eine Breite von 25 Pixeln wurde die Fluoreszenzintensität sowohl im roten (endosomalen) als auch im grünen (liposomalen) Kanal bestimmt, woraus der Korrelationskoeffizient $\mathrm{r}$ berechnet wurde. Lag der Wert von $\mathrm{r}$ zwischen 0,8 und 1 wurden Liposom und Endosom, in Übereinstimmung mit Experimenten an fluoreszierenden Beads (Silvio Rizzoli, persönliche Mitteilung), als kolokalisierend gewertet. Die mit gespiegelten grünen Bildern ermittelte zufällige Kolokalisation war vernachlässigbar.

\subsubsection{Aggregationsassay für Endosomen}

Die Aggregation von Endosomen wurde von Silvio Rizzoli untersucht wie zuvor beschrieben (Geumann et al., 2008). Endosomen aus Baby Hamster Kidney-Zellen wurden verwendet, da diese größer sind als die Endosomen von PC12 Zellen, was die Auswertung erleichterte. Ihre Isolierung erfolgte wie bereits beschrieben ana$\log$ zur Isolierung von PC12-Endosomen (Abschnitt 2.7.2). Anschließend wurden sie entsprechend dem Endosomen-Interaktionsassay inkubiert, wobei ihre Konzentration bei 0,1-0,2 $\mathrm{mg} / \mathrm{ml}$ lag. Nach 45 minütiger Reaktion wurden die Proben auf Deckgläschen zentrifugiert, in eine Haltevorrichtung transferiert und dort unter dem Mikroskop mit dem Styryl Farbstoff FM 2-10 (20 $\mu \mathrm{M}$, Invitrogen) inkubiert. Die Bilder (aufgenommen mittels einer CCD Kamera; 1317 × 1035 Kodakchip) wurden analysiert indem die gesamte Fluoreszenz jedes Bildes zu einem frei gewählten Wert (identisch für alle Bilder in allen Experimenten) normalisiert wurde. Anschließend wurden die Bilder in 13 Streifen mit einer Breite von je 100 Pixeln geteilt und die Standardabweichung für jeden der Streifen bestimmt. Die durchschnittliche Standardabweichung wurde bestimmt und als Indikator für Aggregation im Bild verwendet. Für Bilder, die nur einzelne Endosomen enthielten, war das Fluoreszenzsignal relativ gleichmäßig verteilt und die Standardabweichung entsprechend niedrig, während Aggregate zu konzentrierten, hellen Punkten führten und die Standardabweichung entsprechend hoch war. 


\subsubsection{Endosomen-Interaktionsassay}

\subsubsection{Durchführung}

Dem Endosomen-Interaktionsassay liegen die fluoreszenzmarkierten Endosomen zugrunde. Das Reaktionsvolumen $(50 \mu \mathrm{l})$ enthielt als Endkonzentration $4 \mathrm{mg} / \mathrm{ml}$ PNS, $2 \mathrm{mg} / \mathrm{ml}$ Zytosol, 11,25 mM Hepes (pH 7,0), 1,35 mM Magnesiumacetat, 0,18 mM DTT, 45 mM Kaliumazetat, als ein ATP-regenerierendes System, 3,2 mM ATP, 26 mM Kreatinphosphat und 0,132 mg Kreatinkinase (800 units/mg; Roche, Basel) oder, als ein ATP-depletierendes System, 5 pl Hexokinase (1,500 units/ml gelöst in 250 mM Glukose; Roche). Die Reaktionszeit betrug 45 bis 60 Minuten, danach wurden die Ansätze auf Deckgläschen (18-mm Durchmesser; Marienfeld GmbH, LaudaKönigshofen) gegeben, die sich mit $1 \mathrm{ml}$ PBS in 12-Well Platten befanden, und mit $5900 \times \mathrm{x}$ in einer Heraeus Multifuge 4 für 45 min zentrifugiert. Die Deckgläschen wurden mit einem Zeiss Axiovert 200M Fluoreszenzmikroskop unter Verwendung eines 100x Objektivs (NA 1,4) und den passenden Filtern (Bethani et al., 2007) analysiert.

\subsubsection{Datenanalyse}

Die mikroskopischen Aufnahmen wurden erstellt wie bereits beschrieben (Rizzoli et al., 2006; Geumann et al., 2008). Die im roten bzw. grünen Kanal aufgenommenen Bilder wurden mittels eines selbstgeschriebenen (Silvio Rizzoli) Matlabprogramms (The Mathworks, Inc) analysiert. Hierbei wurden die Bilder zunächst durch einen Hochpass-Filter geschickt, um Rauschen zu entfernen bevor eine Schwelle von 4-6 Fluoreszenzintensitätseinheiten über dem Hintergrund angelegt wurde, um das Signal klar von diesem abtrennen zu können. Alle Objekte die über der Schwelle lagen und größer als ein Pixel waren wurden für die weitere Analyse verwendet. Ihre Intensitätszentren (Mittelpunkte) wurden bestimmt, indem die PSF (point spread function) mit einer Normalverteilung angenähert wurde und um die Verschiebung zwischen rotem und grünen Kanal durch die Verwendung von mehrfarbfluoreszenten TetraSpeck ${ }^{T M}$-Beads (die durch im blauen Kanal aufgenommene Bilder zu identifizieren waren) korrigiert. Anschließend wurden alle Distanzen zwischen den grünen Intensitätszentren und den roten Intensitätszentren bestimmt. Die Distanz jedes grünen Endosoms zum nächstliegenden roten wurde für die weitere Analyse verwendet. Endosomen deren Intensitätszentren innerhalb einer Distanz von 112,5 nm lagen wurden als fusioniert gewertet, während die Distanz von 112,5 bis 137,5 nm nicht weiter betrachtet wurde, da sie nicht eindeutig dem Fusions- oder Docking-Pool zugerechnet werden konnte. Abschließend wurden Endosomen, deren Intensitätszentren in einer Entfernung von 137,5 bis 512,5 nm voneinander lagen, als gedockt gewertet. 
Der für das Docking ermittelte Wert wurde noch um die Endosomendichte auf dem Deckgläschen korrigiert, indem eine Grundlinie (basierend auf dem durchschnittlichen Wert für die Distanzen zwischen 512,5 und 1012,5 nm) subtrahiert wurde.

\subsubsection{Proteinbindung an die endosomale Membran}

Dem Interaktionsassay entsprechende Reaktionsansätze wurden mit den angegebenen Substanzen inkubiert. Anschließend wurde die Membranfraktion durch eine 20 minütige Ultrazentrifugation bei 135.000 x $g$ pelletiert. Für die GDI-behandelten Proben sollten die Bedingungen direkt am Reaktionsstart, d.h. nach 30minütiger Vorinkubation auf Eis, bestimmt werden, daher wurde die Zentrifugationszeit auf 10 Minuten bei 500.000 x $g$ reduziert. Die Pellets wurden in Ladepuffer resuspendiert und mittels Western Blot analysiert. Das Signal wurde densimetrisch bestimmt wie bereits beschrieben (Bethani et al., 2007) und auf das Synaptobrevinsignal normalisiert. Die Kontrollen wurden entweder 60 min im Fall von GTP $\gamma \mathrm{S}$ und Wortmannin oder 10 min im Fall von GDI inkubiert.

\subsubsection{Immunfärbung}

Für die STED Analyse wurden die Proben zunächst auf Objekträger zentrifugiert, für 25 Minuten mit PFA fixiert und nach 15minütiger Blockierung (3\% BSA in PBS) mit den angegebenen primären Antikörpern in einer Verdünnung von 1:80 für eine Stunde inkubiert. Nach dreimaligem Waschen mit PBS-BSA wurden die Proben mit dem sekundären Atto647N-gekoppelten Antikörper $\left(\mathrm{F}_{\mathrm{ab}}\right)$ für zwei Stunden inkubiert (1:80), dreimal mit BSA gewaschen und mit einer Mischung aus PFA (4\%) und Glutaraldehyd (2\%) fixiert. Das PFA Signal wurde mit 0,1 M Ammoniumchlorid in PBS gelöscht. Die Proben wurden erneut mit PBS gewaschen und anschließend in Mowiol eingebettet.

Die Kolokalisation von Endosomen mit Rab5, Rab4 und Caveolin wurde mit konventioneller Fluoreszensmikroskopie untersucht. Dextran-Alexa488 markierte Endosomen wurden zunächst auf Deckgläschen zentrifugiert und nach 15minütiger Blockierung für eine Stunde 1:100 mit dem primären Antikörper inkubiert. Nach dreimaligem Waschen mit BSA-haltigem PBS wurden die Probem 1:200 mit sekundärem Cy3-markiertem Antikörper inkubiert. Nach erneutem Waschen wurden die Proben direkt in einer PBS-haltigen Kammer mikroskopiert. Die Korrelation zwischen den markierten Endosomen und der Immunfärbung wurde mittels line scans (3 Pixel breit, 15 Pixel lang) durch die Endosomen im grünen und die Färbung im roten Kanal bestimmt. Hieraus wurde wie zuvor beschrieben der Korrelationskoeffizient errechnet (Rizzoli et al., 2006) und ein Koeffizient $\geq 0,8$ als Kolokalisation gewertet. 
Abschließend wurde noch um den Wert für rein zufällige Kolokalisation korrigiert, indem die Werte, die sich mit dem gespiegelten roten Kanal ergaben, subtrahiert wurden.

\subsection{STED-Mikroskopie}

In Mowiol eingebettete Proben wurden mit einem TCS STED (Stimulierte Emmissionsdepletierung) superhochaufösendem Fluoreszenzmikroskop von Leica Microsystems GmbH (Mannheim) (1,4 NA, 100x Objektiv) untersucht. Die Anregung erfolgte mit einem $635 \mathrm{~nm}$ Dioden Laser, während die Depletierung durch einen Spectra-Physics MaiTai regulierbaren Laser bei $750 \mathrm{~nm}$ erreicht wurde. Die Signaldetektion erfolgte mittels einer Avalanche Photodiode. Das Auflösungsvermögen des Systems wurde durch die Messung von crimson-fluorescent beads (20 nm Durchmesser, Invitrogen) bestimmt und liegt bei 70-90 $\mathrm{nm}$.

\subsubsection{Größenbestimmung mittels STED-Mikroskopie}

Um die Größe der Endosomen zu bestimmen, die für das Endosomen-Interaktionsassay verwendet wurden, wurde Amino-Dextran mit dem Farbstoff Atto647N (ATTOTEC, Siegen) über seinen Succinimidylester nach einem Standardprotokoll (Invitrogen) markiert. Die Aufnahme von Atto647N-Dextran in die Zellen erfolgte analog zu den Alexa-Dextranen (siehe Abschnitt 2.7.1), wobei sich an die PNS-Präparation noch eine Gradientenaufreinigung anschloss. Die Endosomen wurden auf Deckgläschen zentrifugiert, fixiert und in Mowiol eingebettet bevor sie mit einem STEDMikroskop analysiert wurden. Der Durchmesser der Endosomen wurde bestimmt indem zunächst line scans (11 Pixel breit, 41 Pixel lang) durch die Endosomen durchgeführt und anschließend mittels eines Matlab-Programms (Silvio Rizzoli) LorentzVerteilungen angenähert wurden $\left(\mathrm{y}=\mathrm{y}_{0}+\frac{a}{1+\left(\frac{x-x_{0}}{b}\right)^{2}}\right)$ wobei b die Hälfte des Durchmessers auf halber Höhe darstellt.

\subsubsection{Datenanalyse des Clustering}

Die Endosom- bzw. Liposom-Proben wurden wie im Text beschrieben behandelt und STED-mikroskopisch erfasst. Die Bildverarbeitung erfolgte mit Hilfe eines Matlabprogramms (Silvio Rizzoli), welches zunächst (unter Benutzung von Standardbefehlen/Bibliotheken) durch einen Hochpass-Filter Rauschen entfernte und mit einem $3 * 3$ Pixelraster ( $6^{*} 6$-Pixelraster für die Experimente mit rekombinanten Proteinen) glättete, d.h. der mittlere Pixel erhielt jeweils den Mittelwert des Rasters (siehe Anhang). 
Für jedes Objekt mit einer Größe von von über 300 Pixeln (entspricht einem Durchmesser von ungefähr 200nm) wurde anschließend die Anzahl der lokalen Intensitätsmaxima identifiziert, die als Maß für Proteinanhäufungen/Cluster dienten.

\subsection{Elektronenmikroskopie}

Die Elektronenmikroskopie wurde durchgeführt wie bereits beschrieben (Rizzoli et al., 2006). Die immungefärbten Proben, wurden mit Glutaraldehyd fixiert, in Methylzellulose-Uranylacetat eingebetet und anschließend mit einem CM120 Elektronenmikroskop (Philips) durch eine TVIPS Kamera augenommen. 


\section{Ergebnisse}

\subsection{Das Docking früher Endosomen}

Docking wurde ursprünglich in Neuronen als enger Kontakt zwischen synaptischen Vesikeln und der Plasmamembran und als Vorstufe der Fusion definiert (Schikorski \& Stevens, 2001). Es sollte daher untersucht werden, ob etwas Analoges hierzu auch bei der Fusion zwischen Endosomen beobachtet werden kann und wie dieses gegebenenfalls reguliert wird.

\subsubsection{Aggregationsassay}

Die Untersuchung des Docking von Endosomen wurde von Silvio Rizzoli begonnen, der hierzu das ursprünglich für die Interaktion von Vakuolen entwickelte Aggregationsassay (siehe Einleitung und (Mayer \& Wickner, 1997)) einsetzte. Anstelle von Vakuolen wurden aus Baby Hamster Kidney (BHK)-Zellen isolierte Endosomen verwendet, wobei zunächst durch Zellaufschluss und langsame Zentrifugation postnukleäre Überstände gewonnen und die Endosomen anschließend über eine Saccharosegradienten-Ultrazentrifugation angereichert wurden. Reaktionsansätze mit BHK-Endosomen wurden für 45 Minuten inkubiert und die Proben anschließend in 12- Well Platten auf Deckgläschen zentrifugiert. Um eine mikroskopische Analyse der Aggregatbildung, d.h. der Stärke des Verklumpens, zu ermöglichen, wurde der Farbstoff FM 2-10 auf die Probe gegeben. FM-Farbstoffe zeichnen sich dadurch aus, dass sie deutlich stärker fluoreszieren, wenn sie sich in Membranen befinden, als wenn sie in Lösung vorliegen, was eine selektive Markierung der Organellen erlaubt. Wenn Endosomen aggregieren hat das zur Folge, dass einige Bereiche des Bildes eine sehr hohe Fluoreszenz aufweisen, während andere leer bleiben, d.h. eine sehr geringe Fluoreszenz zeigen. Als Maß für die Stärke der Aggregatbildung wurde daher berechnet, wie sehr die Fluoreszenzintensität innerhalb des aufgenommenen Bildes schwankt, d.h. es wurde zunächst die durchschnittliche Fluoreszenz bestimmt und aus der Summe der Abweichungen die mittlere Standardabweichung berechnet. Wie Abbildung 3.1 zeigt, bestand praktisch kein Zusammenhang zwischen den die Aggregation und den die Fusion bestimmenden Faktoren. 


\section{Ergebnisse}

A

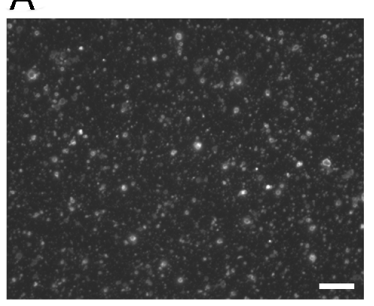

$\mathrm{D}$

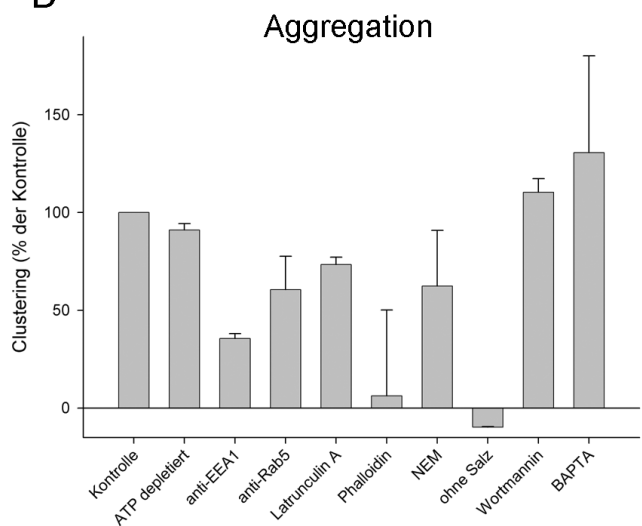

B

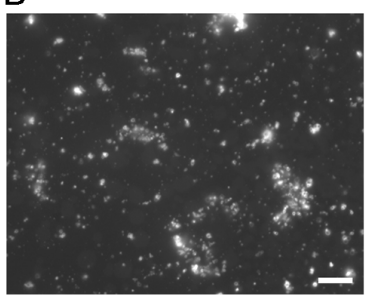

$\mathrm{E}$

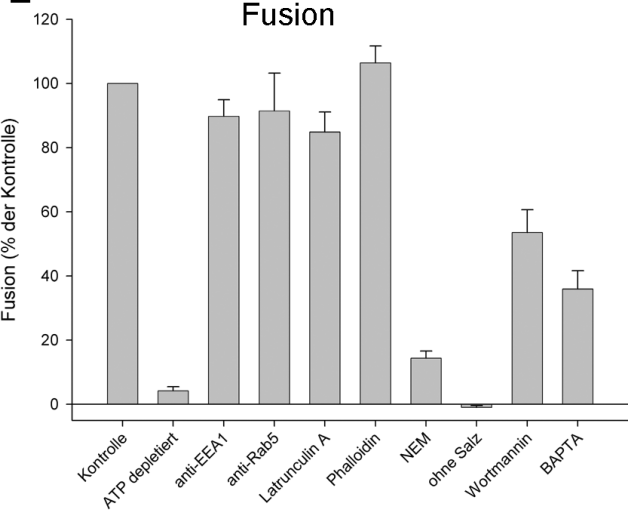

Abbildung 3.1: Vergleich der Aggregation und Fusion früher Endosomen Endosomen aus Baby Hamster Kidney (BHK)-Zellen wurden isoliert und in der Gegenwart von Puffer, Zytosol sowie einem ATP-regenerierenden System für 0 (A) oder 45 Minuten (B) inkubiert. Aliquots der Reaktionen wurden anschließend auf Deckgläschen zentrifugiert und in Gegenwart des Styryl-Farbstoffes FM 2-10, welcher in Membranen stark leuchtet, inkubiert. Die Verwendung eines ATP-verbrauchenden Puffers hat keine Auswirkung auf die Aggregation (C). (D) und (E) zeigen den Mittelwert der Aggregations- bzw. Fusionsrate der Endosomen nach unterschiedlichen Behandlungen aus mindestens 2 unabhängigen Experimenten. 
Besonders auffällig war die ATP-Unabhängigkeit der Aggregatbildung, welche eher auf ein unreguliertes Verklumpen denn ein spezifisches Docking hindeutete. Für das vakuoläre System war zuvor eine ATP-Abhängigkeit (Mayer \& Wickner, 1997) der Aggregation beschrieben worden, allerdings mussten hierzu die Reaktionsbedingungen verglichen mit der normalen Fusionsreaktion deutlich verändert werden (z.B. wurde die Salzkonzentration mehr als halbiert). Gerade die gleichzeitige Untersuchung von Fusion und Docking unter identischen Bedingungen scheint jedoch vielversprechend, um neue Einblicke in die Regulationsmechanismen zu gewinnen. Es wurde daher ein alternativer Ansatz entwickelt, der sich statt auf das Verklumpen von Membranen spezifisch auf die Analyse funktionell aktiver Endosomen konzentrieren sollte.

Alle im folgenden beschriebenen Experimente wurden mit Endosomen aus PC12Zellen durchgeführt, da es sich bei PC12 um eine neurosekretorische Zelllinie handelt bei der ähnlich wie in Neuronen Endo- und Exozytose einer besonders ausgefeilten Regulation unterliegen. Bei der vorliegenden Arbeit konnte auf dem von Dorothea Brandhorst entwickelten Assay zur Endosomenfusion aufgebaut werden (Brandhorst et al., 2006). PC12-Zellen wurden mit an Alexa488 bzw. Alexa594 gekoppeltem Dextran inkubiert, das durch Endozytose in die Zellen aufgenommen wird und sich nach 5 Minuten in frühen Endosomen befindet (Gruenberg \& Howell, 1987). Die Einschleusung von Fluoreszenzfarbstoffen in den Endozytoseweg stellt sicher, das nur funktionell aktive Endosomen markiert werden. Nachdem die Internalisierung auf Eis gestoppt wurde, wurden die Zellen gewaschen, mit einem Kugel-Homogenisator aufgeschlossen und bei 1200xg für 15 Minuten zentrifugiert, um den postnukleären Überstand (PNS) zu erhalten.

\subsubsection{Charakterisierung der Endosomen}

Um einen Eindruck von der Größenverteilung der markierten Endosomen zu bekommen, wurden PC12-Zellen analog mit Atto647N-markiertem Dextran behandelt und das PNS auf Deckgläschen zentrifugiert. Die Verwendung dieses Atto-Farbstoffes ermöglicht den Einsatz eines superhochauflösenden STED-(Stimulated emission depletion) Mikroskops (Klar et al., 2000). Hierbei wird die Region um das Anregungszentrum durch einen zweiten Laser gelöscht, woraus eine Auflösung von 70-90 nm für das von uns verwendete kommerzielle Gerät resultiert, die eine Vermessung der Endosomen ermöglichte. Zur Bildanalyse wurden die Aufnahmen in die Software Matlab importiert. Die Endosomen wurden manuell ausgewählt und ihre Durchmesser dann automatisch durch die Approximation einer Lorentzverteilung an die point spread function (PSF) bestimmt (siehe Abschnitt 2.8.1), wobei sich eine Größenverteilung mit einem Maximum um $200 \mathrm{~nm}$ ergab (siehe Abbildung 3.1.2). Besonders hervor- 


\section{Ergebnisse}

zuheben ist hier, dass weniger als vier Prozent der Endosomen unterhalb (oder in der Region) der Aufösungsgrenze lagen, d.h. dass mit diesem Ansatz zuverlässige Daten gewonnen werden können.

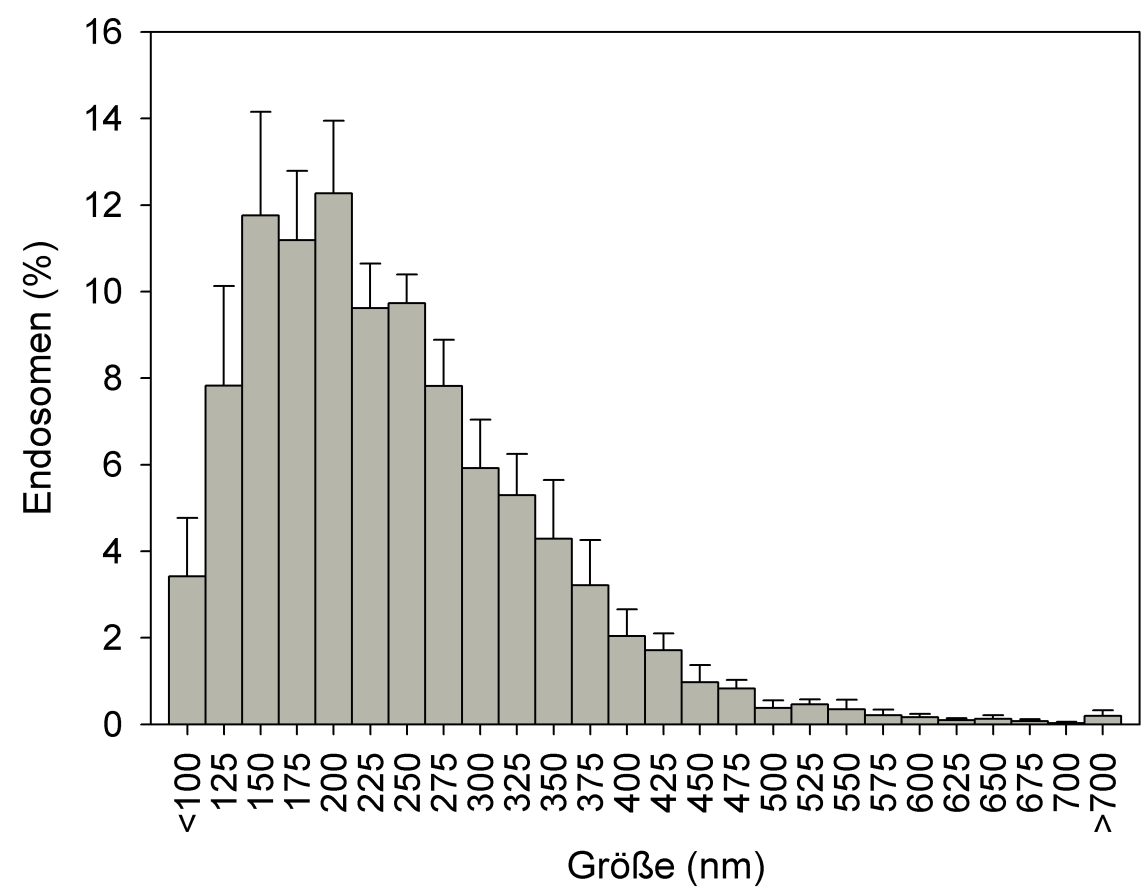

Abbildung 3.2: Die Größenverteilung der markierten Endosomen

Endosomen wurden mittels der Aufnahme von Atto-gekoppeltem Dextran markiert, isoliert und auf Deckgläschen zentrifugiert. Die Analyse der STED-Aufnahmen erfolgte semiautomatisch durch ein Matlab-Programm über die Approximation von Lorentzverteilungen an die point spread function (siehe Material und Methoden). Gezeigt sind die Mittelwerte aus sechs unabhängigen Experimenten mit jeweils mindestens 400 vermessenen Endosomen (+/- Standardfehler).

Bezüglich ihres Gehalts an SNARE-Proteinen wurden die über Dextranmarkierung identifizierbaren Endosomen bereits von Dorothea Brandhorst charakterisiert (Brandhorst et al., 2006), wobei sich ein hoher Grad an Kolokalisation mit den frühendosomalen SNAREs Syntaxin 6, Syntaxin 13, VAMP4 und Vti1a, aber auch Synaptobrevin zeigte. Im Rahmen der vorliegenden Arbeit wurden einige weitere Immunfärbungen für klassische frühendosomale Marker, i.e. Rab4 und Rab5, sowie den Caveolae Marker Caveolin I durchgeführt (Parton \& Simons, 2007), deren Ergebnis in Abbildung 3.3 gezeigt ist. Die Caveolin I-Färbung überlappt praktisch nicht mit den markierten Endosomen, was dafür spricht, dass Dextran unabhängig von Caveolae aufgenommen wird. Stattdessen zeigt sich eine hohe Kolokalisation mit Transferrin (Brandhorst et al., 2006). Der relativ geringe Anteil an Rab4- bzw. Rab5-positiven Endosomen überrascht zunächst, ist aber zumindest teilweise dadurch zu erklären, dass Rab-Proteine keine Transmembrandomäne besitzen, woraus 


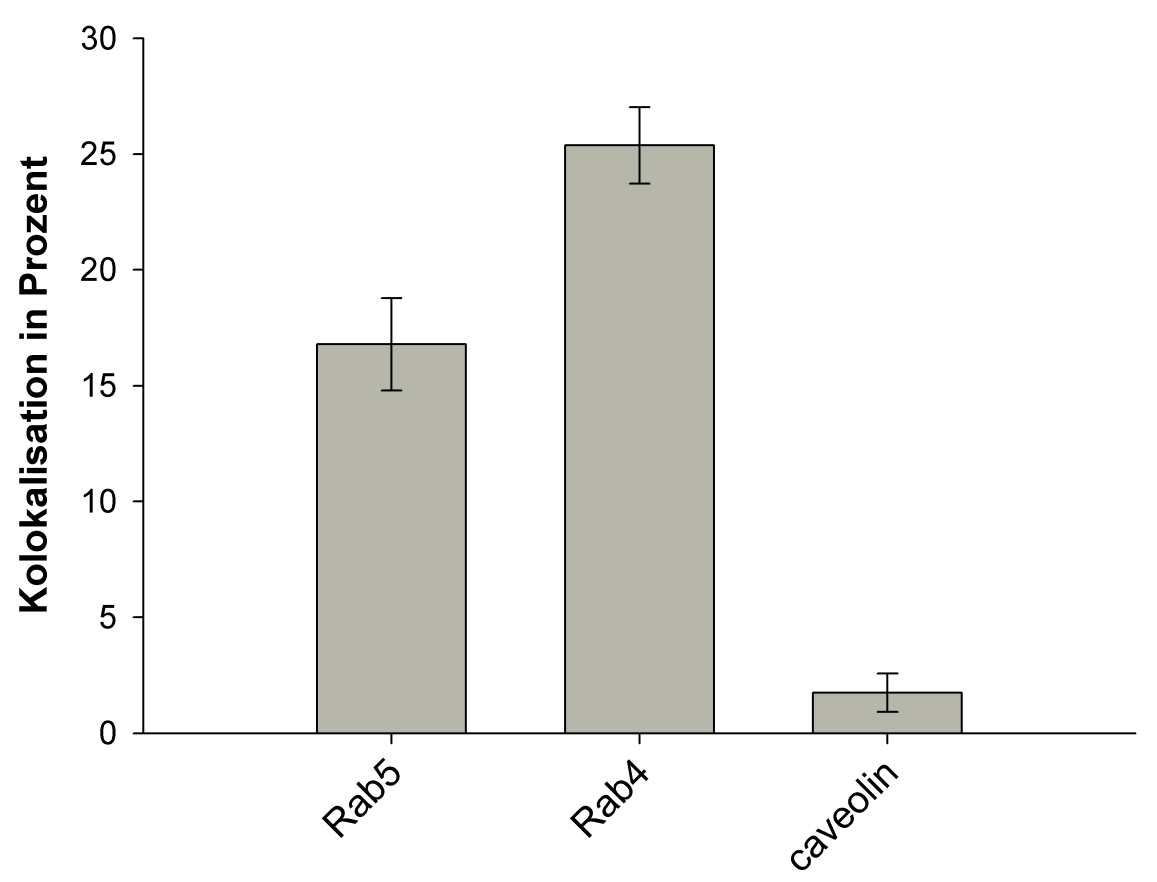

Abbildung 3.3: Kolokalisation von Alexa-Dextran-markierten Endosomen mit Markerproteinen

Durch Aufnahme von Dextran-Alexa594 markierte Endosomen wurden auf Deckgläschen zentrifugiert und mit Antikörpern gegen Rab5, Rab4 und Caveolin-I gefärbt. Die aufgenommenen Bilder wurden mittels line scans analysiert und Korrelationskoeffizienten von über 0,8 wurden als Kolokalisation gewertet (siehe Material und Methoden). Die gezeigten Werte wurden durch Subtraktion der zufälligen Kolokalisation (d.h. der mit dem gespiegelten Bild erlangten) und dem Mitteln von 4-7 unabhängigen Experimenten ( \pm SEM) erhalten. 


\section{Ergebnisse}

eine dynamische Verteilung der Rab-Proteine zwischen Zytosol und Membran folgt, sowie dadurch, dass gegen Rab-Proteine gerichtete Antikörper in der Regel nur eine geringe Qualität besitzen (Reinhard Jahn, persönliche Mitteilung). Insgesamt bestätigen die Ergebnisse der Immunfärbungen, d.h. besonders die hohe Kolokalisation mit Transferrin und frühendosomalen SNAREs, das es sich bei den funktionell markierten Organellen um frühe Endosomen handelt.

\subsubsection{Die Entwicklung des Endosomen-Interaktionsassays}

Endosomen wurden durch die Aufnahme von an Alexa-Farbstoffe gekoppeltem Dextran markiert, die Zellen aufgeschlossen und postnukleäre Überstände präpariert. Diese wurden wie unter Abschnitt 1.1.1 bereits beschrieben in Gegenwart von Zytosol und einem ATP-regenerierenden System für 45 bis 60 Minuten inkubiert, auf Deckgläschen zentrifugiert und mikroskopiert. Zur korrekten Ausrichtung des roten und grünen Kanals wurden mehrfarbige TetraSpeck ${ }^{\mathrm{TM}}-$ Beads verwendet, die im blauen Kanal identifiziert werden konnten.
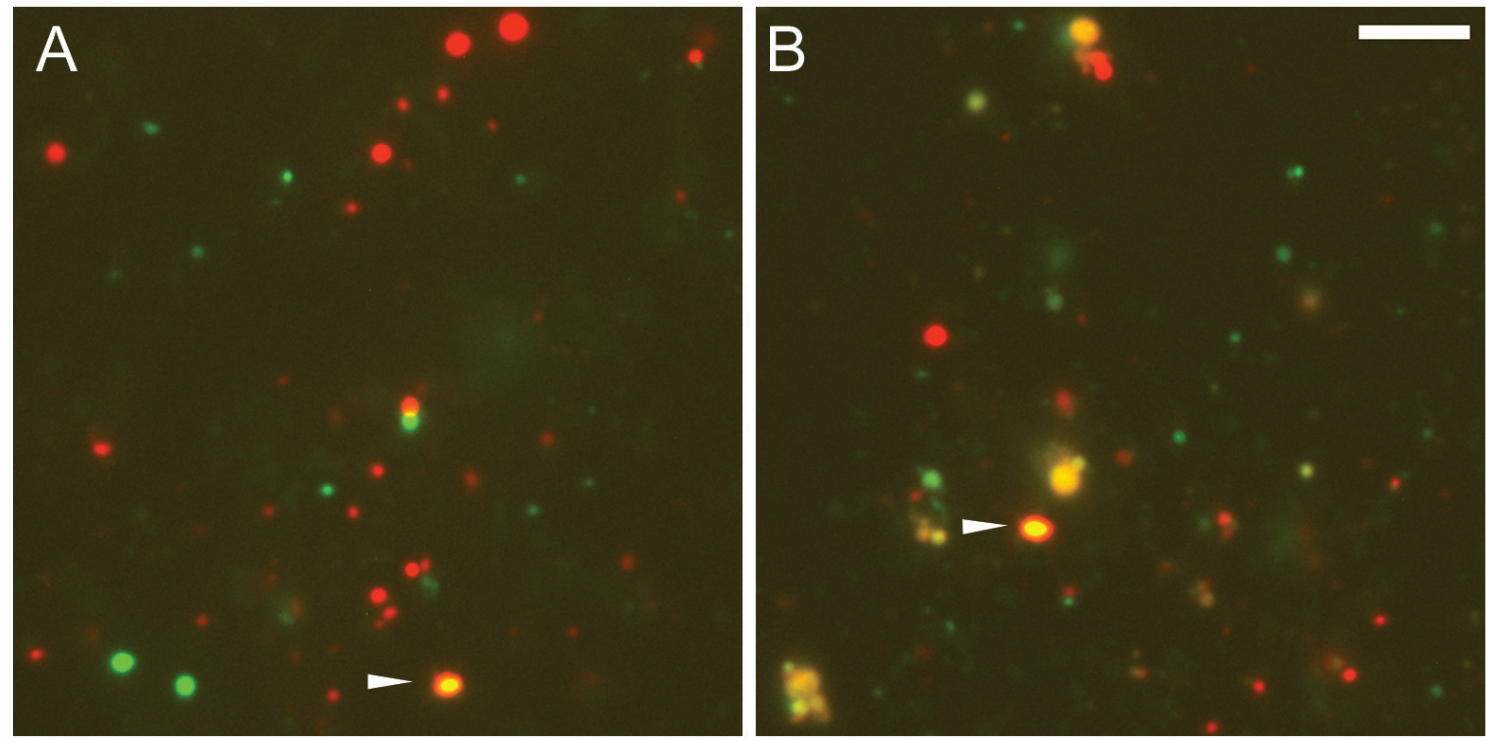

Abbildung 3.4: Endosomen kolokalisieren nur in Gegenwart von ATP Gezeigt ist die Überlagerung des roten und grünen Kanals von repräsentativen Aufnahmen. Markierte postnukleäre Überstände wurden entweder direkt zentrifugiert (A) oder für 60 Minuten inkubiert (B). Nach 60 Minuten zeigt sich deutliche Kolokalisation. Der rote und grüne Kanal wurden durch die mit Pfeilspitzen hervorgehobenen, mehrfarbigen TetraSpeck ${ }^{T M}$-Beads ausgerichtet. Die Balkenbreite beträgt $5 \mu \mathrm{m}$.

Da die Endosomen mit einem Durchmesser von ungefähr $200 \mathrm{~nm}$ (siehe oben) an der Auflösungsgrenze normaler lichtmikroskopischer Methoden liegen, scheint die Unterscheidung zwischen gedockten und fusionierten Endosomen zunächst schwierig. Da die beobachtete Fluoreszenz jedoch von isolierten Objekten ausgeht, ist es 
möglich das Intensitätszentrum (und damit die „Mitte“ des Endosoms) auf ungefähr 5 bis $10 \mathrm{~nm}$ genau zu bestimmen (Cheezum et al., 2001; Thompson et al., 2002), obwohl die Pixelgröße bei $68 \mathrm{~nm}$ liegt. Die Bilder wurden hierzu mit Hilfe eines Matlab-Programms (Silvio Rizzoli) analysiert (siehe Material und Methoden, Abschnitt 2.7.5.2), d.h. es wurde basierend auf den Intensitätszentren für jedes grün markierte Endosom die Distanz zum nächstgelegenen roten Endosom bestimmt. Diese Daten konnten dann als Histogramm aufgetragen werden, wie die Verteilung aus Abbildung 3.5 beispielhaft zeigt. Man erhielt zwei scheinbar getrennte Populationen, wobei eine zwischen 0 und $100 \mathrm{~nm}$ Abstand und die andere zwischen 150 und $500 \mathrm{~nm}$ lag, mit einer Mischpopulation um $125 \mathrm{~nm}$.

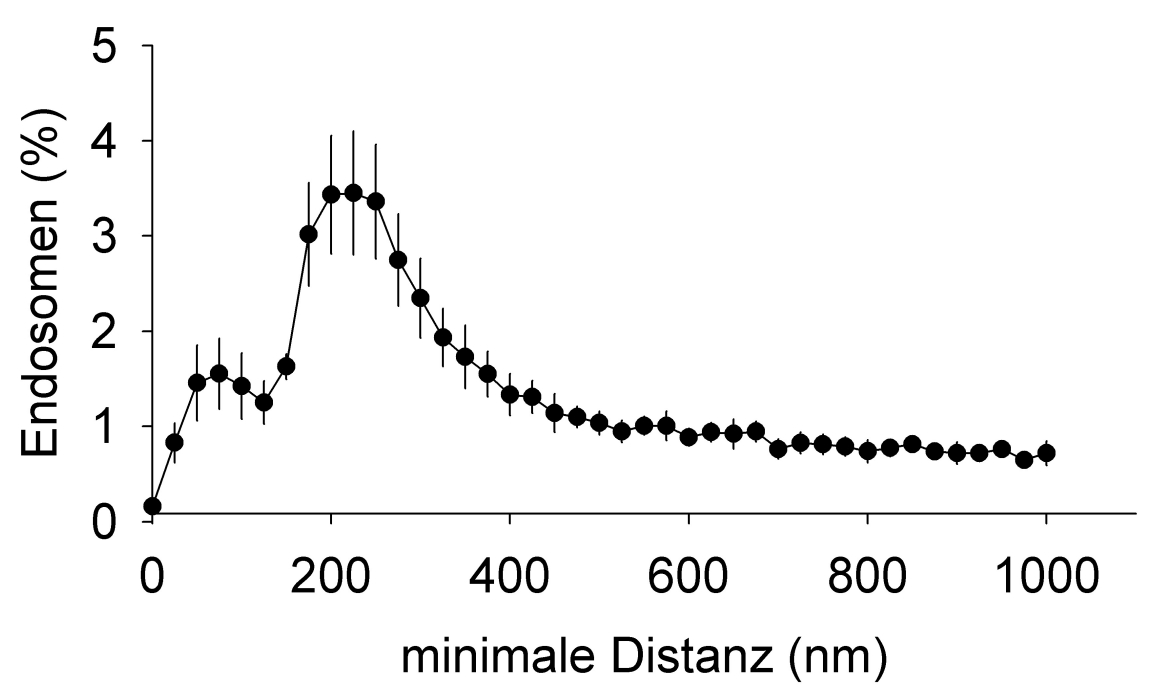

Abbildung 3.5: Beispielverteilung der Endosomenabstände

Postnukleäre Überstände mit markierten Endosomen wurden in der Gegenwart von Zytosol und einem ATP-regenerierenden System für 60 Minuten inkubiert, auf Deckgläschen zentrifugiert und mikroskopiert. Die Distanz jedes grünen Endosoms zu seinem nächstgelegenen roten wurde mittels eines Matlab-Programms bestimmt (siehe Material und Methoden, Abschnitt 2.7.5.2) und als Histogramm in Prozent von hundert aufgetragen. Gezeigt ist der Mittelwert aus neun unabhängigen Experimenten plus Standardfehler.

Was ist nun die Bedeutung dieser Populationen? Um festzustellen, wie eine vollständig fusionierte Gruppe von Endosomen aussehen würde, kamen vielfarbige Tetra Speck ${ }^{\mathrm{TM}}$-Beads mit einem endosomenähnlichen Durchmesser $(0,2 \mu \mathrm{m})$ als Modell zum Einsatz, deren Analyse ein der ersten Population sehr ähnliches Ergebnis zeigt. Zunächst überrascht, dass das Maximum auch hier nicht bei 0 , sondern um $80 \mathrm{~nm}$ liegt. Wenn man jedoch (was näherungsweise zutreffen sollte) annimmt, das die Aufenthaltswahrscheinlichkeit der Endosomen entlang beider Achsen einer Gaussverteilung mit dem Maximum bei 0 folgt und diese unabhängig voneinander sind, was durch die Analyse von Beadverteilungen bestätigt werden konnte (Daten nicht gezeigt), ergibt sich dass dies zu erwarten ist (siehe Anhang, Abschnitt 6.1). Eine 


\section{Ergebnisse}

Mischung von rot fluoreszierenden und grün fluoreszierenden Beads gab hingegen kein Maximum in diesem Bereich, was im Einklang mit früheren Untersuchungen (Bethani et al., 2007; Brandhorst et al., 2006; Rizzoli et al., 2006) zeigt, dass es sich bei der ersten Population um fusionierte Endosomen handelte. Um festzustellen, ob

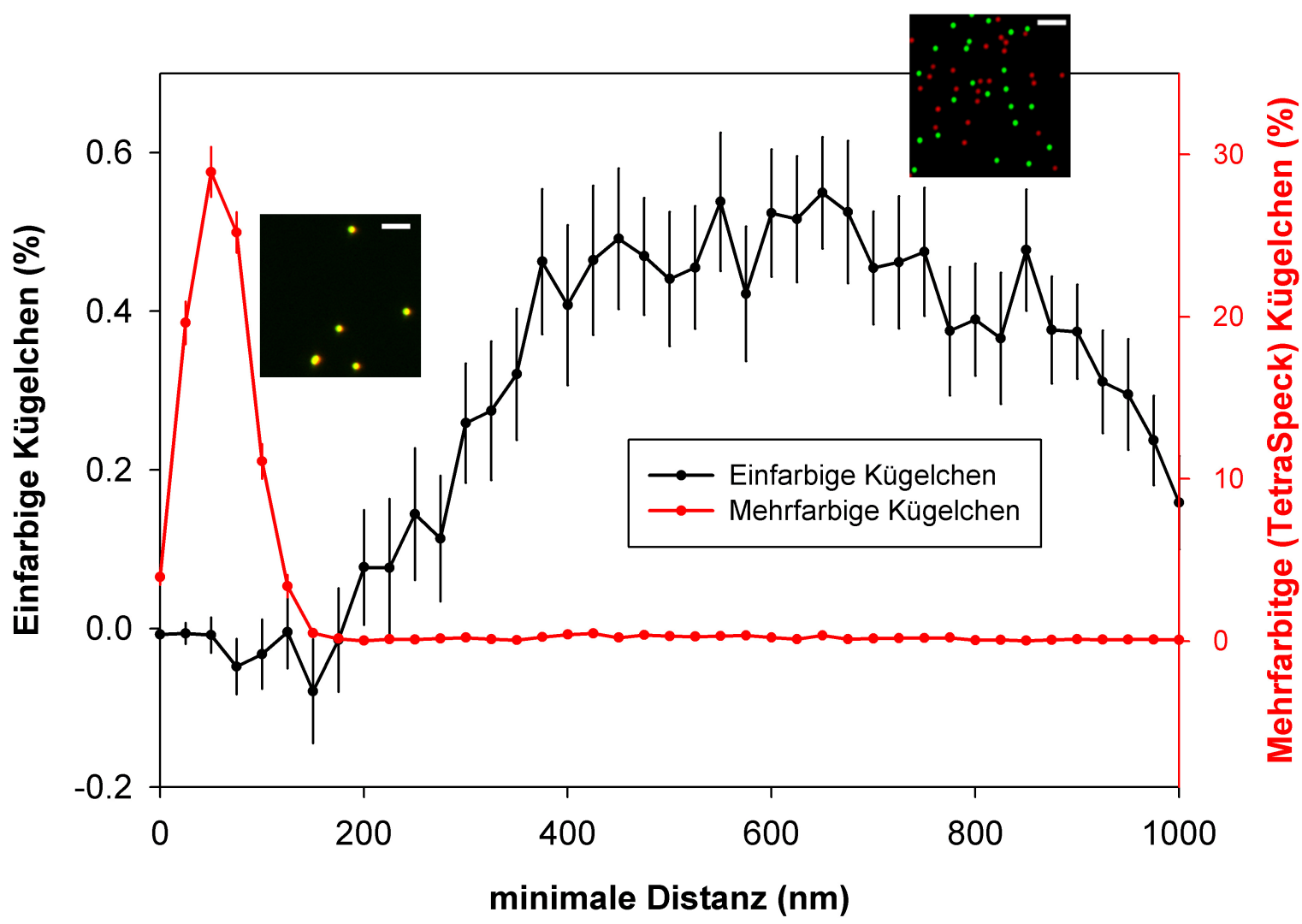

Abbildung 3.6: Abstandsverteilung mit fluoreszierenden Beads

Mehrfarbenfluoreszente TetraSpeck ${ }^{\mathrm{TM}}$-Beads mit $200 \mathrm{~nm}$ Durchmesser wurden als Modell für fusionierte Endosomen verwendet und entsprechend analysiert. Als Modell für nicht-fusionierte Endosomen wurden rot fluoreszierende und grün fluoreszierende Kügelchen benutzt. Die Histogramme wurden für zufällige Kolokalisation korrigiert, indem die Werte für die Kolokalisation der grünen Aufnahme mit den roten Spiegelbildern subtrahiert wurden. Gezeigt ist der Mittelwert von 3 unabhängigen Experimenten, die von Sina Victoria Barysch durchgeführt wurden.

die zweite Population auch auf eine Endosomeninteraktion zurückzuführen ist oder nur ein Artefakt darstellt, wurden die Alexa488- und Alexa594 markierten Endosomen separat inkubiert und erst direkt vor der Zentrifugation gemischt. Wie auf Abbildung $3.7 \mathrm{zu}$ sehen, verschwand in diesem Fall nicht nur die Fusion, sondern auch die zweite Population reduzierte sich stark, was zeigt, dass es sich bei der zweiten Population um miteinander interagierende, aber nicht fusionierte, ergo entweder 
um verklumpte oder gedockte Endosomen handelt, wobei der verbliebende Anteil wahrscheinlich den aus den Endosomendichte resultierenden Hintergrund darstellt.

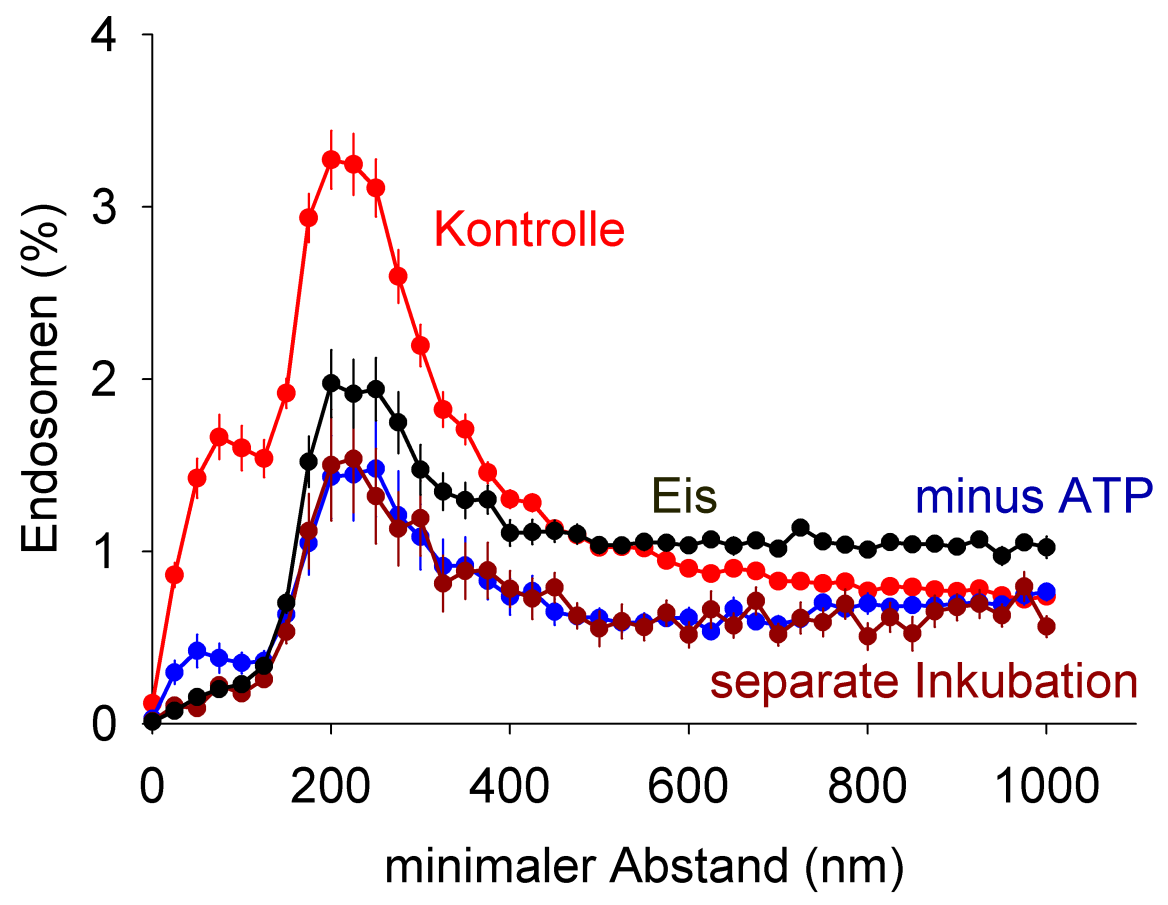

Abbildung 3.7: Abstandsverteilung der Endosomen bei unterschiedlichen Bedingungen

Alexa488- und Alexa595-Dextran markierte Endosomen wurden im Reaktionspuffer gemischt und für 60 Minuten bei $37^{\circ} \mathrm{C}$ inkubiert. Eine Inkubation auf Eis oder die Zugabe eines ATP-verbrauchenden Systems reduzieren nicht nur die Fusion, sondern auch das zweite Maximum praktisch auf die Werte ohne gemeinsame Inkubation. Gezeigt sind die Mittelwerte von 5-9 unabhängigen Experimenten mit Standardfehlern.

\subsubsection{Grundlegende Eigenschaften des Dockings}

Um zu unterscheiden, ob es sich bei der zweiten Population um ein unspezifisches Verklumpen oder ein aktiv reguliertes Docking handelt, wurde die Reaktion neben der Standardreaktion bei $37^{\circ} \mathrm{C}$ auch auf Eis bzw. mit einem ATP-verbrauchenden Puffersystem durchgeführt. Wie Abbildung 3.7 zeigt, reduzierte sich dadurch nicht nur die Menge der fusionierten Endosomen, sondern auch die zweite Population praktisch auf das Niveau der Negativkontrolle (d.h. der separaten Inkubation). Die ATPund Temperaturabhängigkeit spricht klar für einen regulierten, aktiven Prozess, d.h. es handelt sich bei der zweiten Population um gedockte Endosomen.

Eine wichtige Eigenschaft der frühendosomalen Fusion ist ihre Kalziumabhängigkeit (Holroyd et al., 1999). Um herauszufinden, ob diese auch schon für das Docking gegeben ist, wurde der schnelle Kalziumchelator BAPTA zur Reaktion gegeben. Wie 
Abbildung 3.8 zeigt, ist das Docking nicht auf Kalzium angewiesen. Da BAPTA

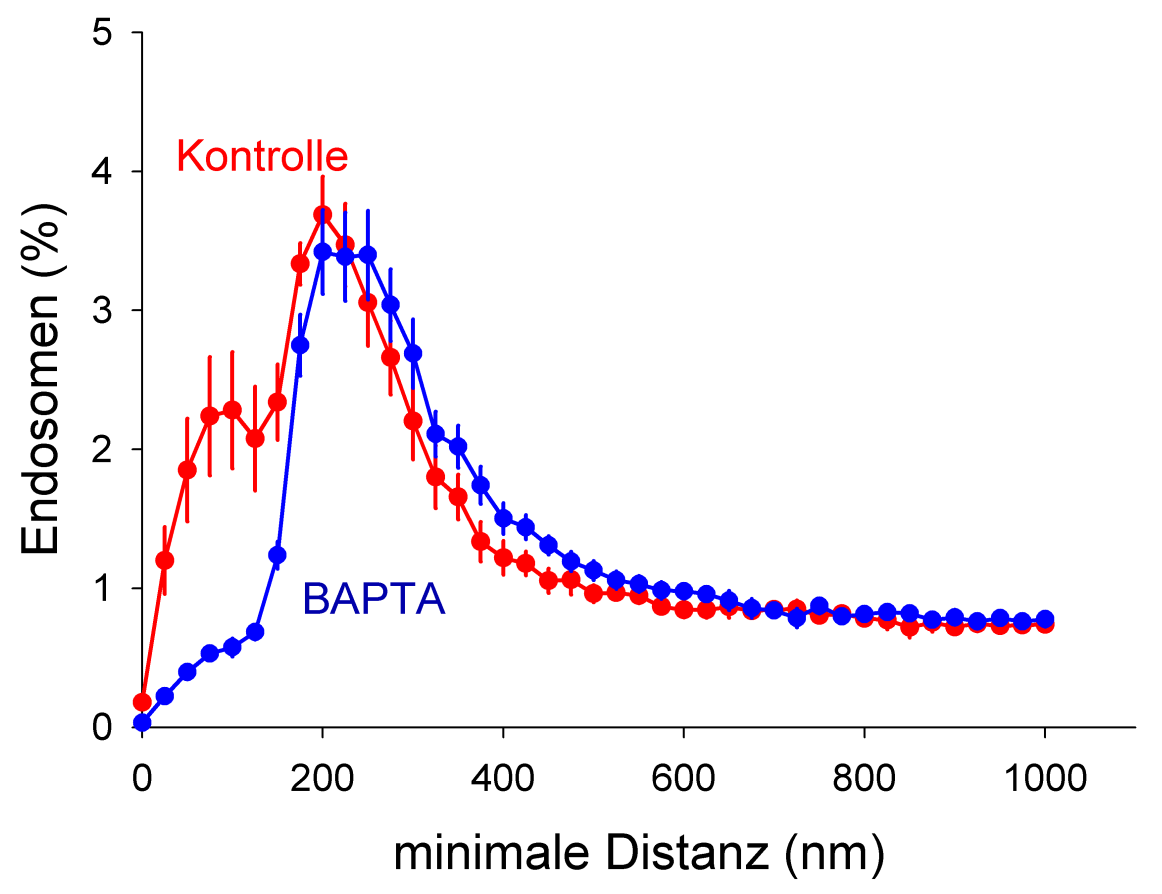

Abbildung 3.8: Die Zugabe von BAPTA reduziert nur die Fusion, aber nicht das Docking von Endosomen

Das Endosomen-Interaktionsassay wurde unter Standardbedingungen oder in Gegenwart des schnellen Kalziumchelators BAPTA $[10 \mathrm{mM}]$ durchgeführt. Gezeigt sind die Mittelwerte von 18 unabhängigen Experimenten \pm Standardfehler.

die Fusion inhibiert, ohne das Docking zu beeinflussen, kann es als Werkzeug verwendet werden, um herauszufinden, ob das Docking ein stabiler Zustand ist, oder ein dynamisches Gleichgewicht zwischen gedockten und freienn Endosomen vorliegt, dessen Erhalt ständige ATP-Zufuhr benötigt. Die Proben wurden für 15 Minuten in der Gegenwart von BAPTA inkubiert, so dass die Endosomen docken (aber nicht fusionieren) konnten und anschließend wurde ein ATP-verbrauchendes System zugegeben und für weitere 45 Minuten inkubiert. Wie der sehr ähnliche Verlauf der Kurven zeigt (Abbildung 3.9), scheint ATP nur zur Initiation des Docking erforderlich zu sein, aber nicht zu dessen Erhalt.

\subsubsection{Sterische Kontrollen und Verdünnung}

Um sicherzugehen, dass der inhibitorische Einfluss von Antikörpern oder anderen zugegebenen Proteinen spezifisch und nicht nur auf sterische Behinderungen zurückzuführen ist, wurden Antikörper gegen die in hoher Konzentration auf der endosomalen Membran vorliegenden (aber höchstwahrscheinlich weder am Docking noch an der Fusion beteiligten) Proteine Synaptophysin und Synaptobrevin eingesetzt, sowie 


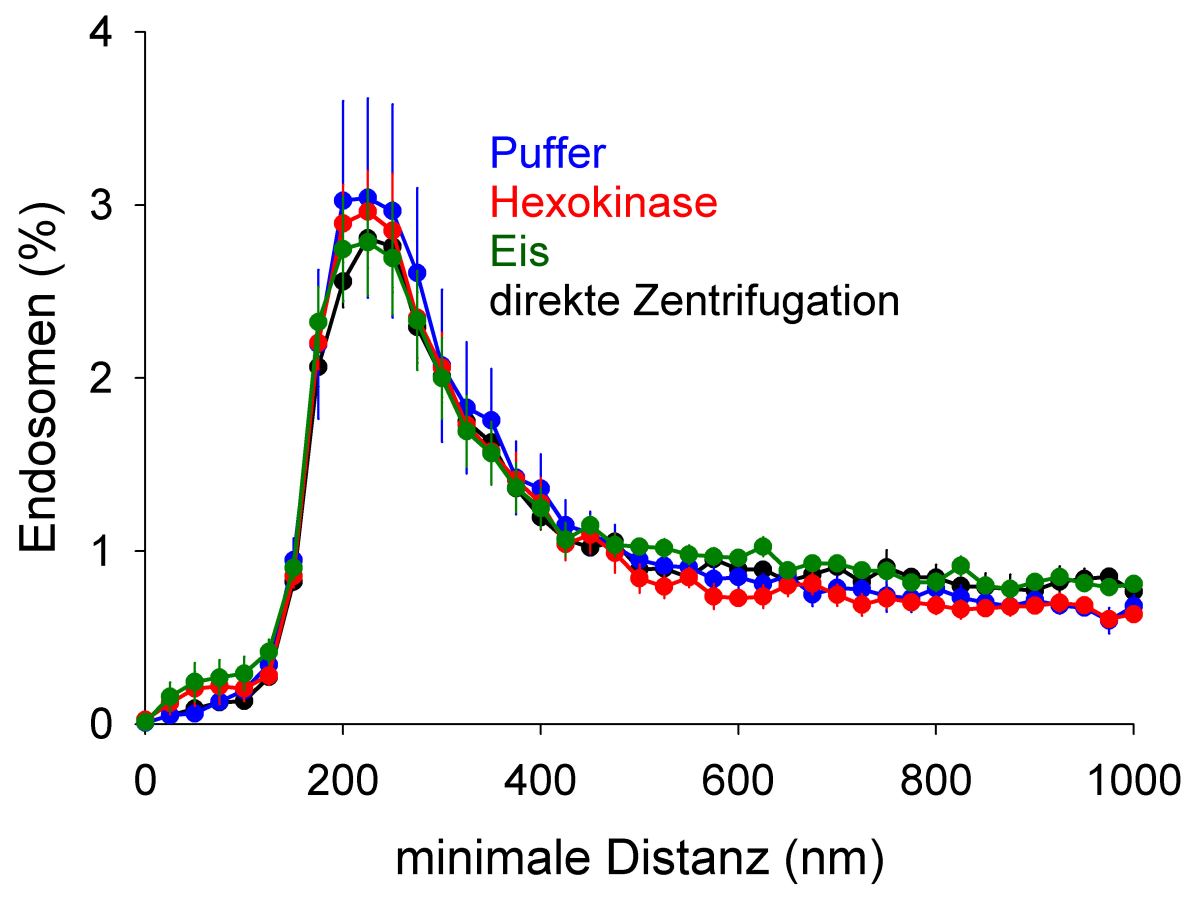

Abbildung 3.9: Das Docking früher Endosomen ist stabil

Reaktionsansätze mit Zytosol, aber ohne zusätzliches ATP, wurden für 15 Minuten in der Gegenwart von BAPTA inkubiert, um Docking zu ermöglichen aber eine Fusion zu verhindern (vgl. Text und Abbildung 3.8 für die Effekte von BAPTA). Die Reaktion wurde dann entweder 1) direkt zentrifugiert 2) auf Eis gestoppt 3) nach Zugabe von Puffer fortgesetzt oder 4) nach Zugabe eines ATP-verbrauchenden Systems fortgesetzt, um zu untersuchen, ob sich die Anzahl der gedockten Endosomen in Abwesenheit von ATP reduziert. Gezeigt sind die Mittelwerte von 3-5 unabhängigen Experimenten (+/- SEM). 
0,18 $\mathrm{mg} / \mathrm{ml} \mathrm{BSA} \mathrm{(welches} \mathrm{in} \mathrm{etwa} \mathrm{der} \mathrm{Proteinmenge} \mathrm{der} \mathrm{in} \mathrm{späteren} \mathrm{Experimenten}$ verwendeten rekombinanten Proteine entspricht). Weder die Antikörper noch das

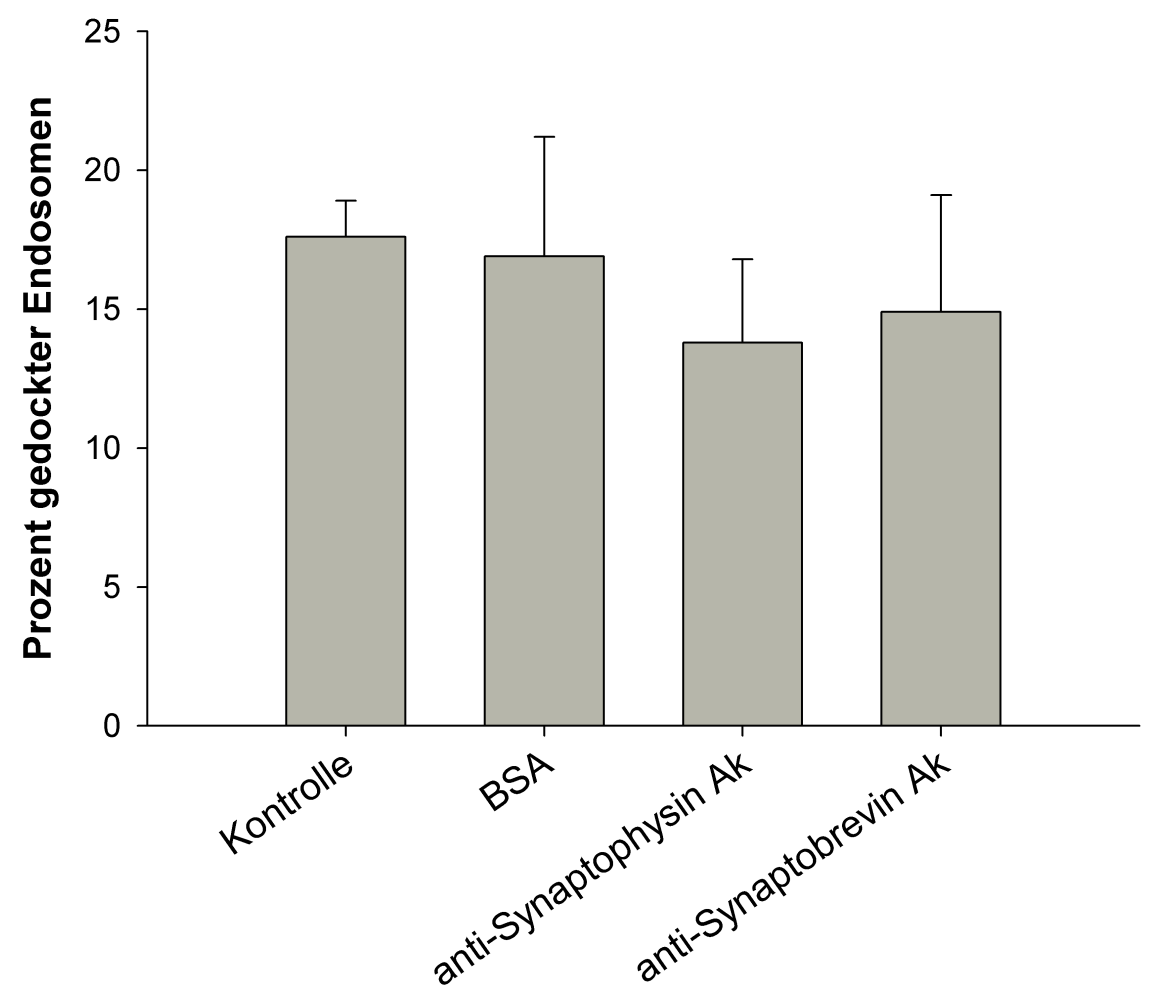

Abbildung 3.10: Kontrollexperimente mit Antikörpern und BSA

Der Einfluss von sterischen Effekten auf das Docking wurde durch Zugabe von BSA $(0,18 \mathrm{mg} / \mathrm{ml})$, anti-Synaptophysin (G96, $3 \mu \mathrm{l}$ Serum pro Reaktion) and anti-Synaptobrevin (Cl 69.1, $3 \mu \mathrm{l}$ ascites pro Reaktion) Antikörpern getestet. Gezeigt sind Mittelwerte von wenigstens 6 unabhängigen Experimenten \pm Standardfehler.

BSA reduzierten das Docking signifikant (siehe Abbildung 3.10), d.h. die Reaktion ist so robust, dass sie auch bei sterischer Behinderung ablaufen kann. Mit anderen Antikörpern oder rekombinanten Proteinen erreichte Hemmeffekte sind daher wahrscheinlich spezifisch.

Ein weiterer Faktor, der bisweilen zur Untersuchung von Docking herangezogen wird, ist die daraus resultierende Verdünnungsresistenz (Mayer \& Wickner, 1997). Hierbei geht man davon aus, dass die Fusion der Organellen nach Eintreten des Docking resistent gegenüber Verdünnung ist, d.h. die Reaktion auch im verdünnten Zustand genauso weiterliefe wie im unverdünnten. Um zu untersuchen, wie sich eine Verdünnung von Endosomen bereits zu Reaktionsbeginn auswirkt, wurde der Standardmix mit Reaktionspuffer um den angegebenen Faktor, d.h. bis zu hundertfach, verdünnt, so dass alle Konzentrationen bis auf die der Endosomen gleich blieben. Aus der Verdünnung der Endosomen resultierte wie Abbildung 3.11 zeigt, interessanterweise 
eine signifikante Reduktion der Fusion, während das Docking praktisch unverändert war.

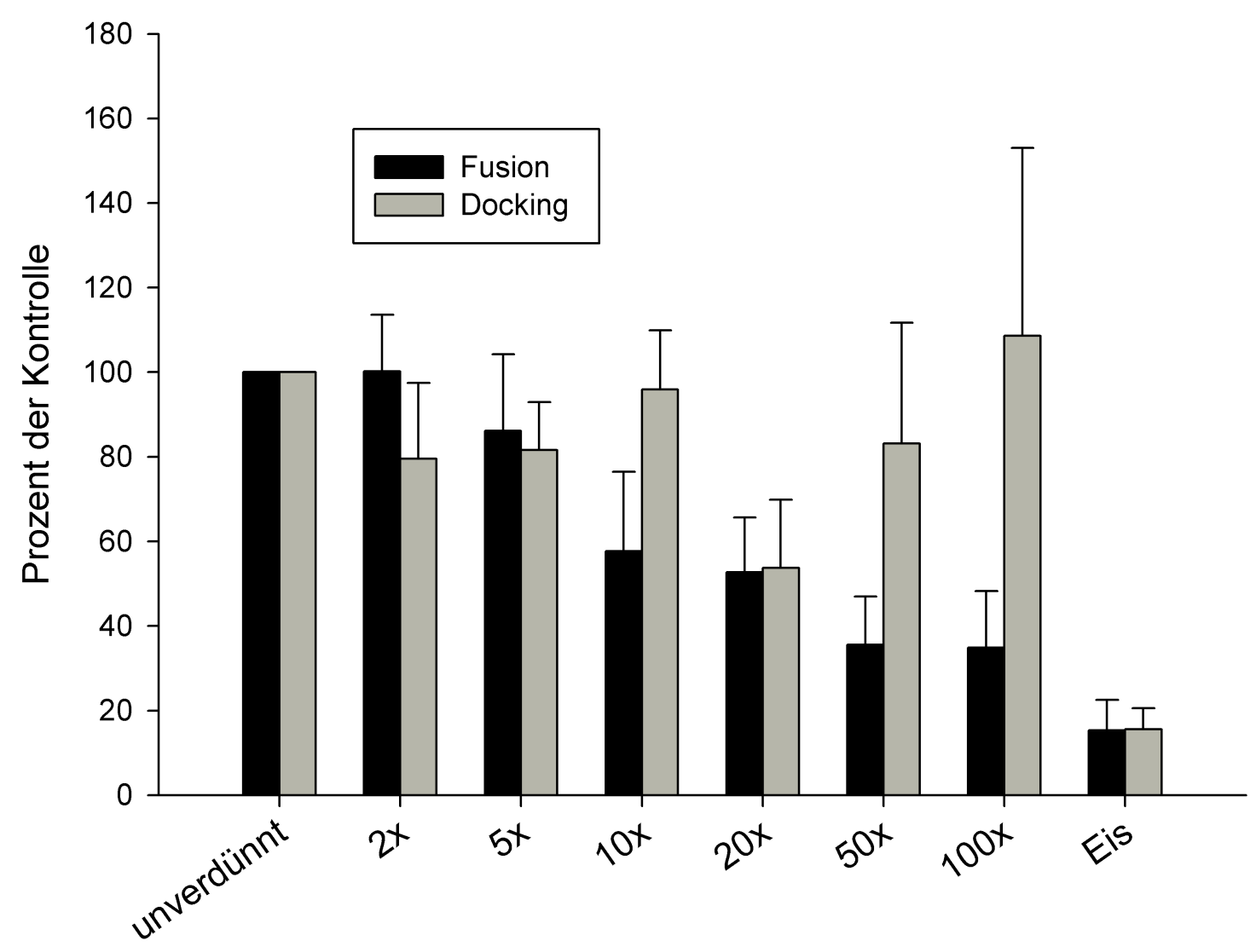

Abbildung 3.11: Verdünnung reduziert die Fusion aber nicht das Docking von Endosomen

Die Endosomenkonzentration im Reaktionsansatz wurde um die angegebenen Faktor reduziert und die Reaktion wie üblich durchgeführt. Die Fusion wurde durch die Verdünnung signifikant reduziert $(\mathrm{p}<0,01)$, während die Endosomen praktisch unverändert aneinander dockten. Gezeigt ist der Mittelwert aus fünf unabhängigen Experimenten mit Standardfehler.

Um dieses Ergebnis besser zu verstehen, wurde ein weiteres Experiment durchgeführt, in dem analysiert werden sollte, wie lange die Endosomen ihre Fusionsfähigkeit behalten. Werden die rot und grün markierten postnukleären Überstände separat für 10 Minuten in dem Reaktionspuffer inkubiert bevor man sie für weitere 45 Minuten kombiniert, fusionieren wesentlich weniger Endosomen als bei sofortigem Mischen (Abbildung 3.12), während das Docking gleich bleibt. Nach ihrer Aktivierung scheint den Endosomen also nur eine sehr begrenzte Zeit zur Verfügung zu stehen, in der sie fusionskompetent sind, während das Docking über einen längern Zeitraum möglich ist. Im verdünnten Zustand treffen einige Endosomen dann nicht schnell genug 


\section{Ergebnisse}

aufeinander, um miteinander zu fusionieren, während der Reaktionszeitraum lang genug ist, dass sie später dennoch aneinander docken können (siehe Diskussion).

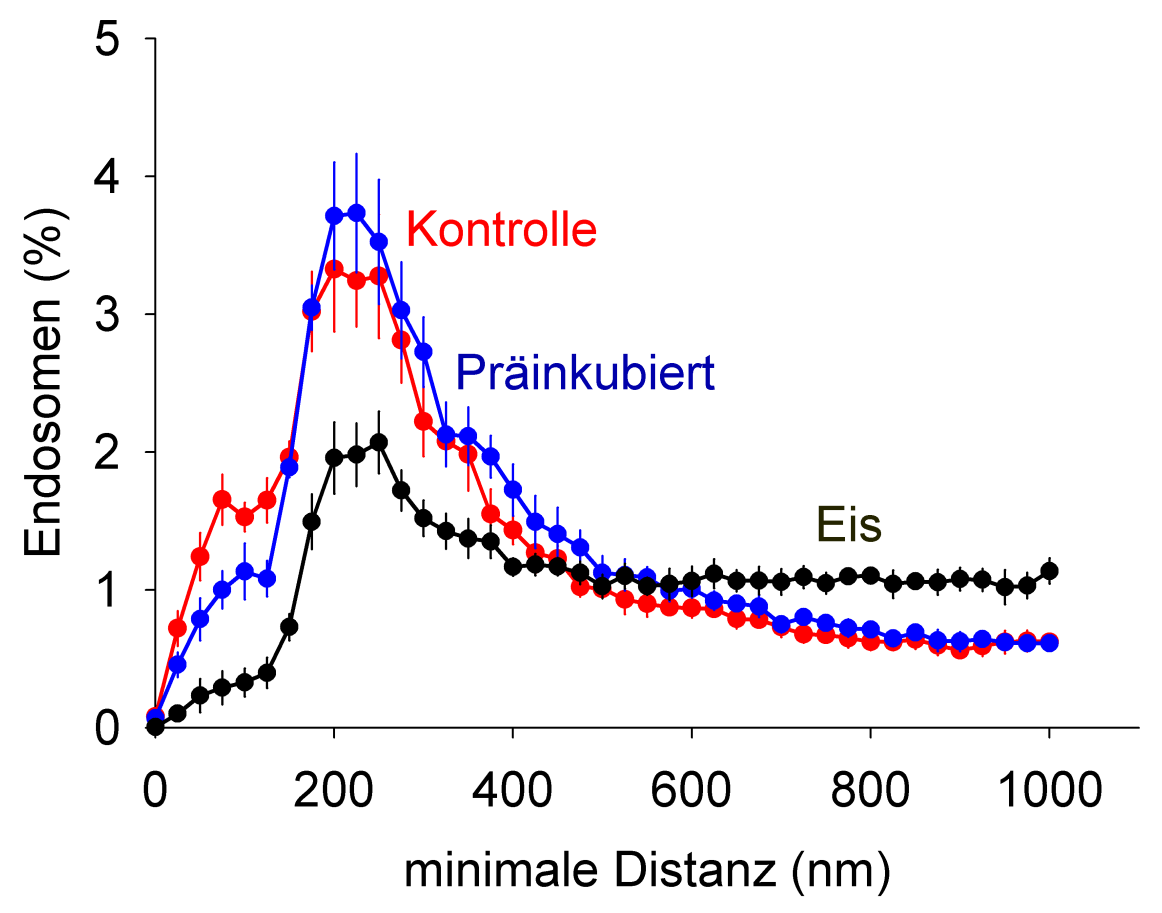

Abbildung 3.12: Der Einfluss von Präinkubation auf die Endosomen-Interaktion Rot und grün markierte Endosomen wurden separat für 10 Minuten bei $37^{\circ} \mathrm{C}$ inkubiert und dann für weitere 45 Minuten vermischt. Während die Anzahl der gedockten Endosomen konstant bleibt, sinkt die der fusionierten signifikant $(\mathrm{p}<0,001)$ um ungefähr 35\%. Gezeigt sind Mittelwerte von sechs unabhängigen Experimenten mit ihren Standardfehlern.

\subsubsection{Die Rolle von SNARE-Proteinen}

Nach der grundlegenden Charakterisierung des Docking sollte untersucht werden, welche Rolle die frühendosomalen SNAREs in diesem Prozess spielen. Hierzu wurden 3 unterschiedliche Methoden eingesetzt, um die Funktion von SNAREs zu inhibieren. SNARE-Proteine liegen in der Membran häufig in einem „inaktiven“ Zustand vor, in dem sie mit anderen SNAREs cis-Komplexe bilden (Bethani et al., 2007) und zunächst eine Aktivierung durch NSF benötigen. Diese Tatsache kann genutzt werden, um die Funktion von SNAREs im Docking zu untersuchen. So blockiert eine inaktive Mutante von $\alpha$ SNAP (L294A), dem Kofaktor von NSF, dessen ATPHydrolyseaktivität und verhindert damit die Dissoziation von cis-SNARE Komplexen, d.h. ihre Aktivierung (Barnard et al., 1997). Diese von Sina Victoria Barysch aus E.coli aufgereinigte Mutante wurde im Überschuss zur Reaktion gegeben, um eine SNARE-Aktivierung zu unterbinden. Während sich die endosomale Fusion dadurch 
deutlich reduzierte, wurde das Docking der Endosomen nur geringfügig beeinträchtigt, wie Abbildung 3.13 zeigt. Die Docking-Reaktion wäre demnach unabhängig von einer SNARE-Funktion.

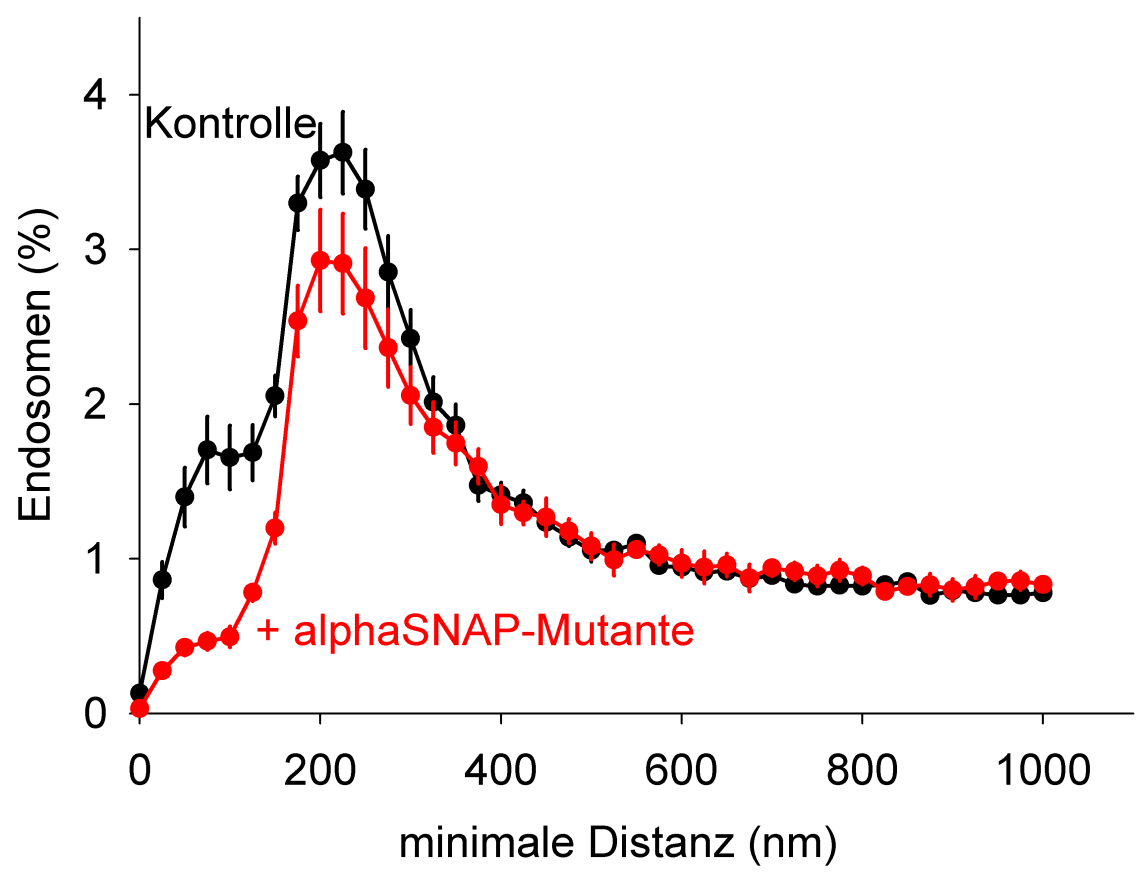

Abbildung 3.13: Docking ist resistent gegenüber NSF-Inhibition

Das Endosomen-Interaktionsassay wurde unter Standardbedingungen oder in Gegenwart von $50 \mu \mathrm{M} \alpha \operatorname{SNAP}(\mathrm{L} 294 \mathrm{~A})$ durchgeführt, um die SNARE-Aktivierung durch NSF zu inhibieren, was eine signifikant reduzierte Fusion zur Folge hatte. Gezeigt ist der Mittelwert von 12 Experimenten mit ihrem Standardfehler.

Eine weitere etablierte Methode, die SNARE-Funktion zu stören, besteht in der Verwendung von löslichen SNARE-Fragmenten (Weber et al., 1998; Zwilling et al., 2007), welche mit den membrangebundenen SNAREs um den Einbau in den core complex konkurrieren. Wurden die zytosolischen Anteile von Syntaxin 6, Syntaxin 13 und Vtila (d.h. die Qabc-SNAREs des frühendosomalen Komplexes) als kompetitive Inhibitoren zur Endosomenreaktion gegeben, reduzierte sich wiederum nur die Fusion signifikant (siehe Abbildung 3.14).

Abschließend wurde die Funktion der frühendosomalen SNAREs durch Zugabe von $\mathrm{F}_{\mathrm{ab}}$-Fragmenten der polyklonalen Antikörper gegen jedes einzelne der vier Proteine inhibiert, ohne dass ein nennenswerter Rückgang des Dockings zu verzeichnen gewesen wäre, wie Abbildung 3.15 zeigt.

Alle drei Varianten SNARE-Funktion zu inhibieren, haben somit kaum Einfluss auf die Docking-Reaktion, was darauf schließen lässt, dass das Docking früher Endosomen im Gegensatz zur Fusion SNARE-unabhängig abläuft. 


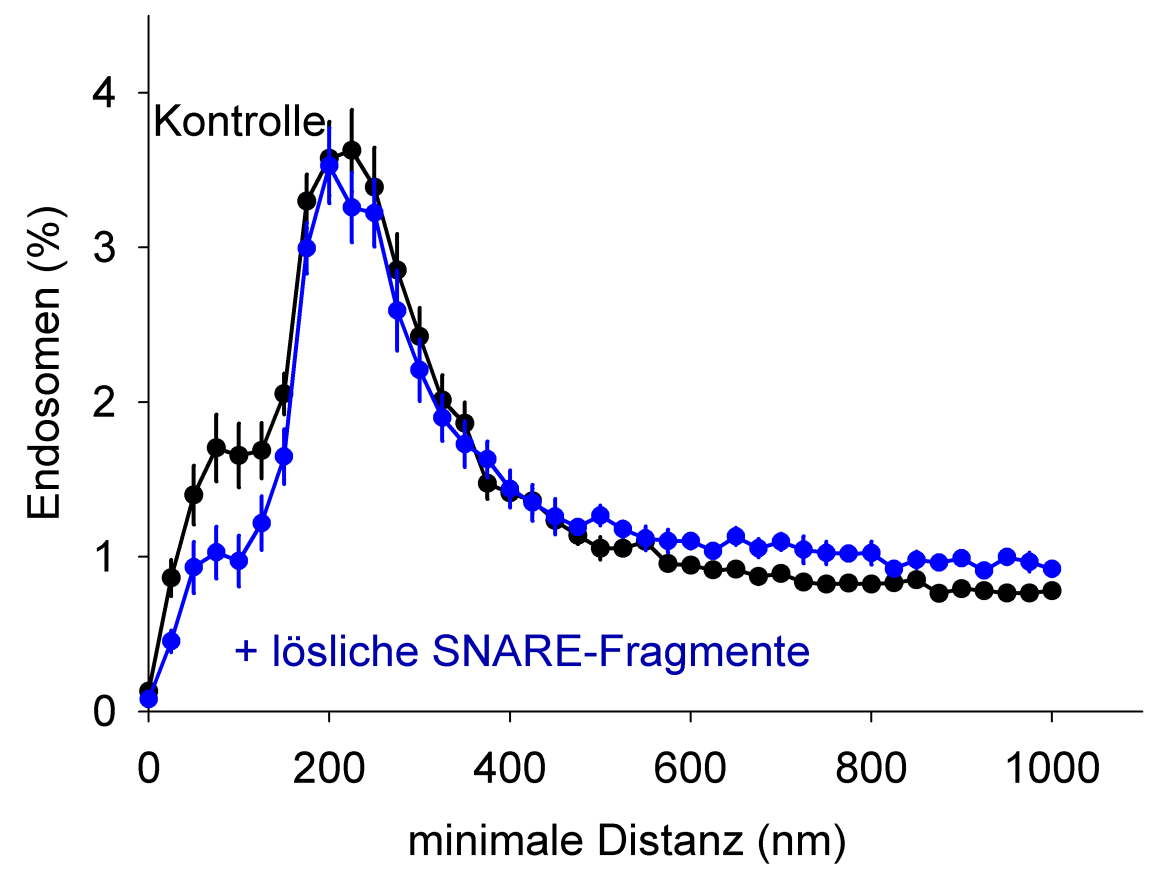

Abbildung 3.14: SNARE-Fragmente inhibieren das Docking nicht

Das Endosomen-Interaktionsassay wurde unter Standardbedingungen oder in Gegenwart von löslichen Fragmenten (je $30 \mu \mathrm{M}$ ) aller drei Q-SNAREs als kompetitiven Inhibitoren durchgeführt. Gezeigt ist der Mittelwert von 7 unabhängigen Experimenten \pm Standardfehler. 


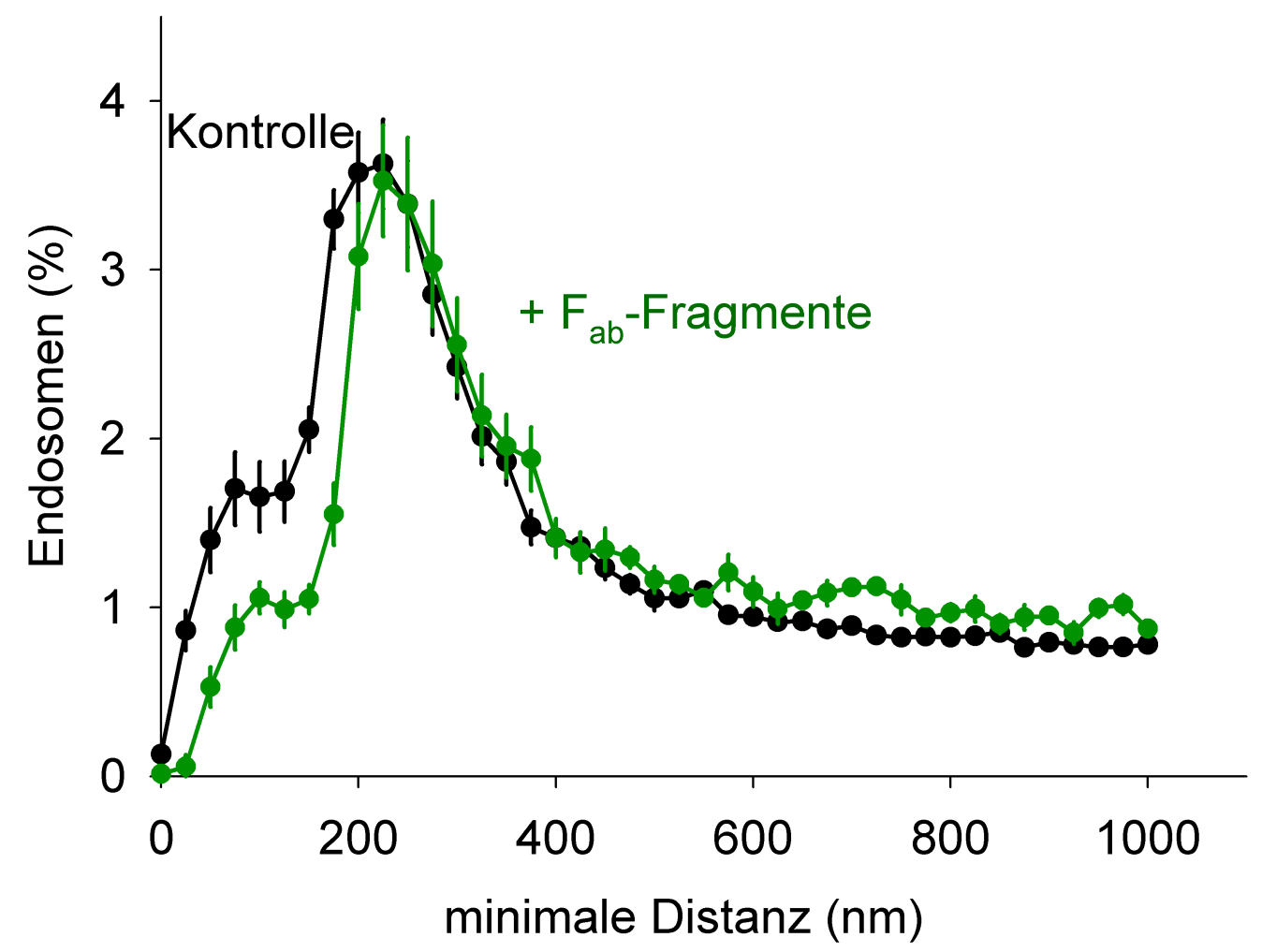

Abbildung 3.15: Der Einfluss von $\mathbf{F}_{\mathbf{a b}}$-Fragmenten auf Fusion und Docking Die Reaktion wurde mit $\mathrm{F}_{\mathrm{ab}}$-Fragmenten gegen alle vier frühendosomalen SNAREs (je $2 \mu \mathrm{g}$ ) 30 Minuten auf Eis vorinkubiert und dann die Inkubation bei $37^{\circ} \mathrm{C}$ für 60 Minuten fortgesetzt. Gezeigt sind die Mittelwerte von 6 unabhängigen Experimenten. 


\subsubsection{Rabs und EEA1}

Die SNARE-Unabhängigkeit des Docking warf die Frage auf, welche anderen Faktoren es kontrollieren könnten. Einer der Kandidaten ist das lange coiled-coil Protein EEA1 (siehe Einleitung), welches nun mit dem neuentwickelten Assay untersucht werden sollte. EEA1 bindet sowohl an Rab5 als auch über seine FYVE Domäne an PI-3-Phosphat. Eine Reduzierung der PI-3-Phosphatkonzentration sollte daher den membrangebundenen, i.e. den aktiven Anteil von EEA1 verringern. Um dies zu erreichen, wurde die Synthese von PI-3-Phosphat durch PI-3-Kinase mit Hilfe des Hemmstoffs Wortmannin blockiert (Shpetner et al., 1996). Wie die Untersuchung der membrangebundenen Fraktion von EEA1 durch Westernblot zeigte, wurde auf diese Weise die Membranfraktion von EEA1 um etwa $75 \%$ reduziert (siehe Abbildung 3.16). Auch funktionell hatte die Inhibition der PI-3-Kinase einen großen Einfluss

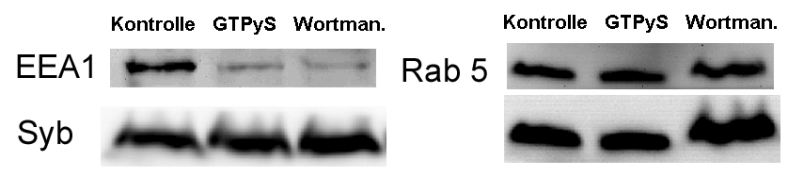

\section{Abbildung 3.16: Der Einfluss von Wortmannin und GTP $\gamma \mathbf{S}$}

Die Reaktionsansätze wurden in Gegenwart des nicht hydrolysierbaren GTP-Analogons GTP $\gamma \mathrm{S}$ bzw. des PI-3-Kinase Inhibitors Wortmannin für 60 Minuten bei $37^{\circ} \mathrm{C}$ inkubiert. Anschließend wurde die Membranfraktion mittels Ultrazentrifugation abgetrennt, das Pellet aufgenommen und durch Westernblot untersucht. Synaptobrevin diente als Ladekontrolle, gezeigt ist ein repräsentativer Blot.

auf das Docking, das dadurch um über 50 Prozent reduziert wurde (siehe Abbildung 3.17). Ähnliches galt, wenn ein FYVE-Peptid, welches mit EEA1 um die Bindung an PI3-Phosphat konkurriert, zur Reaktion gegeben wurde: die Anzahl gedockter Endosomen sank dadurch um 40\%. Allerdings ist EEA1 natürlich nicht das einzige PI3-Phosphat-bindende Protein. Um die Inhibition noch spezifischer zu gestalten wurde daher versucht, seine Funktion durch die Inkubation mit einem polyklonalen Antikörperserum zu blockieren. Die resultierende Verringerung des Docking war, wie Abbildung 3.17 zeigt, mit ungefähr 20 Prozent zwar klein aber signifikant $(p<0,05)$ und konnte durch die Zugabe des Peptides gegen das der Antikörper hergestellt wurde verhindert werden, was des spezifischen Einfluss von EEA1 belegt.

Neben EEA1 kommt, wie in der Einleitung beschrieben, auch anderen Rab5-Effektoren eine wichtige Rolle beim endosomalen Docking zu. Es wurde daher untersucht, wie sich eine Hemmung der gesamten Rab5-Regulation auf das Docking früher Endosomen auswirkt, indem Rabs durch Zugabe des GDP-Dissoziationsinhibitors (GDI) weitgehend von der Membran entfernt wurden, wie der Blot für den frühendosomalen Marker Rab5 beispielhaft zeigt (Abbildung 3.16). 


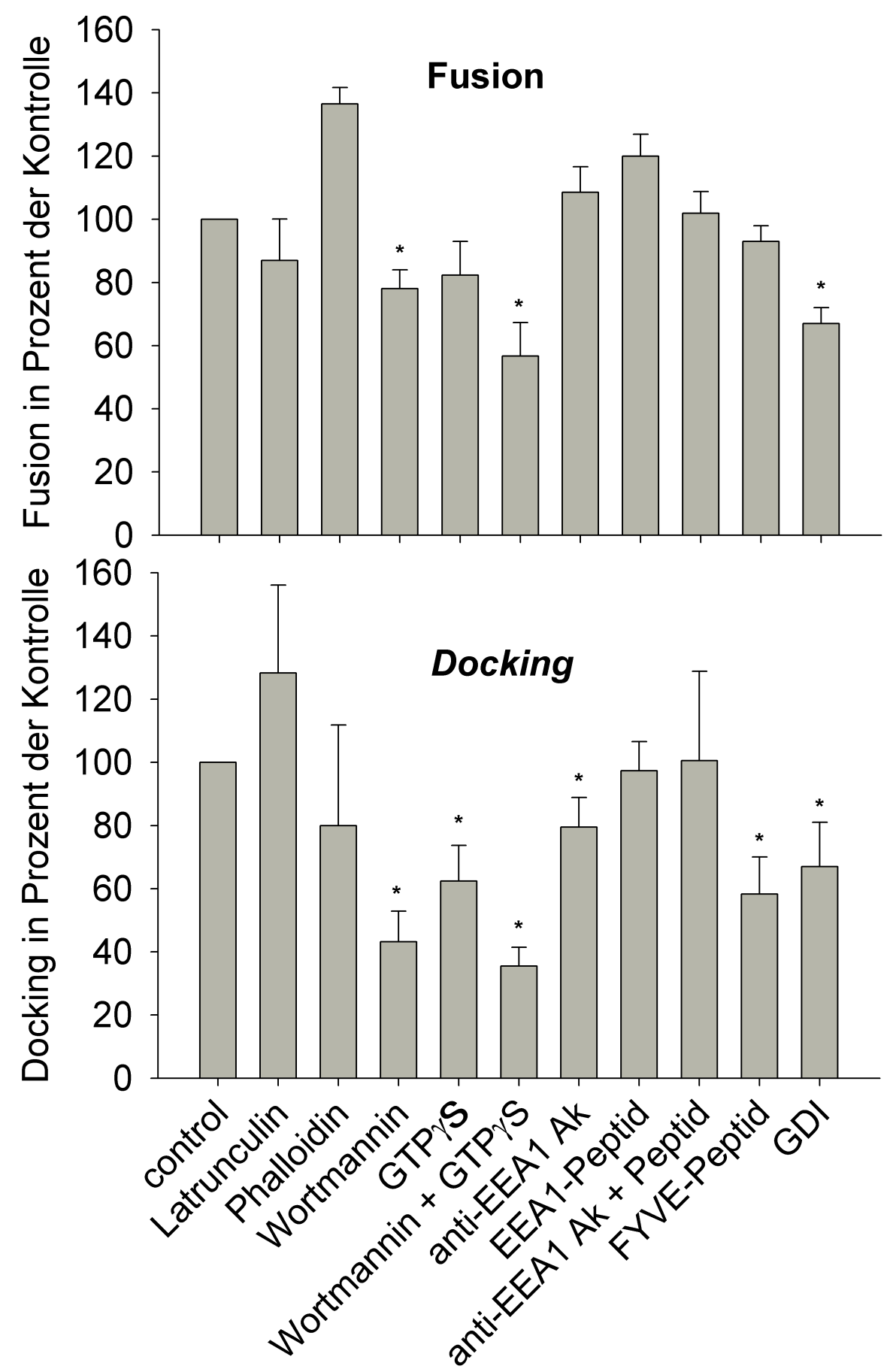

Abbildung 3.17: Analyse potentieller Einflussfaktoren auf Docking und Fusion Fusion (oben) und Docking (unten) früher Endosomen wurden unter dem Einfluss folgender Faktoren untersucht: Latrunculin A $(15 \mu \mathrm{M})$, Phalloidin $(10 \mu \mathrm{M})$, Wortmannin $(50 \mathrm{nM}), \operatorname{GTP} \gamma \mathrm{S}(200 \mu \mathrm{M})$, GDI $(10 \mu \mathrm{M})$, FYVE-Peptid $(600 \mu \mathrm{M})$, anti-EEA1-Serum $(60 \mathrm{\mu l} / \mathrm{ml})$. GDI und das anti-EEA1 Serum wurden für $30 \mathrm{~min}$ auf Eis mit dem Reaktionsansatz vorinkubiert, um eine Rab5 Freisetzung bzw. eine Antikörperbindung zu ermöglichen. Die Balken zeigen die Mittelwerte von 3-11 unabhängigen Experimenten \pm SEM. Signifikante Inhibition im Vergleich zur Kontrolle ist durch einen „*“ hervorgehoben. $(\mathrm{p}<0,05$, student's t-test). 


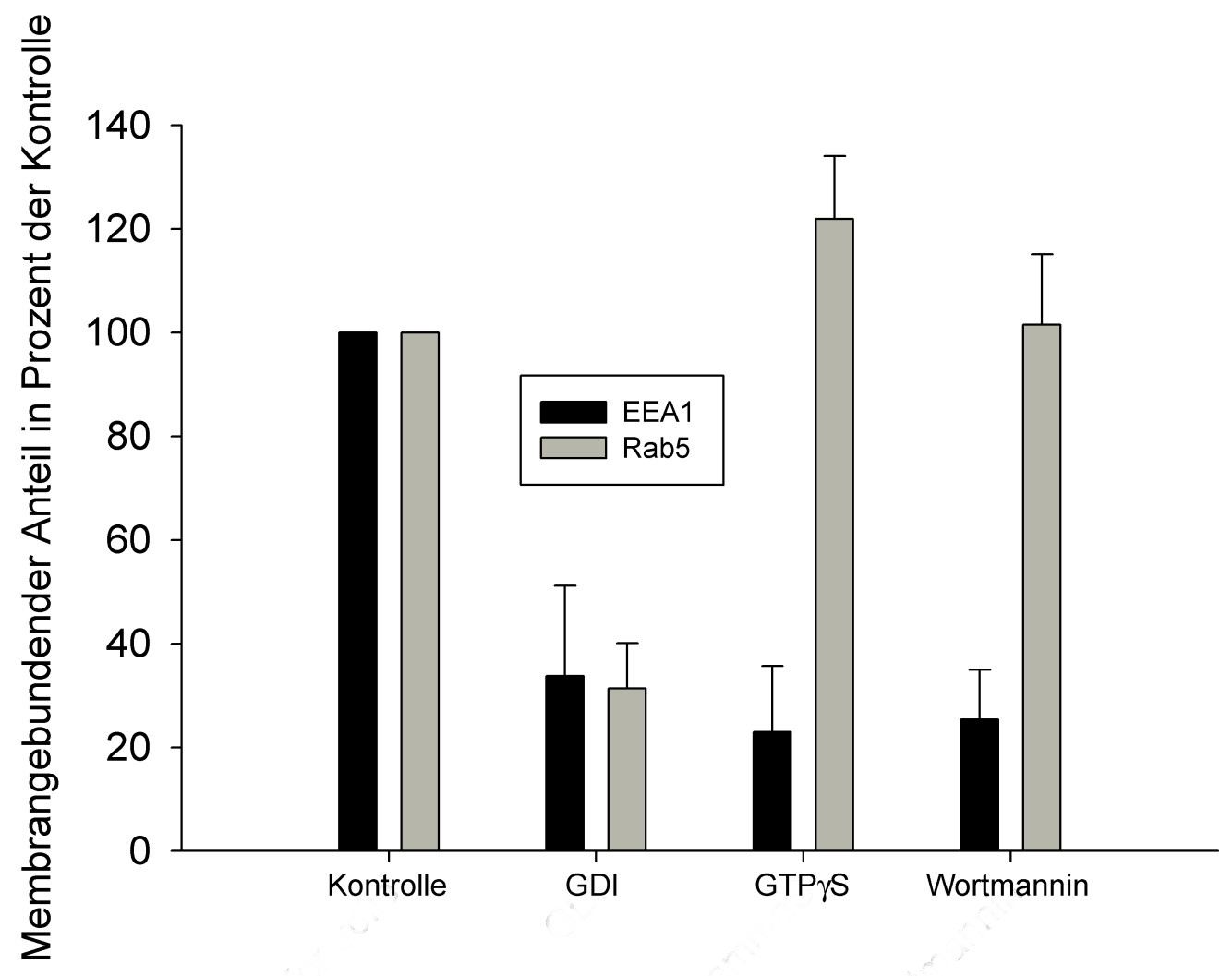

Abbildung 3.18: Membranfreisetzung von Rab5 und EEA1

Nach 60 min Inkubation bei $37^{\circ} \mathrm{C}$ wurden die Reaktionsansätze des EndosomenInteraktionsassays ultrazentrifugiert und die Menge von Rab5 und EEA1 im Pellet durch Westernblot bestimmt. Die ECL-Signale wurden auf das Synaptophysinsignal der Probe (als Ladekontrolle) und die Kontrolle des jeweiligen Experiments normalisiert. Für die GDI-Proben erfolgte die Zentrifugation sofort nach der 30minütigen Vorinkubation auf Eis, um festzustellen, wie schnell das GDI wirkt. Diese Daten sind daher nicht direkt mit den GTP $\gamma$ S und Wortmannin Ergebnissen zu vergleichen, sondern nur mit der eigens durchgeführten Kontrolle. Gezeigt sind die Mittelwerte von 3-4 unabhängigen Experimenten mit Standardfehler. 
GDI bindet Rab5 in seinem inaktiven (GDP gebundenen) Zustand, extrahiert seinen Membrananker und entfernt es von der Membran (Ullrich et al., 1994). Die reduzierte Membranlokalisation von Rab5 ging mit einem entsprechenden Verlust seines Bindungspartners EEA1 einher und auch das Docking war wiederum signifikant verringert. Um zu testen, ob erhöhte Rab5-Level mit einem verstärkten Docking einhergehen, wurde das nicht hydrolysierbare GTP-Analogon GTP $\gamma$ S zur Reaktion gegeben. Wie Abbildung 3.18 zeigt, konnte der membrangebundene Anteil von Rab5 zwar leicht erhöht werden, aber dadurch nahm das Docking nicht zu, sondern ab. Ein wichtiger Grund hierfür ist wahrscheinlich, dass überraschenderweise nach GTP $\gamma \mathrm{S}$ Behandlung weniger EEA1 auf der Membran gefunden wurde (siehe Abbildungen 3.16 und 3.18), was für den Rückgang des Docking verantwortlich sein könnte. Dies deutet auf einen GTP-Hydrolyse abhängigen Schritt in der Rekrutierung von EEA1 hin und zeigt gleichzeitig, dass Rab5 allein nicht ausreicht, um EEA1 an die Membran zu holen (in Übereinstimmung mit (Jones et al., 1998)). Die Identifizierung von EEA1 und Rab5 als zentralen Faktoren des Docking bestätigt frühere Beobachtungen (Christoforidis et al., 1999a) und validiert gleichzeitig die Spezifität des neuentwickelten Assays.

\subsection{Die Fusion früher Endosomen}

\subsubsection{Die Liposomenfusion mittels frühendosomaler SNAREs}

Eines der etabliertesten Systeme, um Membranfusion in vitro zu untersuchen ist der Einsatz von künstlichen Vesikeln, so genannten Liposomen. Deren Fusion lässt sich unter anderem durch das auch in dieser Studie verwendete Dequenching-Assay verfolgen (Struck et al., 1981; Weber et al., 1998). Dabei enthält eine der Liposomenpopulationen NBD-Phosphatidyl-ethanolamin und Rhodamin-Phosphatidylethanolamin in einer so hohen Konzentration (je 1,5\%), dass die NBD-Fluoreszenz durch Rhodamin gelöscht wird. Das heisst, dass von NBD-freigesetzte Licht wird direkt von Rhodamin absorbiert, so dass nur eine geringe Fluoreszenz beobachtet werden kann. Eine Fusion dieser Donor-Liposomen mit unmarkierten Akzeptorliposomen führt zur Verdünnung der Flurophore, einem geringeren Quenching und damit zu einem Anstieg des NBD-Signals.

Dass SNARE Proteine ausreichen, um Liposomen fusionieren zu lassen, wurde ursprünglich 1998 von Weber und seinen Kollegen unter Einsatz der neuronalen SNAREs Syntaxin-1, SNAP-25 und Synaptobrevin gezeigt. Der Nachweis, dass auch die frühendosomalen SNAREs Syntaxin 6, Syntaxin 13, Vti1a und VAMP4 dieses vermögen, wurde erst kürzlich von Daniel Zwilling in einer vorangegangenen Arbeit dieses 
Labors erbracht (Zwilling et al., 2007; Brandhorst et al., 2006). Wie Abbildung 3.19 zeigt, konnte dieses Ergebnis reproduziert werden. Liposomen, die das R-SNARE VAMP4 enthalten, fusionieren mit Liposomen, die die Q-SNAREs Syntaxin 6, Syntaxin 13 und Vtila enthalten. Die Spezifität, d.h. die SNARE-Abhängigkeit, dieser Reaktion lässt sich z.B. dadurch zeigen, dass die Zugabe des löslichen Fragments von VAMP4 (als kompetitiver Inhibitor) die Fusion sehr stark reduziert.

Ein Ziel der vorliegenden Arbeit sollte es sein, die Regulationsmechanismen dieser frühendosomalen SNAREs zu untersuchen. Um herauszufinden, ob lösliche Faktoren eine Rolle bei der Liposomenfusion spielen, wurde die Reaktion in Gegenwart von Zytosol durchgeführt. Wie Abbildung 3.20 zeigt, hat die Zugabe von Zytosol keine Auswirkungen auf die Fusion von Proteoliposomen, was darauf hindeuten könnte, dass eine Regulation der SNARE-Proteine durch Proteine erfolgt, die ebenfalls membrangebunden sind. Interessanterweise führt jedoch die Vorinkubation der markierten Liposomen (VAMP4) mit Zytosol $\left(10 \min 37^{\circ} \mathrm{C}\right) \mathrm{zu}$ einer deutlichen Beschleunigung des Reaktionsverlaufs, wie Abbildung 3.20 zeigt. Der Grund hierfür ist unklar.

\subsubsection{Die Fusion von Proteoliposomen mit Endosomen}

Um das komplette Set der endosomalen Transmembranproteine als potentielle Regulatoren in die Analyse einbeziehen zu können, wurden die unmarkierten AkzeptorLiposomen durch frühe Endosomen ersetzt, so dass einer der beiden Fusionsparnter nun eine native Membran darstellte, während der andere frei modifiziert werden konnte. Die Endosomen wurden aus PC12-Zellen isoliert, indem man, wie zuvor bereits beschrieben, zunächst PNS herstellte und diesen dann einer diskontinuierlichen Saccharose-Ultrazentrifugation unterzog. Hierzu wurde der postnukleäre Überstand 1:1 mit 62\%iger Saccharoselösung gemixt und diese Mischung dann zunächst mit 35\%iger Saccharoselösung, dann mit 25\%iger Saccharoselösung und abschließend mit Homogenisierungspuffer überschichtet. Zwischen der der 35\%igen und der 25\%igen Saccharoselösung bildete sich nach der Zentrifugation eine Bande in der frühe Endosomen angereichert waren. Diese wurde isoliert, aliquotiert und in flüssigem Stickstoff eingefroren. In dieser Weise aufgereinigte Endosomen bildeten die Grundlage der im folgenden beschriebenen Experimente.

\section{Grundlegende Eigenschaften}

Um die Komplexität des Systems nur schrittweise zu steigern, wurden die Experimente zunächst ohne Zusatz von Zytosol durchgeführt. VAMP4-haltige Liposomen 


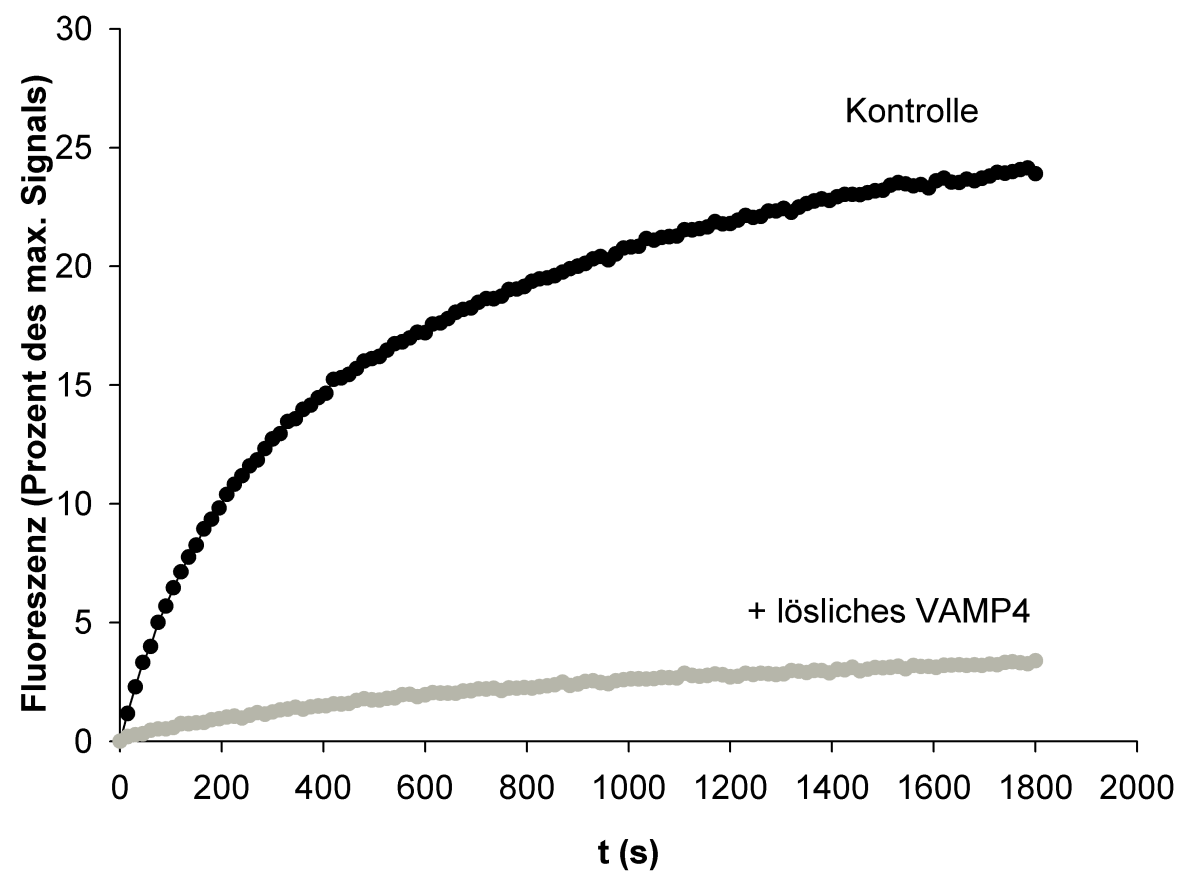

Abbildung 3.19: Liposomenfusion mit endosomalen SNARE-Proteinen

Es wurden NBD/Rhodamin-PE-haltige VAMP4-Liposomen und unmarkierte Syntaxin 6/Syntaxin 13/Vti1a-Liposomen mittels Gelfiltration hergestellt (Methode 1) und bei $37^{\circ} \mathrm{C}$ im Verhältnis von 1:7 inkubiert. Die Fusion der Liposomen führt zu einem Dequenching, dass bei $538 \mathrm{~nm}$ verfolgt werden kann (siehe Material und Methoden, Abschnitt 2.6.2). Nach 30 Minuten wurde 2\%-Triton zur Reaktion gegeben, um das maximal mögliche Dequenching zu erhalten. Die gezeigten Kurven sind auf dieses und die Anfangsfluoreszenz nach folgender Gleichung $\frac{F_{\text {Reaktionsende }}-F_{\text {Reaktionsbeginn }}}{F_{\text {max.Verduennung }}-F_{\text {Rekationsbeginn }}} \bullet 100$ normiert, d.h. sie drücken den prozentualen Anteil am maximal beobachtbaren Signal aus. Die Zugabe von löslichem VAMP4 $(8 \mu \mathrm{M})$ inhibierte die Reaktion stark. 


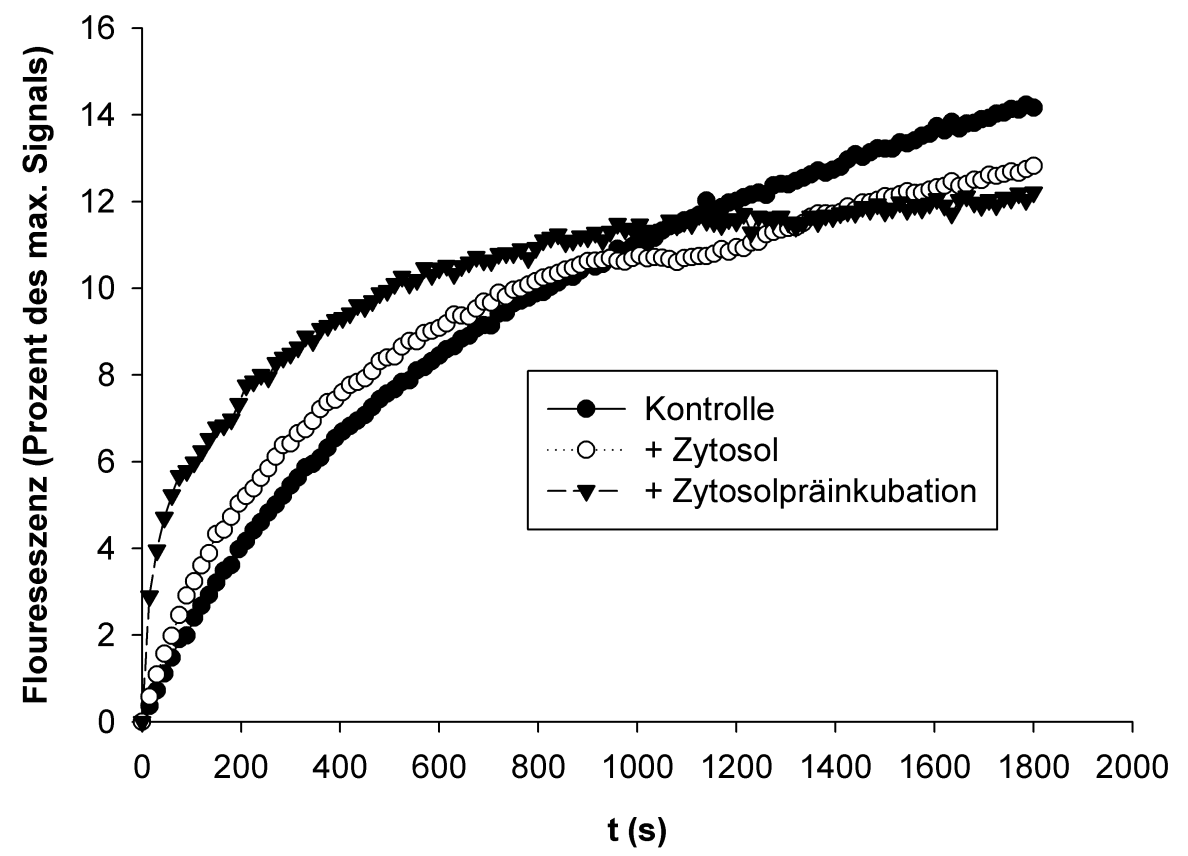

Abbildung 3.20: Der Einfluss von Zytosol auf die Reaktion

NBD/Rhodaminhaltige VAMP4 Liposomen, wurden mit unmarkierten Syntaxin 6/Syntaxin 13/Vtila Liposomen im Verhältnis 1:7 gemischt. Während die Zugabe von Zytosol $(1,4 \mathrm{mg} / \mathrm{ml}$ Endkonzentration) allein kaum Einfluss auf die Reaktion hatte, sorgte eine 10minütige Präinkubation der VAMP4-Liposomen mit Zytosol für eine stark beschleunigte Reaktion. Gezeigt ist der Signalanstieg in Prozent des maximalen Signals für ein repräsentatives Experiment. 
fusionieren mit Endosomen, aber im Gegensatz zur Liposom-Liposom-Fusion ist der Effekt des löslichen VAMP4 als Inhibitor hier nur gering (Abbildung 3.21).

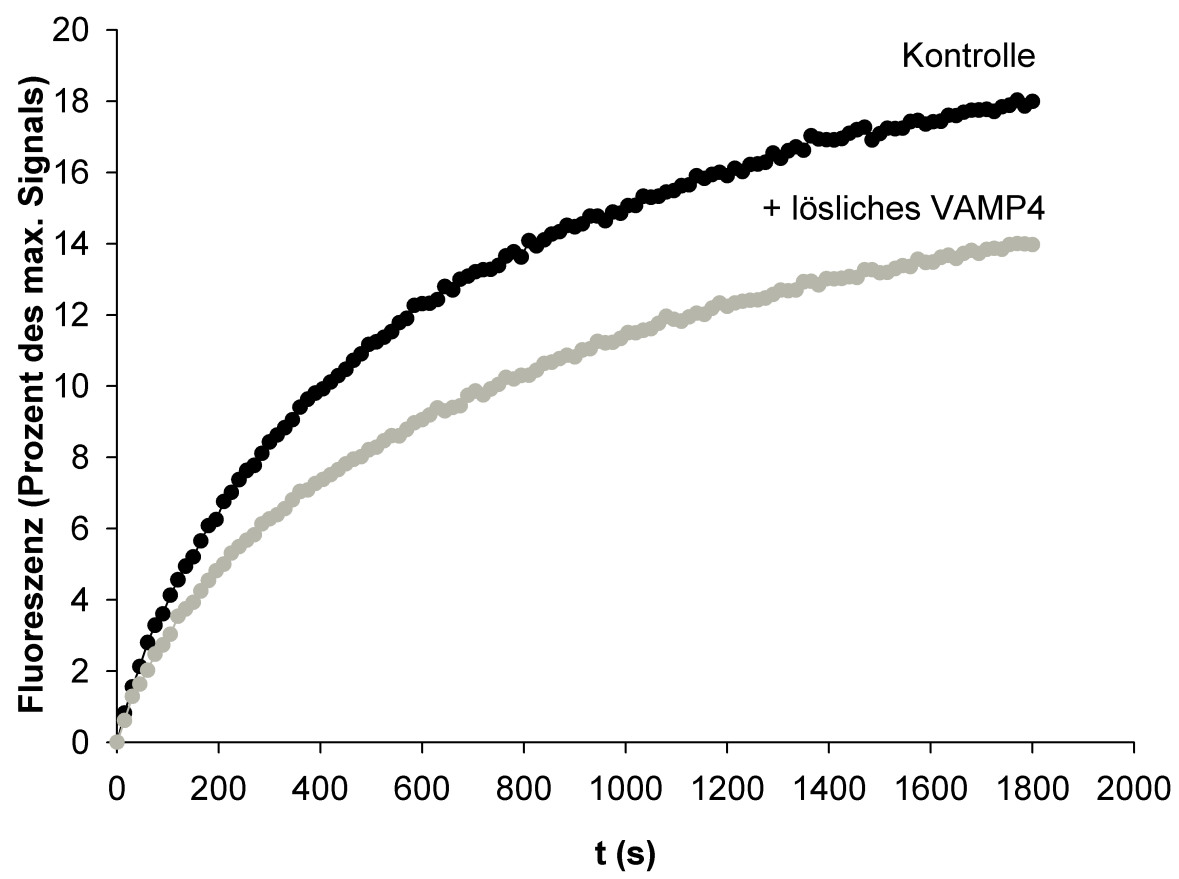

Abbildung 3.21: Die Endosom-Liposom-Fusion lässt sich kaum stoppen PC12-Endosomen wurden mit NBD/Rhodamin-PE enthaltenden VAMP4-Liposomen bei $37^{\circ} \mathrm{C}$ inkubiert. Die Zugabe von löslichem VAMP4 $(10 \mu \mathrm{M})$ hat kaum Einfluss auf die Reaktion. Gezeigt ist ein beispielhaftes Experiment.

Ein möglicher Grund hierfür könnte sein, dass sich in der Endosomenpräparation auch NSF befindet, welches die mit zytosolischem VAMP4 gebildeten Komplexe auflösen und dadurch seine inhibitorische Wirkung verringern könnte. Allerdings konnten proteinfreie Liposomen im Versuch ähnlich gut mit Endosomen fusionieren wie Proteoliposomen (siehe Abbildung 3.22), was auf eine SNARE-unahbängige Reaktion hinweist. Um völlig sicherzugehen, dass die Reaktion unabhängig vom SNARE-Gehalt der Liposomen ist, wurde eine dritte Kontrolle durchgeführt, bei der die Proteoliposomen mit Trypsin behandelt wurden, ohne dass sich die Fusionsrate dadurch erniedrigte. Nach diesen Ergebnissen, stellte sich die Frage, ob die Fusion überhaupt proteinvermittelt ist, oder auf eine Kontamination z.B. mit bivalenten Ionen oder Detergentien zurückzuführen ist. Um dies zu klären, wurden die Endosomen mit Trypsin behandelt und, wie Abbildung 3.23 zeigt, ist endosomales Protein für die Fusion erforderlich. Die Reaktion ist jedoch ATP-unabhängig, d.h. sie lässt sich nicht durch Zugabe eines ATP-verbrauchenden Puffers inhibieren (Daten nicht gezeigt). Auch Kalzium scheint, im Gegensatz zur Endosom-Endosom-Fusion (siehe Abschnitt 3.1.4), keine Rolle zu spielen, da der Chelator BAPTA die Reaktion nicht inhibiert, wie Abbildung 3.24 zeigt. 


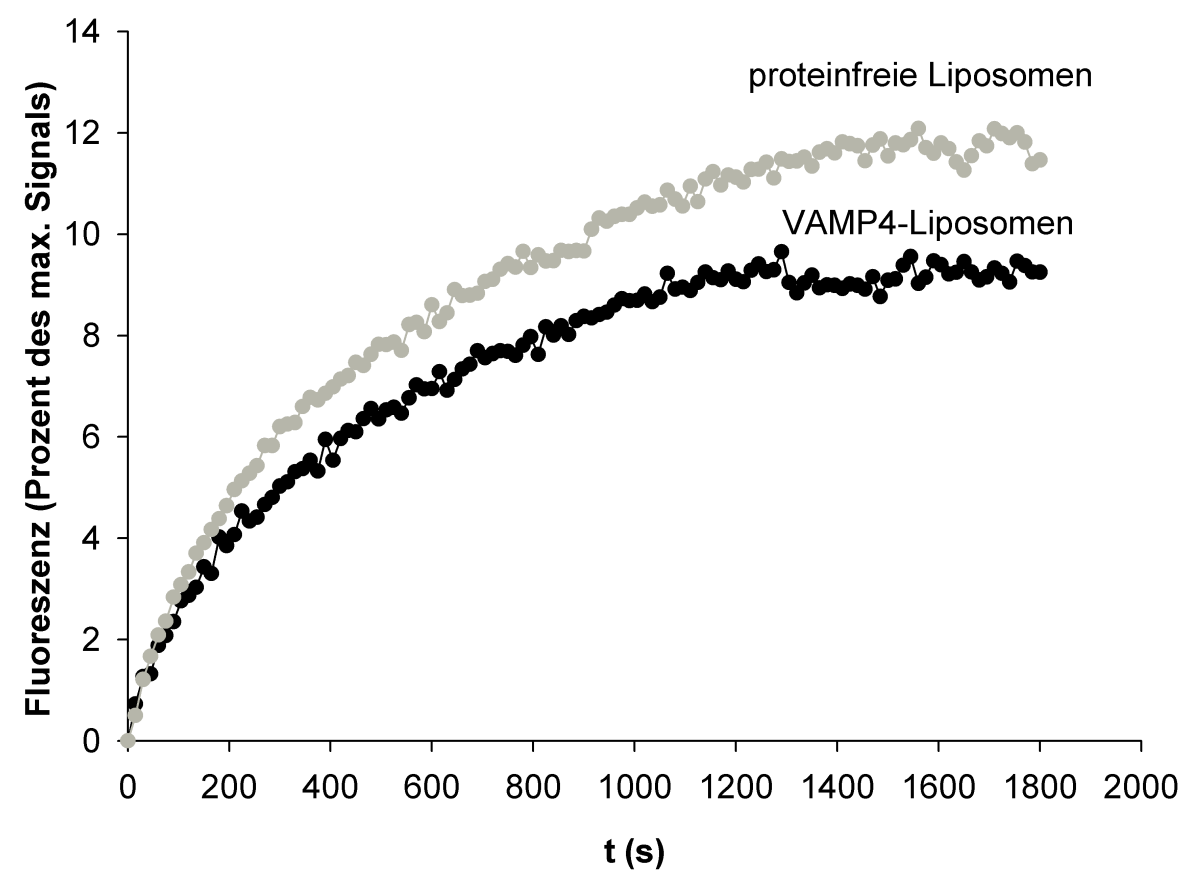

Abbildung 3.22: Proteinfreie Liposomen fusionieren mit Endosomen

VAMP4-haltige und proteinfreie Liposomen wurden mittels Gelfiltration hergestellt und mit Endosomen für 30 Minuten bei $37^{\circ} \mathrm{C}$ inkubiert bevor die Reaktion durch Zugabe von Triton X-100 gestoppt wurde.

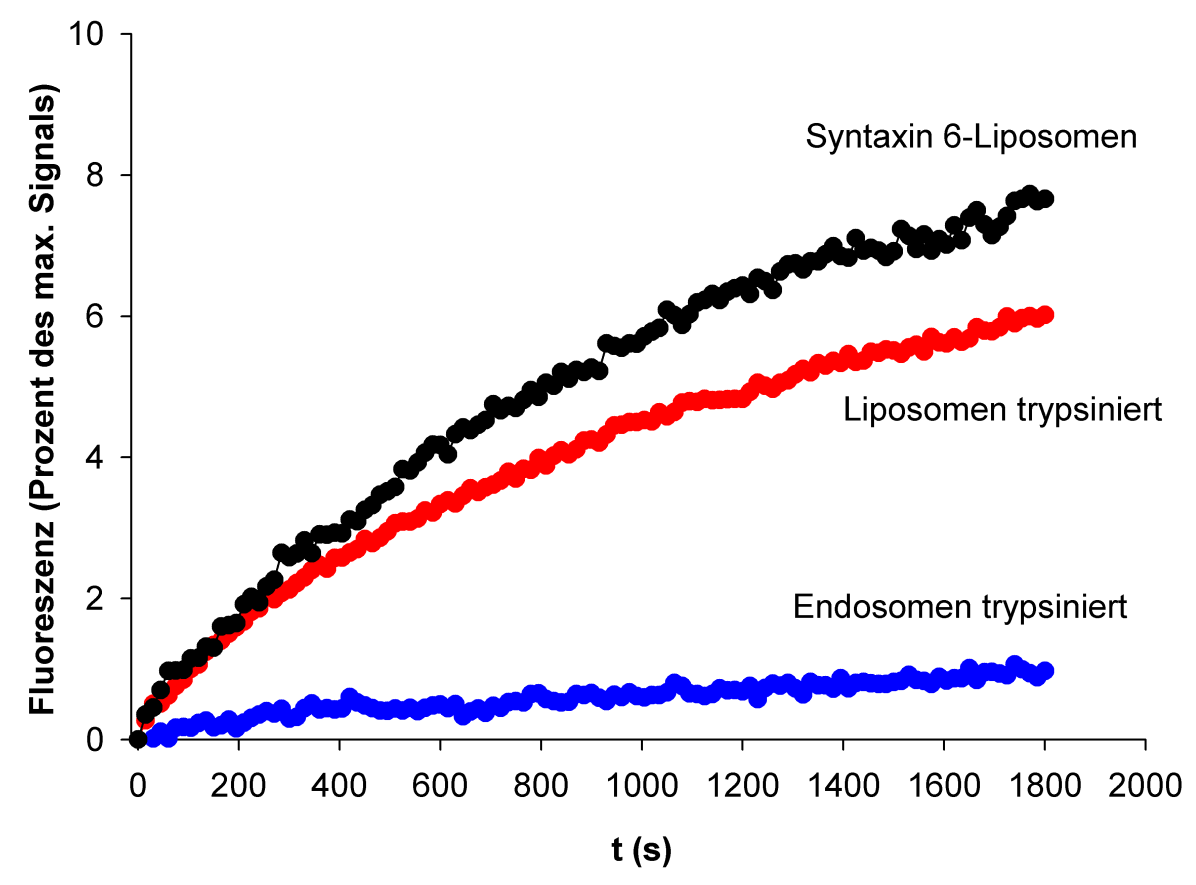

Abbildung 3.23: Der Einfluss von Trypsin auf die Reaktion

Gezeigt ist die Fusion von NBD/Rhodamin-PE markierten Syntaxin 6-Liposomen mit Endosomen. Jeweils Endosomen oder Liposomen wurden mit 0,1 mg/ml Trypsin für $1 \mathrm{~h}$ verdaut woraus für den Endosomenverdau eine deutliche Reduktion der Fusion resultierte. 


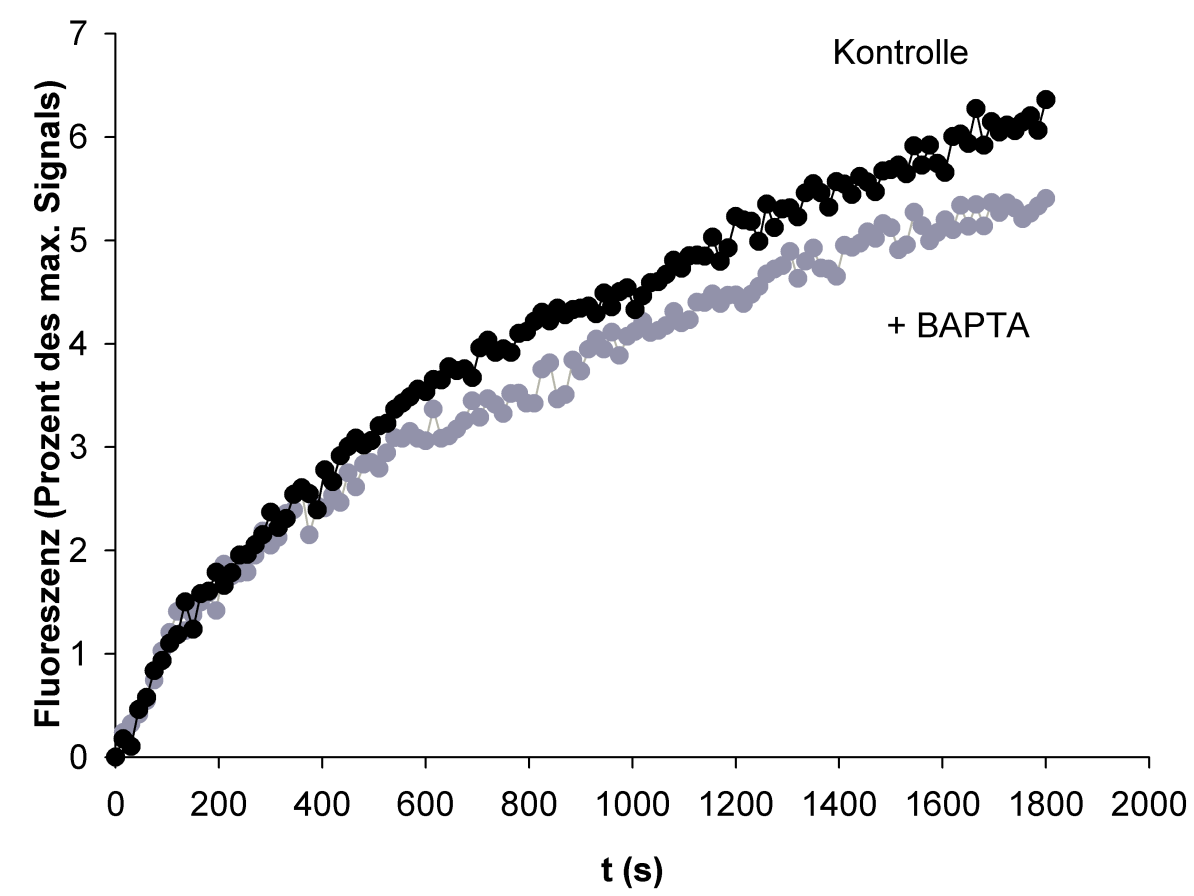

Abbildung 3.24: Der Einfluss von BAPTA auf die Liposom-Endosom-Fusion Die Zugabe von BAPTA $(5 \mathrm{mM})$ zur Reaktion hat keinen Einfluss auf die Fusion von Endosomen mit Liposomen.

Handelt es sich bei der beobachteten Lipidvermischung wirklich um Fusion, oder werden die Ergebnisse durch einen unspezifischen Lipidtransfer verfälscht? Um diese Frage zu beantworten, wurde überprüft, ob neben einem Lipidaustausch auch ein Proteinaustausch stattfindet. Liposomen, welche VAMP4 mit einem N-terminalen HA-tag enthielten, wurden mit Endosomen inkubiert und anschließend auf zur Einbettung für die Elektronenmikroskopie geeignete Folie zentrifugiert. Die Proben wurden einer anti-HA und anti-Synaptophysin Immunogoldfärbung unterzogen, um sowohl das liposomale als auch das endosomale Protein identifizieren zu können. Anschließend wurde die Probe fixiert, eingebettet und elektronenmikroskopisch untersucht. Wie Abbildung 3.25C zeigt, finden sich HA-VAMP4 und Synaptophysin auf derselben Membran, es hat also echte Fusion stattgefunden. Daraus folgt, dass zur Fusion von Endosomen mit Liposomen keine Proteine in der liposomalen Membran notwendig sind.

\section{Kolokalisation}

Um zu erfahren, ein wie hoher Anteil der Endosomen und Liposomen im Ansatz miteinander reagiert und damit für das Dequenchingsignal verantwortlich ist wurde ihre Kolokalsiation untersucht. Die Endosomen wurden hierzu mit Octadecylrhodamin 

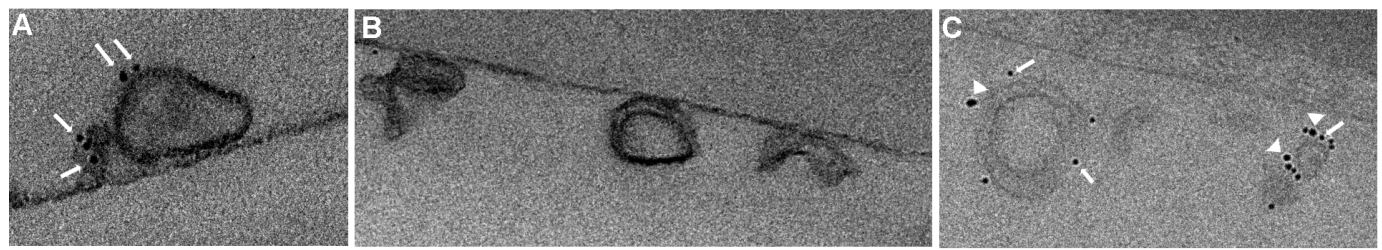

\section{Abbildung 3.25: Endosomale und liposomale Proteine finden sich nach der Fu- sion in derselben Membran}

Endosomen wurden mit HA-VAMP4 Liposomen inkubiert, auf Plastik immungefärbt, eingebettet und elektronenmikroskopisch untersucht. (A) anti-HA Immunfärbung von Liposomen und Endosomen, (B) ohne Liposomen, und (C) Doppelfärbung anti-HA 6 nMGold(schmale Pfeile) und anti-Synaptophysin 10 nM-Gold (breite Pfeile).

gefärbt, indem PNS 20 Minuten mit diesem in die Membran inserierenden Flurophor inkubiert wurde. Durch die Ultrazentrifugation zur Endosomenanreicherung wurde nicht eingebautes Rhodamin abgetrennt. Bei der Herstellung der Liposomen wurde statt NBD/Rhodamin der ebenfalls PE-gekoppelte Farbstoff OregonGreen ${ }^{\mathrm{TM}}$ eingebaut, um die Liposomen von den Endosomen unterscheiden zu können. Um Zentrifugationsartefakte zu vermeiden (Liposomen, die fusioniert haben sind schwerer und werden daher mit höherer Wahrscheinlichkeit auf dem Deckgläschen landen, usw.) und die Erstellung einer Zeitreihe zu ermöglichen wurden die Reaktionsansätze in Agarose „eingefroren”. Tiefschmelzende Agarose wurde kurz oberhalb ihres Schmelzpunktes gehalten, mit der Probe gemischt und auf eisgekühlte Objektträger aufgebracht. Nachdem die Agarose fest geworden war, wurden die Proben mikroskopiert. Die Kolokalisationsbestimmung von Endosomen und Liposomen erfolgte mittels line scans, d.h. der Bestimmung des Fluoreszenzmusters über 25 Pixel hinweg, durch im Fokus liegende Endosomen und die Berechnung ihres Korrelationskoeffizienten mit Hilfe eines Matlab-Programms (siehe Material und Methoden). Wie Abbildung 3.26 zeigt, wird ein sehr hoher Grad an Kolokalisation (d.h. Endosomen und Liposomen deren line scan Korrelationskoeffizient über 0,8 liegt) erreicht. Interessanterweise tritt selbst bei den trypsinierten Endosomen eine hohe Kolokalisation mit den Liposomen auf. Obwohl trypsinierte Endosomen, wie durch das Dequenchingassay festgestellt, nicht mehr fusionieren, zeigt ihre Kolokalisation, dass sie noch aneinander haften können. Auch bei dauerhaftem Kontakt zwischen Liposomen und Endosomen kommt es also nicht automatisch zu einer Fusion der beiden Membranen, sondern es ist immer die Mitwirkung zumindest der endosomalen Proteine erforderlich. Dies bestätigt frühere Beobachtungen, das eine vorangehende Aggregation von Liposomen (mittels Biotin-Streptavidin) kaum Auswirkung auf die Fusionsreaktion hat (Schuette et al., 2004). 


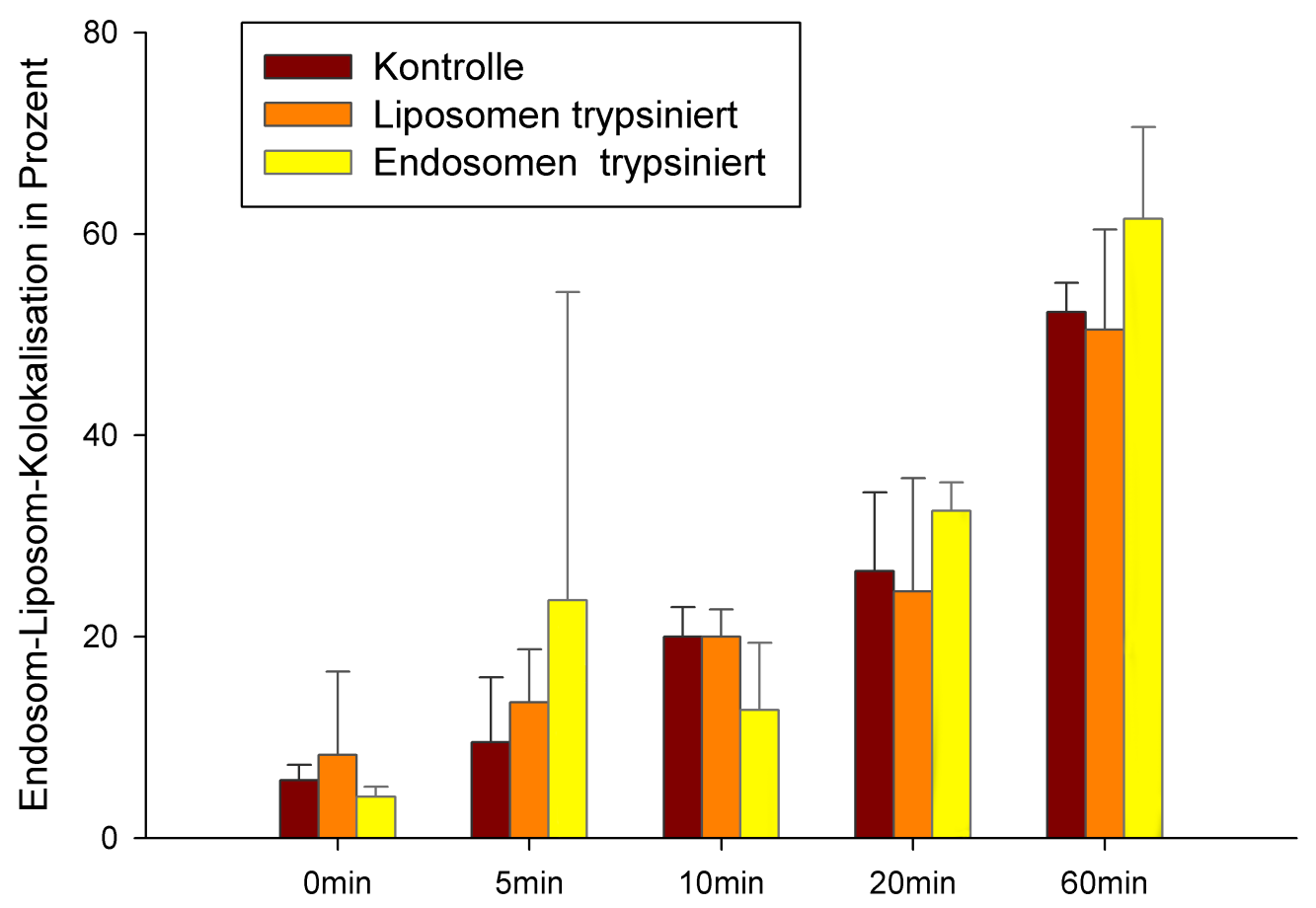

Abbildung 3.26: Der Einfluss von Trypsin auf Kolokalisation von Endosomen mit Liposomen

PNS wurde mit Octadecylrhodamin inkubiert und die markierten Endosomen durch Ultrazentrifugation isoliert. Die Endosomen wurden mit OregonGreen-PE haltigen VAMP4Liposomen inkubiert. Nach den angegebenen Zeiten wurden Proben genommen und in tiefschmelzender Agarose „eingefroren”, mikroskopiert und mittels eines Matlab-Programms durch line scans auf Kolokalisation untersucht (siehe Material und Methoden, Abschnitt 2.7.3). Eine Trypsinierung der Liposomen oder der Endosomen vor Reaktionsbeginn hatte keinen Einfluss auf das Ergebnis. Gezeigt ist der Mittelwert aus mindestens 3 unabhängigen Experimenten mit Standardfehler. 


\section{Lysophosphatidylcholin}

Um die Endosom-Liposom-Fusion weiter zu charakterisieren, sollte getestet werden, ob sie sich durch Lysophosphatidylcholin (LPC) inhibieren lässt. LPC weist eine für Membranlipide untypische - invers zylindrische - Struktur auf, d.h. seine Kopfgruppe besitzt einen größeren Querschnitt als sein Fettsäureanteil, wodurch die Bildung eines Fusionsintermediates, des sogenannten „fusion stalks“ gestört wird (Vogel et al., 1993) Dies liegt daran, dass es aufgrund seiner Form die für die Kur-

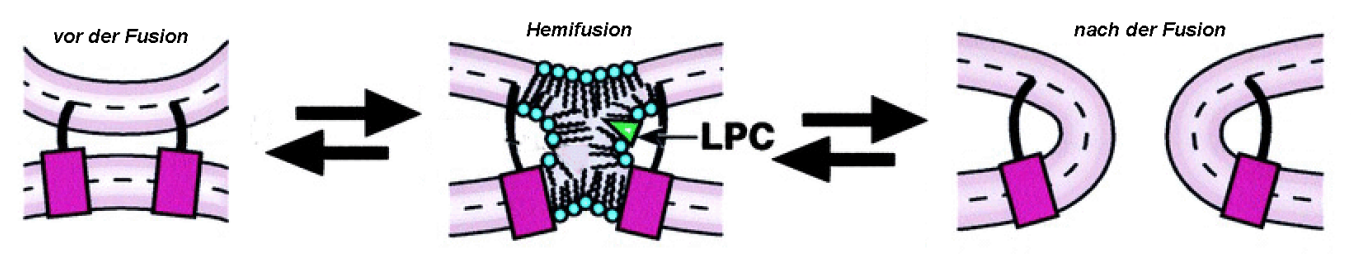

Abbildung 3.27: LPC inhibiert die Bildung des fusion stalks

Die Fusion von Membranen läuft in der Regel über einen fusion stalk. Dessen Bildung erfordert jedoch eine starke Membrankrümmung, die durch invers konkave Lipide wie Lysophosphatidylcholin inhibiert wird. (modifiziert nach (Chernomordik \& Kozlov, 2003))

vatur der Membran notwendigen Kompression behindert, wie Abbildung 3.27 zeigt. Lysophosphatidylcholin inseriert sich selbständig in Membranen und seine Zugabe zur Liposom-Endosom-Fusionsreaktion vermindert das beobachtete Dequenching dosisabhängig (siehe Abbildung 3.28), was einen weiteren Beleg für das Vorliegen von echter Fusion liefert. Proteoliposomen sind hiervon jedoch wiederum genauso betroffen wie trypsinierte Liposomen.

\section{Annexine}

Ein Faktor, der für die SNARE-unabhängige Fusion verantwortlich sein könnte, ist Annexin II, welches einen Hauptbestandteil der bei der endosomalen Fusion übertragenen Proteine bildet (Emans et al., 1993). Die Phospholipidbindung von Annexinen ist normalerweise kalziumunabhängig und hätte daher durch die Zugabe von BAPTA verhindert werden müssen, allerdings wurde für Annexin II eine Kalziumabhängigkeit in der Gegenwart von Cholesterin beschrieben (Zeuschner et al., 2001). Um zu untersuchen, ob Annexin II in unserem System eine Rolle spielt, wurden daher Liposomen hergestellt bei denen das Cholesterin durch Phosphatidylserin ersetzt war. Wie Abbildung 3.29 zeigt, hat der Cholesterolgehalt weder einen Einfluss auf die Reaktion selbst noch auf die fusionsfördernde Wirkung des Zytosols, eine Rolle von Annexin II in diesem Prozess ist daher sehr unwahrscheinlich. Insgesamt scheint die Lipidzusammensetzung der Liposomen wenig entscheident für die Fusion zu sein, wie spätere Versuche in anderem Zusammenhang zeigen sollten (siehe Abbildung 3.39). 


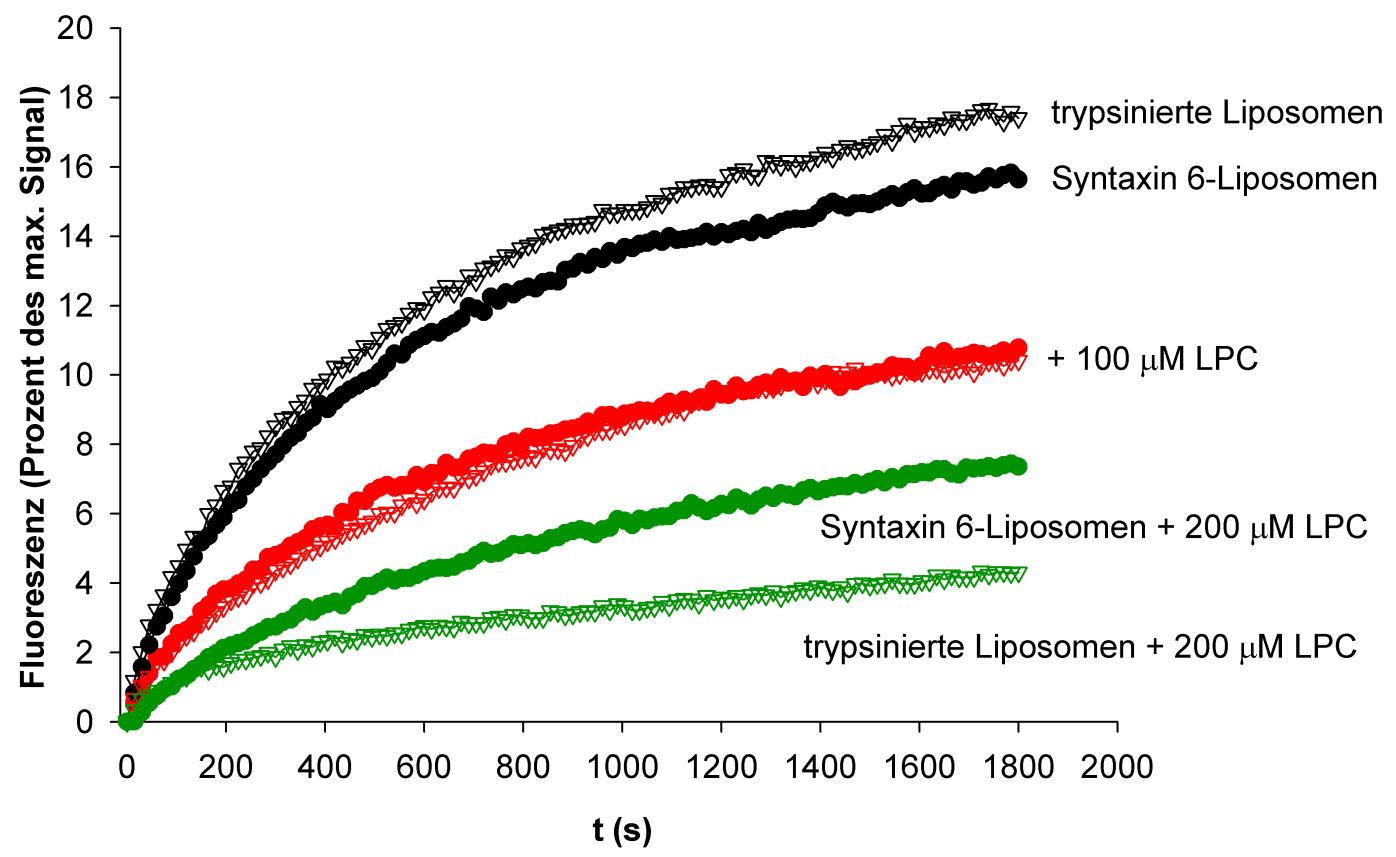

Abbildung 3.28: Der Einfluss von LPC auf die Fusion von Endosomen mit Liposomen

Lysophosphatidylcholin (CMC 0,7 mM) wurde als inverted cone lipid in der angegebenen Konzentration direkt zur Fusionsreaktion aus Endosomen und Syntaxin 6-Liposomen gegeben, um den Reaktionsmechanismus zu untersuchen. Gezeigt ist ein repräsentatives Experiment. 


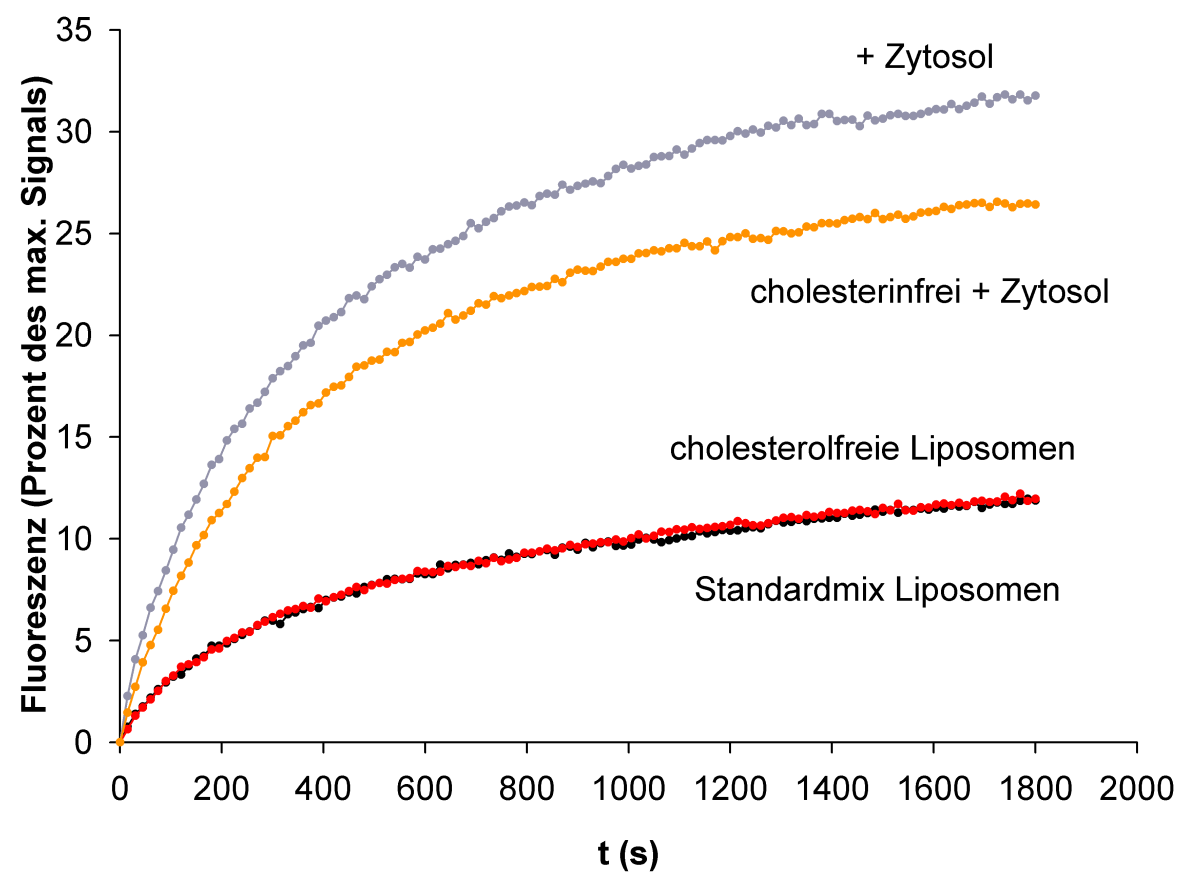

Abbildung 3.29: Der Einfluss von Cholesterin auf die Fusion von Endosomen mit Liposomen

Im Lipidmix wurde Cholesterin durch Phosphatidylserin ersetzt, die Liposomen nach dem Standardprotokoll (Methode 1) hergestellt und mit Endosomen inkubiert. Weder die normale Reaktion noch die Aktivierung durch Zytosol $(1,4 \mathrm{mg} / \mathrm{ml})$ verändert sich wesentlich ohne Cholesterin. 


\section{Krümmungsstress und Variationen der Liposomenherstellung}

Die Eignung der in dieser Studie verwendeten Liposomen für Fusionsstudien ist in jüngerer Vergangenheit in Frage gestellt worden (Chen et al., 2006; Dennison et al., 2006), da ihr geringer Radius von ungefähr 15 nm (Schuette et al., 2004) eine hohe Membranspannung zu Folge habe, der sie sehr instabil mache. Um dieser Kritik zu begegnen wurden auch Liposomen hergestellt, die einen größeren Durchmesser von ungefähr $180 \mathrm{~nm}$ (mit dynamischer Lichtstreuung bestimmt) aufwiesen (Methode 2). Das zu inkoorporierende Protein wurde in diesem Fall zunächst in einen octylglucosidhaltigen Puffer überführt, mit Lipiden im selben Puffer gemischt und gegen BioBeads in HB500 über Nacht bei Raumtemperatur dialysiert (modifiziert nach (Parmar et al., 1999)) um das Detergenz zu entfernen. Um die Einbaueffizienz zu überprüfen, wurden die Liposomen abzentrifugiert und der Proteingehalt des Pellets mit dem des zehnfach angereicherten Überstands verglichen. Wie Abbildung 3.30 zeigt, gelangt ein Großteil des Proteins in die Membran. Dass es dort dem Verdau durch Trypsin zugänglich ist, spricht zudem für seine korrekte Orientierung. Bei der Inkubation mit Endosomen ergab sich für proteinfreie Liposomen eine Reduktion der Fusion im Vergleich mit den SNARE-haltigen, die übrigen Ergebnisse waren jedoch ähnlich zu den kleineren Liposomen, d.h. die trypsinierten Liposomen fusionierten weiterhin effizient (siehe Abbildung 3.31).

\section{Pellet 10x Überstand}

\section{Kontrolle Trypsin Kontrolle Trypsin}

\section{Abbildung 3.30: VAMP4-Einbau und Orientierung in großen Liposomen}

VAMP4-Liposomen wurden per Dialyse hergestellt und für 10 Minuten bei 16.000x $g$ zentrifugiert. Die Proteine aus dem Überstand wurden mit Aceton $\left(-20^{\circ} \mathrm{C}\right)$ gefällt und Pellet und Überstand im Verhältnis 1:10 aufs Gel aufgetragen und gegen VAMP4 geblottet. Analog wurde mit VAMP4-Liposomen verfahren, die für $1 \mathrm{~h}$ bei $37^{\circ} \mathrm{C}$ mit Trypsin verdaut worden waren, um die Proteinorientierung zu überprüfen.

Da bei dieser Art der Liposomenherstellung unter Umständen multilaminare Strukturen gebildet werden (Parmar et al., 1999), wurde zuletzt auch noch ein zweistufiges Verfahren eingesetzt, welches von Matias Hernandez für die neuronalen SNAREProteine etabliert worden war (Methode 3). Die Lipide werden zunächst in einer 3:1 Mischung von Äther und HB500 aufgenommen und mit Ultraschall behandelt. Der Äther wird dann unter Vakuum langsam abgezogen und die entstehenden Liposomen werden durch zwei Filter gedrückt (zunächst 400 nm dann 100 nm Porengröße). In einem zweiten Schritt werden diese Liposomen mit dem zu inkorporierenden Protein und Octylglucosid versetzt, welches die Membran destabilisiert und einen Einbau des 


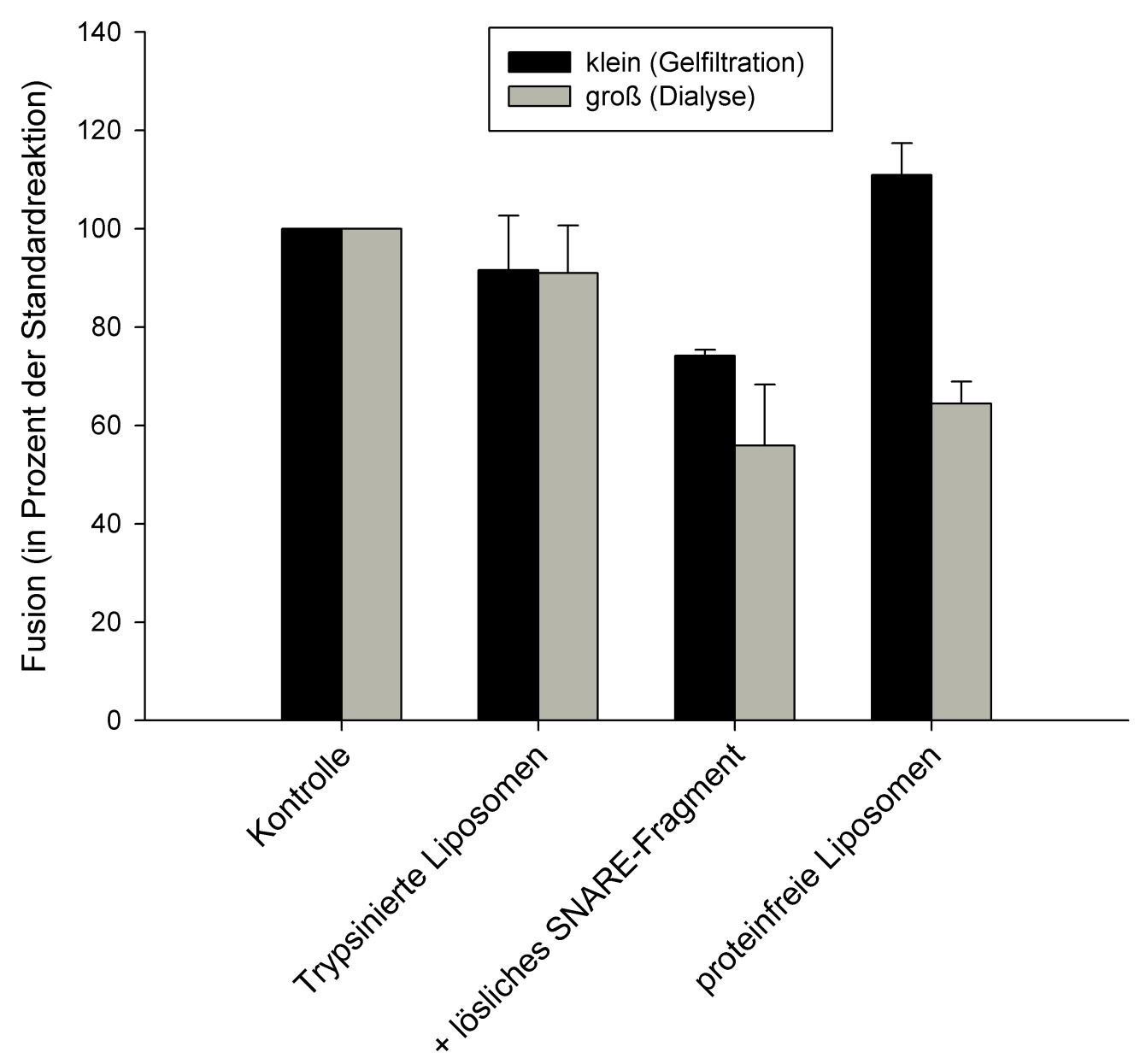

Abbildung 3.31: Die Fusion großer und kleiner Liposomen im Vergleich Mittels Dialyse hergestellte Liposomen (Methode 2) haben einen deutlich größeren Durchmesser, was sich zwar nicht auf die Fusion der trypsinierten, aber auf die der proteinfreien Liposomen auswirkt. Gezeigt sind die Mittelwerte der Fusion von Endosomen mit Liposomen aus mindestens 3 unabhängigen Experimenten. 
Proteins ermöglicht. Das Detergenz wird über Nacht durch Dialyse gegen BioBeadhaltigen HB500-Puffer entfernt und man erhält Proteoliposomen mit einem Durchmesser von ungefähr hundert Nanometern (bestimmt mit statischer Lichtstreuung, Matias Hernandez, persönliche Mitteilung). Diese wurden ebenfalls in der Fusion mit Endosomen getestet (siehe Abbildung 3.32). Der Verdau der Liposomen blieb, wie bei den kleineren Liposomen, wiederum ohne Effekt. Im Unterschied zu den durch Gelfiltration hergestellten Liposomen (Methode 1), scheint sich die Anwesenheit der Transmembrandomäne in diesem Fall jedoch fusionsfördernd auszuwirken, wie der Vergleich zwischen trypsinierten und proteinfreien Liposomen zeigt. Anstatt

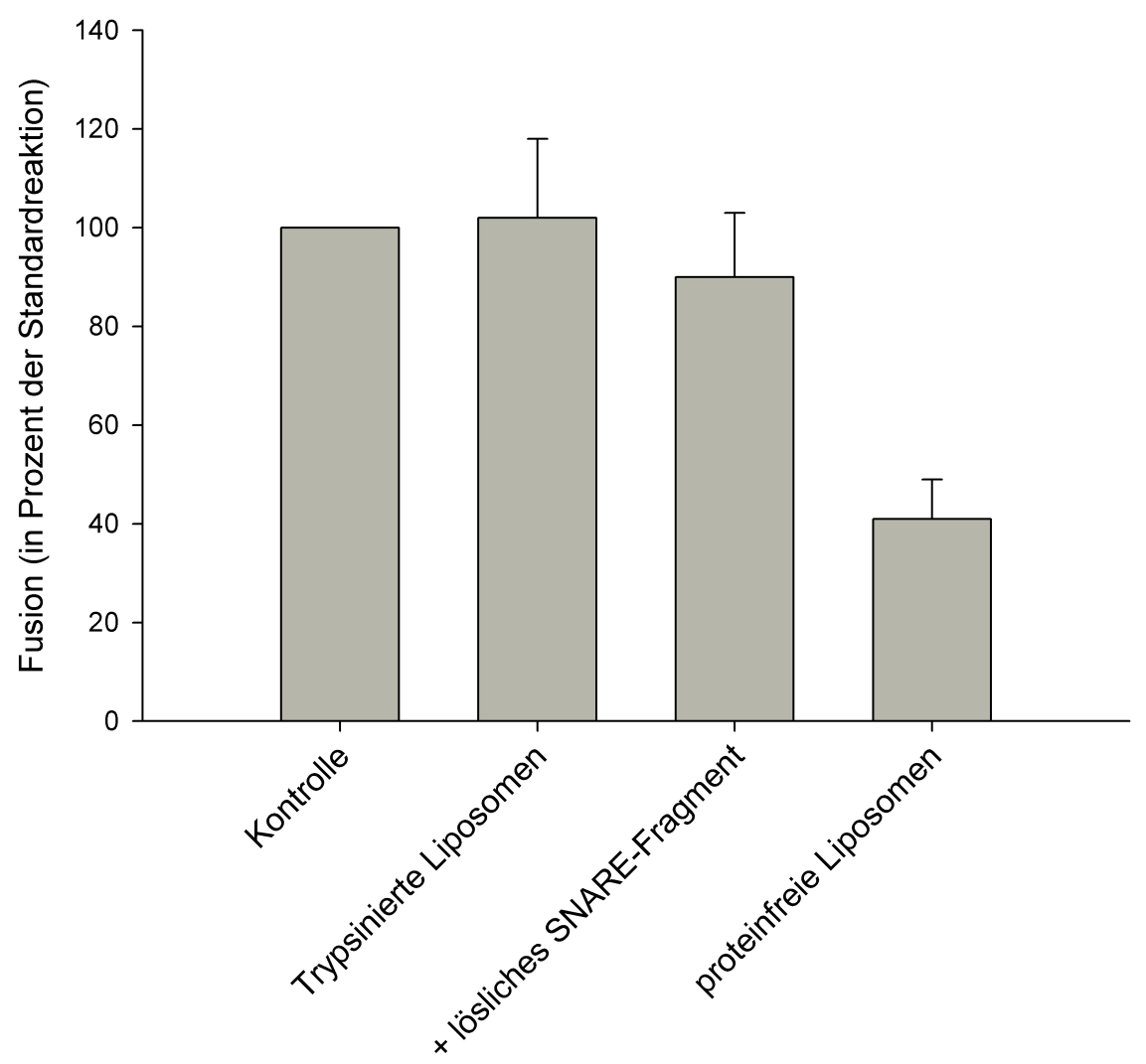

Abbildung 3.32: Analyse der nach Methode 3 hergestellten Liposomen

Es wurden zunächst leere Liposomen mittels Umkehrphasenevaporation hergestellt und in diese dann VAMP4, Syntaxin 6 oder alle 3 Q-SNAREs (mit ähnlichen Ergebnissen) eingebaut, indem die Liposomen mit den Proteinen in Gegenwart von Octylglucosid inkubiert wurden und das Detergenz dann über Nacht gegen HB500 mit BioBeads ausdialysiert wurde (Methode 3). Gezeigt sind die Mittelwerte der Fusion dieser Liposomen mit Endosomen aus mindestens 4 unabhängigen Experimenten mit Standardfehler.

oder im Zusammemspiel mit der Transmembrandomäne könnten allerdings auch die beim Trypsinverdau entstandenen Fragmente für diesen Effekt verantwortlich sein. 


\subsubsection{Rekonstituierte Endosomen}

Abschließend sollte untersucht werden, ob sich auf der Endosomenoberfläche vielleicht auch inhibitorische Proteine befinden, die die Fusion regulieren. Einen Hinweis darauf bot die Tatsache, dass trypsinierte Endosomen verklumpen, wie in Abbildung 3.33 gezeigt, wobei dies jedoch auch einfach auf eine starke Hydrophobizität der endosomalen Membran nach Entfernen der Proteine zurückzuführen sein könnte.

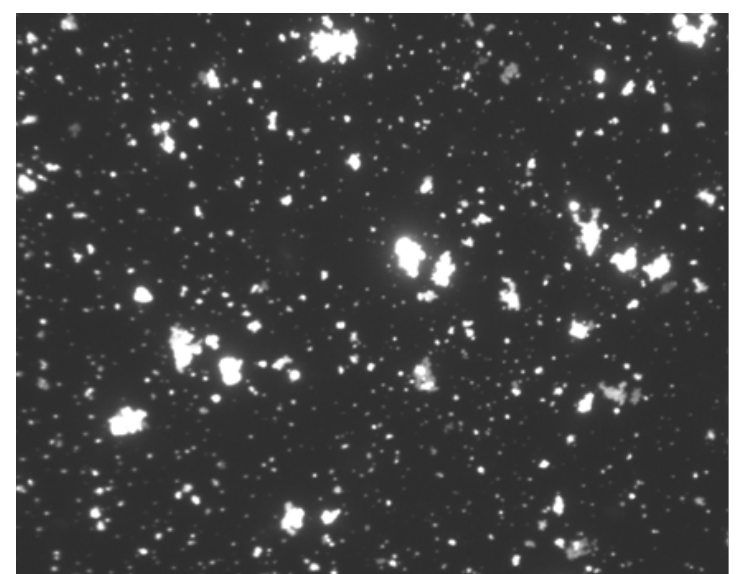

Trypsinierte Endosomen

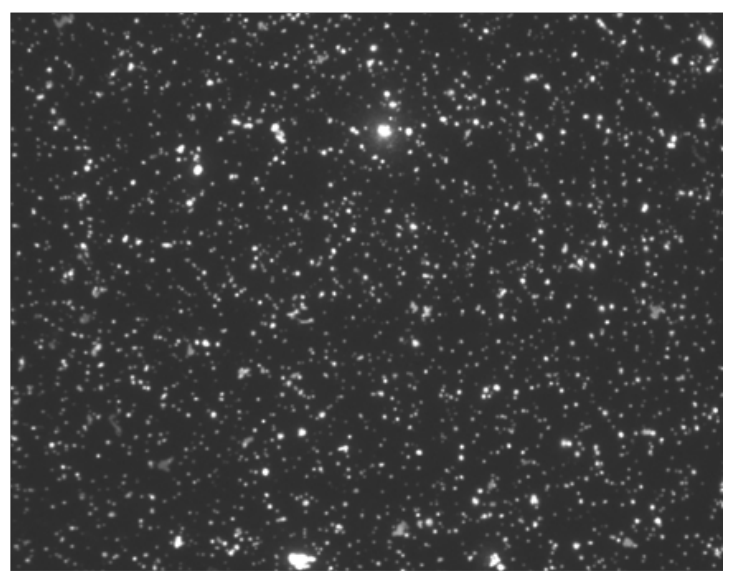

Kontroll Endosomen

Abbildung 3.33: Trypsinierte Endosomen neigen zum Verklumpen Octadecylrhodamin-markierte Endosomen wurden mit $0,1 \mathrm{mg} / \mathrm{ml}$ Trypsin oder unbehandelt für $1 \mathrm{~h}$ inkubiert und dann auf Deckgläschen zentrifugiert und mikroskopiert. Im Fall der Trypsinbehandlung links zeigt sich ein deutliches Verklumpen.

Um das endosomale System möglichst detailgetreu abzubilden wurden Endosomen mit Octylglucosid solubilisiert und der unlösliche Teil durch Ultrazentrifugation abgetrennt. Der Überstand wurde nach Zugabe von Lipiden (modifiziert nach (Sato \& Wickner, 1998)) über Nacht gegen HB500 (mit BioBeads) dialysiert, um daraus Liposomen mit einer endosomenähnlichen Zusammensetzung zu generieren. Für die untersuchten Proteine war dieser Prozess grundsätzlich erfolgreich, obwohl der Einbau für die einzelnen Proteine unterschiedlich gut war, wie die Westernblots in Abbildung 3.34 zeigen. Die Orientierung wurde durch Trypsinverdau analysiert, wobei invers orientierte Proteine vor Verdau geschützt sein sollten, der praktisch vollständige Abbau zeigt also einen ganz überwiegend korrekten Einbau. Nichtsdestotrotz verhielten sich diese „rekonstituierten Endosomen“ in ihrer Fusion eher wie Proteoliposomen, denn wie Endosomen, d.h. ihre Trypsinierung hatte nur einen geringen Einfluss auf die Fusion (siehe Abblidung 3.35). Allerdings war dieser größer als bei „normalen“ Proteoliposomen. Ein weiterer Erfolg war insofern zu verzeichnen, als die Reaktion nun eine partielle Hemmung durch den Kalzium-Chelator BAPTA zeigte, was sie näher an die Endosom-Endosom-Fusion rückt (vgl. erstes Kapitel). 


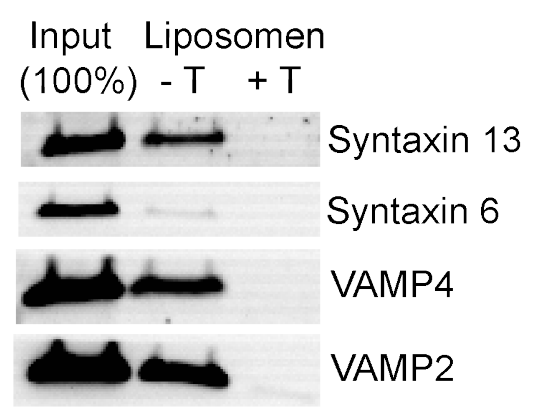

\section{Abbildung 3.34: Rekonstitutionseffizienz nach Solubilisierung}

Endosomen wurden mit Octylglucosid solubilisiert, der unlösliche Anteil durch Ultrazentrifugation abgetrennt und der Überstand nach Zugabe von Lipiden gegen HB150 (150 mM KCl, 20 mM Hepes, 1 mM DTT) dialysiert, um Liposomen mit endosomenähnlicher Zusammensetzung herzustellen. Die gebildeten Liposomen wurden anschließend auf einem Nycodenzgradienten flotiert, um die Protein-Inkorporation zu überprüfen. Die korrekte Orientierung wurde durch einen Trypsinverdau $\left(0,1 \mathrm{mg} / \mathrm{ml}, 1 \mathrm{~h} 37^{\circ} \mathrm{C}\right)$ untersucht. Gezeigt sind Einbau und Orientierung für ein beispielhaftes Experiment im Vergleich zu den anfangs eingesetzten Endosomen durchgeführt von Broder Schmidt (Rotationsstudent).

\subsection{Endosomale Proteindomänen}

Nach dem 1972 von Singer und Nicolson vorgeschlagenen Flüssigphasenmodell (Singer \& Nicolson, 1972), das davon ausging, dass sich Proteine völlig frei in der Membran bewegen können, sollte es eigentlich keine Rolle spielen, ob sich die SNAREs auf einer ansonsten leeren Membran befinden oder im Kontext der anderen endosomalen Proteine. Mit der Feststellung, dass sich die meisten Proteine nicht frei in der Membran bewegen können und dem Aufkommen der lipid raft Hypothese (siehe Einleitung), wurde jedoch klar, dass die Membranstruktur sehr wohl einer Spezialisierung unterliegt. So konnte z.B. gezeigt werden das Exozytose und Endozytose in spezialisierten Membranbereichen auftreten, die durch Cluster von SNARE-Proteinen gekennzeichnet sind (siehe Abschnitt 1.3).

Im Rahmen der vorliegenden Studie sollte untersucht werden, ob SNAREs und assoziierte Proteine in den endosomalen Membran in Domänen vorliegen, worüber noch sehr wenig bekannt ist, da frühe Endosomen aufgrund ihrer geringen Größe einer lichtmikrokopischen Untersuchung nur schwer zugänglich sind, sich nun aber durch das superhochauflösende STED-Mikroskop analysieren lassen (Klar et al., 2000). Vorangegangene Studien von Silvio Rizzoli hatten gezeigt, dass Synaptophysin Proteindomänen auf Endosomen bildet, welche in normaler konfokaler Mikroskopie verborgen geblieben waren, wie Abbildung 3.36 zeigt. Die Existenz dieser Domänen konnte elektronenmikroskopisch bestätigt werden und war abhängig vom Cholesteringehalt der Endosomen, da $\beta$-methyl-Cyclodextrin die Domänen zerstörte.

Die funktionelle Bedeutung cholesterinabhängiger Domänen wurde getestet, indem 


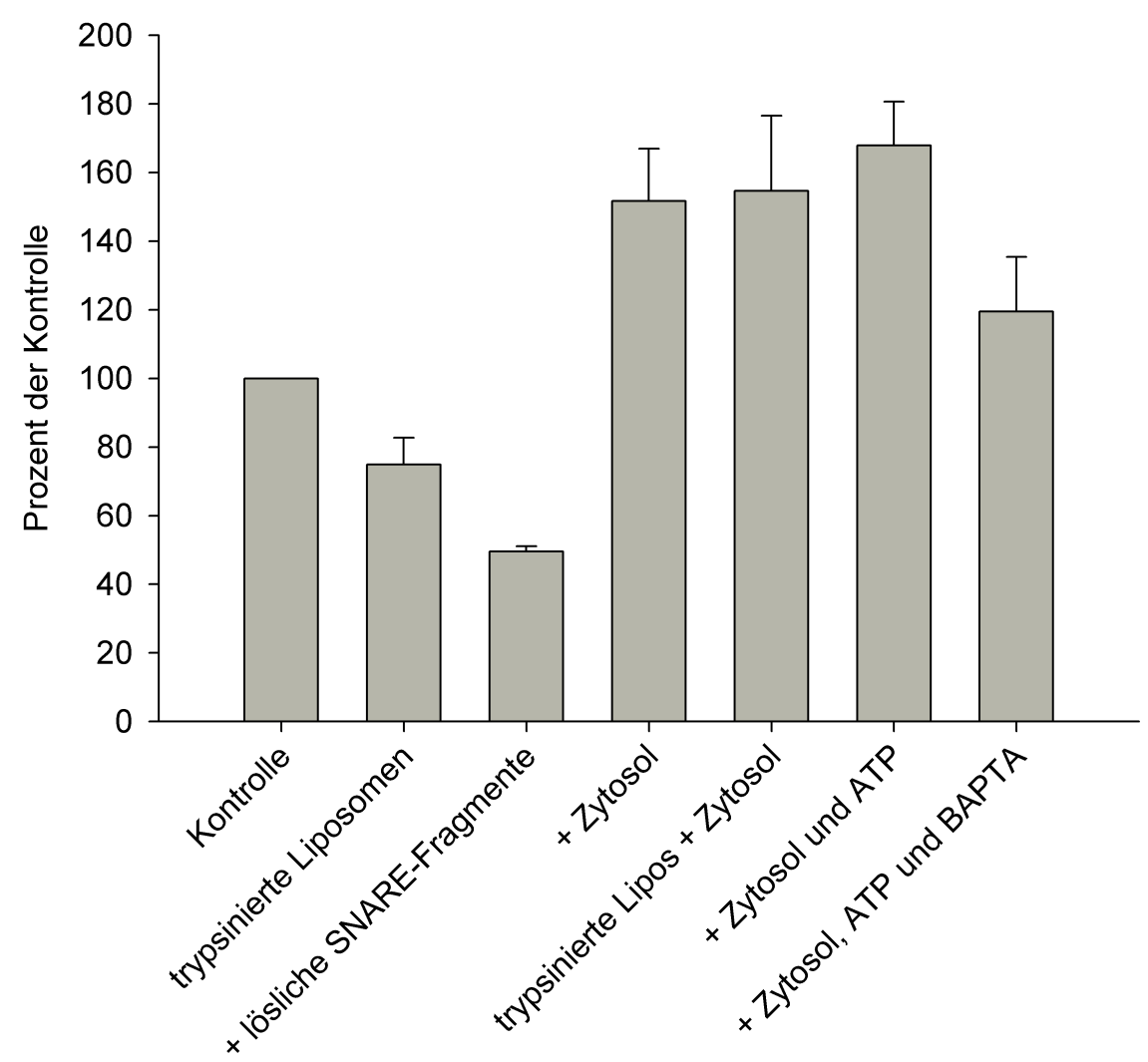

Abbildung 3.35: Proteoliposomen mit endosomenähnlicher Zusammensetzung Endosomen wurden mit $5 \%$ Octylglucosid solubilisiert, ultrazentrifugiert und der Überstand mit Lipiden (einschließlich NBD/Rhodamin-PE) gemixt. Der Protein/Lipid/Detergens-Mix wurde dann über Nacht gegen HB150 mit BioBeads dialysiert und mit Endosomen fusioniert. Gezeigt sind die Mittelwerte von 2-8 unahängigen Experimenten. 

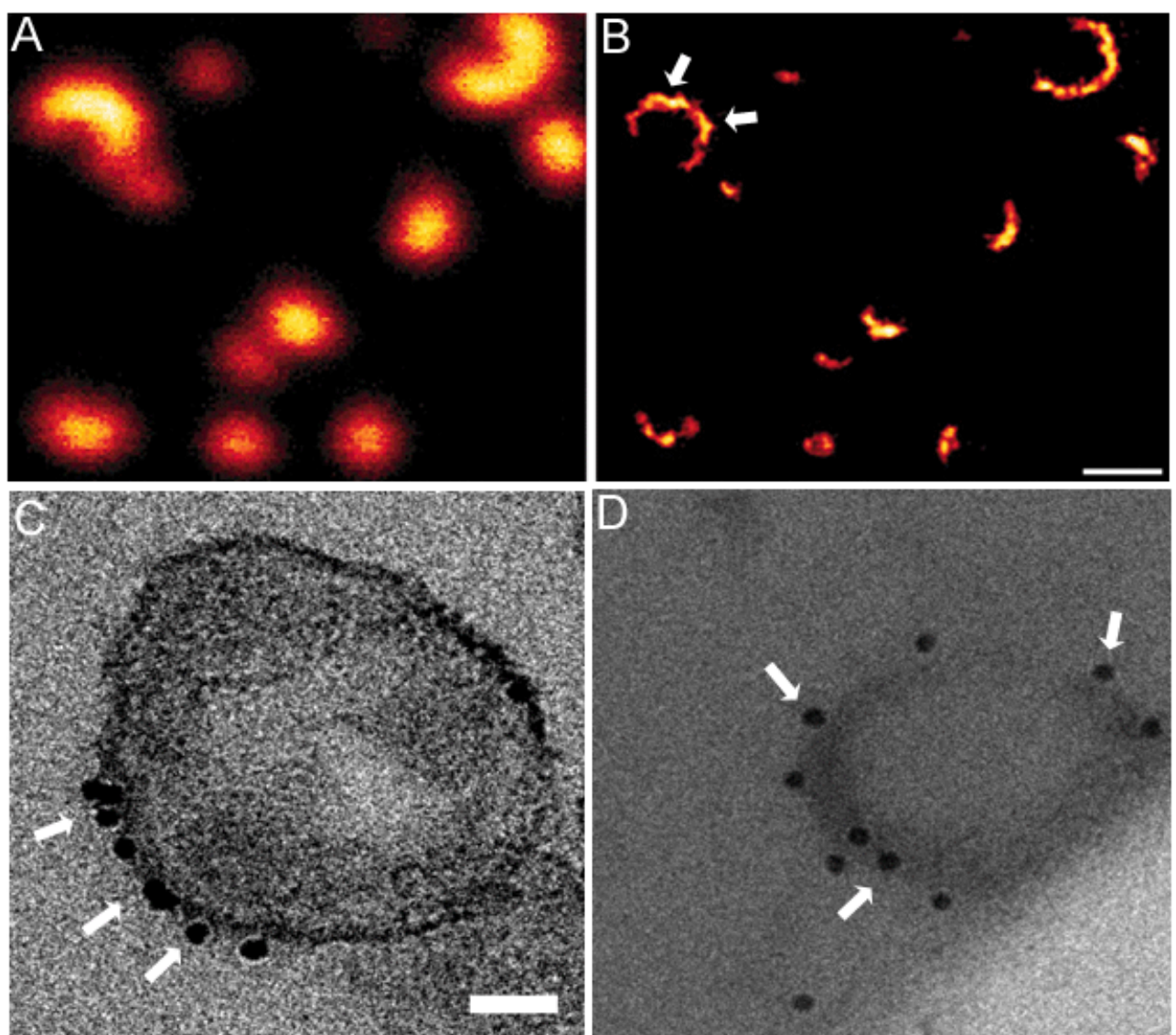

Abbildung 3.36: STED-Mikroskopie macht Synaptophysindomänen sichtbar Gradientenangereichterte Endosomen wurden auf Deckgläschen zentrifugiert, fixiert und mit einem monoklonalen anti-Synaptophysin-Aantikörper und darauf folgend einem sekundären Atto647N-gekoppelten Ziege-Anti-Maus-Antikörper inkubiert. Die Detektion erfolgte entweder mit konventioneller Konfokalmikroskopie (A) oder superhochauflösender STED-Mikroskopie (B). Für die elektronenmikroskopische Untersuchung wurden unbehandelte, oder cyclodextrinbehandelte Proben eingebettet $(\mathrm{C}+\mathrm{D})$. Balken: $200 \mathrm{~nm}$ für Lichtund $50 \mathrm{~nm}$ für Elektronenmikroskopie. (STED und Konfokalaufnahmen Silvio Rizzoli, EM Dietmar Riedel) 


\section{Ergebnisse}

untersucht wurde, wie sich eine verminderte Cholesterolkonzentration auf die Fusionsfähigkeit von frühen Endosomen auswirkt. Der Einsatz von cyclodextrinbehandeltem PNS für das oben beschriebene Endosomen-Interaktionsassay reduzierte die Fusionsrate im Vergleich zur unbehandelten Kontrolle um 80\% (Abbildung 3.37) und auch das Docking reduziert sich entsprechend (Daten nicht gezeigt), was nahelegt, dass nicht nur Synaptophysin Domänen auf frühen Endosomen bildet.

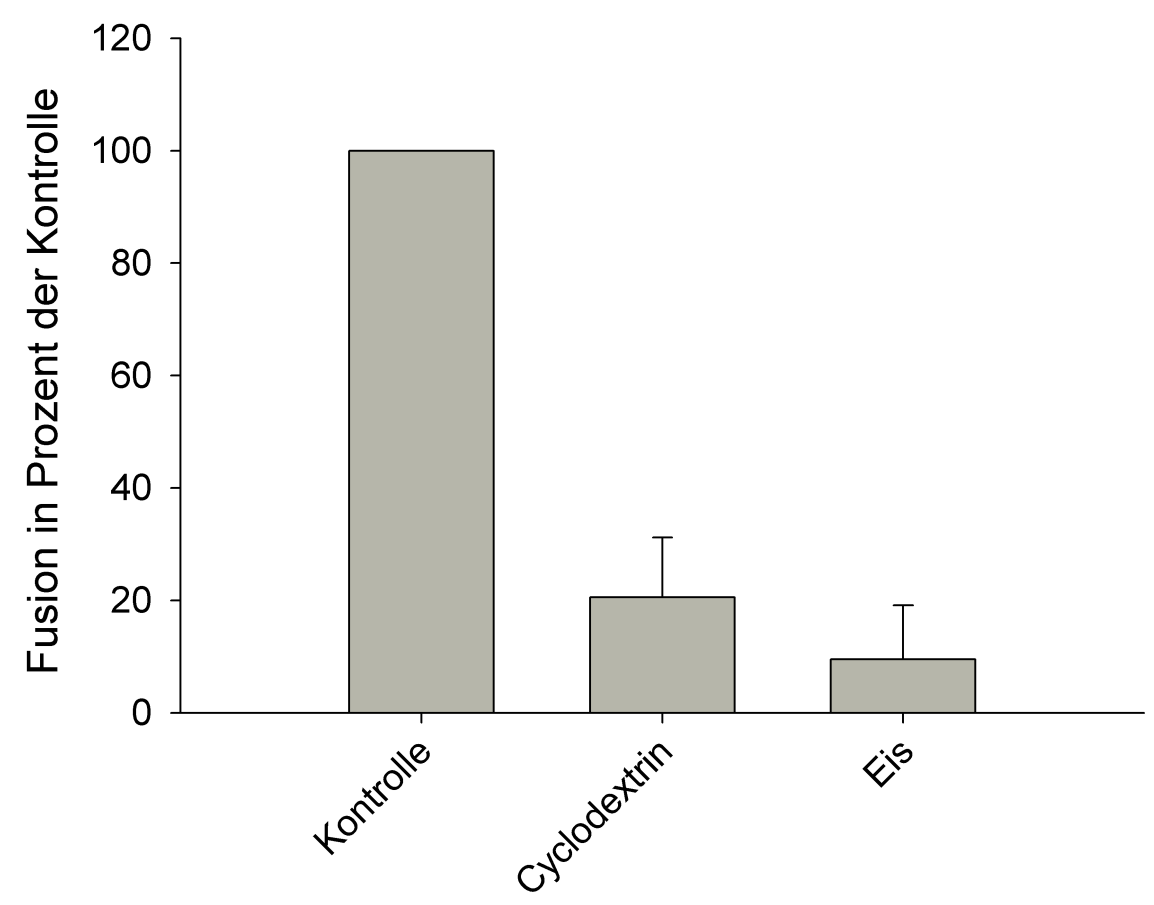

Abbildung 3.37: Der Einfluss von Cyclodextrin auf die Fusion von Endosomen Markiertes PNS wurde für 10 Minuten mit $6 \mathrm{mg} / \mathrm{ml} \beta$-methyl-Cyclodextrin präinkubiert, bevor es im Endosomen-Interaktionsassay eingesetzt wurde. Gezeigt sind die Mittelwerte aus 3 unahbängigen Experimenten (für die Eiskontrolle nur 2).

\subsubsection{Der Einfluss von Lipiden auf die Domänen}

Über die membranstrukturierende Funktion von Cholesterin ist schon vieles bekannt. Neben seiner Beteiligung an der Bildung von lipid rafts liegt dies vor allem daran, dass mit $\beta$-methyl-Cyclodextrin und wirkungsvollen Inhibitoren der Cholesterinsynthese (Mukherjee \& Maxfield, 2004) gleich zwei Werkzeuge existieren, welche erlauben, den Cholesteringehalt von Membranen zu verändern. Für die meisten anderen Lipide ist es weitaus schwieriger, wenn nicht gar unmöglich, direkten Einfluss auf ihre Membrankonzentration zu nehmen. Wie in Abschnitt 3.2 gezeigt, fusionieren jedoch Liposomen sehr effizient mit Endosomen, was einen neuartige, weniger 
invasive Möglichkeit eröffnet, die endosomale Lipidzusammensetzung zu verändern. Neben Cholesterin und Sphingolipiden werden besonders Phosphatidylinositol und seinen Derivaten regulatorische Funktionen zugeschrieben, so dass zunächst eine Veränderung der Konzentration von PI selbst und $\mathrm{PIP}_{2}$ im Vordergrund stand. Um einen großen Einfluss auf die endosomale Lipidzusammensetzung durch die Fusion mit Liposomen zu erreichen, sollte der Anteil an PI bzw. $\mathrm{PIP}_{2}$ an der liposomalen Membran natürlich möglichst hoch sein. Gleichzeitig musste aber sichergestellt werden, dass ein hoher Anteil dieser sauren Lipide sich nicht negativ auf die Fusion auswirkt. Diese Frage wurde zunächst untersucht, indem Liposomen mit 55\% PI, sowie solche mit 20\% $\mathrm{PIP}_{2}$ hergestellt wurden, welche außerdem Phosphatidylethanolamin-gekoppeltes OregonGreen enthielten, um ihre Kolokalisation mit Octadecylrhodamin-markierten Endosomen untersuchen zu können. Wie die Analyse nach einstündiger Inkubation bei $37^{\circ} \mathrm{C}$ und anschließender Zentrifugation auf Deckgläschen zeigt, ist die Kolokalisation von Liposomen mit Endosomen trotz des hohen Anteils von PI bzw. $\mathrm{PIP}_{2}$ in der liposomalen Membran sehr hoch (siehe Abbildung 3.38). Um sicherzugehen, dass diese hohe Kolokalisation für eine
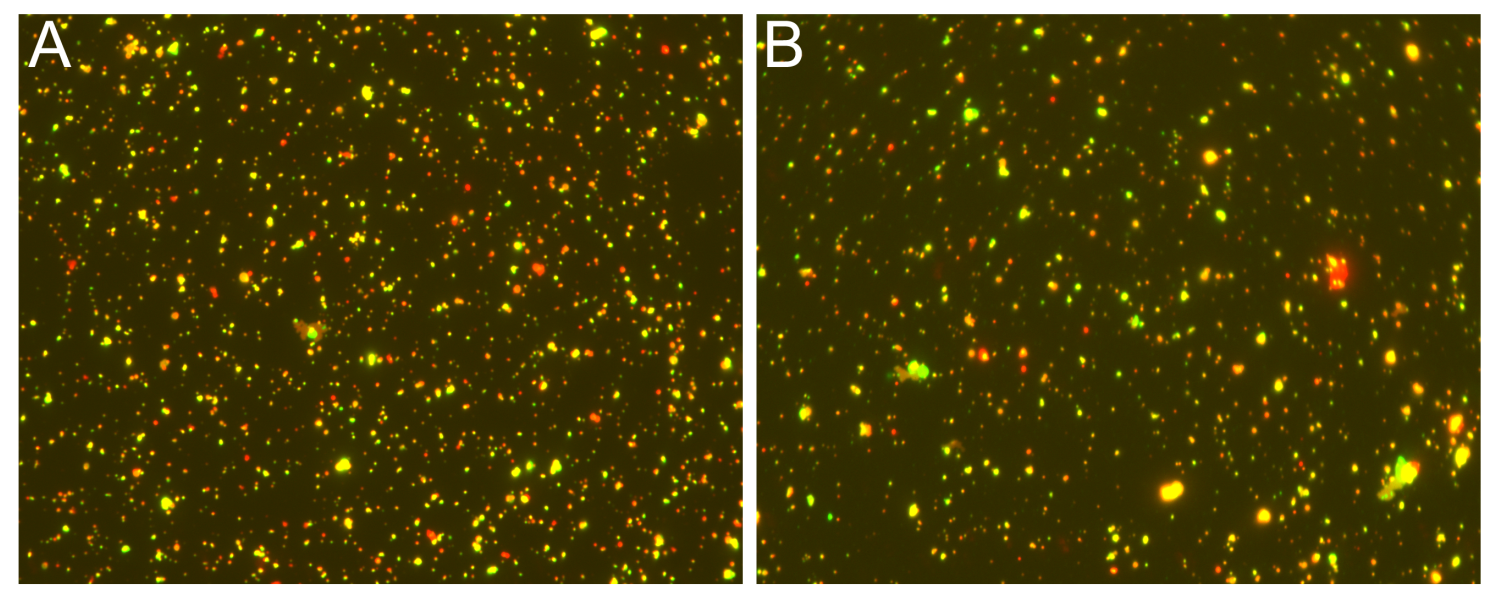

Abbildung 3.38: Die Kolokalisation von Endosomen mit Liposomen unterschiedlicher Zusammensetzung

Gradientenangereichte Endosomen (rot durch Octadecylrhodamin) wurden mit OregonGreen-Phosphatidylethanolamin haltigen Liposomen (grün) für 60 Minuten bei $37^{\circ} \mathrm{C}$ inkubiert und anschließend auf Deckgläschen zentrifugiert. Gezeigt sind repräsentative Aufnahmen von Reaktionen welche Liposomen mit 55\% PI (A) bzw. 20\% $\mathrm{PIP}_{2}$ (B) enthielten.

echte Lipidvermischung (d.h. Fusion) steht, wurde das bereits im zweiten Abschnitt eingeführte Dequenching-Assay (Struck et al., 1981), eingesetzt, welches sowohl für die PI und $\mathrm{PIP}_{2}$ reichen Liposomen, als auch für cholesterinreiche Liposomen eine dem Standardlipidmix ähnliche Lipidvermischung zeigte. Kolokalisation schien in diesem Fall also ein guter Indikator zu sein und konnte genutzt werden, um solche Endosomen, welche mit Liposomen fusioniert haben zu identifizieren. Für die Analy- 
A

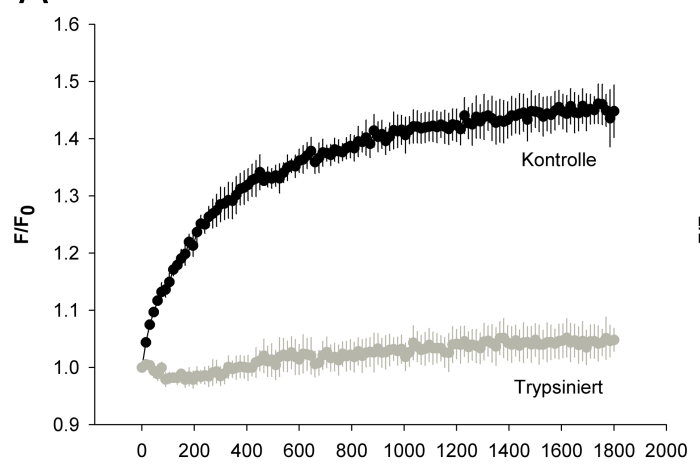

C

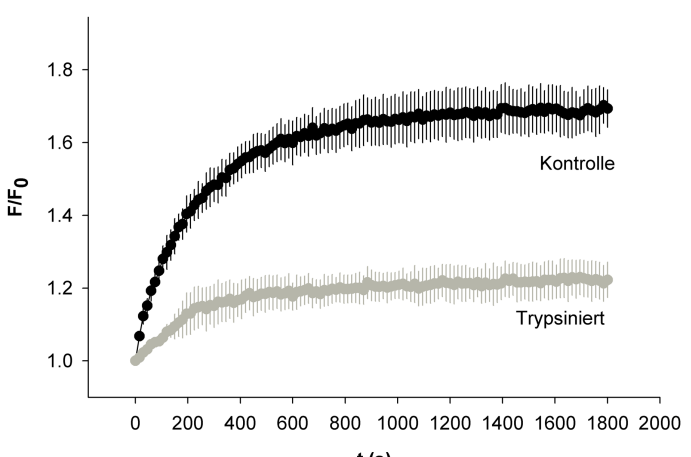

$t(s)$

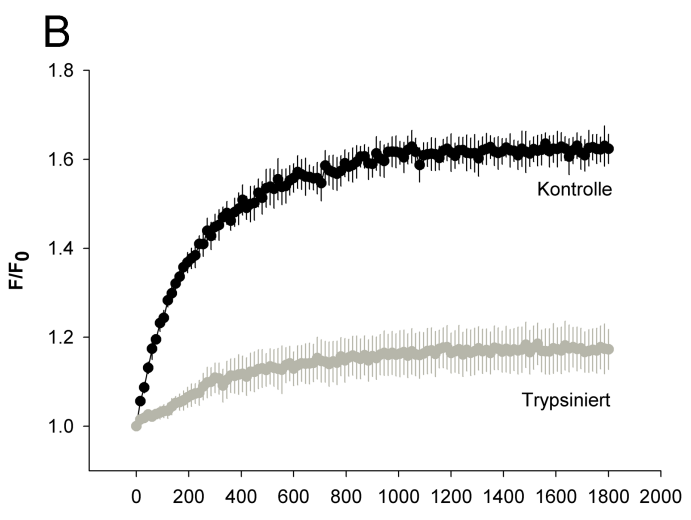

D $t(s)$

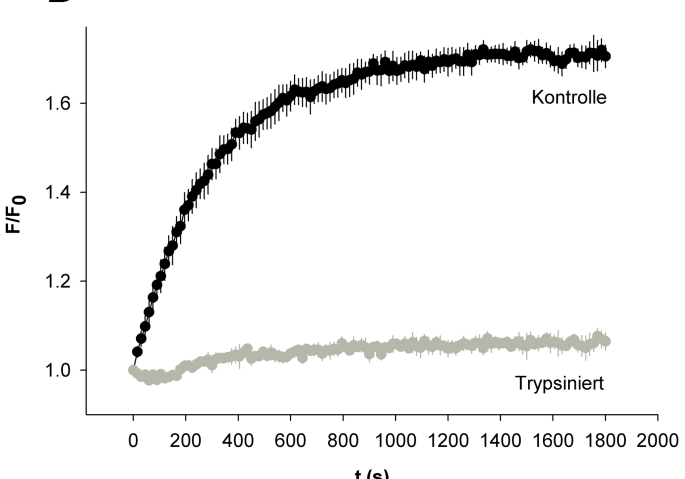

$t(s)$

Abbildung 3.39: Die Fusion von Endosomen mit Liposomen unterschiedlicher Lipidzusammensetzung

Gezeigt ist die Zeitreihe des Dequenchingsignals bezogen auf den Ausgangswert für die Fusion von Endosomen mit Liposomen der üblichen Zusammensetzung (50\% PC, $20 \%$ PE, je 10\% PI, PS, Cholesterin) (A), sowie cholesterolreicher (55\%, B), phosphatidylinositolreicher $(55 \%, \mathrm{C})$ als auch $\mathrm{PIP}_{2}$-reicher $(20 \%, \mathrm{D})$ Liposomen bei $37^{\circ} \mathrm{C}$. Gezeigt sind die Mittelwerte von jeweils drei Experimenten mit Standardfehler. 
se der Proteindomänen auf frühen Endosomen kommen unterschiedliche Indikatoren in Betracht, wobei einer der naheliegendsten ihre Anzahl zu sein scheint. Die Zahl der Proteindomänen lässt sich relativ leicht bestimmen, da jede Proteinanhäufung zu einem lokalen Maximum der Fluoreszenzintensität führen sollte, deren Anzahl sich mit automatisierte Bildanalyse bestimmten lässt (siehe Material und Methoden).

Ansätze mit Octadecylrhodamin-markierten, aufgereinigten Endosomen wurden für 60 Minuten mit den unterschiedlichen Liposomen inkubiert, auf Deckgläschen zentrifugiert, fixiert und einer Immunfärbung gegen Synaptophysin unterzogen. Die in Mowiol eingebetteten Proben wurden anschließend mit einem STED-Mikroskop analysiert. Der Vergleich der Synaptophysindomänen auf unfusionierten Endosomen mit den durch Liposomenfusion veränderten Endosomen ergab unabhängig von den eingesetzten Liposomen keine Unterschiede wie Abbildung 3.40 zeigt. Abgesehen von einer Cholesterinentfernung durch Cyclodextrin, die wie auf Abbildung 3.42 zu sehen einen drastischen Rückgang der Synaptophysincluster zur Folge hat, scheinen diese Cluster daher relativ stabil zu sein. Die Auswertung der Fluoreszenzbilder zeigt, dass die Fusion mit Liposomen eine starke Größenzunahme der Endosomen um ca. $120 \mathrm{~nm}$ und damit einer Zunahme der Oberfläche um ungefähr 80\% bewirkt, wie in Abbildung 3.41 gezeigt ist. Trotz dieser starken Verdünnung nimmt die Anzahl der Cluster nicht ab. Andererseits erhöht sie sich auch nicht, was zeigt, dass unter physiologischen Bedingungen weder PI, $\mathrm{PIP}_{2}$ noch Cholesterin limitierend für die Anzahl der Synaptophysincluster sind. Im weiteren sollte daher der Einfluss von Proteinen auf die Domänenstruktur untersucht werden.

\subsubsection{Der Einfluss von Proteinen auf die endosomalen Domänen}

Eine Klasse von Proteinen für die eine Rolle bei der Differenzierung der Membran in Domänen vorgeschlagen wurde sind die Rab-Proteine, im Falle von frühen Endosomen besonders Rab5 (siehe Einleitung, sowie (Zerial \& McBride, 2001)). Um den Einfluss von Rab-Proteinen auf die endosomalen Proteindomänen zu untersuchen, wurden die Endosomen für 60 Minuten mit $10 \mu \mathrm{M}$ Rab-GDI und 4 mM GDP bzw. als Kontrolle mit PBS bei $37^{\circ} \mathrm{C}$ inkubiert bevor sie auf Deckgläschen zentrifugiert und wie zuvor analysiert wurden. Es wurden Immunfärbungen mit Antikörpern gegen die endosomalen SNARE-Proteine Syntaxin 6, Syntaxin 13, Syntaxin 16 und VAMP4 durchgeführt aber für keines der untersuchten Proteine ergab sich eine signifikante Änderung in der Membranverteilung (Abbildung 3.43), obwohl sowohl Syntaxin 6 als auch Syntaxin 13 an den Rab5-Effektor EEA1 binden (McBride et al., 1999; Mills et al., 2001). Der Einfluss von Rab-Proteinen auf die endosomale Membranorganisation scheint daher begrenzt zu sein. 


\section{Ergebnisse}

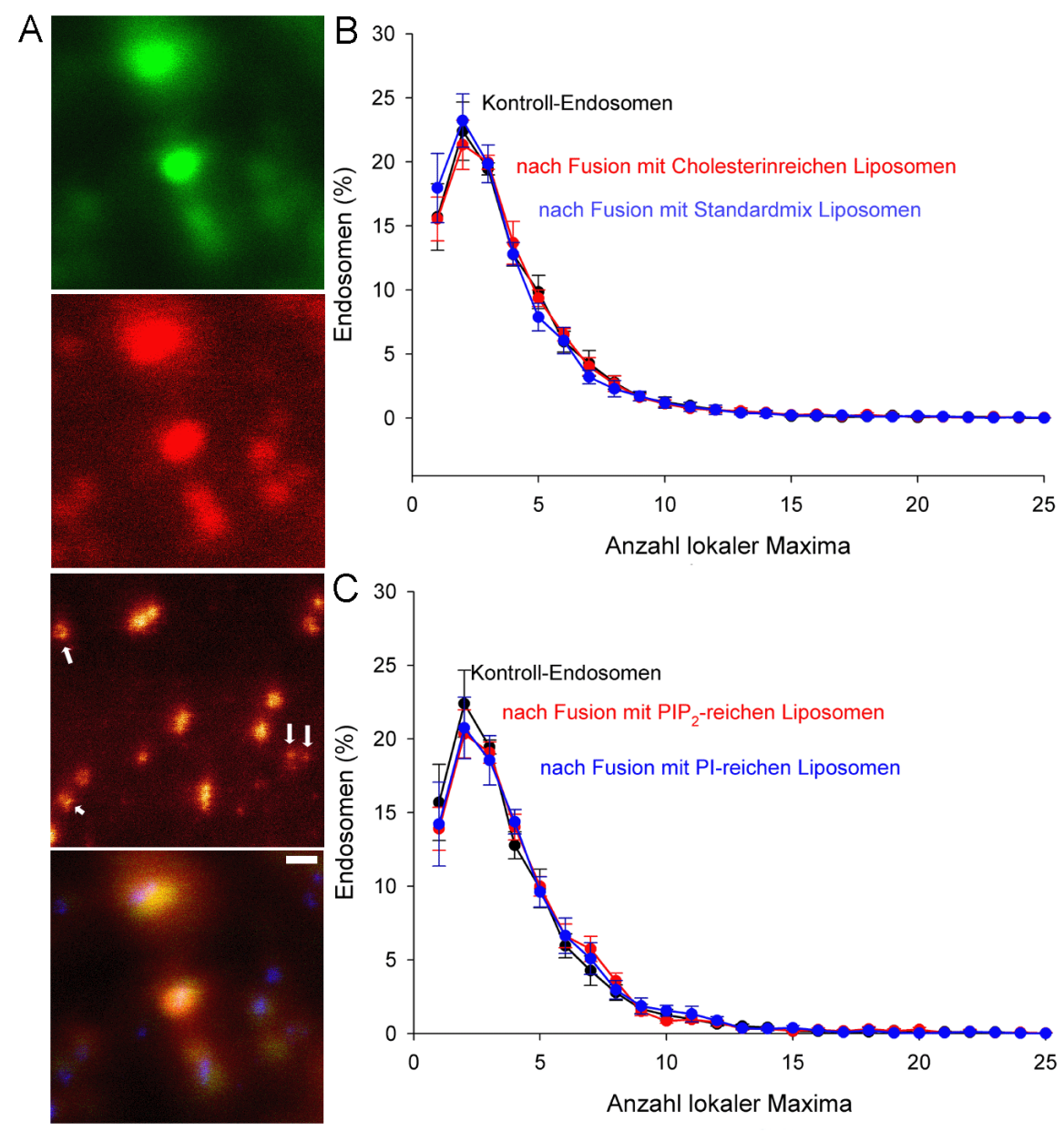

Abbildung 3.40: Analyse der Synaptophysindomänen nach Fusion mit Liposomen

Endosomen wurden für 60 Minuten mit Liposomen inkubiert, anschließend auf Deckgläschen zentrifugiert, fixiert und mit anti-Synaptophysin-Antikörpern immungefärbt. Der sekundäre anti-Maus-Antikörper war Atto-gekoppelt und ermöglichte den Einsatz von STED-Mikroskopie zur Analyse der Proben. Die Anzahl der lokalen SynaptophysinMaxima pro Endosom wurde Mithilfe eines Mathlabprogramms bestimmt (siehe Material und Methoden). (A) zeigt einen Ausschnitt aus einer Aufnahmereihe. Die grünen liposomalen Lipide überlappen stark mit dem roten, endosomalen Membranfarbstoff. Das dritte Bild zeigt die STED-Aufnahme einer Synaptophysinfärbung der mit PI-Liposomen fusionierten Endosomen, das vierte die Überlagerung der drei Kanäle. Die unterschiedliche Behandlung der Endosomen mit Liposomen (B und C) führt nicht zu einer veränderten Domänenstruktur, gezeigt sind die Mittelwerte aus je mindestens 4 unabhängigen Experimenten mit den resultierenden Standardfehlern. 


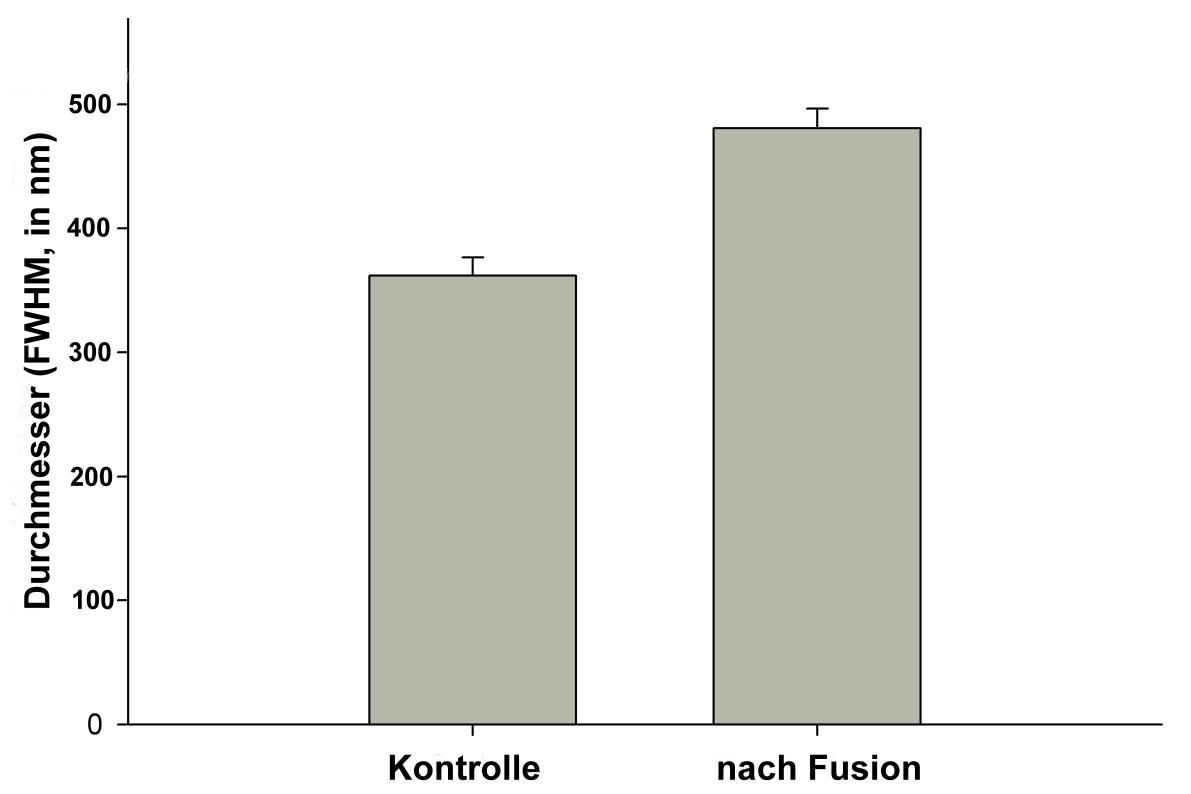

Abbildung 3.41: Größenzunahme der Endosomen durch Fusion mit Liposomen In den für die Clusterauswertung verwendeten Experimenten wurden die Endosomen im roten Kanal identifiziert und ihre unfusionierte Größe (daher die in den ausschließlich Endosomen enthaltenen Proben) mit der der fusionierten Endosomen (gezeigt für die Inkubation mit cholesterolreichen Liposomen) verglichen. Gezeigt sind die Mittelwerte aus 6 unahbängigen Experimenten.

Wie würde sich ein Protein verhalten, das von außen neu in Endosomen gelangt? Um zwischen dem endogenen Protein und dem neu eingeführten unterscheiden zu können, wurde VAMP4 mit einem HA-tag an seinem N-terminus versehen. Die Einführung des Proteins in die endosomale Membran sollte durch Fusion mit HA-VAMP4Liposomen erfolgen. HA-VAMP4 ließ sich in E.coli exprimieren und analog dem normalen Protein über Affinitäts- und Ionenaustauscherchromatographie aufreinigen. Im Vergleich zu VAMP4-Liposomen war die Fusionsrate von HA-VAMP4 Liposomen leicht reduziert, wie Abbildung 3.44 zeigt, aber für das geplante Experiment mehr als ausreichend. Endosomen wurden nun mit OregonGreen ${ }^{\text {TM}}-P E-m a r k i e r t e n$ HA-VAMP4 Liposomen 60 Minuten bei $37^{\circ} \mathrm{C}$ inkubiert, auf Deckgläschen zentrifugiert, fixiert und gegen den HA-tag immungefärbt. Mit dem STED-Mikroskop wurden Aufnahmen von den Proben gemacht, welche analog zu den zuvor beschriebenen Experimenten auf die Anzahl der Domänen untersucht wurden. Dabei stellte der Ausschluss kleiner Objekte sicher, dass nur Endosomen und nicht die kleinen unfusionierten Liposomen untersucht wurden. Zum Vergleich wurde auch die Domänenstruktur von HA-VAMP4 auf großen, mittels Umkehrphasenevaporation hergestellten Liposomen untersucht, d.h. diese wurden ebenfalls auf Deckgläschen zentrifugiert und dann analog behandelt. Die direkte Gegenüberstellung der Verteilung von HA-VAMP4 auf Liposomen und Endosomen weist interessanterweise kaum Unterschiede auf, wie Abbildung 3.45 zeigt. Um festzustellen, ob dies auch für andere 


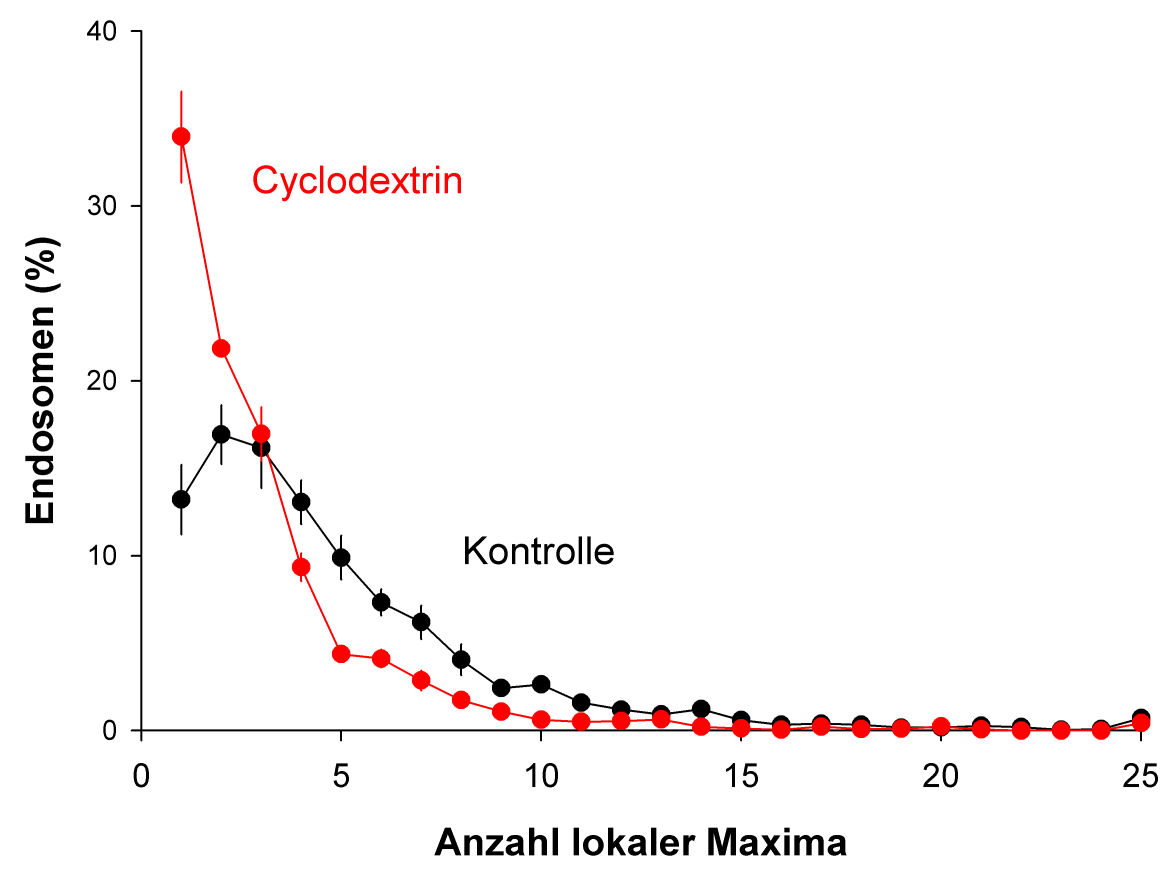

Abbildung 3.42: Der Einfluss von Cyclodextrin auf die Anzahl der Synaptophysindomänen

Endosomen wurden mit oder ohne Cyclodextrin inkubiert, auf Deckgläschen zentrifugiert und einer Immunfärbung unterzogen. Die Proben wurden mit einem STED-Mikroksop aufgenommen und die Bilder mittels eine Matlabprogramms analysiert, welches die Anzahl lokaler Maxima pro Endosom bestimmte (siehe Material und Methoden, Abschnitt 2.8.2). Gezeigt sind die Mittelwerte von 3 unabhängigen Experimenten, die von Christina Schäfer durchgeführt wurden. 

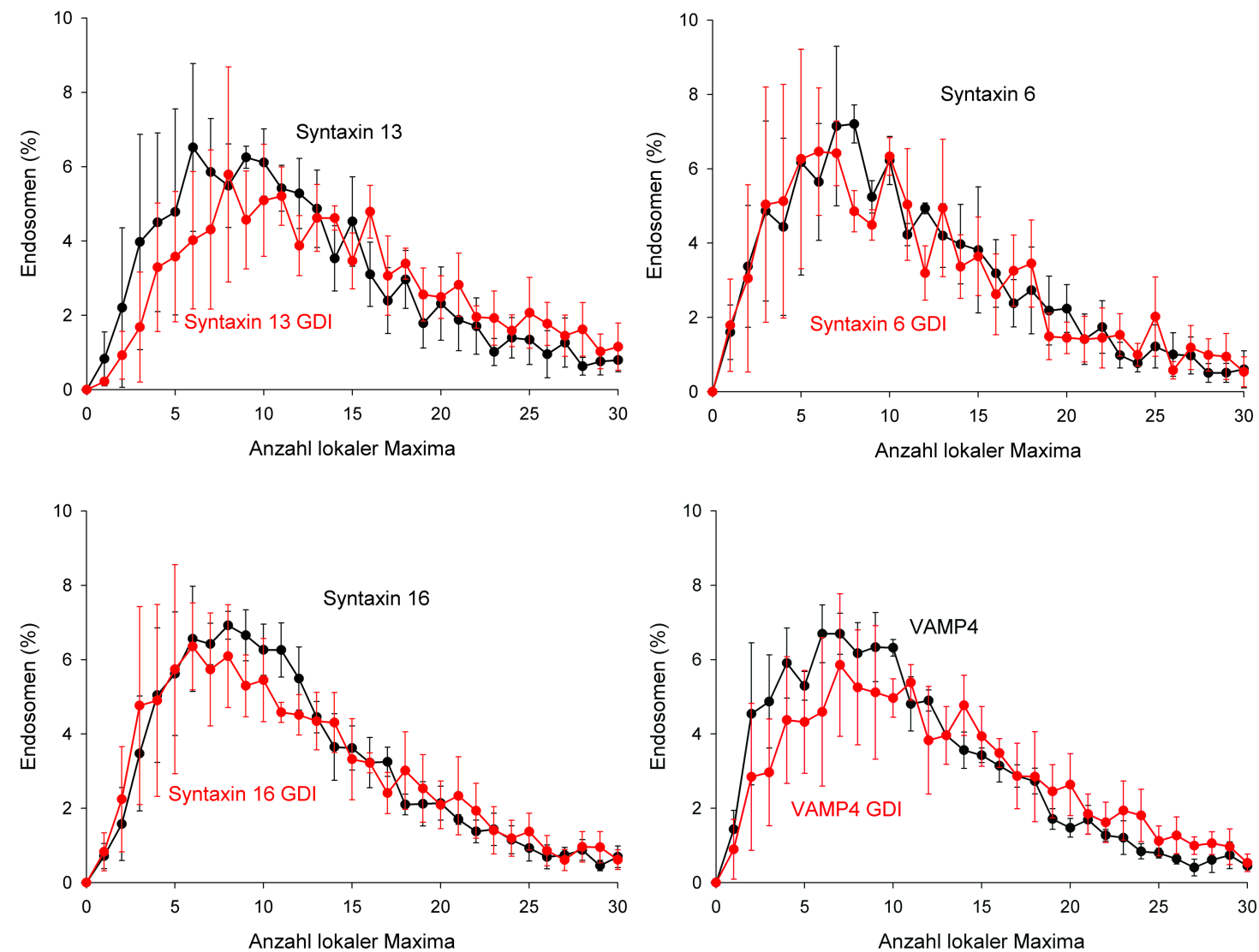

Abbildung 3.43: Der Einfluss von GDI auf SNARE-Domänen

Rab-Proteine wurden durch 30minütige Inkubation von Endosomen mit $10 \mu \mathrm{M}$ GDI und $4 \mathrm{mM}$ GDP von der Membran entfernt und die Domänenstruktur dieser Endosomen mit der PBS-behandelten Kontrolle verglichen. Für keines der untersuchten Proteine konnte eine signifikante Änderung festgestellt werden. Gezeigt sind die Mittelwerte von je 3 unabhängigen Experimenten mit Standardfehler. 
3 Ergebnisse

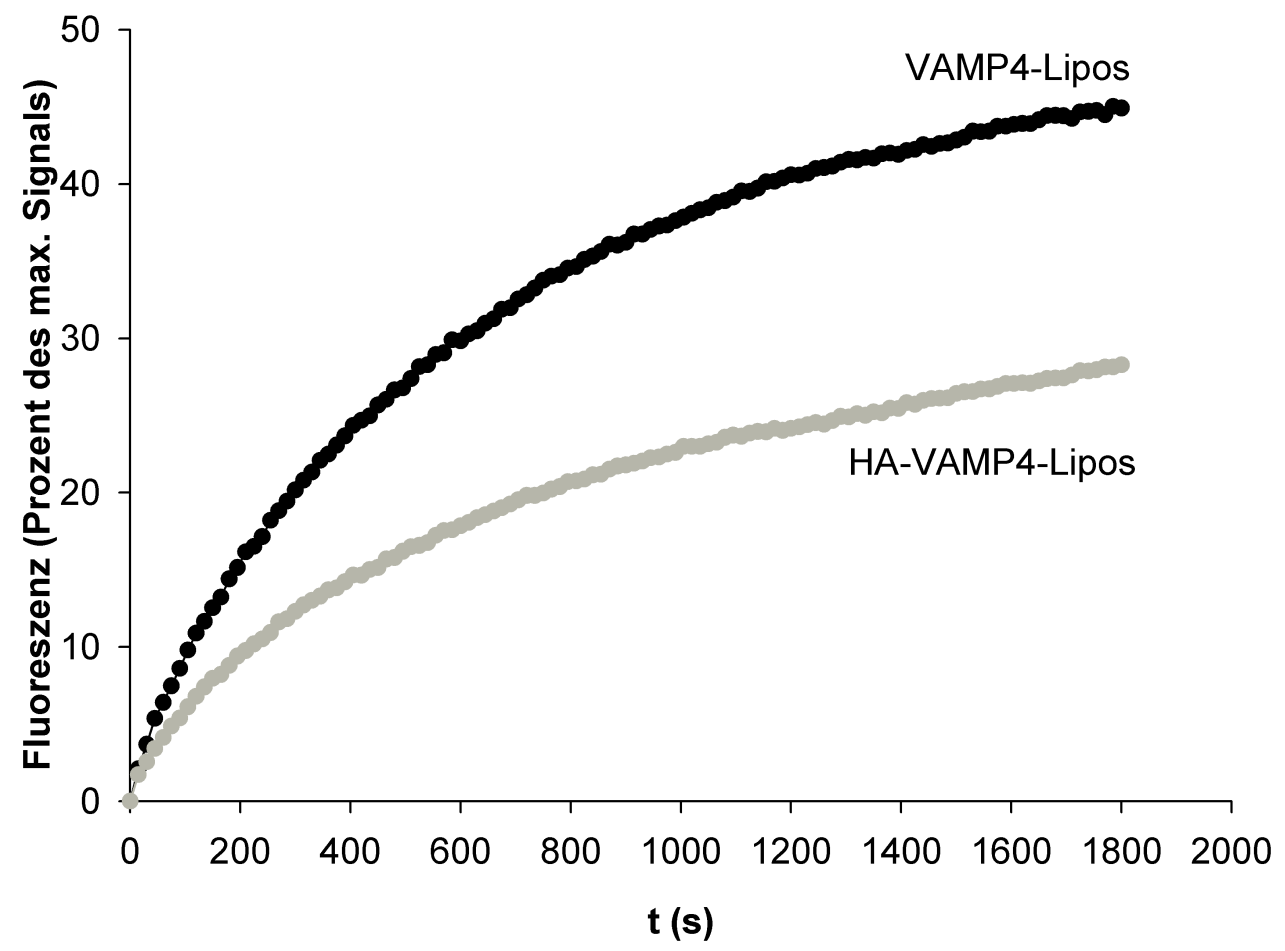

Abbildung 3.44: HA-tag VAMP4 ist funktional

Liposomen, die VAMP4 oder HA-VAMP4 enthielten wurden mittels Gelfiltration hergestellt, mit Endosomen inkubiert und die Lipidvermischung verfolgt. 


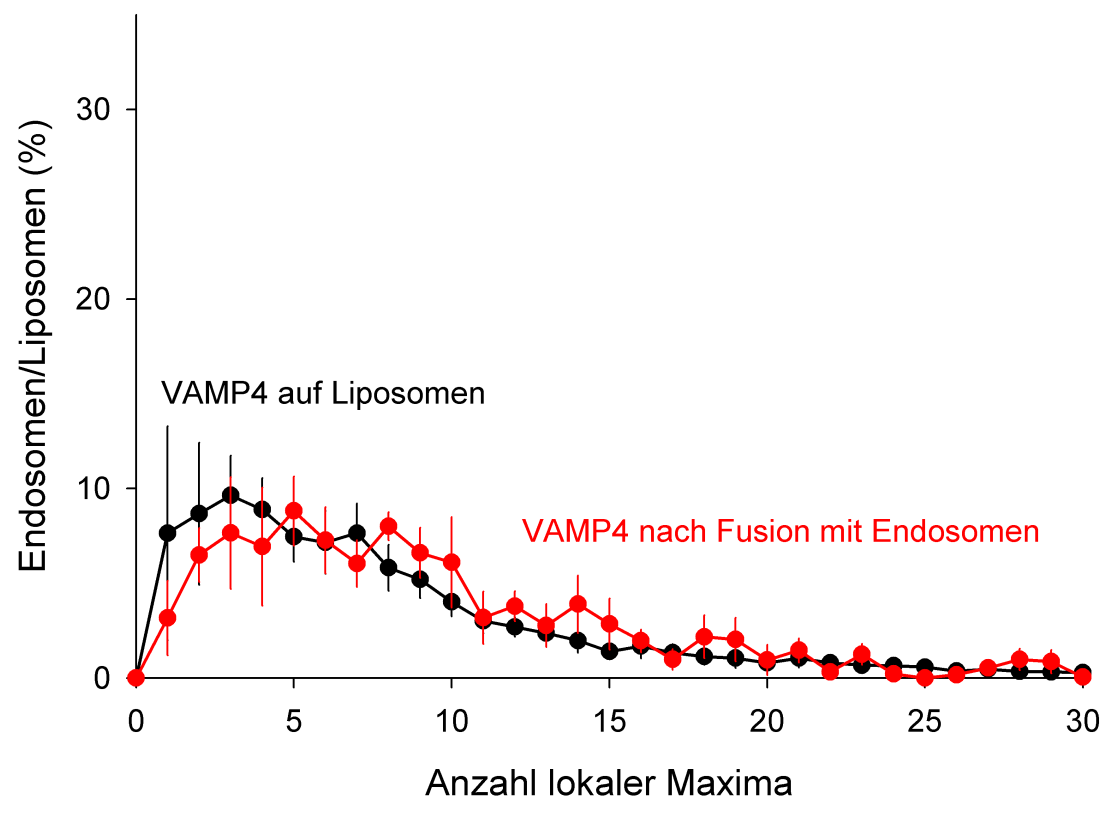

Abbildung 3.45: Die HA-VAMP4-Struktur auf Liposomen und Endosomen ähnelt sich

HA-VAMP4 Liposomen wurden mittels Gelfiltration hergestellt und mit Endosomen für $1 \mathrm{~h}$ inkubiert, um sie fusionieren zu lassen. Zum Vergleich wurden mittels Umkehrphasenevaporation große HA-VAMP4 Liposomen hergestellt. Beide Proben wurden analog auf Deckgläschen zentrifugiert, fixiert und einer anti-HA-Immunfärbung unterzogen. Die mit einem STED-Mikroskop gemachten Aufnahmen wurden anschließend durch ein MatlabProgramm auf die Domänenstruktur analysiert. Gezeigt sind Mittelwerte von 3 unabhängigen Experimenten mit Standardfehler. 


\section{Ergebnisse}

Proteine zutrifft, wurde Myc-tag Syntaxin-1 rekombinant hergestellt, das bereits von Matthew Holt auf seine Fusionsaktivität getestet worden war, und analog zu VAMP4 auf Liposomen und mit Liposomen fusionierten Endosomen untersucht. In diesem

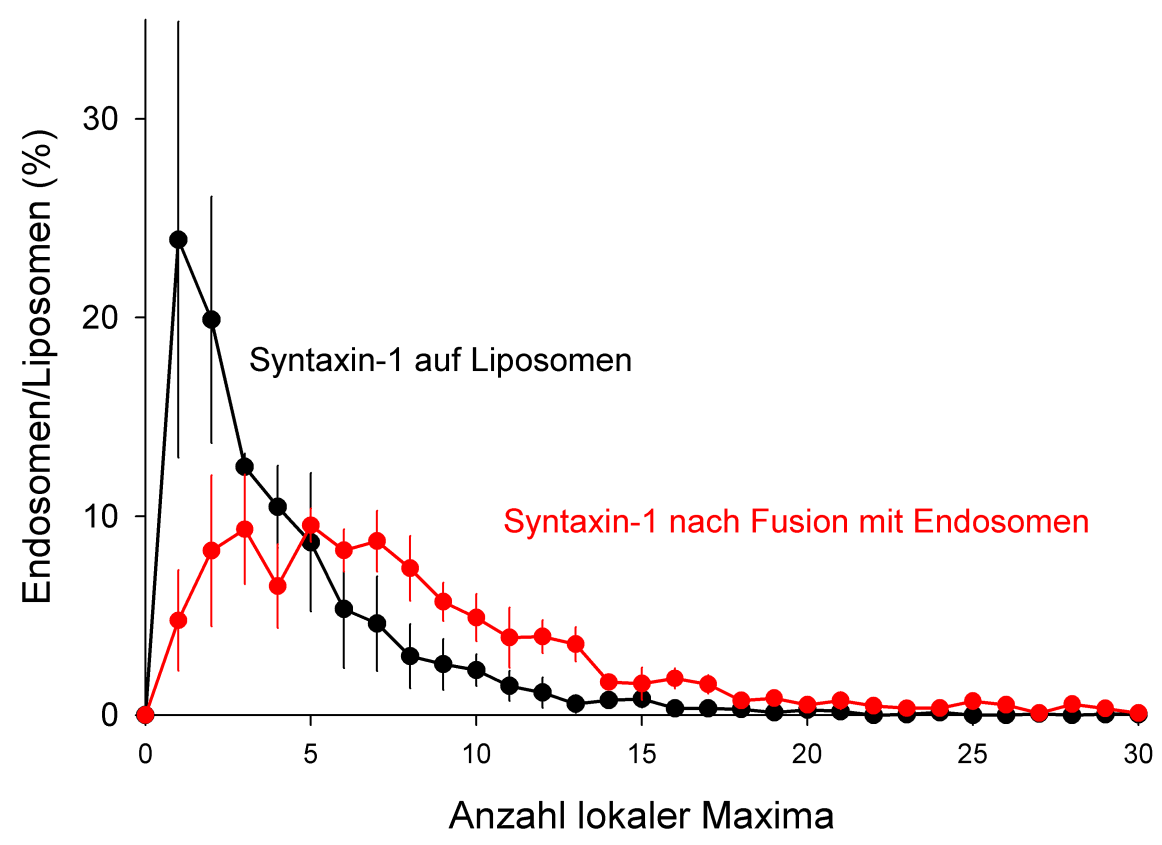

Abbildung 3.46: Myc-Syntaxin-1 formt mehr Domänen auf Endosomen als auf Liposomen

Myc-tag Syntaxin-1 wurde analog zu HA-VAMP4 in seiner Verteilung auf großen Liposomen und Endosomen verglichen. Gezeigt sind die Mittelwerte von 3 unabhängigen Experimenten.

Fall ergaben sich signifikante Unterschiede (Abbildung 3.46). Myc-Syntaxin-1 bildet nur wenige Domänen auf der liposomalen Membran, aber zahlreiche, sobald es sich in Endosomen befindet. Möglicherweise findet es dort „Andockstellen“ vor (siehe Diskussion). Die Unterschiede zwischen den beiden SNAREs Syntaxin-1 und VAMP4 sind zunächst überraschend, zeigen jedoch, wie individuell die Proteindomänenstruktur determiniert zu werden scheint. Für Syntaxin-1-Cluster auf der Plasmamembran sind die entscheidenden Faktoren bereits intensiv untersucht worden (siehe (Lang, 2007) zur Übersicht). Neben der Transmembrandomäne und dem SNARE-Motiv, ist dort auch Cholesterin wichtig. 


\section{Diskussion}

\subsection{Ein neues Docking-Assay}

Wie bereits in der Einführung beschrieben wird schon seit längerem darüber diskutiert, ob die Rolle von SNARE-Proteinen über ihre Funktion als Vermittler der Membranfusion hinausgeht. Für Hefevakuolen (Mayer \& Wickner, 1997; Ungermann et al., 1998) und vor kurzem auch für synaptische Vesikel (Hammarlund et al., 2007, 2008) ist eine Beteiligung der SNARE-Proteine am Docking beschrieben worden, welche nun auch im endosomalen System getestet werden sollte. Das ursprünglich für Vakuolen entwickelte Aggregationsassay hat sich hierbei als wenig geeignet herausgestellt, so dass ein neues, fluoreszenzbasierendes Assay entwickelt wurde, welchem eine funktionelle Markierung der Endosomen zugrunde liegt. Das beschriebene Assay ermöglicht eine parallele Untersuchung von Docking und Fusion, wodurch die Auswirkungen bestimmter Einflüsse auf diese beiden direkt verglichen werden konnten. Dabei zeigte sich, dass Docking und Fusion offensichtlich unabhängig voneinander reguliert werden. So ist der Anteil der gedockten Endosomen deutlich größer als der der fusionierten und einige Inhibitoren wie Wortmannin haben einen stärkeren Einfluss auf die Anzahl der gedockten als auf die Anzahl der fusionierten Endosomen (siehe Abbildung 3.17). Dagegen ist das Docking weniger anfällig für Verdünnung (siehe Abbildung 3.11).

Die zunächst überraschende Beobachtung, dass die Fusion von der Verdünnung der Endosomen deutlich stärker betroffen war, wird verständlich, wenn man die Ergebnisse des Präinkubationsexperiments bedenkt (siehe Abbildung 3.12). Wenn die rot und grün markierten Endosomen separat für 10 Minuten bei $37^{\circ} \mathrm{C}$ im Reaktionsmix inkubiert werden, bevor sie für weitere 45 Minuten kombiniert werden, reduziert sich die Fusion signifikant $(\mathrm{p}<0,05)$ während das Docking praktisch unverändert bleibt. Dieses Ergebnis deutet darauf hin, dass die Endosomen nach ihrer Aktivierung bzw. ihrem Priming schnell miteinander fusionieren müssen (was im verdünnten Zustand nur bedingt möglich ist), oder ansonsten ihre Fusionsfähigkeit verlieren. Dieses Ergebnis steht im Einklang mit früheren Beobachtungen im endosomalen System (Barbieri et al., 1998) bzw. bei Hefevakuolen (Mayer \& Wickner, 1997; Xu et al., 1997), wo ein labiler Zustand nach Aktivierung durch NSF beschrieben wurde. Für S. cere- 
visiae wurde dies auf die Freisetzung von Vam6/2p zurückgeführt, welche auf Sec18 (das Hefeortholog von NSF)-Aktivität folgt (Price et al., 2000). Der Mechanismus der Inaktivierung im endosomalen System ist noch unbekannt, wobei auch hier der Verlust eines nicht wieder rekrutierbaren Faktors vorliegen könnte.

\subsection{Der Einfluss von SNARE-Proteinen auf das Docking}

Dass weder die Blockierung der NSF-Aktivität, noch die Zugabe von rekombinanten SNAREs oder $\mathrm{F}_{\mathrm{ab}}$-Fragmenten gegen die endosomalen SNAREs einen Einfluss auf das Docking hatten (siehe Abbildungen 3.13-3.15) macht eine direkte Beteiligung von SNARE-Proteinen am Docking früher Endosomen sehr unwahrscheinlich. Dies steht im Gegensatz zu Beobachtungen, die bei der homotypischen Interaktion von Hefevakuolen gemacht wurden. Während natürlich die Möglichkeit besteht, dass unterschiedliche Systeme unterschiedlich reguliert werden, so gibt es doch auch einige experimentelle Details, die hier eine Rolle spielen könnten. Einer der Hauptanhaltspunkte für eine Rolle von SNAREs im Docking von Vakuolen ist die Beobachtung, dass trans-SNARE-Komplexe gebildet wurden, obwohl die Fusion durch den späten, d.h. Post-docking, Inhibitor microcystin-LR blockiert wurde (Ungermann et al., 1998). Dies führte zu dem Schluss, das die SNARE-Komplexbildung nur für das stabile Docking, aber nicht für die Fusion verantwortlich sein könnte. Es hat sich jedoch inzwischen herausgestellt, dass es sich bei der inhibitorischen Wirkung von microcystin-LR um ein Artefakt handelt. Der Inhibitor reduziert nicht die Fusion von Vakuolen selbst, sondern hemmt die Aktivierung des im Versuchsaufbau verwendeten Signalenzyms Alkalische Phosphatase (Jun \& Wickner, 2007). Von einer Entkopplung der Fusion von der trans-SNARE-Komplexbildung kann also nicht mehr ausgegangen werden. Einen anderen Hinweis auf die SNARE-Abhängigkeit des Dockings liefert die Tatsache, dass die Aggregation von Vakuolen ATP und NSFAktivität benötigt (Mayer \& Wickner, 1997). Die Ergebnisse sind hier allerdings nicht eindeutig, so wurde z.B. in einer anderen Studie mit dem gleichen Assay eine SNARE-Unabhängigkeit der Aggretation beschrieben (Wang et al., 2003). Ebenfalls problematisch scheinen die gegenüber der Fusionsreaktion deutlich veränderten Pufferbedingungen im Aggregationsassy (Mayer \& Wickner, 1997), schließlich wäre zu erwarten, dass einander bedingende Reaktionen wie Docking und Fusion unter den gleichen Reaktionsbedingungen ablaufen können. Als weiterer Hinweis auf eine SNARE-Beteiligung am Docking gewertet, dass scheinbar trans-SNARE-Komplexe mittels NSF dissoziiert werden können, ohne dass die Fusion beeinflusst wird (Ungermann et al., 1998, 1999; Peters et al., 2001). In diesem Fall wird jedoch nach wie 
vor diskutiert, ob es sich wirklich um trans-Komplexe handelte, oder nicht vielleicht doch eher um - in zuvor fusionierten Vakuolen gebildete - cis-Komplexe.

\section{Verbindende Elemente}

Während die in der vorliegenden Arbeit präsentierten Daten gegen eine funktionelle Beteiligung von SNARE-Proteinen am Dockingprozess sprechen, so soll doch keineswegs eine Interaktion von SNAREs mit dem Dockingapparat ausgeschlossen werden. So bindet EEA1 z.B. Syntaxin 6 (Mills et al., 2001) und Syntaxin 13 (McBride et al., 1999), d.h. zwei der an der Fusion früher Endosomen beteiligten SNARE-Proteine. Es ist gut vorstellbar, dass solche Interaktionen eine Rolle bei der Regulation des Übergangs vom Docking zur Fusion spielen (Sztul \& Lupashin, 2006). Außerdem kann nicht ausgeschlossen werden, dass SNAREs einen gedockten Zustand stabilisieren. Während bei Endosomen von einem mehr oder weniger konstitutiven Übergang vom Docking zur Fusion auszugehen ist, könnte dies besonders bei stärker regulierten Reaktionen wie der Exozytose synaptischer Vesikel eine Rolle spielen, wo nach dem Docking noch ein Priming erforderlich ist (Klenchin \& Martin, 2000). Neuere Beobachtungen scheinen für dieses System eine Beteiligung des SNAREs Syntaxin-1 nahezulegen, da die Anzahl gedockter Vesikel in Caenorhabditis elegans nach dessen knock-out signifikant reduziert ist (Hammarlund et al., 2007). Allerdings ist dieser Befund nach wie vor umstritten (de Wit et al., 2006) und indirekte Effekte durch den knock-out eines so zentralen Proteins kaum auszuschließen, so dass weitere Experimente erforderlich sind, um abschließend zu klären, ob SNAREs eine Rolle beim Docking synaptischer Vesikel spielen. Für das Docking von Endosomen ist dies nach den vorliegenden Ergebnissen nicht der Fall.

\subsection{Der Einfluss von SNARE Proteinen auf die Fusion}

Seit ihrer Entdeckung 1993 (Söllner et al., 1993) wurde die Rolle von SNAREProteinen als Vermittler der Membranfusion in zahlreichen Studien in vivo und in vitro belegt (siehe (Jahn \& Scheller, 2006) zur Übersicht). Im Einklang mit vorhergehenden Untersuchungen des frühendosomalen Systems (Brandhorst et al., 2006; Rizzoli et al., 2006) zeigt denn auch die vorliegende Arbeit eine klare SNAREAbhängigkeit der Fusionsreaktion (siehe Abbildungen 3.13 bis 3.15). Obwohl sich die Zugabe von rekombinanten SNARE-Fragmenten als kompetitive Inhibitoren, sowie der Einsatz von $\mathrm{F}_{\mathrm{ab}}$-Fragmenten und die Blockade der NSF-Aktivität nicht auf das Docking auswirkten, wurde die Fusion durch jede dieser Behandlungen signifikant $(\mathrm{p}<0,05)$ reduziert. 


\subsubsection{Die Fusion von Liposomen und Endosomen}

Im Gegensatz hierzu können auch proteinfreie Liposomen mit Endosomen fusionieren (siehe Abbildung 3.22). Mehrere Faktoren könnten hierbei eine Rolle spielen. Möglicherweise handelt es sich bei der beobachteten Lipidvermischung nicht um eine Fusion, sondern nur um einen Lipidtransfer. Die Bedingungen unter denen wir Lipidvermischung beobachten, machen dies jedoch sehr unwahrscheinlich. So wird ein Lipidtransfer in der Regel ATP-abhängig von Enzymen vermittelt, während die Dequenchingreaktion ATP-unabhängig abläuft. Desweiteren kann die Reaktion durch das invers-zylindrische Lipid Lysophosphatidylcholin inhibiert werden (siehe Abbildung 3.28), was nahelegt, dass die Bildung eines fusion stalks erfolgt (Vogel et al., 1993), während es sich auf einen reinen Lipidaustausch nicht auswirken sollte. Im Gegensatz zu dem früher verwendeten Octadecylrhodamin ist für das in dieser Studie eingesetzte, an Phosphatidyethanolamin-gekoppelte Rhodamin auch kein unspezifischer Transfer bekannt (Kuwana et al., 1995). Ein weiterer Nachweis für das Vorliegen von Fusion wäre durch einen Vergleich der Größenverteilung zu Beginn und nach Ende der Reaktion zu erbringen (Schuette et al., 2004). Die heterogene Größenverteilung der Endosomen (siehe Abbildung 3.2) machte dies schwierig, mit den größeren, durch Methode 2 hergestellten, Liposomen war es jedoch möglich eine durchschnittliche Größenzunahme um $120 \mathrm{~nm}$ zu beobachten (siehe Abbildung 3.41). Desweiteren konnte mit Immunogoldfärbung und anschließender Elektronenmikroskopie gezeigt werden, dass HA-VAMP4 aus Proteoliposomen in endosomale Strukturen gelangt, d.h. nicht nur Lipide, sondern auch Proteine ausgetauscht werden (siehe Abbildung 3.25). Es handelt sich bei der beobachteten Lipidvermischung also wirklich um Fusion.

\subsubsection{Unterschiede zwischen Liposomen und Endosomen}

Die Fusion von Liposomen und Endosomen ist offensichtlich proteinabhängig, wie der Trypsinverdau der Endosomen zeigt (siehe Abbildung 3.23). Allerdings ist auf der liposomalen Seite kein Protein erforderlich (siehe Abbildung 3.22), was einen durch SNARE-Komplexbildung vermittelten Prozess aussschließt. Ähnliche Probleme bei der Rekonstitution einer SNARE-abhängigen Fusion finden sich auch bei der Fusion von Proteoliposomen mit Golgivesikeln (Thomas Söllner, persönliche Mitteilung), während sich die Fusion von Proteoliposomen mit synaptischen Vesikeln spezifisch, d.h. SNARE- abhängig, darstellen lässt (Holt et al., 2008). Interessanterweise gilt dies nicht nur für die Rekonstitution des neuronalen Qabc-Komplexes in Liposomen, sondern auch für die des endosomalen Qabc-Komplexes (Daten nicht gezeigt). Ein wichtiger Unterschied zwischen synaptischen Vesikeln auf der einen und Golgive- 
sikeln bzw. Endosomen auf der anderen Seite ist, dass erstere in höherer Reinheit gewonnen werden können (Takamori et al., 2006). Die Koaufreinigung fusionsfördernder Substanzen mit Golgivesikeln und Endosomen ist daher höchstwahrscheinlich ein Grund für die zwischen Endosomen und Liposomen beobachtete Fusion. Dafür spricht auch, dass das Zytosol selbst fusionsfördernd wirkt (siehe Abbildungen 3.29 und 3.35). Allerdings konnte ein Waschen der Endosomen mit 40 mM EDTAhaltigem Puffer diese Fusion nicht unterbinden (Daten nicht gezeigt). Ein Einfluss von Annexinen konnte aufgrund der Kalzium- und Cholesterolunabhängigkeit weitestgehend ausgeschlossen werden (siehe Abbildung 3.30) Die hier beschriebenen Ergebnisse befinden sich im Einklang mit früheren Beobachtungen einer Fusion von proteinfreien Liposomen mit Endosomen. Auch in diesem Fall konnte die Fusion durch eine Trypsinierung der Endosomen unterbunden werden (Vidal \& Hoekstra, 1995).

Ein Unterschied zwischen Liposomen und Endosomen liegt in der vergleichsweise leeren Oberfläche der Proteoliposomen, die eine Fusion mit der sehr interaktionsfreudigen endosomalen Membran erleichtern könnte. Einen Hinweis hierauf liefert sowohl die Beobachtung, dass trypsinierte Endosomen stark verklumpen (siehe Abbildung 3.34) als auch die leicht erhöhte Spezifität von Proteoliposomen, die aus solubilisierten Endosomen hergestellt wurden (siehe Abbildung 3.36). Letzteres könnte damit zusammenhängen, das intrazelluläre Inhibitoren der Membranfusion eine Rolle spielen, die nur SNAREs enthaltenen Proteoliposomen fehlen. So reduziert z.B. das BEACH-Protein LvsB anscheinend die Fusion von frühen Endosomen mit Lysosomen (Kypri et al., 2007), wobei der genaue Mechanismus noch unklar ist. Desweiteren sind auch inhibitorische SNARE-Moleküle beschrieben worden, die über die Bildung von nicht-fusogenen Komplexen wirken sollen (Varlamov et al., 2004).

\section{Der Einfluss der Transmembrandomäne}

Dass trypsinierte Liposomen eine höhere Fusionsrate zeigen als proteinfreie, könnte entweder daran liegen, dass beim Verdau der SNARE-Proteine fusogene Fragmente gebildet werden, oder die Transmembrandomänen einen fusionsfördernden Einfluss haben. Während ersteres nicht ausgeschlossen werden kann, scheint dieser Effekt, da er für unterschiedliche SNARE-Proteine beobachtet wurde, eher auf einen in SNARE-Transmembrandomänen konservierten Mechanismus zu sprechen. So wurde in früheren Studien eine fusionsinduzierende Wirkung von Transmembrandomänen auf die Liposom-Liposom-Fusion nachgewiesen (Langosch et al., 2001). SNARE-Transmembrandomänen enthalten überdurchschnittlich viele hydrophobe, $\beta$-verknüpfte Aminosäuren, d.h. Valin und Isoleucin (Langosch et al., 2001). In einer hydrophoben Umgebung könnten diese $\beta$-Faltblatt fördernde Aminosäuren die 
Helixstruktur stören und lokale Membrandefekte hervorrufen, die eine Fusion begünstigen (Langosch et al., 2007). Unterstützt wird diese Annahme dadurch, dass Isoleucin, zusammen mit dem Helix-destabilisierenden Glycin, ebenfalls gehäuft in viralen Fusionsproteinen vorkommt (Cleverley \& Lenard, 1998).

\subsection{Regulation und Funktion des SNARE-Clustering}

Docking und Fusion sind Prozesse, die an spezialisierten Membrandomänen ablaufen. So definieren z.B. Syntaxin-1- und Syntaxin-4-Cluster Regionen für das Docking und die Fusion sekretorischer Granula bzw. Caveolae auf der Plasmamembran (Lang et al., 2001; Ohara-Imaizumi et al., 2004; Predescu et al., 2005). Über die Differenzierung der endosomalen Membran ist trotz einiger Hinweise auf PI3-PhosphatDomänen (Gillooly et al., 2003) oder Rab-Domänen (Zerial \& McBride, 2001) deutlich weniger bekannt, da Endosomen aufgrund ihrer geringeren Größe einer fluoreszenzmikroskopischen Analyse nur sehr eingeschränkt zugänglich waren. Die superhochaufösende STED-Mikroskopie (Klar et al., 2000), die in dieser Arbeit eingesetzt werden konnte, hat eine Analyse endosomaler Membrandomänen ermöglicht, wobei das Verhalten von SNARE-Clustern und dem SNARE-Bindungspartner Synaptophysin im Fokus des Interesses stand.

\subsubsection{Der Einfluss von Lipiden auf die Domänenstruktur}

Vorangegangene Arbeiten von Silvio Rizzoli hatten ergeben, dass Synaptophysin und einige SNARE-Proteine cholesterinabhängige Cluster auf frühen Endosomen bilden, wie die Abbildungen 3.36 und 3.42 anhand von Synaptophysin beispielhaft zeigen. Der Einfluss von Cholesterin auf Synaptophysin steht im Einklang mit früheren Studien in denen eine direkte Interaktion der beiden beschrieben worden ist (Thiele et al., 2000). Da die Behandlung mit $\beta$-Methyl-Cyclodextrin jedoch eine sehr aggresive Methode darstellt, die Membranzusammensetzung zu verändern und noch dazu auf Cholesterin beschränkt ist, kam im Rahmen der vorliegenden Arbeit auch ein weniger invasives Verfahren, d.h. die Fusion von Endosomen mit Liposomen unterschiedlicher Zusammensetzung zum Einsatz, das durch die im Abschnitt 3.2 beschriebenen Ergebnisse ermöglicht worden war. Obwohl eine deutliche Zunahme der Membranoberfläche erreicht werden konnte, hatte die resultierende Absenkung der Cholesterinkonzentration keinen Einfluss auf die Anzahl der Synaptophysincluster (siehe Abbildungen 3.41 und 3.40), was auf eine relativ hohe Stabilität dieser Cluster hindeutet. Interessanterweise führte auch eine Erhöhung des Cholesteringehalts gegenüber der nativen Situation, welche durch Fusion der Endosomen mit cholesterin- 
reichen Liposomen erreicht werden konnte, nicht zu einer verstärkten Clusterbildung. Dies deutet darauf hin, das für die Bildung von Synaptophysindomänen bereits sättigende Konzentrationen von Cholesterin in Endosomen vorliegen. Die endosomale Lipidzusammensetzung entspricht in etwa der der Plasmamembran, das heisst der Cholesterinanteil liegt bei ungefähr 30-40\% (Evans \& Hardison, 1985).

\subsubsection{Die Beziehung zwischen Cholesterin und lipid rafts}

Cholesterin besitzt verglichen mit seinem hydrophoben Anteil nur eine sehr kleine hydrophile Kopfgruppe und muss auch auf die Kopfgruppen anderer Lipide zurückgreifen, um Kontakt mit Wasser zu vermeiden (Huang \& Feigenson, 1999), wobei spezifische Interaktionen besonders mit Sphingomyelin als Kristallisationspunkte zur Bildung von Membrandomänen dienen könnten (Simons \& Ikonen, 1997; McConnell \& Radhakrishnan, 2003). Cholesterol und Sphingomyelin finden sich denn auch angreichert in Fraktionen, welche in kaltem Triton X-100 unlöslich sind, eines der ursprünglichen Kriterien für die sogenannten lipid rafts (siehe Einleitung).

Lipid rafts stellen eine Membranphase dar, die als „flüssig geordnet” $\left(l_{o}\right)$ bezeichnet wird (Ipsen et al., 1987), was Cholesterin z.B. dadurch erreicht, dass es die Freiheitsgrade der Phospholipidalkylketten einschränkt, während die umgebende Membranphase als „flüssig-ungeordnet” $\left(l_{d}\right)$ gilt (Mukherjee \& Maxfield, 2004). An den Übergängen zwischen diesen Phasen tritt eine sogenannte line tension auf, die unter anderem daraus resultiert, dass die Membran in der $1_{o}$-Phase ca. $10 \%$ dicker ist als in der $l_{d}$-Phase (hydrophobic mismatch). Dadurch werden die Lipide in der Grenzregion deformiert (Lundbaek et al., 2003). Interessanterweise zeigt Cholesterin selbst keine hohe Präferenz für die $1_{o}$-Phase (Veatch \& Keller, 2003). Eine seiner Funktionen könnte in der Stabilisierung der Phasenübergänge von $l_{o}$ zu $l_{d}$, daher einer Verringerung der line tension, liegen, wodurch auch kleinere Domänen aufrechterhalten werden können. So findet man Cholesterin an den Rändern von Domänen (Needham et al., 1988) und seine Extraktion führt zu drastischen Phasentrennungen, d.h. der Bildung von sehr großen Domänen statt vieler kleiner (Hao et al., 2001).

\subsubsection{Cholesterin und SNARE-Cluster}

Zum Einfluss von Cholesterin auf die Membranverteilung besonders der neuronalen SNARE-Proteine exisitieren zahlreiche Studien. So konnte z.B. durch Vernetzungsexperimente gezeigt werden, dass Syntaxin-1 direkt mit Cholesterin aber nicht mit Phosphatidylcholin interagiert (Lang et al., 2001) und dass eine Entfernung von Cholesterin durch $\beta$-methyl-Cyclodextrin zur Auflösung der Syntaxin-1-cluster 
auf der Plamamembran führt. Ob die Cholesterinabhängigkeit z.B. der Syntaxin-1cluster jedoch gleichbedeutend mit einer Lokalisation in lipid rafts ist, ist umstritten. Die Ergebnisse zur Kofraktionierung von Syntaxin-1 mit DRMs (detergent resistant membranes) widersprechen einander (Chamberlain et al., 2001; Lang et al., 2001). Die teils sehr unterschiedlichen Ergebnisse, die bei der Analyse von DRMs erzielt wurden (Lang, 2007), sowie deutliche Zweifel daran, ob sie tatsächliche physiologische Zustände wiederspiegeln (Heerklotz, 2002; Munro, 2003), hat dazu geführt, dass auf einem Keystone Symposium 2006 eine neue Definition von membrane rafts verfasst wurde. Diese greift nicht mehr auf die Unlöslichkeit in Detergenz zurück, und gibt auch die Theorie, dass rafts allein durch die Interaktion von Lipiden entstehen, zugunsten einer Mischung aus Protein-Protein, Protein-Lipid und Lipid-LipidWechselwirkungen auf (Pike, 2006). So wurde im Rahmen dieser Arbeit auch nicht der Versuch unternommen, zu klären, ob sich die endosomalen SNAREs in DRMs befinden, während für die Diskussion der Begriff lipid rafts beibehalten wurde, da er besonders den älteren Studien konzeptionell zugrunde liegt. Unumstritten ist die funktionelle Bedeutung von Cholesterin, so führt eine $\beta$-methyl-Cyclodextrinbehandlung zu um 50\% reduzierter Exocytose in PC12-Zellen (Lang et al., 2001) und inhibiert z.B. auch die Endozytose von Transferrinrezeptoren (Rodal et al., 1999; Subtil et al., 1999) in guter Übereinstimmung mit der beobachteten Blockierung der endosomalen Fusion (siehe Abbildung 3.37).

Ob sich Syntaxin-1 in 1o-Phasen anreichert, ist in Modellmembranen untersucht worden, wo diese Phasen durch die Wahl einer geeigneten, d.h. cholesterin- und sphingomyelinreichen Lipidmischung erzeugt werden können. Sowohl Syntaxin-1 als auch VAMP2 weisen in diesen Studien eine Präferenz für die ungeordnete, lipid raft-unähnliche Phase auf (Bacia et al., 2004), wobei dieses Ergebnis im Falle von VAMP2 mit Vorsicht zu interpretieren ist, da es intrazellulär palmityliert vorliegt, was seine Präferenz für die raft-Phase erhöhen könnte (el-Din el Husseini \& Bredt, 2002). Interessanterweise steigt die Assoziation von Proteinen mit lipid rafts, wenn sie oligomerisiert vorliegen, wie durch Vernetzungsexperimente gezeigt werden konnte (Holowka \& Baird, 2001). Somit wären auch kooperative Mechanismen zur Domänenbildung möglich.

\subsubsection{Die Regulation der Cluster durch Protein-Protein-Interaktionen}

Neben einer Regulation der Proteindomänen durch Lipide kommt natürlich auch eine Regulation durch Protein-Protein-Wechselwirkungen in Betracht, wobei homound heterotypische Interaktionen zu unterscheiden sind. 


\subsubsection{Homotypische Interaktionen}

Für Syntaxin-1 ist eine Homooligomerisierung über seine Transmembrandomäne (Laage et al., 2000), sowie über sein SNARE-Motiv (Sieber et al., 2006, 2007) beschrieben worden. Daraus könnte gefolgert werden, dass Syntaxin-1 auch auf Modellmembranen Cluster formen sollte, was interessanterweise bei Rekonstitution in giant unilamellar vesicles nicht der Fall ist (Bacia et al., 2004). Und auch der Vergleich der Myc-Syntaxin-1 Verteilung auf Liposomen mit der auf Endosomen zeigt deutlich mehr Cluster auf der nativen Membran (siehe Abbildung 3.46). Letzteres könnte einfach auf die größere Anzahl von zur Komplexbildung verfügbaren Syntaxin-1 Proteinen nach der Fusion zurückzuführen sein, da die Zahl der Syntaxin-1 Cluster auch in PC12-Zellen gut mit der Expressionshöhe von Syntaxin-1 korreliert (Sieber et al., 2006). Eine weitere Möglichkeit für die höhere Anzahl der Myc-Syntaxin-1 Cluster auf der endosomalen Membran wäre, dass die liposomale Cholesterolkonzentration mit $10 \%$ limitierend ist, was mit einer endosomenähnlicherer Lipidzusammensetzung (s.o.) untersucht werden könnte. Ähnlich wie auf der Plasmamembran (Sieber et al., 2007) scheint es auch auf Endosomen zu einem dynamischen Austausch zwischen freien und in Cluster vorliegenden Syntaxinen zu kommen, so dass sich das durch Fusion eingeführte Myc-Syntaxin-1 in die bereits vorhandenen Cluster integrieren kann. Die Zentren dieser Cluster sind zwar wahrscheinlich aufgrund ihrer dichten Packung funktionell nicht aktiv (Sieber et al., 2007), aber dafür ihre Umgebung (Lang et al., 2001; Ohara-Imaizumi et al., 2004) für die die Cluster als eine Art Reservoir dienen könnten (Bethani et al., 2007; Sieber et al., 2007).

Über potentielle homotypische Interaktionen von VAMP4 ist weitaus weniger bekannt als über die von Syntaxin-1. Dass HA-VAMP4 bereits auf Liposomen Cluster zu bilden scheint (siehe Abbildung 3.45), ist daher interessant. Es könnte sich hierbei jedoch theoretisch auch um ein durch den Antikörper verursachtes Artefakt handeln, d.h. ein nur antikörperinduziertes Clustering, obwohl es unwahrscheinlich scheint, dass die VAMP4-Verteilung auf fixierten Endosomen dann genauso aussehen sollte.

\subsubsection{Heterotypische Interaktionen}

Einer der Kandidaten für die Bildung von Proteindomänen ist Rab5, das eine zentrale Rolle im Docking zu spielen scheint und schon früher als Membranorganisator vorgeschlagen wurde (Christoforidis et al., 1999a; McBride et al., 1999; Zerial \& McBride, 2001). Wie in der Einleitung beschrieben erhöht Rab5 die lokale Konzentration von PI3-Phosphat und rekrutiert zahlreiche Effektoren über einen autokatalytischen Mechanismus an die Membran, unter Ihnen EEA1. EEA1 bindet sowohl an Syntaxin 6 als auch an Syntaxin 13 und scheint mit mit letzterem sowie mit NSF 


\section{Diskussion}

hochmolekulare Cluster auf der frühendosomalen Membran zu bilden. Die lokale Konzentrierung seiner Effektoren scheint daher einen Weg darzustellen, durch den Rab5 Einfluss auf die Domänenbildung nimmt (siehe Abschnitt 1.4.2). Ein weiterer, eher indirekter Mechanismus, liegt in der Modulation des zellulären Cholesterintransports, z.B. durch Rab11, welches sich hauptsächlich auf Recyclingendosomen findet (Hölttä-Vuori et al., 2002). Rab5 (und andere potentiell gebundene Rabs) können durch Zugabe von GDI von der Membran entfernt werden (Ullrich et al., 1994). Trotz der hohen Effizienz der Extraktion und dem folgenden Verlust von EEA1 von der Membran (vgl. Abbildung 3.18), ändert sich, wie Abbildung 3.43 zeigt, weder die Domänenstruktur der Interaktionspartner Syntaxin 6 und Syntaxin 13 (McBride et al., 1999; Mills et al., 2001) noch die Verteilung der anderen untersuchten SNAREs Syntaxin 16 und VAMP4. Rab5 mag daher zwar eine Funktion bei der Initialisierung von SNARE-Domänen besitzen, hat aber offensichtlich keine zentrale Rolle für deren Erhalt, was gut mit früheren Beobachtungen der Abwesenheit von Rab5 selbst von Syntaxin 13-EEA1-NSF-Clustern übereinstimmt (McBride et al., 1999).

Trotz des Bestehens von spezialisierten Regionen, scheint die endosomale Membran keineswegs statisch zu sein, wie die effiziente Mischung mit den liposomalen Lipiden (siehe Abbildung 3.40) und Proteinen (siehe Abbildung 3.25) zeigt. Verglichen mit der Plasmamembran ist über die endosomalen Domänen noch praktisch nichts bekannt, ihre Erforschung verspricht jedoch für die Zukunft ein tieferes Verständnis intrazellulärer Transportprozesse. 


\subsection{Schlussfolgerungen}

Die vorliegenden Ergebnisse verdeutlichen die Vor- aber auch die Nachteile von in vitro-Ansätzen. Während es nicht möglich war, Endosomen adäquat durch Liposomen zu ersetzen, konnte mit isolierten Endosomen ein gut funktionierendes DockingAssay aufgebaut werden, das eine viel höhere Manipulierbarkeit aufweist, als es in vivo möglich gewesen wäre, und dass dadurch zu klaren Aussagen führte. Auch die durch die Fusion mit Liposomen erreichte Veränderung der Lipidzusammensetzung war so nur in vitro durchführbar und lieferte wertvolle Aufschlüsse über Regulationsmechanismen. Der vollständige Zusammenbau eines Endosoms aus seinen Einzelteilen bleibt ein lohnendes Ziel, um seine Funktionsweise besser zu verstehen, er ist aber, wie die vorliegenden Daten zeigen, nicht trivial. Der Ansatz mit der kompletten Mischung aus endosomalen Proteinen und Lipiden zu beginnen und vielleicht einzelne Teile hieraus vor dem Zusammenbau zu entfernen scheint in die richtige Richtung zu führen, erfordert aber noch deutliche Optimierung. Im Gegensatz dazu kann das Docking-Assay problemlos zu einer weiteren Verfeinerung und Ausweitung der Analyse z.B. auf andere PI3-bindenden Proteine wie Rabenosyn-5 genutzt werden. Und auch die Untersuchungen der Lipidabhängigkeit müssen nicht auf Synaptophysin-Cluster beschränkt bleiben, sondern können leicht auf die anderen für Fusion und Docking relevanten Proteine ausgedehnt werden, um so einen vollständigen Überblick zu gewinnen. 
4 Diskussion 


\section{Kurzfassung}

Ein Großteil des intrazellulären Transports erfolgt über das Abschnüren, den Transport und die anschließende Fusion von Vesikeln, wobei dieser letzte Schritt von SNARE-Proteinen bewerkstelligt wird. Neben deren Funktion in der Fusion wird schon seit einiger Zeit auch über eine Beteiligung an dem, der Fusion vorausgehenden Prozess des Docking, d.h. der stabilen Verknüpfung der Organellen spekuliert. Diese Frage wurde in der vorliegenden Arbeit an frühen Endosomen untersucht. Frühe Endosomen bilden ein zentrales Sortierungskompartiment, in dem die meisten Endozytoserouten zusammenlaufen und können untereinander fusionieren, was sie zu einem viel genutzten Modellsystem gemacht hat. Um den Einfluss der SNAREProteine auf das Docking von frühen Endosomen analysieren zu können, musste zunächst ein geeignetes Assay entwickelt werden, da sich das für das vakuoläre System bekannte Aggregationsassay als nicht geeignet herausstellte. Mit dem neuen Assay konnte gezeigt werden, dass zwar EEA1 und Rab5 wie erwartet wichtig für das Docking von frühen Endosomen sind, dass dieses aber von einer SNARE-Funktion unabhängig ist, da weder das Verhindern der SNARE-Aktivierung durch mutiertes $\alpha$ SNAP, noch die Zugabe von löslichen SNARE-Fragmenten oder gegen die SNAREs gerichteter $\mathrm{F}_{\mathrm{ab}}$-Fragmente einen großen Einfluss auf das Docking hatte, während die Fusion signifikant inhibiert wurde.

Versuche, die SNARE-Regulation über die Rekonstitution der endosomalen SNAREs in Liposomen und anschließende Fusion mit frühen Endosomen zu analysieren, haben sich als sehr schwierig herausgestellt. Das Problem lag hierbei nicht etwa darin, dass keine Fusion erzielt worden wäre, sondern im Gegenteil daran, dass selbst proteinfreie Liposomen mit Endosomen fusionierten und zwar in vergleichbarem Umfang und praktisch identischer Kinetik wie SNARE-haltige Liposomen. Durch die Vergrößerung der Liposomen (und den dadurch reduzierte Krümmungsstress) stieg die Spezifität der Reaktion etwas an, so dass Proteoliposomen doppelt so stark mit Endosomen fusionierten wie proteinfreie Liposomen. Der vielversprechendste Weg scheint jedoch ein top-down Ansatz zu sein, d.h. Endosomen zu solubilisieren, einzelne Proteine über Immundepletion aus dieser Mischung zu entfernen und aus den verbleibenden Proteinen und Lipiden über Detergenzentfernug Proteoliposomen mit sehr endosomenähnlicher Zusammensetzung zu erzeugen. 


\section{Kurzfassung}

Für das Docking und die Fusion von Endosomen ist das Zusammenwirken von zahlreichen Faktoren erforderlich, welche in der Regel in spezialisierten Membrandomänen konzentriert vorliegen. Die Regulation dieser Domänen ist jedoch noch weitgehend unklar und wurde daher im letzten Teil der vorliegenden Arbeit für SNAREs und Synaptophysin untersucht. Bisher war es aufgrund der geringen Größe von Endosomen (ungefähr $200 \mathrm{~nm}$ Durchmesser) sehr schwer, Aussagen über unterschiedliche endosomale Domänen zu treffen, da sie im Bereich der Auflösungsgrenze konventioneller Lichtmikroskopie liegen. Für die vorliegende Studie konnte jedoch auf die neuentwickelte STED-Mikroskopie zurückgegriffen werden, wobei das verwendete kommerziell erhältliche Gerät eine Auflösung von 70-90 nm besitzt und die endosomale Membran dadurch einer Analyse zugänglich machte. Das im zweiten Abschnitt gewonnene Wissen über die Fusion von Liposomen mit Endosomen konnte hier genutzt werden, um über diese Fusion die Lipidzusammensetzung der Endosomen zu verändern. Allerdings führten weder erhöhte Cholesterinkonzentrationen noch die Zufuhr von PI und $\mathrm{PIP}_{2}$ zu einer Veränderung in der Zahl der Cluster, was auf eine relative Stabilität dieser hindeutet. Interessanterweise scheinen auch die als Membranorganisatoren ins Spiel gebrachten Rab-Proteine keineswegs essentiell für diese Domänen zu sein, da die Extraktion der Rab-Proteine durch GDI praktisch keinen Einfluss auf die Domänenanzahl der untersuchten Proteine hatte. 


\section{Summary}

Most intracellular transport processes occur via budding and fusion of vesicles, where fusion is dependent on SNARE proteins. Fusion is preceded by docking, the close contact of vesicles which has been proposed to depend on SNARE proteins as well from work in C. elegans and $S$. Cerevesiae. As this is still heavily debated the role of SNAREs in docking was analysed for early endosomes. Early endosomes form the first compartment reached by most routes of endocytosis and can undergo homotypic fusion which has rendered them a widely used model system. A new fluorescence based assay was developed which allowed to monitor their docking and fusion in parallel. Previous suggestions of EEA1 and Rab5 as important docking factors could be confirmed whereas no influence of SNARE proteins was found. Even though SNARE-function was blocked by three different means: competitive inhibition, antibodies and block of activation, docking remained intact whereas fusion was reduced significantly. A role of SNARE-function in early endosomal docking could therefore be ruled out.

A different set of experiments aimed at the analysis of SNARE-regulation by use of a minimal system, i.e. proteoliposomes containing early endosomal SNARE proteins. Even though these proteoliposomes can fuse with each other in a SNARE-specific manner, fusion of proteoliposomes with endosomes was dependent on endosomal but not on liposomal protein content, i.e. trypsinated proteoliposomes reached similar fusion rates with endosomes as control proteoliposomes. The specificity of fusion could be increased when endosomes were solubilised completely and these mixtures were used for proteoliposome formation. Immunodepletion of selected proteins from these mixtures before reconstitution might therefore be used in the future to adress their role even though the assay has to be optimised further beforehand.

Fusion and docking take place at specialised regions of the plasma membrane. Therefore, it was analysed how SNARE proteins and the vesicle marker synaptophysin distribute on endosomes. Domain analysis was performed with the recently developed superresolution STED-Microscope. The high fusion rate of liposomes with endosomes could finally be used in this context as a relatively non-invasive tool to change the lipid composition of early endosomes and thereby address the role of lipids in domain formation and stability. This was feasible because fusion was not 
dependent on a certain lipid composition so that liposomes with high concentrations for example of phosphatidyl inositol could be used to have a large impact on the endosomal lipid composition. Nevertheless the cluster of synaptophysin remained intact and were only destroyed after treatment with $\beta$-methyl-cyclodextrin showing that its domains are rather stable. Interesting differences were observed between the distribution of syntaxin-1 on pure lipid membranes and endosomes as it formed much more clusters on the latter. 


\section{Literaturverzeichnis}

Advani, R. J., Bae, H. R., Bock, J. B., Chao, D. S., Doung, Y. C., Prekeris, R., Yoo, J. S., \& Scheller, R. H. (1998). Seven novel mammalian SNARE proteins localize to distinct membrane compartments. J Biol Chem, 273(17), 10317-10324.

Allan, B. B., Moyer, B. D., \& Balch, W. E. (2000). Rab1 recruitment of p115 into a cis-SNARE complex: programming budding COPII vesicles for fusion. Science, 289(5478), 444-448.

Antonin, W., Holroyd, C., Tikkanen, R., Honing, S., \& Jahn, R. (2000). The RSNARE endobrevin/VAMP-8 mediates homotypic fusion of early endosomes and late endosomes. Mol Biol Cell, 11(10), 3289-98.

Bacia, K., Schuette, C. G., Kahya, N., Jahn, R., \& Schwille, P. (2004). SNAREs prefer liquid-disordered over "raft"(liquid-ordered) domains when reconstituted into giant unilamellar vesicles. J Biol Chem, 279(36), 37951-37955.

Barbieri, M. A., Hoffenberg, S., Roberts, R., Mukhopadhyay, A., Pomrehn, A., Dickey, B. F., \& Stahl, P. D. (1998). Evidence for a symmetrical requirement for Rab5-GTP in in vitro endosome-endosome fusion. J Biol Chem, 273(40), $25850-5$.

Barnard, R. J., Morgan, A., \& Burgoyne, R. D. (1997). Stimulation of NSF ATPase activity by alpha-SNAP is required for SNARE complex disassembly and exocytosis. J Cell Biol, 139(4), 875-83.

Bethani, I., Lang, T., Geumann, U., Sieber, J. J., Jahn, R., \& Rizzoli, S. O. (2007). The specificity of SNARE pairing in biological membranes is mediated by both proof-reading and spatial segregation. EMBO J, 26(17), 3981-92.

Block, M. R., Glick, B. S., Wilcox, C. A., Wieland, F. T., \& Rothman, J. E. (1988). Purification of an N-ethylmaleimide-sensitive protein catalyzing vesicular transport. Proc Natl Acad Sci US A, 85(21), 7852-7856.

Bock, J. B., Klumperman, J., Davanger, S., \& Scheller, R. H. (1997). Syntaxin 6 functions in trans-Golgi network vesicle trafficking. Mol Biol Cell, 8(7), 12611271. 
Bock, J. B., Matern, H. T., Peden, A. A., \& Scheller, R. H. (2001). A genomic perspective on membrane compartment organization. Nature, 409(6822), 839841.

Bradford, M. M. (1976). A rapid and sensitive method for the quantitation of microgram quantities of protein utilizing the principle of protein-dye binding. Anal Biochem, 72, 248-254.

Braell, W. A. (1987). Fusion between endocytic vesicles in a cell-free system. Proc Natl Acad Sci U S A, 84(5), 1137-1141.

Brandhorst, D., Zwilling, D., Rizzoli, S. O., Lippert, U., Lang, T., \& Jahn, R. (2006). Homotypic fusion of early endosomes: SNAREs do not determine fusion specificity. Proc Natl Acad Sci U S A, 103(8), 2701-6.

Broadie, K., Prokop, A., Bellen, H. J., O’Kane, C. J., Schulze, K. L., \& Sweeney, S. T. (1995). Syntaxin and synaptobrevin function downstream of vesicle docking in Drosophila. Neuron, 15(3), 663-73.

Brose, N., Petrenko, A. G., Südhof, T. C., \& Jahn, R. (1992). Synaptotagmin: a calcium sensor on the synaptic vesicle surface. Science, 256(5059), 1021-1025.

Burkhardt, P., Hattendorf, D. A., Weis, W. I., \& Fasshauer, D. (2008). Munc18a controls SNARE assembly through its interaction with the syntaxin N-peptide. EMBO J, 27(7), 923-933.

Cai, H., Reinisch, K., \& Ferro-Novick, S. (2007). Coats, tethers, Rabs, and SNAREs work together to mediate the intracellular destination of a transport vesicle. Dev Cell, 12(5), 671-82.

Chamberlain, L. H., Burgoyne, R. D., \& Gould, G. W. (2001). SNARE proteins are highly enriched in lipid rafts in PC12 cells: implications for the spatial control of exocytosis. Proc Natl Acad Sci U S A, 98(10), 5619-5624.

Cheever, M. L., Sato, T. K., de Beer, T., Kutateladze, T. G., Emr, S. D., \& Overduin, M. (2001). Phox domain interaction with PtdIns(3)P targets the Vam7 t-SNARE to vacuole membranes. Nat Cell Biol, 3(7), 613-618.

Cheezum, M. K., Walker, W. F., \& Guilford, W. H. (2001). Quantitative comparison of algorithms for tracking single fluorescent particles. Biophys J, 81(4), 23782388 .

Chen, X., Araç, D., Wang, T.-M., Gilpin, C. J., Zimmerberg, J., \& Rizo, J. (2006). SNARE-mediated lipid mixing depends on the physical state of the vesicles. Biophys J, 90(6), 2062-2074.

Chernomordik, L. V., \& Kozlov, M. M. (2003). Protein-lipid interplay in fusion and fission of biological membranes. Annu Rev Biochem, 72, 175-207. 
Choudhury, A., Marks, D. L., Proctor, K. M., Gould, G. W., \& Pagano, R. E. (2006). Regulation of caveolar endocytosis by syntaxin 6-dependent delivery of membrane components to the cell surface. Nat Cell Biol, 8(4), 317-328.

Christoforidis, S., McBride, H. M., Burgoyne, R. D., \& Zerial, M. (1999a). The Rab5 effector EEA1 is a core component of endosome docking. Nature, 397(6720), 6215.

Christoforidis, S., Miaczynska, M., Ashman, K., Wilm, M., Zhao, L., Yip, S. C., Waterfield, M. D., Backer, J. M., \& Zerial, M. (1999b). Phosphatidylinositol-3OH kinases are Rab5 effectors. Nat Cell Biol, 1(4), 249-52.

Clary, D. O., Griff, I. C., \& Rothman, J. E. (1990). SNAPs, a family of NSF attachment proteins involved in intracellular membrane fusion in animals and yeast. Cell, 61(4), 709-721.

Cleverley, D. Z., \& Lenard, J. (1998). The transmembrane domain in viral fusion: essential role for a conserved glycine residue in vesicular stomatitis virus $\mathrm{G}$ protein. Proc Natl Acad Sci U S A, 95(7), 3425-3430.

Conibear, E., \& Stevens, T. H. (2000). Vps52p, Vps53p, and Vps54p form a novel multisubunit complex required for protein sorting at the yeast late Golgi. Mol Biol Cell, 11(1), 305-323.

Cook, N. R., Row, P. E., \& Davidson, H. W. (2004). Lysosome associated membrane protein 1 (Lamp1) traffics directly from the TGN to early endosomes. Traffic, 5(9), 685-699.

de Wit, H., Cornelisse, L. N., Toonen, R. F., \& Verhage, M. (2006). Docking of secretory vesicles is syntaxin dependent. PLoS ONE, 1, e126.

Dennison, S. M., Bowen, M. E., Brunger, A. T., \& Lentz, B. R. (2006). Neuronal SNAREs do not trigger fusion between synthetic membranes but do promote PEG-mediated membrane fusion. Biophys J, 90(5), 1661-1675.

Edelmann, L., Hanson, P. I., Chapman, E. R., \& Jahn, R. (1995). Synaptobrevin binding to synaptophysin: a potential mechanism for controlling the exocytotic fusion machine. EMBO J, 14(2), 224-31.

el-Din el Husseini, A., \& Bredt, D. S. (2002). Protein palmitoylation: a regulator of neuronal development and function. Nat Rev Neurosci, 3(10), 791-802.

Emans, N., Gorvel, J. P., Walter, C., Gerke, V., Kellner, R., Griffiths, G., \& Gruenberg, J. (1993). Annexin II is a major component of fusogenic endosomal vesicles. J Cell Biol, 120(6), 1357-1369.

Evans, W. H., \& Hardison, W. G. (1985). Phospholipid, cholesterol, polypeptide and 
glycoprotein composition of hepatic endosome subfractions. Biochem J, 232(1), $33-36$.

Fasshauer, D., Antonin, W., Margittai, M., Pabst, S., \& Jahn, R. (1999). Mixed and non-cognate SNARE complexes. Characterization of assembly and biophysical properties. J Biol Chem, $274(22)$, 15440-15446.

Fasshauer, D., Sutton, R. B., Brunger, A. T., \& Jahn, R. (1998). Conserved structural features of the synaptic fusion complex: SNARE proteins reclassified as Qand R-SNAREs. Proc Natl Acad Sci U S A, 95(26), 15781-6.

Fischer von Mollard, G., Stahl, B., Walch-Solimena, C., Takei, K., Daniels, L., Khoklatchev, A., De Camilli, P., Sudhof, T. C., \& Jahn, R. (1994). Localization of Rab5 to synaptic vesicles identifies endosomal intermediate in synaptic vesicle recycling pathway. Eur J Cell Biol, 65(2), 319-26.

Fujiwara, T., Mishima, T., Kofuji, T., Chiba, T., Tanaka, K., Yamamoto, A., \& Akagawa, K. (2006). Analysis of knock-out mice to determine the role of HPC1/syntaxin 1A in expressing synaptic plasticity. J Neurosci, 26(21), 5767-76.

Gerst, J. E. (2003). SNARE regulators: matchmakers and matchbreakers. Biochim Biophys Acta, 1641(2-3), 99-110.

Geumann, U., Barysch, S. V., Hoopmann, P., Jahn, R., \& Rizzoli, S. O. (2008). SNARE function is not involved in early endosome docking. Mol Biol Cell, 19(12), $5327-5337$.

Geuze, H. J., Slot, J. W., Strous, G. J., Lodish, H. F., \& Schwartz, A. L. (1983). Intracellular site of asialoglycoprotein receptor-ligand uncoupling: double-label immunoelectron microscopy during receptor-mediated endocytosis. Cell, 32(1), $277-287$.

Gillooly, D. J., Raiborg, C., \& Stenmark, H. (2003). Phosphatidylinositol 3phosphate is found in microdomains of early endosomes. Histochem Cell Biol, 120(6), 445-453.

Grote, E., Baba, M., Ohsumi, Y., \& Novick, P. J. (2000). Geranylgeranylated SNAREs are dominant inhibitors of membrane fusion. J Cell Biol, 151 (2), 453-66.

Gruenberg, J. (2001). The endocytic pathway: a mosaic of domains. Nat Rev Mol Cell Biol, 2(10), 721-730.

Gruenberg, J., \& Howell, K. E. (1987). An internalized transmembrane protein resides in a fusion-competent endosome for less than 5 minutes. Proc Natl Acad Sci U S A, 84(16), 5758-62.

Hammarlund, M., Palfreyman, M. T., Watanabe, S., Olsen, S., \& Jorgensen, E. M. (2007). Open syntaxin docks synaptic vesicles. PLoS Biol, 5(8), e198. 
Hammarlund, M., Watanabe, S., Schuske, K., \& Jorgensen, E. M. (2008). CAPS and syntaxin dock dense core vesicles to the plasma membrane in neurons. J Cell Biol.

Hao, M., Mukherjee, S., \& Maxfield, F. R. (2001). Cholesterol depletion induces large scale domain segregation in living cell membranes. Proc Natl Acad Sci U S A, 98(23), 13072-13077.

Heerklotz, H. (2002). Triton promotes domain formation in lipid raft mixtures. Biophys J, 83(5), 2693-2701.

Hermann, G. J., Thatcher, J. W., Mills, J. P., Hales, K. G., Fuller, M. T., Nunnari, J., \& Shaw, J. M. (1998). Mitochondrial fusion in yeast requires the transmembrane GTPase Fzo1p. J Cell Biol, 143(2), 359-373.

Hess, D. T., Slater, T. M., Wilson, M. C., \& Skene, J. H. (1992). The 25 kDa synaptosomal-associated protein SNAP-25 is the major methionine-rich polypeptide in rapid axonal transport and a major substrate for palmitoylation in adult CNS. J Neurosci, 12(12), 4634-4641.

Heumann, R., Kachel, V., \& Thoenen, H. (1983). Relationship between NGFmediated volume increase and "priming effectïn fast and slow reacting clones of PC12 pheochromocytoma cells. Role of cAMP. Exp Cell Res, 145(1), 179-90.

Hinners, I., Wendler, F., Fei, H., Thomas, L., Thomas, G., \& Tooze, S. A. (2003). AP-1 recruitment to VAMP4 is modulated by phosphorylation-dependent binding of PACS-1. EMBO Rep, 4(12), 1182-1189.

Hölttä-Vuori, M., Tanhuanpää, K., Möbius, W., Somerharju, P., \& Ikonen, E. (2002). Modulation of cellular cholesterol transport and homeostasis by Rab11. Mol Biol Cell, 13(9), 3107-3122.

Holowka, D., \& Baird, B. (2001). Fc(epsilon)RI as a paradigm for a lipid raftdependent receptor in hematopoietic cells. Semin Immunol, 13(2), 99-105.

Holroyd, C., Kistner, U., Annaert, W., \& Jahn, R. (1999). Fusion of endosomes involved in synaptic vesicle recycling. Mol Biol Cell, 10(9), 3035-44.

Holt, M., Riedel, D., Stein, A., Schuette, C., \& Jahn, R. (2008). Synaptic vesicles are constitutively active fusion machines that function independently of $\mathrm{Ca} 2+$. Curr Biol, 18(10), 715-722.

Horiuchi, H., Lippé, R., McBride, H. M., Rubino, M., Woodman, P., Stenmark, H., Rybin, V., Wilm, M., Ashman, K., Mann, M., \& Zerial, M. (1997). A novel Rab5 GDP/GTP exchange factor complexed to Rabaptin-5 links nucleotide exchange to effector recruitment and function. Cell, 90(6), 1149-1159. 
Huang, J., \& Feigenson, G. W. (1999). A microscopic interaction model of maximum solubility of cholesterol in lipid bilayers. Biophys J, 76 (4), 2142-2157.

Huttner, W. B., Schiebler, W., Greengard, P., \& De Camilli, P. (1983). Synapsin I (protein I), a nerve terminal-specific phosphoprotein. III. Its association with synaptic vesicles studied in a highly purified synaptic vesicle preparation. J Cell Biol, 96(5), 1374-88.

Ipsen, J. H., Karlström, G., Mouritsen, O. G., Wennerström, H., \& Zuckermann, M. J. (1987). Phase equilibria in the phosphatidylcholine-cholesterol system. Biochim Biophys Acta, 905(1), 162-172.

Itin, C., Rancaño, C., Nakajima, Y., \& Pfeffer, S. R. (1997). A novel assay reveals a role for soluble N-ethylmaleimide-sensitive fusion attachment protein in mannose 6-phosphate receptor transport from endosomes to the trans Golgi network. J Biol Chem, 272(44), 27737-27744.

Jacobson, K., Sheets, E. D., \& Simson, R. (1995). Revisiting the fluid mosaic model of membranes. Science, 268(5216), 1441-1442.

Jahn, R. (2004). Principles of exocytosis and membrane fusion. Ann N Y Acad Sci, 1014, 170-178.

Jahn, R., \& Scheller, R. H. (2006). SNAREs-engines for membrane fusion. Nat Rev Mol Cell Biol, 7(9), 631-43.

Jahn, R., Schiebler, W., Ouimet, C., \& Greengard, P. (1985). A 38,000-dalton membrane protein (p38) present in synaptic vesicles. Proc Natl Acad Sci U S A, 82(12), 4137-41.

Jones, A. T., Mills, I. G., Scheidig, A. J., Alexandrov, K., \& Clague, M. J. (1998). Inhibition of endosome fusion by wortmannin persists in the presence of activated Rab5. Mol Biol Cell, 9(2), 323-32.

Jun, Y., \& Wickner, W. (2007). Assays of vacuole fusion resolve the stages of docking, lipid mixing, and content mixing. Proc Natl Acad Sci US A, 104(32), $13010-5$.

Klar, T. A., Jakobs, S., Dyba, M., Egner, A., \& Hell, S. W. (2000). Fluorescence microscopy with diffraction resolution barrier broken by stimulated emission. Proc Natl Acad Sci U S A, 97(15), 8206-8210.

Klenchin, V. A., \& Martin, T. F. (2000). Priming in exocytosis: attaining fusioncompetence after vesicle docking. Biochimie, 82(5), 399-407.

Kloepper, T. H., Kienle, C. N., \& Fasshauer, D. (2007). An elaborate classification of SNARE proteins sheds light on the conservation of the eukaryotic endomembrane system. Mol Biol Cell, 18(9), 3463-3471. 
Kraynack, B. A., Chan, A., Rosenthal, E., Essid, M., Umansky, B., Waters, M. G., \& Schmitt, H. D. (2005). Dsl1p, Tip20p, and the novel Dsl3(Sec39) protein are required for the stability of the $\mathrm{Q} / \mathrm{t}-\mathrm{SNARE}$ complex at the endoplasmic reticulum in yeast. Mol Biol Cell, 16(9), 3963-3977.

Kreykenbohm, V., Wenzel, D., Antonin, W., Atlachkine, V., \& von Mollard, G. F. (2002). The SNAREs vtila and vtilb have distinct localization and SNARE complex partners. Eur J Cell Biol, 81(5), 273-280.

Kuwana, T., Mullock, B. M., \& Luzio, J. P. (1995). Identification of a lysosomal protein causing lipid transfer, using a fluorescence assay designed to monitor membrane fusion between rat liver endosomes and lysosomes. Biochem J, 308 ( Pt 3), 937-946.

Kypri, E., Schmauch, C., Maniak, M., \& Lozanne, A. D. (2007). The BEACH protein LvsB is localized on lysosomes and postlysosomes and limits their fusion with early endosomes. Traffic, 8(6), 774-783.

Laage, R., Rohde, J., Brosig, B., \& Langosch, D. (2000). A conserved membranespanning amino acid motif drives homomeric and supports heteromeric assembly of presynaptic SNARE proteins. J Biol Chem, 275(23), 17481-17487.

Lang, T. (2007). SNARE proteins and 'membrane rafts'. J Physiol, 585(Pt 3), 693-698.

Lang, T., Bruns, D., Wenzel, D., Riedel, D., Holroyd, P., Thiele, C., \& Jahn, R. (2001). SNAREs are concentrated in cholesterol-dependent clusters that define docking and fusion sites for exocytosis. EMBO J, 20(9), 2202-2213.

Langosch, D., Crane, J. M., Brosig, B., Hellwig, A., Tamm, L. K., \& Reed, J. (2001). Peptide mimics of SNARE transmembrane segments drive membrane fusion depending on their conformational plasticity. J Mol Biol, 311(4), 709-721.

Langosch, D., Hofmann, M., \& Ungermann, C. (2007). The role of transmembrane domains in membrane fusion. Cell Mol Life Sci, 64 (7-8), 850-864.

Lawe, D. C., Chawla, A., Merithew, E., Dumas, J., Carrington, W., Fogarty, K., Lifshitz, L., Tuft, R., Lambright, D., \& Corvera, S. (2002). Sequential roles for phosphatidylinositol 3-phosphate and Rab5 in tethering and fusion of early endosomes via their interaction with EEA1. J Biol Chem, $277(10), 8611-7$.

Low, S. H., Vasanji, A., Nanduri, J., He, M., Sharma, N., Koo, M., Drazba, J., \& Weimbs, T. (2006). Syntaxins 3 and 4 are concentrated in separate clusters on the plasma membrane before the establishment of cell polarity. Mol Biol Cell, 17(2), 977-989. 
Lundbaek, J. A., Andersen, O. S., Werge, T., \& Nielsen, C. (2003). Cholesterolinduced protein sorting: an analysis of energetic feasibility. Biophys J, 84(3), 2080-2089.

Mayer, A., \& Wickner, W. (1997). Docking of yeast vacuoles is catalyzed by the Ras-like GTPase Ypt7p after symmetric priming by Sec18p (NSF). J Cell Biol, 136(2), 307-17.

Mayorga, L. S., Beron, W., Sarrouf, M. N., Colombo, M. I., Creutz, C., \& Stahl, P. D. (1994). Calcium-dependent fusion among endosomes. J Biol Chem, 269(49), 30927-34.

McBride, H. M., Rybin, V., Murphy, C., Giner, A., Teasdale, R., \& Zerial, M. (1999). Oligomeric complexes link Rab5 effectors with NSF and drive membrane fusion via interactions between EEA1 and syntaxin 13. Cell, 98(3), 377-86.

McConnell, H. M., \& Radhakrishnan, A. (2003). Condensed complexes of cholesterol and phospholipids. Biochim Biophys Acta, 1610(2), 159-173.

McNew, J. A., Parlati, F., Fukuda, R., Johnston, R. J., Paz, K., Paumet, F., Söllner, T. H., \& Rothman, J. E. (2000a). Compartmental specificity of cellular membrane fusion encoded in SNARE proteins. Nature, 407(6801), 153-159.

McNew, J. A., Weber, T., Parlati, F., Johnston, R. J., Melia, T. J., Söllner, T. H., \& Rothman, J. E. (2000b). Close is not enough: SNARE-dependent membrane fusion requires an active mechanism that transduces force to membrane anchors. J Cell Biol, 150(1), 105-117.

Mills, I. G., Urbe, S., \& Clague, M. J. (2001). Relationships between EEA1 binding partners and their role in endosome fusion. J Cell Sci, 114(Pt 10), 1959-65.

Mukherjee, S., \& Maxfield, F. R. (2004). Membrane domains. Annu Rev Cell Dev Biol, 20, 839-866.

Munro, S. (2003). Lipid rafts: elusive or illusive? Cell, 115(4), 377-388.

Murray, J. T., Panaretou, C., Stenmark, H., Miaczynska, M., \& Backer, J. M. (2002). Role of Rab5 in the recruitment of hVps34/p150 to the early endosome. Traffic, 3(6), 416-427.

Needham, D., McIntosh, T. J., \& Evans, E. (1988). Thermomechanical and transition properties of dimyristoylphosphatidylcholine/cholesterol bilayers. Biochemistry, $27(13), 4668-4673$.

O'Connor, V., Heuss, C., De Bello, W. M., Dresbach, T., Charlton, M. P., Hunt, J. H., Pellegrini, L. L., Hodel, A., Burger, M. M., Betz, H., Augustine, G. J., \& Schafer, T. (1997). Disruption of syntaxin-mediated protein interactions blocks neurotransmitter secretion. Proc Natl Acad Sci U S A, 94(22), 12186-91. 
Ohara-Imaizumi, M., Nishiwaki, C., Nakamichi, Y., Kikuta, T., Nagai, S., \& Nagamatsu, S. (2004). Correlation of syntaxin-1 and SNAP-25 clusters with docking and fusion of insulin granules analysed by total internal reflection fluorescence microscopy. Diabetologia, 47(12), 2200-2207.

Parlati, F., McNew, J. A., Fukuda, R., Miller, R., Söllner, T. H., \& Rothman, J. E. (2000). Topological restriction of SNARE-dependent membrane fusion. Nature, 407(6801), 194-198.

Parmar, M. M., Edwards, K., \& Madden, T. D. (1999). Incorporation of bacterial membrane proteins into liposomes: factors influencing protein reconstitution. Biochim Biophys Acta, 1421(1), 77-90.

Parton, R. G., \& Simons, K. (2007). The multiple faces of caveolae. Nat Rev Mol Cell Biol, 8(3), 185-194.

Peter, F., Nuoffer, C., Schalk, I., \& Balch, W. E. (1995). Expression and purification of recombinant His6-tagged guanine nucleotide dissociation inhibitor and formation of its Rab1 complex. Methods Enzymol, 257, 80-83.

Peters, C., Bayer, M. J., Buhler, S., Andersen, J. S., Mann, M., \& Mayer, A. (2001). Trans-complex formation by proteolipid channels in the terminal phase of membrane fusion. Nature, 409 (6820), 581-8.

Pike, L. J. (2006). Rafts defined: a report on the Keystone Symposium on Lipid Rafts and Cell Function. J Lipid Res, 47(7), 1597-1598.

Poirier, M. A., Xiao, W., Macosko, J. C., Chan, C., Shin, Y. K., \& Bennett, M. K. (1998). The synaptic SNARE complex is a parallel four-stranded helical bundle. Nat Struct Biol, 5(9), 765-769.

Predescu, S. A., Predescu, D. N., Shimizu, K., Klein, I. K., \& Malik, A. B. (2005). Cholesterol-dependent syntaxin-4 and SNAP-23 clustering regulates caveolar fusion with the endothelial plasma membrane. J Biol Chem, 280(44), 37130-37138.

Price, A., Wickner, W., \& Ungermann, C. (2000). Proteins needed for vesicle budding from the Golgi complex are also required for the docking step of homotypic vacuole fusion. J Cell Biol, 148(6), 1223-29.

Rizo, J., \& Südhof, T. C. (2002). Snares and Munc18 in synaptic vesicle fusion. Nat Rev Neurosci, 3(8), 641-653.

Rizzoli, S. O., Bethani, I., Zwilling, D., Wenzel, D., Siddiqui, T. J., Brandhorst, D., \& Jahn, R. (2006). Evidence for early endosome-like fusion of recently endocytosed synaptic vesicles. Traffic, 7(9), 1163-76.

Roberts, R. L., Barbieri, M. A., Pryse, K. M., Chua, M., Morisaki, J. H., \& Stahl, 
P. D. (1999). Endosome fusion in living cells overexpressing GFP-rab5. J Cell Sci, 112 ( Pt 21), 3667-3675.

Rodal, S. K., Skretting, G., Garred, O., Vilhardt, F., van Deurs, B., \& Sandvig, K. (1999). Extraction of cholesterol with methyl-beta-cyclodextrin perturbs formation of clathrin-coated endocytic vesicles. Mol Biol Cell, 10(4), 961-974.

Roth, M. G. (2006). Clathrin-mediated endocytosis before fluorescent proteins. Nat Rev Mol Cell Biol, 7(1), 63-68.

Sacher, M., Barrowman, J., Wang, W., Horecka, J., Zhang, Y., Pypaert, M., \& Ferro-Novick, S. (2001). TRAPP I implicated in the specificity of tethering in ER-to-Golgi transport. Mol Cell, 7(2), 433-42.

Sato, K., \& Wickner, W. (1998). Functional reconstitution of ypt7p GTPase and a purified vacuole SNARE complex. Science, 281(5377), 700-702.

Schägger, H., \& von Jagow, G. (1987). Tricine-sodium dodecyl sulfatepolyacrylamide gel electrophoresis for the separation of proteins in the range from 1 to $100 \mathrm{kDa}$. Anal Biochem, 166 (2), 368-379.

Schikorski, T., \& Stevens, C. F. (2001). Morphological correlates of functionally defined synaptic vesicle populations. Nat Neurosci, 4(4), 391-5.

Schuette, C. G., Hatsuzawa, K., Margittai, M., Stein, A., Riedel, D., Kuster, P., Konig, M., Seidel, C., \& Jahn, R. (2004). Determinants of liposome fusion mediated by synaptic SNARE proteins. Proc Natl Acad Sci U S A, 101(9), 2858-63.

Sesaki, H., \& Jensen, R. E. (2001). UGO1 encodes an outer membrane protein required for mitochondrial fusion. J Cell Biol, 152(6), 1123-1134.

Shpetner, H., Joly, M., Hartley, D., \& Corvera, S. (1996). Potential sites of PI-3 kinase function in the endocytic pathway revealed by the PI-3 kinase inhibitor, wortmannin. J Cell Biol, 132(4), 595-605.

Sieber, J. J., Willig, K. I., Heintzmann, R., Hell, S. W., \& Lang, T. (2006). The SNARE motif is essential for the formation of syntaxin clusters in the plasma membrane. Biophys J, 90(8), 2843-2851.

Sieber, J. J., Willig, K. I., Kutzner, C., Gerding-Reimers, C., Harke, B., Donnert, G., Rammner, B., Eggeling, C., Hell, S. W., Grubmüller, H., \& Lang, T. (2007). Anatomy and dynamics of a supramolecular membrane protein cluster. Science, 317(5841), 1072-1076.

Simons, K., \& Ikonen, E. (1997). Functional rafts in cell membranes. Nature, 387(6633), 569-572. 
Simonsen, A., Gaullier, J. M., D’Arrigo, A., \& Stenmark, H. (1999). The Rab5 effector EEA1 interacts directly with syntaxin-6. J Biol Chem, $274(41), 28857-$ 28860 .

Singer, S. J., \& Nicolson, G. L. (1972). The fluid mosaic model of the structure of cell membranes. Science, 175(23), 720-731.

Söllner, T., Bennett, M. K., Whiteheart, S. W., Scheller, R. H., \& Rothman, J. E. (1993). A protein assembly-disassembly pathway in vitro that may correspond to sequential steps of synaptic vesicle docking, activation, and fusion. Cell, 75(3), 409-18.

Smith, P. D., Liesegang, G. W., Berger, R. L., Czerlinski, G., \& Podolsky, R. J. (1984). A stopped-flow investigation of calcium ion binding by ethylene glycol bis(beta-aminoethyl ether)-N,N'-tetraacetic acid. Anal Biochem, 143(1), 188195.

Steegmaier, M., Klumperman, J., Foletti, D. L., Yoo, J. S., \& Scheller, R. H. (1999). Vesicle-associated membrane protein 4 is implicated in trans-Golgi network vesicle trafficking. Mol Biol Cell, 10(6), 1957-1972.

Stenmark, H., Aasland, R., Toh, B. H., \& D’Arrigo, A. (1996). Endosomal localization of the autoantigen EEA1 is mediated by a zinc-binding FYVE finger. $J$ Biol Chem, 271 (39), 24048-24054.

Stenmark, H., Parton, R. G., Steele-Mortimer, O., Lutcke, A., Gruenberg, J., \& Zerial, M. (1994). Inhibition of rab5 GTPase activity stimulates membrane fusion in endocytosis. EMBO J, 13(6), 1287-96.

Stenmark, H., Vitale, G., Ullrich, O., \& Zerial, M. (1995). Rabaptin-5 is a direct effector of the small GTPase Rab5 in endocytic membrane fusion. Cell, 83(3), 423-32.

Stroupe, C., Collins, K. M., Fratti, R. A., \& Wickner, W. (2006). Purification of active HOPS complex reveals its affinities for phosphoinositides and the SNARE Vam7p. EMBO J, 25(8), 1579-1589.

Struck, D. K., Hoekstra, D., \& Pagano, R. E. (1981). Use of resonance energy transfer to monitor membrane fusion. Biochemistry, 20 (14), 4093-4099.

Subtil, A., Gaidarov, I., Kobylarz, K., Lampson, M. A., Keen, J. H., \& McGraw, T. E. (1999). Acute cholesterol depletion inhibits clathrin-coated pit budding. Proc Natl Acad Sci U S A, 96(12), 6775-6780.

Sun, W., Yan, Q., Vida, T. A., \& Bean, A. J. (2003). Hrs regulates early endosome fusion by inhibiting formation of an endosomal SNARE complex. J Cell Biol, 162 (1), 125-37. 
Sztul, E., \& Lupashin, V. (2006). Role of tethering factors in secretory membrane traffic. Am J Physiol Cell Physiol, 290(1), C11-26.

Takamori, S., Holt, M., Stenius, K., Lemke, E. A., Gronborg, M., Riedel, D., Urlaub, H., Schenck, S., Brugger, B., Ringler, P., Muller, S. A., Rammner, B., Grater, F., Hub, J. S., De Groot, B. L., Mieskes, G., Moriyama, Y., Klingauf, J., Grubmuller, H., Heuser, J., Wieland, F., \& Jahn, R. (2006). Molecular anatomy of a trafficking organelle. Cell, 127(4), 831-46.

Thiele, C., Hannah, M. J., Fahrenholz, F., \& Huttner, W. B. (2000). Cholesterol binds to synaptophysin and is required for biogenesis of synaptic vesicles. Nat Cell Biol, 2(1), 42-49.

Thompson, R. E., Larson, D. R., \& Webb, W. W. (2002). Precise nanometer localization analysis for individual fluorescent probes. Biophys J, 82(5), 2775-2783.

Titorenko, V. I., \& Rachubinski, R. A. (2000). Peroxisomal membrane fusion requires two AAA family ATPases, Pex1p and Pex6p. J Cell Biol, 150(4), 881-886.

Towbin, H., Staehelin, T., \& Gordon, J. (1989). Immunoblotting in the clinical laboratory. J Clin Chem Clin Biochem, 27(8), 495-501.

Tsien, R. Y. (1980). New calcium indicators and buffers with high selectivity against magnesium and protons: design, synthesis, and properties of prototype structures. Biochemistry, 19(11), 2396-2404.

Ullrich, O., Horiuchi, H., Bucci, C., \& Zerial, M. (1994). Membrane association of Rab5 mediated by GDP-dissociation inhibitor and accompanied by GDP/GTP exchange. Nature, 368(6467), 157-60.

Ungermann, C., Sato, K., \& Wickner, W. (1998). Defining the functions of transSNARE pairs. Nature, 396(6711), 543-8.

Ungermann, C., Wickner, W., \& Xu, Z. (1999). Vacuole acidification is required for trans-SNARE pairing, LMA1 release, and homotypic fusion. Proc Natl Acad Sci $U S A, 96(20), 11194-9$.

Varlamov, O., Volchuk, A., Rahimian, V., Doege, C. A., Paumet, F., Eng, W. S., Arango, N., Parlati, F., Ravazzola, M., Orci, L., Söllner, T. H., \& Rothman, J. E. (2004). i-SNAREs: inhibitory SNAREs that fine-tune the specificity of membrane fusion. J Cell Biol, 164(1), 79-88.

Veatch, S. L., \& Keller, S. L. (2003). A closer look at the canonical 'Raft Mixture' in model membrane studies. Biophys J, 84(1), 725-726.

Vidal, M., \& Hoekstra, D. (1995). In vitro fusion of reticulocyte endocytic vesicles with liposomes. J Biol Chem, 270(30), 17823-17829. 
Vogel, S. S., Leikina, E. A., \& Chernomordik, L. V. (1993). Lysophosphatidylcholine reversibly arrests exocytosis and viral fusion at a stage between triggering and membrane merger. J Biol Chem, 268(34), 25764-25768.

Wang, L., Merz, A. J., Collins, K. M., \& Wickner, W. (2003). Hierarchy of protein assembly at the vertex ring domain for yeast vacuole docking and fusion. $J$ Cell Biol, $160(3), 365-74$.

Waters, M. G., Clary, D. O., \& Rothman, J. E. (1992). A novel 115-kD peripheral membrane protein is required for intercisternal transport in the Golgi stack. $J$ Cell Biol, 118(5), 1015-1026.

Weber, T., Zemelman, B. V., McNew, J. A., Westermann, B., Gmachl, M., Parlati, F., Sollner, T. H., \& Rothman, J. E. (1998). SNAREpins: minimal machinery for membrane fusion. Cell, 92(6), 759-72.

Wendler, F., \& Tooze, S. (2001). Syntaxin 6: the promiscuous behaviour of a SNARE protein. Traffic, 2(9), 606-611.

Whiteheart, S. W., Griff, I. C., Brunner, M., Clary, D. O., Mayer, T., Buhrow, S. A., \& Rothman, J. E. (1993). SNAP family of NSF attachment proteins includes a brain-specific isoform. Nature, 362(6418), 353-355.

Willig, K. I., Rizzoli, S. O., Westphal, V., Jahn, R., \& Hell, S. W. (2006). STED microscopy reveals that synaptotagmin remains clustered after synaptic vesicle exocytosis. Nature, 440(7086), 935-9.

Xu, Z., Mayer, A., Muller, E., \& Wickner, W. (1997). A heterodimer of thioredoxin and $\mathrm{I}(\mathrm{B}) 2$ cooperates with Sec18p (NSF) to promote yeast vacuole inheritance. $J$ Cell Biol, 136(2), 299-306.

Yang, B., Gonzalez, L., Prekeris, R., Steegmaier, M., Advani, R. J., \& Scheller, R. H. (1999). SNARE interactions are not selective. Implications for membrane fusion specificity. J Biol Chem, 274(9), 5649-5653.

Zeng, Q., Tran, T. T. H., Tan, H.-X., \& Hong, W. (2003). The cytoplasmic domain of Vamp4 and Vamp5 is responsible for their correct subcellular targeting: the Nterminal extenSion of VAMP4 contains a dominant autonomous targeting signal for the trans-Golgi network. J Biol Chem, 278(25), 23046-23054.

Zerial, M., \& McBride, H. (2001). Rab proteins as membrane organizers. Nat Rev Mol Cell Biol, 2(2), 107-117.

Zeuschner, D., Stoorvogel, W., \& Gerke, V. (2001). Association of annexin 2 with recycling endosomes requires either calcium- or cholesterol-stabilized membrane domains. Eur J Cell Biol, 80(8), 499-507. 
Zwilling, D., Cypionka, A., Pohl, W. H., Fasshauer, D., Walla, P. J., Wahl, M. C., \& Jahn, R. (2007). Early endosomal SNAREs form a structurally conserved SNARE complex and fuse liposomes with multiple topologies. EMBO J, 26(1), 9-18. 


\section{Anhang}

\subsection{Rayleigh Verteilung von Abständen zwischen Intensitätzentren}

Nehmen wir an die Abstandsmessungen zwischen dem roten und grünen Kanal eines mehrfarbigen Beads folgt sowohl auf der x, als auch der y-Achse einer Gaussverteilung mit dem Maximum bei $\mathrm{x}=0$ und $\mathrm{y}=0$ was für Abstände unterhalb der point spread function vernünftig erscheint. Die Verteilung $\mathrm{P}_{\mathrm{x}}$ lässt sich dann mit der Standardformel für die Normalverteilung beschreiben mit (Standardabweichung $:=\sigma$ )

$\mathrm{P}_{\mathrm{x}}(\mathrm{x})=\frac{1}{\sigma \sqrt{2 \pi}} e^{\frac{x^{2}}{2 \sigma^{2}}}$

und entsprechend für $\mathrm{P}_{y}(\mathrm{y})$.

Die vorliegenden Ergebnisse zeigen ausserdem das $\mathrm{P}_{x}$ und $\mathrm{P}_{y}$ unkorreliert sind. In diesem Fall wird die Wahrscheinlichkeitsfunktion der Abstände $\mathrm{r}=\sqrt{x^{2}+y^{2}}$ durch eine Rayleighverteilung bestimmt.

$\mathrm{P}_{\mathrm{r}}=\frac{r}{\sigma^{2}} e^{\frac{r^{2}}{2 \sigma^{2}}}$

Obwohl die Einzelfunktionen $\mathrm{P}_{x}$ und $\mathrm{P}_{y}$ jeweils ein Maximum bei $\mathrm{x}=0$, bzw. $\mathrm{y}=0$ haben ist der Wert dieser Funktion im Einklang mit den experimentellen Beobachtungen dort Null. Ihr Maximum liegt bei $\sigma$.

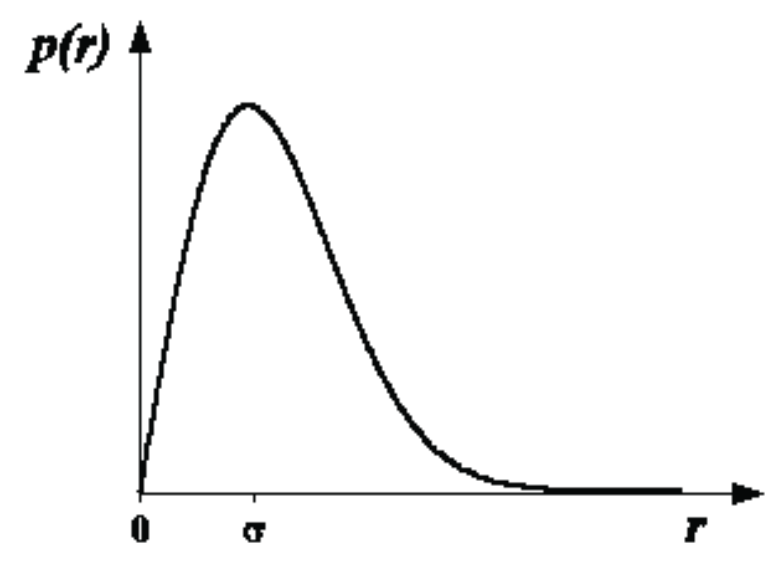

Abbildung 6.1: Rayleighverteilung 


\subsection{Endosomen-Interaktionsprogramm}

function automatic_spots;

fusion_cutoff=100;

$\%$ defining the "mother" folder

thefolder='P: \imaging \01082008';

cellb $\{1\}=$ 'controls1';

cellb $\{2\}=$ 'controls2';

$\% \% \% \%$ filters

redfilter $=$ highpassfilter $([1035,1317], 0.006,100)$;

greenfilter $=$ highpassfilter $([1035,1317], 0.01,50)$;

$\% \% \% \%$ start names loop

for abcdef=1:numel(cellb)

name $=\operatorname{cellb}\{$ abcdef $\}$;

cd(strcat(thefolder,' ',name));

percentage $=[] ;$ phony_percentage $=[] ;$

percentage_red=[];phony_percentage_red=[];

new_mins $=[]$;

nr_smalls=[];

$\%$ figuring out how many images are there

[stat,mess $]=$ fileattrib('blue*tif');

$\% \% \% \%$ start images loop

for $\mathrm{klm}=1$ :numel(mess)

$\% \% \% \% \% \% \% \% \% \% \% \% \% \% \% \% \% \% \% \% \% \% \% \% \% \% \% \% \%$ reading files

if numel(mess $)<10$

redimg=imread(strcat('red',num2str(klm),'.tif'));

greenimg =imread(strcat('green',num2str(klm),'.tif'));

blueimg =imread(strcat('blue',num2str(klm),'.tif'));

else

if $\mathrm{klm}<10$

redimg =imread(strcat('red0',num2str(klm),'.tif'));

greenimg =imread(strcat('green0',num2str(klm),'.tif'));

blueimg =imread(strcat('blue0',num2str(klm),'.tif'));

else

redimg=imread(strcat('red',num2str(klm),'.tif')); 
greenimg =imread(strcat('green',num2str(klm),'.tif'));

blueimg=imread(strcat('blue',num2str(klm),'.tif'));

end;

end;

\%\%\%\%\%\%\%\%\%\%\%\%\%\%\%\%\%\%\%\%\%\%filtering

$\mathrm{F}=\mathrm{fft} 2($ double(redimg $))$

$\mathrm{G}=$ redfilter. ${ }^{*} \mathrm{~F}$;

$\mathrm{g}=\operatorname{real}(\operatorname{ifft} 2(\mathrm{G}))$;

$\operatorname{maxim}=\max (\max (\mathrm{g}))$;

$\operatorname{minim}=\min (\min (\mathrm{g}))$;

$\mathrm{g}(:,:)=\mathrm{g}(:,:)-\operatorname{minim} ;$

$\mathrm{g}=\mathrm{g} * 511 /$ maxim;

redimg $=[] ;$ redimg $=\mathrm{g}$;

$\mathrm{F}=\mathrm{ftt} 2$ (double(greenimg));

$\mathrm{G}=$ greenfilter.*F;

$\mathrm{g}=\operatorname{real}(\operatorname{ifft} 2(\mathrm{G}))$;

$\operatorname{maxim}=\max (\max (\mathrm{g}))$;

$\operatorname{minim}=\min (\min (\mathrm{g}))$;

$\mathrm{g}(:,:)=\mathrm{g}(:,:)-\operatorname{minim} ;$

$\mathrm{g}=\mathrm{g} * 511 / \operatorname{maxim} ;$

greenimg $=[$; greenimg $=\mathrm{g}$;

redimg2=[]; redimg2(:,:)=redimg(:,:);

greenimg2=[]; greenimg2(:,:)=greenimg(:,:);

blueimg2=[]; blueimg2(:,:)=blueimg(:,:);

blue_cutoff=round $($ mean $($ mean $($ blueimg2 $)))+13$;

red_cutoff $=$ round $($ mean $($ mean $($ redimg2 $)))+3$;

green $\_$cutoff $=\operatorname{round}(\operatorname{mean}(\operatorname{mean}($ greenimg2 $)))+6$;

$\% \% \% \% \% \% \% \% \% \%$ finding the spots and their centers

ccc $=$ find(blueimg $2<$ blue_cutoff); blueimg2 $(\mathrm{ccc})=0$;

bluebw=[]; bluebw=bwlabel(blueimg2);

bluex $=[] ;$ bluey $=[]$;

bbb=bwmorph(bluebw,'clean');

bluebw=bwlabel(bbb);

for $\mathrm{i}=1: \max (\max (\mathrm{bluebw}))$ 


\section{Anhang}

$\mathrm{ccc}=$ find $($ bluebw $==\mathrm{i})$;

blueimg=blueimg2;

$\mathrm{xxx}=$ find $($ bluebw $<\mathrm{i} \mid$ bluebw $>\mathrm{i}) ;$

blueimg $(\mathrm{xxx})=0$;

$[\mathrm{xx}, \mathrm{yy}, \mathrm{mm}]=$ find(blueimg);

$\mathrm{mm}=\operatorname{double}(\mathrm{mm})$;

bluex $($ numel $($ bluex $)+1)=\operatorname{sum}\left(\right.$ xx. $\left.^{*} \mathrm{~mm}\right) / \operatorname{sum}(\mathrm{mm})$;

bluey $($ numel(bluey $)+1)=\operatorname{sum}\left(\right.$ yy. $\left.{ }^{*} \mathrm{~mm}\right) / \operatorname{sum}(\mathrm{mm})$;

end;

ccc $=$ find $($ redimg $2<$ red_cutoff $) ;$ redimg $2(\mathrm{ccc})=0$;

redbw $=[] ;$ redbw $=$ bwlabel $($ redimg2);

$\operatorname{redx}=[] ; \operatorname{redy}=[] ;$

bbb= bwmorph(redbw,'clean');

redbw $=$ bwlabel $(\mathrm{bbb})$;

if $\max (\max (\mathrm{redbw}))<3000$

for $\mathrm{i}=1: \max (\max ($ redbw $))$

$\mathrm{ccc}=$ find $($ redbw $==\mathrm{i})$;

redimg $=$ redimg 2 ;

$\mathrm{xxx}=$ find $($ redbw $<\mathrm{i} \mid$ redbw $>\mathrm{i})$;

$\operatorname{redimg}(\mathrm{xxx})=0$;

$[\mathrm{xx}, \mathrm{yy}, \mathrm{mm}]=$ find(redimg);

$\mathrm{mm}=\operatorname{double}(\mathrm{mm})$;

$\operatorname{redx}(\operatorname{numel}(\operatorname{redx})+1)=\operatorname{sum}\left(x x .^{* m m}\right) / \operatorname{sum}(\mathrm{mm}) ;$

$\operatorname{redy}(\operatorname{numel}(\operatorname{redy})+1)=\operatorname{sum}\left(\right.$ yy. $\left.^{*} \mathrm{~mm}\right) / \operatorname{sum}(\mathrm{mm})$;

end;

else

$\operatorname{redx}=[1: 1: 1000]$

redy $=[1: 1: 1000]$

end;

$\mathrm{ccc}=$ find $($ greenimg $2<$ green_cutoff $) ;$ greenimg $2(\mathrm{ccc})=0$;

greenbw $=[]$; greenbw $=$ bwlabel $($ greenimg2 $)$;

green $x=[]$; greeny $=[]$;

bbb=bwmorph(greenbw,'clean');

greenbw $=$ bwlabel $(\mathrm{bbb})$; 
if $\max (\max ($ greenbw $))<3000$

for $\mathrm{i}=1: \max (\max ($ greenbw $))$

$\mathrm{ccc}=$ find $($ greenbw $==\mathrm{i})$;

greenimg $=$ greenimg2;

$\mathrm{xxx}=$ find $($ greenbw $<\mathrm{i} \mid$ greenbw $>\mathrm{i})$;

greenimg $(\mathrm{xxx})=0$;

$[\mathrm{xx}, \mathrm{yy}, \mathrm{mm}]=$ find $($ greenimg $)$;

$\mathrm{mm}=\operatorname{double}(\mathrm{mm})$;

$\operatorname{greenx}(\operatorname{numel}(\operatorname{greenx})+1)=\operatorname{sum}\left(\mathrm{xx} .{ }^{*} \mathrm{~mm}\right) / \operatorname{sum}(\mathrm{mm})$;

$\operatorname{greeny}($ numel $($ greeny $)+1)=\operatorname{sum}($ yy.*mm $) / \operatorname{sum}(\mathrm{mm})$;

end;

else green $x=[1: 1: 1000]$;

greeny $=[1: 1: 1000]$;

end;

$\%$ finding the beads, "eliminating" the extra beads, and using bead 1 to

$\%$ get the green and red bead center coordinates

abs_distance $=25$;

if numel(bluex $>1)$

bead_counter $=0$;

while abs_distance $>4$ \& bead_counter $<$ numel(bluex)

bead_counter=bead_counter +1 ;

$\mathrm{x}=$ bluex(bead_counter);

y=bluey(bead_counter);

$\operatorname{distx}=[; ; \operatorname{disty}=[] ;$

distx $=$ redx;

disty $=$ redy;

$\operatorname{distx}(:)=\operatorname{distx}(:)-\mathrm{x}$;

$\operatorname{disty}(:)=\operatorname{disty}(:)-y$;

$\operatorname{distx}(:)=\operatorname{distx}(:) .^{\wedge} 2$;

$\operatorname{disty}(:)=\operatorname{disty}(:) .^{\wedge} 2$;

$\operatorname{dist} \mathrm{x}=\operatorname{dist} \mathrm{x}+$ disty;

$\operatorname{distx}(:)=\operatorname{sqrt}(\operatorname{distx}(:))$;

$\mathrm{mmm}=\min (\min (\operatorname{distx}))$;

$\mathrm{xxx}=\mathrm{find}(\operatorname{dist} \mathrm{x}==\mathrm{mmm}) ;$ 


\section{Anhang}

red_centerx $=\operatorname{redx}(\operatorname{xxx}(1))$;

red_centery $=\operatorname{redy}(\operatorname{xxx}(1))$;

$\% \operatorname{redx}(x x x)=9999$;

$\operatorname{distx}=[] ; \operatorname{disty}=[] ;$

distx=greenx;

disty=greeny;

$\operatorname{distx}(:)=\operatorname{distx}(:)-\mathrm{x} ;$

$\operatorname{disty}(:)=\operatorname{disty}(:)-y$;

$\operatorname{distx}(:)=\operatorname{distx}(:) .^{\wedge} 2$;

$\operatorname{disty}(:)=\operatorname{disty}(:) .^{\wedge} 2$;

distx $=$ dist $\mathrm{x}+$ disty;

$\operatorname{distx}(:)=\operatorname{sqrt}(\operatorname{distx}(:))$;

$\mathrm{mmm}=\min (\min ($ distx $)) ;$

$\mathrm{xxx}=\mathrm{find}(\operatorname{dist} \mathrm{x}==\mathrm{mmm}) ;$

green_center $\mathrm{x}=\operatorname{green} \mathrm{x}(\operatorname{xxx}(1))$;

green_centery=greeny $(\operatorname{xxx}(1))$;

diff $x=$ green_centerx-red_center $x$

diffy=green_centery-red_centery

abs_distance $=\operatorname{sqrt}\left(\operatorname{diffx}^{\wedge} 2+\operatorname{diffy}^{\wedge} 2\right) ;$

end;

for $\mathrm{k}=1$ :numel(bluex)

$\mathrm{x}=$ bluex $(\mathrm{k})$;

$\mathrm{y}=\operatorname{bluey}(\mathrm{k})$;

$\operatorname{distx}=[] ;$ disty $=[]$;

distx $=$ redx;

disty=redy;

$\operatorname{distx}(:)=\operatorname{distx}(:)-x ;$

$\operatorname{disty}(:)=\operatorname{disty}(:)-y$;

$\operatorname{distx}(:)=\operatorname{distx}(:) .^{\wedge} 2$;

$\operatorname{disty}(:)=\operatorname{disty}(:) .^{\wedge} 2$;

$\operatorname{distx}=\operatorname{dist} x+$ disty;

$\operatorname{distx}(:)=\operatorname{sqrt}(\operatorname{distx}(:)) ;$

$\mathrm{mmm}=\min (\min (\operatorname{distx})) ;$

$\mathrm{xxx}=\mathrm{find}(\operatorname{dist} \mathrm{x}==\mathrm{mmm})$; 


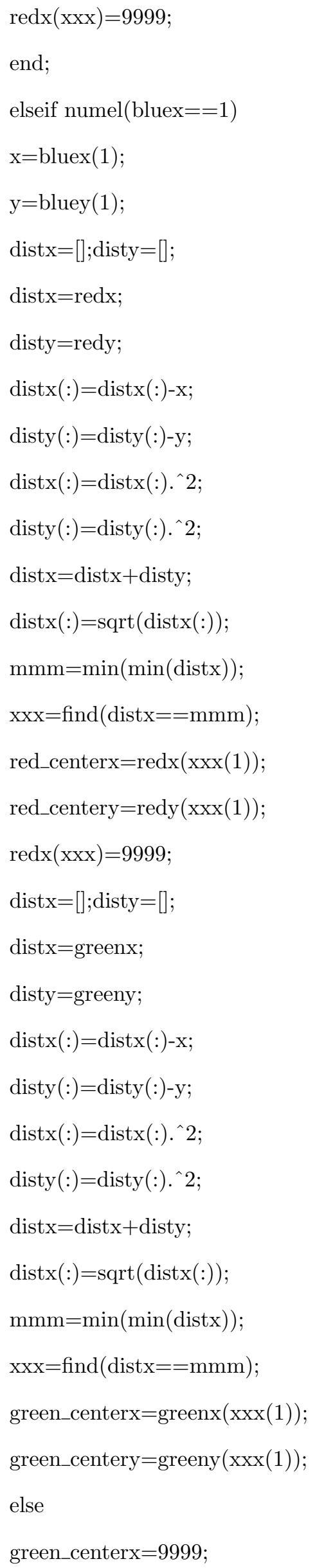




\section{Anhang}

green_centery $=9999$;

red_centerx $=0$;

red_centery $=0$;

green $x=[1: 1: 1000]$;

greeny $=[1: 1: 1000]$;

$\operatorname{redx}=[1: 1: 1000]$;

redy $=[1: 1: 1000] ;$

end;

numel(redx)

numel(greenx)

diffx=green_centerx-red_centerx

diffy=green_centery-red_centery

$\operatorname{red} x=\operatorname{redx}+\operatorname{diffx}$;

redy $=$ redy + diffy;

$\operatorname{abs\_ distance}=\operatorname{sqrt}\left(\operatorname{diffx} x^{\wedge} 2+\operatorname{diffy}^{\wedge} 2\right)$;

$\% \% \% \% \% \% \% \% \% \% \% \% \% \% \% \% \% \% \%$ Working on the files

if numel(greenx $)<3000 \&$ abs_distance $<4 \&$ numel $($ redx $)<3000$

$\operatorname{disp}($ 'hhfgh');

allx $=[$ greenx,redx $]$;

ally $=[$ greeny,redy $]$;

phony_redx=redx;

phony_redy=1317-redy;

minimuri $=[]$

for $\mathrm{k}=1$ :numel(greenx)

$\mathrm{x}=\operatorname{green} \mathrm{x}(\mathrm{k})$;

$\mathrm{y}=\operatorname{greeny}(\mathrm{k})$;

$\operatorname{distx}=[] ;$ disty $=[] ;$

$\operatorname{distx}=\operatorname{redx}$;

$\operatorname{disty}=$ redy;

$\operatorname{distx}(:)=\operatorname{distx}(:)-\mathrm{x} ;$

$\operatorname{disty}(:)=\operatorname{disty}(:)-y$;

$\operatorname{distx}(:)=\operatorname{distx}(:) .^{\wedge} 2 ;$

$\operatorname{disty}(:)=\operatorname{disty}(:) .^{\wedge} 2$;

dist $\mathrm{x}=\operatorname{dist} \mathrm{x}+$ disty; 
$\operatorname{distx}(:)=\operatorname{sqrt}(\operatorname{distx}(:)) ;$

$\mathrm{mmm}=\min (\min (\operatorname{distx}))$;

$\operatorname{minimuri}(\mathrm{k})=\mathrm{mmm}$;

end;

minimuri $=$ minimuri $* 68$;

bbb=find(minimuri<fusion_cutoff);

percentage $($ numel $($ percentage $)+1)=\operatorname{numel}(\mathrm{bbb}) * 100 / \operatorname{numel}($ minimuri $)$;

percentage_red(numel(percentage_red) +1$)=\operatorname{numel}(\mathrm{bbb}) * 100 / \operatorname{numel}(\operatorname{redx})$;

minimuri $=[]$;

for $\mathrm{k}=1$ :numel(greenx)

$\mathrm{x}=\operatorname{greenx}(\mathrm{k})$;

$\mathrm{y}=\operatorname{greeny}(\mathrm{k})$;

$\operatorname{distx}=[] ; \operatorname{disty}=[] ;$

distx=phony_redx;

disty=phony_redy;

$\operatorname{distx}(:)=\operatorname{distx}(:)-\mathrm{x}$;

$\operatorname{disty}(:)=\operatorname{disty}(:)-y$;

$\operatorname{distx}(:)=\operatorname{distx}(:) .^{\wedge} 2$;

$\operatorname{disty}(:)=\operatorname{disty}(:) .^{\wedge} 2$

dist $=$ dist + disty;

$\operatorname{distx}(:)=\operatorname{sqrt}(\operatorname{distx}(:))$;

$\mathrm{mmm}=\min (\min (\operatorname{distx}))$;

$\operatorname{minimuri}(\mathrm{k})=\mathrm{mmm}$;

end;

minimuri $=$ minimuri $* 68$;

$\mathrm{bbb}=$ find(minimuri $<$ fusion_cutoff);

phony_percentage(numel(phony_percentage) +1$)=\operatorname{numel}(\mathrm{bbb}) * 100 /$ numel(minimuri);

phony_percentage_red(numel(phony_percentage_red) +1$)=$ numel(bbb)*100/numel(phony_redx);

image_mins $=[]$;

image_neighs $=[$;

aaaa $=$ find $($ allx $<1350)$;

allx $=$ allx (aaaa);

ally=ally(aaaa);

$\mathrm{bbbb}=$ find $($ ally $<1350)$; 


\section{Anhang}

allx $=$ allx $(\mathrm{bbbb})$;

ally $=$ ally $(\mathrm{bbbb})$;

for $\mathrm{k}=2$ :numel(allx)-1

$\mathrm{x}=\operatorname{all} \mathrm{x}(\mathrm{k})$

$\mathrm{y}=\operatorname{ally}(\mathrm{k})$;

distx $=[] ;$ disty $=[] ;$

$\operatorname{dist} x=a l l x ; \operatorname{distx}=[\operatorname{distx}(1: k-1), \operatorname{distx}(\mathrm{k}+1$ :numel $(\operatorname{distx}))]$;

$\operatorname{disty}=$ ally; $\operatorname{disty}=[\operatorname{disty}(1: \mathrm{k}-1), \operatorname{disty}(\mathrm{k}+1$ :numel(disty $))]$;

$\operatorname{distx}(:)=\operatorname{distx}(:)-\mathrm{x} ;$

$\operatorname{disty}(:)=\operatorname{disty}(:)-y$;

$\operatorname{distx}(:)=\operatorname{distx}(:) .^{\wedge} 2$;

$\operatorname{disty}(:)=\operatorname{disty}(:) .^{\wedge} 2$;

distx $=$ dist + disty;

$\operatorname{distx}(:)=\operatorname{sqrt}(\operatorname{distx}(:))$;

$\mathrm{mmm}=\min (\min (\operatorname{distx})) ;$

image_mins $(\mathrm{k}-1)=\mathrm{mmm}$;

new_mins $($ numel(new_mins $)+1)=$ mmm;

$\mathrm{ccx}=$ find $(\operatorname{distx}<7.352)$;

image_neighs $(\mathrm{k}-1)=$ numel $(\mathrm{ccx})$;

$\operatorname{nr} \_$smalls $($numel $($nr_smalls $)+1)=\operatorname{numel}(\operatorname{ccx})$;

end;

image_mins=image_mins $* 68$;

dlmwrite(strcat('mindists_',name, num2str(klm),'.txt'),image_mins');

dlmwrite(strcat('neigh_nr_',name, num2str(klm), '.txt'),image_neighs');

$\mathrm{x}=[0: 1: 10]$;

histo=hist(nr_smalls, $\mathrm{x})$;

histo=histo*100/numel(nr_smalls);

dlmwrite(strcat('hist_neigh_nr_',name, num2str(klm),'.txt'),histo');

$\mathrm{x}=[0: 25: 10000]$;

histo=hist(image_mins, $\mathrm{x})$;

histo $=$ histo*100/numel(image_mins);

dlmwrite(strcat('hist_mindists_',name, num2str(klm), '.txt'),histo');

end;

end; 
aaa $=[]$

if numel(percentage) $>0$

aaa $(:, 1)=$ percentage';

aaa $(:, 2)=$ phony_percentage';

aaa $(:, 3)=$ percentage_red';

aaa $(:, 4)=$ phony_percentage_red';

dlmwrite(strcat(num2str(fusion_cutoff),'perc',name,'.txt'), aaa,'\t');

new_mins $=$ new_mins $* 68$;

dlmwrite(strcat('total_mindists_',name,'.txt'),new_mins');

dlmwrite(strcat('total_neigh_nr_,',name,'.txt'),nr_smalls');

$\mathrm{x}=[0: 1: 10]$

histo $=$ hist $\left(\mathrm{nr} \_\right.$smalls, $\left.\mathrm{x}\right)$;

histo $=$ histo $^{*} 100 /$ numel(nr_smalls);

dlmwrite(strcat('total_hist_neigh_nr_',name,'.txt'),histo');

$\mathrm{x}=[0: 25: 10000]$

histo $=$ hist(new_mins, $\mathrm{x}$ );

histo $=$ histo $* 100 /$ numel(new_mins);

dlmwrite(strcat('total_hist_mindists_',name,'.txt'),histo');

end;

end; 


\subsection{Programm zur Domänenanalyse}

function sroi

global list mapname b movi rows cols A i xx yy zz iii bbb q s ijj jjj r1 firstred olds inner_radius outer_radius matrix

backmatrix

global alignsx alignsy rect fused not_fused

thefolder='P: $\backslash$ STED $\backslash 24062008$ ';

cellb $\{1\}=$ 'cholesterola';

for abcdef=1:numel(cellb)

cd(strcat(thefolder,'`',cellb\{abcdef\}));

[stat, mess] $=$ fileattrib $\left(* \cdot{ }^{\prime} \cdot \mathrm{xml}\right)$;

termination='_ch00';qqq='.tif';

for $\mathrm{klm}=1$ :round(numel(mess)/2)

shortname $=\operatorname{mess}(2 * k l m-1) \cdot \operatorname{Name}\left(\operatorname{numel}\left(\operatorname{mess}\left(2^{*} \mathrm{klm}-1\right) \cdot \operatorname{Name}\right)-11\right.$ :numel(mess $(2 * k l m-1) \cdot$ Name $\left.)-4\right)$;

shortname $2=\operatorname{mess}(2 * k l m) . \operatorname{Name}(\operatorname{numel}(\operatorname{mess}(2 * \mathrm{klm}) . \operatorname{Name})-11: \operatorname{numel}(\operatorname{mess}(2 * \mathrm{klm}) . \mathrm{Name})-4)$;

[stat1, mess1] =fileattrib(strcat('*', shortname, ${ }^{*},{ }^{\prime}$, .tif'));

[stat2, mess2] =fileattrib(strcat('*', ,shortname2, ${ }^{*},{ }^{\prime}$, .tif'));

if numel $(\operatorname{mess} 1)==3 \& \operatorname{numel}(\operatorname{mess} 2)==1$

r3=strcat(shortname,termination);

$\mathrm{r} 1=\operatorname{strcat}\left(\mathrm{r} 3(1: \mathrm{numel}(\mathrm{r} 3)-1),{ }^{\prime}{ }^{\prime}\right)$;

$\mathrm{r} 2=\operatorname{strcat}\left(\mathrm{r} 3(1: \mathrm{numel}(\mathrm{r} 3)-1),{ }^{\prime}{ }^{\prime}\right)$;

r4=strcat(shortname2,termination);

movi=[]; movi_binned=[];

$a b c=i m r e a d(\operatorname{strcat}(r 3, q q q))$;

$\operatorname{movi}(:,:, 1)=\operatorname{abc}(:,:)$;

$\mathrm{abc}=\operatorname{imread}(\operatorname{strcat}(\mathrm{r} 4, \mathrm{qqq}))$;

$\operatorname{movi}(:,:, 2)=\operatorname{abc}(:,:)$;

sroi_align;

old_movi=movi;

movi $=[]$;

r11=strcat(r1,qqq);

$\mathrm{abc}=$ imread(r11);

$\operatorname{movi}(:,:, 1)=\operatorname{abc}(:,:)$;

$a b c=i m r e a d(\operatorname{strcat}(r 2, q q q))$; 
$\operatorname{movi}(:,:, 2)=\operatorname{abc}(:,:)$;

$\operatorname{movi}(:,:, 3)=$ old_movi( $(:,:, 1)$;

$\operatorname{movi}(:,:, 4)=$ old_movi $(:,:, 2)$;

sroi_auto_spots;

end;

end;

end;

function sroi_align;

global movi rows cols A d c xx yy zz iii bbb ccc ijj q s jjj r

hfig=gcf;

himg=image(movi(:,:,1),'tag','himg'); \%

\%************ SET ALIGNMODE AND dd HERE

alignmode $=2 ; \% 1=$ align to previous $; 2=$ align $=$ first in list

$\mathrm{dd}=50 ; \% \%$ size difference of larger window to scan

$\% * * * * * * * * * * * * * * * * * * * * * * * * * * * * * * * * * * * * * * * * * * * * * * * * * * *$

drawnow;

set(himg,'cdata',movi(:,:,1)); \%set(hfs,'value',1);

jmin=q;\%round(get(hffs,'value'));

jmax $=\mathrm{s} ; \%$ round (get(hlfs,'value'));

$\% \% \% \% \% \% \% \% \% \% \%$ Align: set up 2 squares

[pos1 $]=\left[\begin{array}{llll}200 & 100 & 600 & 300\end{array}\right]$;

$\mathrm{xl}=\operatorname{pos} 1(1) ; \mathrm{yl}=\operatorname{pos} 1(2) ; \mathrm{wd}=\operatorname{pos} 1(3) ; \mathrm{ht}=\operatorname{pos} 1(4) ;$

rectangle('position',pos1,'edgecolor','r')

$\mathrm{sz} 0=\operatorname{size}(\operatorname{movi}(:,:, 1)) ; \operatorname{szx}=\mathrm{sz} 0(2) ; \mathrm{szy}=\mathrm{sz} 0(1) ; \%$ rows, cols

$\mathrm{Xl}=\max (1, \mathrm{xl}-\mathrm{dd}) ;$

$\mathrm{Yl}=\max (1, \mathrm{yl}-\mathrm{dd})$;

$\mathrm{Xu}=\min (\operatorname{szx}, \mathrm{xl}+\mathrm{wd}+\mathrm{dd})$;

$\mathrm{Yu}=\min (\mathrm{szy}, \mathrm{yl}+\mathrm{ht}+\mathrm{dd})$;

$\operatorname{pos} 2=[\mathrm{Xl}, \mathrm{Yl}, \mathrm{Xu}-\mathrm{Xl}+1, \mathrm{Yu}-\mathrm{Yl}+1]$;

rectangle('position',pos2,'edgecolor','r')

drawnow

$\% \% \% \% \% \% \% \% \% \% \% \%$ Align: Find best fit positions

xyalign $(1,1)=0 ; \operatorname{xyalign}(1,2)=0$;

if $($ alignmode $==2$ ); \% align to first in list 


\section{Anhang}

$\mathrm{a}=\operatorname{double}(\operatorname{movi}(\mathrm{yl}: \mathrm{yl}+\mathrm{ht}, \mathrm{xl}: \mathrm{xl}+\mathrm{wd}, \mathrm{jmin})) ; \%$ align square $=$ first in list

end

for $\mathrm{jj}=\mathrm{jmin}+1: \mathrm{jmax}$

disp (jmax-jj)

if $($ alignmode $==1)$;

$\mathrm{a}=\operatorname{double}(\operatorname{movi}(\mathrm{yl}: \mathrm{yl}+\mathrm{ht}, \mathrm{xl}: \mathrm{xl}+\mathrm{wd}, \mathrm{jj}-1)) ; \%$ align square $=$ previous

end

mindiff $0=1 \mathrm{e} 12$;

for $\mathrm{xx}=\mathrm{Xl}: \mathrm{Xu}-\mathrm{wd}$

for $\mathrm{yy}=\mathrm{Yl}: \mathrm{Yu}-\mathrm{ht}$

$\mathrm{b}=\operatorname{double}(\operatorname{movi}(\mathrm{yy}: \mathrm{yy}+\mathrm{ht}, \mathrm{xx}: \mathrm{xx}+\mathrm{wd}, \mathrm{jj})) ; \%$ cutout to test

$\mathrm{d} 1=(\mathrm{a}-\mathrm{b}) \cdot *(\mathrm{a}-\mathrm{b})$

$\mathrm{d} 2=\operatorname{sum}(\operatorname{sum}(\mathrm{d} 1))$;

if $(\mathrm{d} 2<$ mindiff0)

$\operatorname{mindiff0}=\mathrm{d} 2 ; \operatorname{xyalign}(\mathrm{jj}, 1)=\mathrm{xl}-\mathrm{xx} ; \operatorname{xyalign}(\mathrm{jj}, 2)=\mathrm{yl}-\mathrm{yy} ;$

end

end

end

if (alignmode $==1) ; \%$ align to previous image in stack

$\mathrm{c}=\operatorname{double}(\operatorname{movi}(:,,, j \mathrm{j})) ; \operatorname{szy}=\operatorname{size}(\mathrm{c}, 1) ; \operatorname{szx}=\operatorname{size}(\mathrm{c}, 2)$;

$\mathrm{dx}=\operatorname{xyalign}(\mathrm{jj}, 1) ; \mathrm{dy}=\mathrm{xyalign}(\mathrm{jj}, 2) ;$

$\mathrm{yl} 2=1^{*}(\mathrm{dy}>=0)+(-\mathrm{dy}+1) *(\mathrm{dy}<0) ; \mathrm{yu} 2=\operatorname{szy}^{*}(\mathrm{dy}<=0)+(\operatorname{szy}-\mathrm{dy}) *(\mathrm{dy}>0) ;$

$\mathrm{xl} 2=1^{*}(\mathrm{dx}>=0)+(-\mathrm{dx}+1)^{*}(\mathrm{dx}<0) ; \mathrm{xu} 2=\mathrm{Szx}^{*}(\mathrm{dx}<=0)+(\operatorname{szx}-\mathrm{dx})^{*}(\mathrm{dx}>0) ;$

$\mathrm{d}=\mathrm{c}(\mathrm{yl} 2 \mathrm{yu} 2, \mathrm{xl} 2 \mathrm{xu} 2) ; \%$ cutout region to move

$\mathrm{xx} 2=1^{*}(\mathrm{dx}<=0)+(\mathrm{dx}+1)^{*}(\mathrm{dx}>0) ; \mathrm{yy} 2=1^{*}(\mathrm{dy}<=0)+(\mathrm{dy}+1)^{*}(\mathrm{dy}>0) ;$

$\mathrm{e}=\operatorname{bbblock}(\mathrm{xx} 2, \mathrm{yy} 2, \mathrm{zeros}(\mathrm{szy}, \mathrm{szx}), \mathrm{d})$;

$\operatorname{movi}(:,,, j j)=\operatorname{uint16}(e) ; \operatorname{set}($ himg,'cdata',movi(:,:,jj));

end

end

if (alignmode $==2$ ); \% align all to first in list

for $\mathrm{jj}=\mathrm{jmin}+1$ :jmax

$\mathrm{c}=\operatorname{double}(\operatorname{movi}(:,, ; \mathrm{jj})) ; \mathrm{szy}=\operatorname{size}(\mathrm{c}, 1) ; \mathrm{szx}=\operatorname{size}(\mathrm{c}, 2)$;

$\mathrm{dx}=\mathrm{xyalign}(\mathrm{jj}, 1) ; \mathrm{dy}=\mathrm{xyalign}(\mathrm{jj}, 2) ;$

$\mathrm{yl} 2=1 *(\mathrm{dy}>=0)+(-\mathrm{dy}+1) *(\mathrm{dy}<0) ; \mathrm{yu} 2=\operatorname{Szy}^{*}(\mathrm{dy}<=0)+(\operatorname{szy}-\mathrm{dy}) *(\mathrm{dy}>0) ;$ 
$\mathrm{xl} 2=1 *(\mathrm{dx}>=0)+(-\mathrm{dx}+1) *(\mathrm{dx}<0) ; \mathrm{xu} 2=\operatorname{szx} *(\mathrm{dx}<=0)+(\operatorname{szx}-\mathrm{dx}) *(\mathrm{dx}>0)$

$\mathrm{d}=\mathrm{c}(\mathrm{yl} 2: \mathrm{yu} 2, \mathrm{xl} 2 \mathrm{xu} 2) ; \%$ cutout region to move

$\mathrm{xx} 2=1^{*}(\mathrm{dx}<=0)+(\mathrm{dx}+1) *(\mathrm{dx}>0) ; \mathrm{yy} 2=1 *(\mathrm{dy}<=0)+(\mathrm{dy}+1) *(\mathrm{dy}>0) ;$

$\mathrm{e}=\operatorname{bbblock}(\mathrm{xx} 2, \mathrm{yy} 2, \mathrm{zeros}(\mathrm{szy}, \mathrm{szx}), \mathrm{d})$;

$\operatorname{movi}(:,,, j \mathrm{j})=$ uint16(e); set(himg,'cdata',movi(:,:,jj));

end

end

setappdata(hfig,'movi',movi);

$\mathrm{xx}=[] ; \mathrm{yy}=[] ; \mathrm{zz}=[] ;$

function sroi_auto_spots;

global list mapname b movi rows cols A i xx yy zz iii bbb q s ijj jjj r1 olds inner_radius outer_radius matrix

fused $=[] ;$ not_fused $=[] ;$

sizeul=size(movi);

image_height=sizeul $(1)$;

image_width=sizeul $(2)$;

size_cutoff $=300$;

redfilter=highpassfilter([image_height, image_width],0.01,10);

$\mathrm{H}=$ fspecial('average',5);

redimg=imfilter(movi(:,:,4), H, 'replicate');

\%\%\%\%\%\%\%\%\%\%\%\%\%\%\%\%\%\%\%\%\%\%\%\%\%\%\%\%\%\%\%\%\%filtering

$\mathrm{F}=\mathrm{ftt} 2(\operatorname{double}($ redimg $))$

$\mathrm{G}=$ redfilter. ${ }^{*} \mathrm{~F}$;

$\mathrm{g}=\operatorname{real}(\operatorname{ifft} 2(\mathrm{G}))$;

$\operatorname{maxim}=\max (\max (\mathrm{g}))$;

$\operatorname{minim}=\min (\min (\mathrm{g}))$;

$\mathrm{g}(:,:)=\mathrm{g}(:,:)-\operatorname{minim} ;$

$\mathrm{g}=\mathrm{g} * 511 / \operatorname{maxim} ;$

redimg2 $=[] ;$ redimg2 $=\mathrm{g}$;

\%\%\%\%\%\%\%\%\%\%\%\%\%\%\%\%\%\%\%\%\%\%\%\%\%\%\%\%\%\%\%\%\%\%\% \% thresholding

red_cutoff=round $($ mean $($ mean $($ redimg2 $)))+50$;

$\% \% \% \% \% \% \% \% \% \% \% \% \% \% \% \% \% \% \% \% \% \% \%$ finding the spots and their centers

ccc $=$ find $($ redimg $2<$ red_cutoff $) ;$ redimg $2(\operatorname{ccc})=0$;

redbw $=[] ;$ redbw $=$ bwlabel $($ redimg2); 


\section{Anhang}

$\operatorname{redx}=[] ;$ redy $=[] ;$

$\mathrm{bbb}=$ bwmorph(redbw,'clean');

redbw $=$ bwlabel $(\mathrm{bbb})$;

\%figure;

subplot(2,1,1); image(movi(:,:,4),'cdatamapping','scaled');axis equal; subplot $(2,1,2)$; image(redbw);axis equal;

drawnow;

if $\max (\max (\mathrm{redbw}))<500$

for $\mathrm{i}=1: \max (\max ($ redbw $))$

$\mathrm{xxx}=$ find $(\mathrm{redbw}==\mathrm{i})$;

pixel_number $=\operatorname{numel}(\mathrm{xxx})$;

if numel $(\mathrm{xxx})>$ size_cutoff

$\mathrm{yy}=$ floor(xxx/image_height $)$;

$\mathrm{xx}=\mathrm{rem}(\mathrm{xxx}$, image_height $)$;

$\operatorname{ccc}=$ find $(x \mathrm{x}==0)$;

$\mathrm{xx}(\mathrm{ccc})=$ image_height;

$\mathrm{yy}(\mathrm{ccc})=\mathrm{yy}(\mathrm{ccc})-1 ;$

$\mathrm{yy}=\mathrm{yy}+1 ;$

$\mathrm{aa}=[]$

$\mathrm{aa}=\operatorname{movi}(\min (\min (\mathrm{xx})): \max (\max (\mathrm{xx})), \min (\min (\mathrm{yy})): \max (\max (\mathrm{yy})), 4) ;$

$\mathrm{H}=$ fspecial('average', 3 );

newpic1=imfilter(aa, H, 'replicate');

$\operatorname{minim}=\min (\min ($ newpic1 $))$;

$\operatorname{maxim}=\max (\max ($ newpic 1$))$;

newpic1 = newpic1 - mean2(newpic1)-round $((\operatorname{maxim}-\operatorname{minim}) / 10)$;

$\mathrm{H}=$ fspecial('average', 3 );

I2=imfilter(newpic1, H, 'replicate');

\%figure; surface(double(I2),'edgecolor','none');

$\mathrm{B}=$ imregionalmax $(\mathrm{I} 2)$;

newbw $=$ bwlabel $(B)$;

number $=\max (\max ($ newbw $))$;

green $=\operatorname{movi}(\min (\min (x x)): \max (\max (x x)), \min (\min (y y)): \max (\max (y y)), 1)$;

red $=\operatorname{movi}(\min (\min (x x)): \max (\max (x x)), \min (\min (y y)): \max (\max (y y)), 2) ;$

$\mathrm{H}=$ fspecial('average',3); 


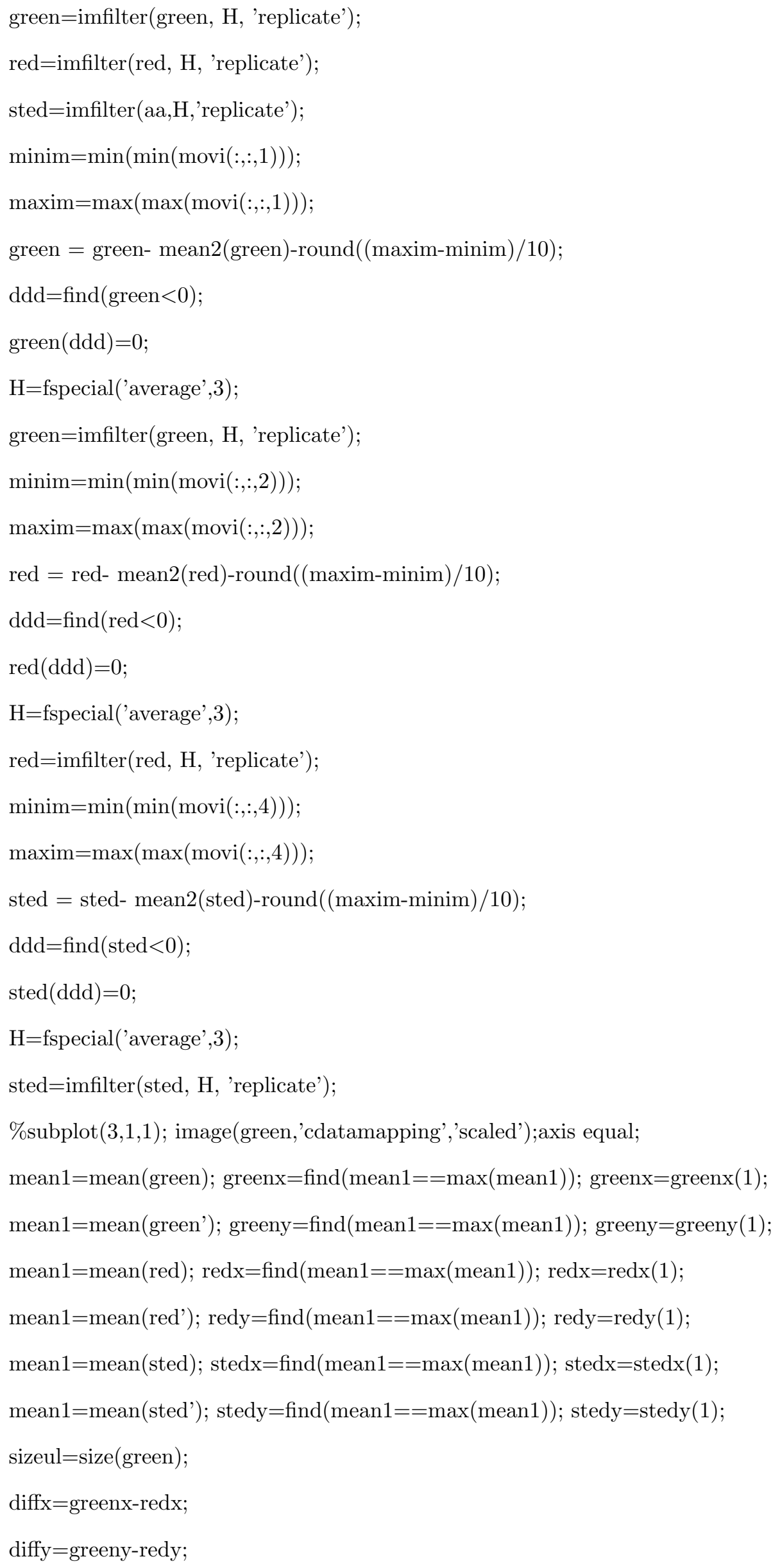




\section{Anhang}

$\operatorname{diffx} 2=$ greenx-stedx;

diffy $2=$ greeny-stedy;

$\operatorname{diffx} 3=$ redx-stedx;

diffy $3=$ redy-stedy;

abs_distance $=\operatorname{sqrt}\left(\operatorname{diffx}{ }^{\wedge} 2+\operatorname{diffy}^{\wedge} 2\right) * 10.091$

abs_distance $2=\operatorname{sqrt}\left(\operatorname{diffx} 22^{\wedge} 2+\operatorname{diffy} 2 \wedge 2\right)^{*} 10.091$

abs_distance $3=\operatorname{sqrt}\left(\operatorname{diffx} 33^{\wedge} 2+\operatorname{diffy} 3{ }^{\wedge} 2\right)^{*} 10.091$

$\%$ pause $(0.05)$

if abs_distance $<130$ \& abs_distance $2<130$ \& abs_distance $3<150 \&$ (abs_distance+abs_distance $2+$ abs_distance3) $<300$

size_fused =size(fused);

fused $($ size_fused $(1)+1,1)=$ number;

fused $($ size_fused $(1)+1,2)=$ pixel_number;

else

size_fused=size(not_fused);

$\operatorname{not} \_$fused $($size_fused $(1)+1,1)=$ number;

not_fused(size_fused $(1)+1,2)=$ pixel_number;

end;

end;

end;

end;

dlmwrite(strcat('fused',r1(1:numel(r1)-5),'.txt'), fused);

dlmwrite(strcat('not_fused',r1(1:numel(r1)-5),'.txt'), not_fused);

\%highpassfilter.m - Creates highpass Butterworth filter in two dimensions.

$\%$ HIGHPASSFILTER - Constructs a high-pass butterworth filter.

$\%$

$\%$ usage: $\mathrm{f}=$ highpassfilter(sze, cutoff, $\mathrm{n}$ )

$\%$

\% where: sze is a two element vector specifying the size of filter

$\%$ to construct.

$\%$ cutoff is the cutoff frequency of the filter $0-0.5$

$\% \mathrm{n}$ is the order of the filter, the higher $\mathrm{n}$ is the sharper

$\%$ the transition is. ( $\mathrm{n}$ must be an integer $>=1$ ).

$\%$

$\%$ The frequency origin of the returned filter is at the corners. 
$\%$

\% See also: LOWPASSFILTER, HIGHBOOSTFILTER, BANDPASSFILTER

$\%$

\% Peter Kovesi pk@cs.uwa.edu.au

\% Department of Computer Science \& Software Engineering

$\%$ The University of Western Australia

$\%$

\% October 1999

function $\mathrm{f}=$ highpassfilter(sze, cutoff, $\mathrm{n}$ )

if cutoff $<0 \mid$ cutoff $>0.5$

error('cutoff frequency must be between 0 and 0.5 ');

end

if $\operatorname{rem}(\mathrm{n}, 1) \sim=0 \mid \mathrm{n}<1$

error('n must be an integer $>=1$ ');

end

$\mathrm{f}=1.0$ - lowpassfilter(sze, cutoff, $\mathrm{n})$;

\% LOWPASSFILTER - Constructs a low-pass butterworth filter.

$\%$

$\%$ usage: $\mathrm{f}=$ lowpassfilter(sze, cutoff, $\mathrm{n}$ )

$\%$

$\%$ where: sze is a two element vector specifying the size of filter

$\%$ to construct [rows cols].

$\%$ cutoff is the cutoff frequency of the filter $0-0.5$

$\% \mathrm{n}$ is the order of the filter, the higher $\mathrm{n}$ is the sharper

$\%$ the transition is. ( $\mathrm{n}$ must be an integer $>=1$ ).

$\%$ Note that $\mathrm{n}$ is doubled so that it is always an even integer.

$\%$

$\% 1$

$\% \mathrm{f}=$

$\% 2 \mathrm{n}$

$\% 1.0+(\mathrm{w} /$ cutoff $)$

$\%$

$\%$ The frequency origin of the returned filter is at the corners.

$\%$ 


\section{Anhang}

\% See also: HIGHPASSFILTER, HIGHBOOSTFILTER, BANDPASSFILTER

$\%$

\% Copyright (c) 1999 Peter Kovesi

\% School of Computer Science \& Software Engineering

\% The University of Western Australia

$\%$ http://www.csse.uwa.edu.au/

$\%$

\% Permission is hereby granted, free of charge, to any person obtaining a copy $\%$ of this software and associated documentation files (the "Software"), to deal $\%$ in the Software without restriction, subject to the following conditions:

$\%$

$\%$ The above copyright notice and this permission notice shall be included in $\%$ all copies or substantial portions of the Software.

$\%$

$\%$ The Software is provided "as is", without warranty of any kind.

\% October 1999

\% August 2005 - Fixed up frequency ranges for odd and even sized filters

$\%$ (previous code was a bit approximate)

function $\mathrm{f}=$ lowpassfilter(sze, cutoff, $\mathrm{n}$ )

if cutoff $<0 \mid$ cutoff $>0.5$

error('cutoff frequency must be between 0 and 0.5 ');

end

if $\operatorname{rem}(\mathrm{n}, 1) \sim 0 \mid \mathrm{n}<1$

error('n must be an integer $>=1$ ');

end

if length(sze) $==1$

rows $=$ sze; cols $=$ sze;

else

rows $=\operatorname{sze}(1) ; \operatorname{cols}=\operatorname{sze}(2) ;$

end

\% Set up X and Y matrices with ranges normalised to +/- 0.5

$\%$ The following code adjusts things appropriately for odd and even values

$\%$ of rows and columns.

if $\bmod (\operatorname{cols}, 2)$ 
xrange $=[-($ cols- -1$) / 2:(\operatorname{cols}-1) / 2] /(\operatorname{cols}-1) ;$

else

xrange $=[-\operatorname{cols} / 2:(\operatorname{cols} / 2-1)] /$ cols;

end

if $\bmod ($ rows, 2$)$

yrange $=[-($ rows- 1$) / 2:($ rows- 1$) / 2] /($ rows- 1$) ;$

else

yrange $=[$-rows $/ 2:($ rows $/ 2-1)] /$ rows;

end

$[\mathrm{x}, \mathrm{y}]=\operatorname{meshgrid}($ xrange, yrange $) ;$

radius $=\operatorname{sqrt}\left(\mathrm{x} \cdot{ }^{\wedge} 2+\mathrm{y} \cdot{ }^{\wedge} 2\right) ; \% \mathrm{~A}$ matrix with every pixel $=$ radius relative to centre.

$\mathrm{f}=\operatorname{ifftshift}\left(1 . /\left(1.0+(\right.\right.$ radius.$/$ cutoff $\left.\left.) .^{\wedge}\left(2^{*} \mathrm{n}\right)\right)\right) ; \%$ The filter 
6 Anhang 


\section{Danksagung}

Mein Dank gilt Prof. Reinhard Jahn für seine Unterstützung und die Möglichkeit an so spannenden Projekten in seinem Labor zu arbeiten.

Herzlich danken möchte ich auch Dr. Silvio Rizzoli, der mich in die Welt der Endosomen eingeführt hat, für viele gute Ideen, die mir das Leben sehr erleichtert haben, die Daten des Aggregationsassays und die Anfertigung der Matlabprogramme.

Mein Dank gilt weiterhin:

Prof. Nils Brose und Prof. Michael Thumm für die Begleitung meiner Arbeit, sowie Prof. Ralf Ficner für die Bereitschaft das Zweitgutachten zu erstellen,

Sina Victoria Barysch für die verwendeten Bead-Experimente, ein Teil der Verdünnungsexperimente und die $\alpha$ SNAP-Mutante,

Dr. Daniel Zwilling für die Einführung in die Arbeit mit frühendosomalen SNAREs und das Geschenk der gegen diese gerichteten $\mathrm{F}_{a b}$-Fragmente,

Christina Schäfer für die Kopplung von Atto647N an Amino-Dextran und die Synaptobrevin-(+/- Cyclodextrin)-Experimente,

Broder Schmidt für den Einsatz während seines Praktikums, der sich in dem Blot der „rekonstituierten Endosomen” niederschlug,

Dr. Dietmar Riedel für die elektronenmikroskopischen Aufnahmen,

Prof. Roger Goody für das zunächst verwendete Rab-GDI Protein, sowie Prof. Marino Zerial für das Rab-GDI-Plasmid,

Dr. Gottfried Mieskes für das schnelle und unkomplizierte Lösen aller großen und kleinen Probleme des Laboralltags,

Ioanna Bethani, Matias Hernandez, Dr. Matthew Holt und Dr. Alexander Stein für hilfreiche Vorschläge und wertvolle Diskussionen, sowie auch den anderen Mitgliedern der Abteilung Neurobiologie für die gute Laboratmosphäre,

der DFG und dem CMPB für die Finanzierung,

meinen Eltern für ihre Unterstützung, ohne die ich es nicht so weit gebracht hätte, und meiner wunderbaren Freundin Constanze, die mir das Leben während meiner Doktorarbeit versüßt hat. 
6 Anhang 


\section{Lebenslauf}

16.8.1979 Geburt in Hannover

Eltern: Ina und Rainer Geumann

Ausbildung

1986-1999 Schulbesuch in Gehrden (Abitur am Matthias-Claudius-Gymnasium)

2000-2005 Biochemiestudium an der Universität Leipzig

2002-2003 Erasmusaufenthalt an der University of Glasgow

2005 Diplomarbeit „Evolutive Entwicklung des CXCR2 Rezeptors“ am Institut für Biochemie der Universität Leipzig bei Prof. Annette BeckSickinger

2005-2009 Promotion am MPI für biophysikalische Chemie in der Abteilung Neurobiologie bei Prof. Reinhard Jahn

Stipendien und Preise

2000-2005 Stipendiat der Studienstiftung des deutschen Volkes

2002-2003 Erasmusstipendium

2002-2003 Auslandsstipendium der Studienstiftung

2003 Martin Smellie Memorial Prize (Jahrgangsbester Biochemie)

2005-2008 DFG Promotionsstipendium

Publikationen

Rosenkilde, MM, David, R, Oerlecke, R, Benned-Jensen, T, Geumann, U, Beck-Sickinger, AG and Schwartz, TW Conformational constraining of inactive and active States of a seven transmembrane receptor by metal ion site engineering in the extracellular end of transmembrane segment V. Mol Pharmacol. 70(6):1892-901. (2006).

Bethani, I, Lang, T, Geumann, U, Sieber, JJ, Jahn, R, and Rizzoli, SO The specificity of SNARE pairing in biological membranes is mediated by both proof-reading and spatial segregation. EMBO J. 26(17):3981-92 (2007)

Geumann, U, Barysch, SV, Hoopmann, P, Jahn, R and Rizzoli, SO SNARE Function Is Not Involved in Early Endosome Docking. Mol Biol Cell. (2008) 